Marcelo Greco

\title{
ANÁLISE DE PROBLEMAS DE CONTATO/IMPACTO EM ESTRUTURAS DE COMPORTAMENTO NÃO LINEAR PELO MÉTODO DOS ELEMENTOS FINITOS
}

\begin{abstract}
Tese apresentada à Escola de Engenharia de São Carlos, da Universidade de São Paulo, como parte dos requisitos para obtenção do título de Doutor em Engenharia de Estruturas.
\end{abstract}

Orientador: Professor Associado Humberto Breves Coda

São Carlos

2004 
À minha querida esposa Jisela 


\section{AGRADECIMENTOS}

A Deus, por tudo.

Aos meus queridos pais, Pedro e Jurema;

Ao meu grande irmão Juliano, pela amizade e incentivo;

Ao meu orientador, Humberto Breves Coda, pelas idéias, paciência e dedicação, enfim, pela excelente orientação e amizade;

À Maria Nadir Minatel, pela presteza e eficiência no trabalho;

Às funcionárias da secretaria, Rosi e Marta, e aos funcionários Chico e Toninho, pela competência no serviço e bom atendimento;

À Fundação de Amparo à Pesquisa do Estado de São Paulo (FAPESP), pela bolsa e apoio financeiro, sem os quais não seria possível a realização deste trabalho;

Aos bons amigos feitos no departamento: Yuri, Valentim, Rodrigo, Rejane, Patrick, Patrícia, Paccola, Luciano, Leandro, Gerson e Daniel.

Aos membros da banca de defesa, professores Laier, Balthazar, Jonas e Marcílio, pelas valiosas contribuições para melhoria da tese. 


\section{RESUMO}

GRECO, M. (2004). Análise de problemas de contato/impacto em estruturas de comportamento não linear pelo método dos elementos finitos. São Carlos, 2004. 153p. Tese (Doutorado) - Escola de Engenharia de São Carlos, Universidade de São Paulo.

Trata de formulações e algoritmos para a análise não linear em problemas de impacto bidirecional entre estruturas reticuladas. São apresentadas novas formulações posicionais para problemas não lineares geométricos para os casos estático e dinâmico, baseadas no método dos elementos finitos. As formulações desenvolvidas são estendidas para problemas de impacto bidirecional entre estruturas reticuladas e anteparo rígido. Utiliza-se o método do multiplicador de Lagrange para impor as restrições de contato. Uma pesquisa foi realizada para se encontrar integrador temporal estável para análises de impacto. Desenvolveu-se uma nova estratégia de previsão do impacto, através da teoria de problemas potenciais e do método dos elementos de contorno. Por fim, a formulação é adaptada para o estudo de impacto bidirecional entre estruturas reticuladas, adotando-se algoritmo de retorno geométrico, no qual consideram-se situações com e sem atrito. São apresentados diversos exemplos numéricos, comparando-se resultados obtidos com soluções analíticas e numéricas de outros trabalhos. A formulação desenvolvida ainda considera efeitos elastoplásticos nos membros estruturais e ligações com deslocamentos livres nas conexões nodais, possibilitando a análise de mecanismos flexíveis.

Palavras-chave: análise não linear; contato; impacto; elementos finitos. 


\section{ABSTRACT}

GRECO, M. (2004). Nonlinear structural contact/impact analysis problems using the finite element method. São Carlos, 2004. 153p. Ph.D. Thesis - Escola de Engenharia de São Carlos, Universidade de São Paulo.

This work deals with formulations and algorithms for nonlinear bi-directional impact analysis between reticulated structures. New positional formulations for static and dynamic nonlinear cases are presented, both based on the finite element method. The developed formulations are extended to bi-directional impact problem between reticulated structures and rigid wall, using the Lagrange multiplier method to impose contact conditions. An appropriated time integration scheme is used to alleviate the numerical errors due high frequency vibrations occurring in the impact. Finally, the formulation is adapted for the bi-directional impact between reticulated structures. During the thesis several numerical examples are presented, comparing the obtained results with analytical and other numerical responses. The developed formulation also considers elastoplastic effects in structural members and nodal connections with free displacements.

Keywords: nonlinear analysis; contact; impact; finite elements. 


\section{LISTA DE SIGLAS}

CPN Condição de Penetração Nula

EF Elemento Finito

MEC Método dos Elementos de Contorno

MEF Método dos Elementos Finitos

PTV Princípio dos Trabalhos Virtuais

VPC Valor Principal de Cauchy 


\section{LISTA DE SÍMBOLOS}

\begin{tabular}{|c|c|}
\hline$\Pi$ & Funcional de energia potencial \\
\hline$U_{t}$ & Energia de deformação total \\
\hline $\mathrm{P}$ & Energia potencial das forças externas; força externa aplicada \\
\hline$\varepsilon$ & Medida de deformações \\
\hline$X$ & Posições nodais \\
\hline E & Módulo de elasticidade longitudinal \\
\hline$I$ & Inércia da seção transversal \\
\hline$A$ & Área da seção transversal \\
\hline$\rho$ & Densidade \\
\hline$L$ & Comprimento do elemento finito \\
\hline$F$ & Força externa aplicada \\
\hline$\nabla g\left(X^{0}\right)$ & Matriz Hessiana \\
\hline$g\left(X^{0}\right)$ & Vetor dos resíduos \\
\hline$\omega$ & Rotação \\
\hline$\theta$ & Ângulo do elemento finito \\
\hline$\sigma_{y}$ & Tensão de escoamento \\
\hline$\varepsilon_{y}$ & Deformação relacionada à tensão de escoamento \\
\hline$\varepsilon_{p}$ & Deformação plástica \\
\hline$K$ & Módulo plástico \\
\hline$H$ & Módulo de encruamento cinemático \\
\hline$K_{c}$ & Energia cinética \\
\hline$K_{a}$ & Perda de energia devido ao amortecimento \\
\hline$M$ & Matriz de massa \\
\hline$c_{m}$ & Coeficiente de amortecimento proporcional à massa \\
\hline$C$ & Matriz de amortecimento \\
\hline$t$ & Variável tempo \\
\hline$\Delta t$ & Intervalo de integração temporal \\
\hline$\gamma, \beta$ & Constantes de integração temporal de Newmark \\
\hline$U$ & Deslocamento; grau de liberdade \\
\hline$\eta$ & Direção normal em relação ao contorno integrado \\
\hline$\Gamma$ & Direção tangencial em relação ao contorno integrado \\
\hline
\end{tabular}




$\begin{array}{ll}\Omega & \text { Domínio de integração } \\ \chi & \text { Ângulo de retorno } \\ R & \text { Coeficiente de retorno } \\ \lambda & \text { Multiplicador de Lagrange } \\ \delta & \text { Distância inicial entre pontos que poderão entrar em contato } \\ F^{C O N} & \text { Forças de contato } \\ F^{E X T} & \text { Forças externas } \\ T O L & \text { Tolerância } \\ X^{E} & \text { Posições nodais da estrutura alvo } \\ \mu & \text { Coeficiente de atrito de Coulomb } \\ V & \text { Volume inicial do corpo analisado } \\ \xi & \text { Parâmetro adimensional }\end{array}$




\section{SUMÁRIO}

1 INTRODUÇÃO 1

2 REVISÃO BIBLIOGRÁFICA 3

3 FORMULAÇÃO NÃO LINEAR GEOMÉTRICA APLICADA A 11 PROBLEMAS ESTÁTICOS DE ESTRUTURAS RETICULADAS PLANAS

3.1 Considerações iniciais 11

$\begin{array}{ll}3.2 \text { Equacionamento } & 11\end{array}$

3.3 Passos algébricos necessários para implementação da formulação 19

3.4 Comentário final sobre a formulação 25

3.5 Exemplos numéricos 26

3.5.1 Viga em balanço com carga transversal aplicada na extremidade livre 26

3.5.2 Viga em balanço com momento aplicado na extremidade livre 28

3.5.3 Pilar com carga excêntrica 30

3.5.4 Viga elastoplástica bi-apoiada com carga no meio do vão 31

3.5.5 Viga elastoplástica em balanço com carga transversal aplicada na extremidade 32 livre

3.5.6 Quadro elástico articulado em forma de losango submetido a duas cargas 34 aplicadas em sentidos opostos

3.5.7 Quadro submetido a duas cargas aplicadas em sentidos opostos 36

3.5.8 Contato entre estrutura anelar e anteparo rígido 39

4 FORMULAÇÃO NÃO LINEAR GEOMÉTRICA APLICADA A 42 PROBLEMAS DINÂMICOS DE ESTRUTURAS RETICULADAS PLANAS

4.1 Considerações iniciais $\quad 42$

4.2 Equacionamento 42

$\begin{array}{lll}4.3 & \text { Exemplos numéricos } & 47\end{array}$

$\begin{array}{ll}\text { 4.3.1 Viga engastada amortecida } & 47\end{array}$

4.3.2 Sistema massa-mola com plastificação na mola 48

4.3.3 Não linearidade geométrica em viga bi-engastada 49

4.3.4 Não linearidade geométrica em viga engastada 51

4.3.5 Lâmina flexível giratória 54

4.3.6 Mecanismo flexível articulado $\quad 58$

4.3.7 Mecanismo de Peaucellier flexível 62 
5 IMPACTO ENTRE ESTRUTURAS RETICULADAS PLANAS E ANTEPARO RÍGIDO

5.1 Considerações iniciais

5.2 Algoritmo de identificação do impacto 68

5.3 Atrito no contato 76

5.4 O multiplicador de Lagrange $\quad 78$

5.5 Formulação de impacto baseada no multiplicador de Lagrange 79

5.6 O problema da integração temporal no impacto 81

5.7 Exemplos numéricos $\quad 84$

5.7.1 Impacto unidirecional entre duas barras $\quad 84$

5.7.2 Impacto bidirecional de anel em anteparo rígido inclinado 92

5.7.3 Impacto bidirecional de anel em anteparo rígido 95

5.7.4 Impacto bidirecional de anel em anteparo rígido em forma de $\mathrm{V} \quad 98$

6 IMPACTO ENTRE ESTRUTURAS RETICULADAS PLANAS 103

6.1 Considerações iniciais 103

6.2 Algoritmo de retorno e distribuição das forças de contato 103

$\begin{array}{ll}6.3 \text { Impacto nodal } & 106\end{array}$

$\begin{array}{ll}6.4 \text { Condições iniciais } & 107\end{array}$

$\begin{array}{lll}6.5 & \text { Exemplos numéricos } & 108\end{array}$

$\begin{array}{lll}\text { 6.5.1 Impacto entre duas estruturas anelares } & 108\end{array}$

6.5.2 Impacto entre três estruturas anelares 112

$\begin{array}{ll}\text { 6.5.3 Estrutura anelar confinada em quadro flexível } & 115\end{array}$

7 CONCLUSÕES E CONSIDERAÇÕES FINAIS

$\begin{array}{lll}7.1 \text { Conclusões } & 118\end{array}$

$\begin{array}{ll}7.2 \text { Considerações finais e desenvolvimentos futuros } & 119\end{array}$

REFERÊNCIAS BIBLIOGRÁFICAS 123

APÊNDICE 1 - TRANSFORMAÇÃO DE COORDENADAS 134

APÊNDICE 2 - SISTEMA DE EQUAÇÕES 136

APÊNDICE 3 - MODELO CONSTITUTIVO ELASTOPLÁSTICO 139

APÊNDICE 4 - CONEXÃO NODAL 144

APÊNDICE 5 - EQUAÇÕES DE INTEGRAÇÃO TEMPORAL DE 147

NEWMARK

APÊNDICE 6 - MODELO DE ATRITO DE COULOUMB 150

ÍNDICE 153 


\section{INTRODUÇÃO}

O objetivo principal desta tese é desenvolver formulação e código computacional, baseado no Método dos Elementos Finitos (MEF), para análise de problemas de impacto bidirecional entre estruturas reticuladas planas ${ }^{1}$. Para se atingir plenamente este objetivo são necessários vários pré-requisitos teóricos intermediários, comentados a seguir.

No projeto de estruturas, o problema fundamental é encontrar uma solução que apresente bom desempenho estrutural (estrutura previsível e segura) com baixo custo econômico. Para atingir este objetivo, os projetistas tendem a utilizar materiais de melhor desempenho e conseqüentemente estruturas cada vez mais leves e esbeltas. Assim, é necessário se utilizar teorias mais complexas, como as formulações não lineares, para aproveitar o máximo possível as características dos materiais utilizados e tipologias geométricas, dentro dos critérios de segurança e utilização das estruturas.

O conteúdo da tese envolve três tipos de comportamento não linear: a não linearidade geométrica, relacionada à influência das mudanças de geometria da estrutura na resposta, a não linearidade física, relacionada aos materiais de que é constituída a estrutura e a não linearidade de contato, relacionada às mudanças nas condições de contorno e iniciais na estrutura ${ }^{2}$.

Para analisar o comportamento não linear geométrico nas estruturas será utilizada uma nova formulação baseada nas posições nodais dos Elementos Finitos (EF), desenvolvida em CODA (2003) e CODA \& GRECO (2003) para problemas estáticos e elasticamente lineares. A formulação foi estendida pelo doutorando para problemas estáticos com não linearidade física, considerando-se modelo constitutivo elastoplástico bi-linear (com encruamento positivo). Na seqüência do trabalho, a formulação estática

\footnotetext{
${ }^{1}$ Considera-se estrutura reticulada aquela constituída por elementos prismáticos (elementos em que as dimensões longitudinais sejam maiores que as dimensões transversais).

${ }^{2}$ As condições de contorno estão relacionadas às posições (ou deslocamentos) e forças, enquanto as condições iniciais estão relacionadas à variável tempo.
} 
não linear física e geométrica foi adaptada para o caso do problema dinâmico, ocasião na qual se desenvolveu um novo algoritmo de integração temporal, baseado na família de integradores temporais de Newmark, adequado e eficiente na solução do problema. A formulação dinâmica desenvolvida além de resolver problemas com grandes deflexões e rotações nas estruturas, com ou sem não linearidade física, também foi adaptada para solução de problemas de multicorpos (caso dos mecanismos). Finalmente, as formulações desenvolvidas foram generalizadas para consideração dos problemas de impacto bidirecional de estrutura e anteparo rígido e entre estruturas. No caso dos problemas de impacto utilizaram-se multiplicadores de Lagrange e constantes de integração temporal adequadas para solução do problema.

As estruturas são consideradas nesta tese como constituídas de material homogêneo ${ }^{3}$ e isótropo ${ }^{4}$.

Nas implementações computacionais das formulações desenvolvidas durante o doutorado foi utilizada a linguagem de programação FORTRAN77 (compilador Powerstation 4.0).

No próximo capítulo da tese será apresentada uma revisão bibliográfica sobre os temas abordados, como não linearidade geométrica, dinâmica não linear e formulações para problemas de contato/impacto. Apenas os trabalhos considerados mais relevantes serão descritos e comentados de maneira mais detalhada.

Na seqüência é apresentado o cerne do trabalho, contendo quatro capítulos relacionados ao impacto bidirecional. A não linearidade geométrica é fundamental na análise e, portanto, no capítulo 3 é apresentada a formulação posicional não linear geométrica estática, base para a influência da mudança de geometria das estruturas nos problemas de impacto. No capítulo 4 a formulação não linear geométrica é estendia para os problemas dinâmicos, com aplicações em problemas envolvendo multicorpos. No capítulo 5 é apresentada a formulação para problemas de impacto bidirecional entre estrutura reticulada e anteparo rígido. No capítulo 6 é apresentada a formulação para problemas de impacto bidirecional entre estruturas reticuladas.

Por fim são apresentadas as conclusões e as considerações finais sobre a tese, com algumas sugestões para futuros trabalhos. Após as referências bibliográficas são apresentados ainda seis apêndices ao trabalho.

\footnotetext{
${ }^{3} \mathrm{O}$ material apresenta as mesmas propriedades elásticas em qualquer ponto.

${ }^{4} \mathrm{O}$ comportamento do material é o mesmo em todas as direções.
} 


\section{REVISÃO BIBLIOGRÁFICA}

O comportamento não linear relacionado a grandes mudanças de geometria nas estruturas, onde não são válidas as aproximações da teoria linear, são de interesse em vários campos da Engenharia (Aeronáutica, Civil, Mecânica, etc). A análise não linear geométrica em estruturas é complexa e existem poucas soluções analíticas disponíveis, geralmente encontradas para problemas com geometria simples como as vigas engastadas apresentadas em BISSHOPP \& DRUCKER (1945). Em termos de soluções analíticas destaca-se o artigo de MATTIASSON (1981) que apresenta respostas, obtidas pela solução de integrais do tipo elíptica, para problemas de viga engastada, quadro articulado e quadro rígido. No próximo capítulo serão apresentados os três exemplos do artigo de MATTIASSON como base de validação para as aplicações numéricas.

$\mathrm{Na}$ literatura existem diversas formulações baseadas no MEF para resolver problemas de não linearidade geométrica em estruturas. Estas formulações apresentam diferenças na descrição de coordenadas. A descrição Lagrangiana mede as mudanças de configuração nas estruturas a partir de um referencial fixo no espaço, e pode ser total, atualizada ou parcialmente atualizada. Portanto todas as operações, inclusive as derivadas, são feitas a partir de uma posição conhecida. $\mathrm{O}$ termo atualizado se refere à última configuração em equilíbrio do sistema de referência. Se a configuração de referência é atualizada durante os incrementos de carga, ou tempo, então a formulação é chamada de atualizada; se a configuração de referência é atualizada apenas no início dos incrementos de carga, então a formulação é chamada de parcialmente atualizada; se a configuração de referência é sempre fixa, tomada como a configuração inicial, então a formulação é chamada de total. Estas definições dos tipos de descrições Lagrangianas podem ser encontradas, por exemplo, em WONG \& TINLOI (1990). Formulações que trabalham com a descrição Lagrangiana atualizada podem ser encontradas nos artigos de MEEK \& TAN (1984), GADALA et al. (1984) e GATTASS \& ABEL (1987). O artigo de GADALA ainda apresenta em detalhes as diferenças entre as formulações 
Lagrangiana total e atualizada. Formulações que trabalham com a descrição Lagrangiana parcialmente atualizada podem ser encontrados nos artigos de PETERSON \& PETERSSON (1985) e WONG \& TINLOI (1990). Formulações que trabalham com a descrição Lagrangiana total podem ser encontrados nos artigos de MONDKAR \& POWELL (1977), SURANA (1983) e SCHULZ \& FILIPPOU (1990). A descrição Euleriana mede as mudanças de configuração nas estruturas a partir de um referencial móvel no espaço. Portanto todas as operações, inclusive as derivadas, são feitas a partir de uma posição do referencial, em princípio, desconhecida. Formulações que trabalham com a descrição Euleriana podem ser encontrados nos artigos de ORAN \& KASSIMALI (1976) e IZZUDDIN \& ELNASHAI (1993). A formulação co-rotacional também é muito utilizada na solução de problemas não lineares geométricos e consiste na utilização de sistemas de coordenadas locais nos elementos finitos, tornando possível a consideração dos efeitos de curvatura. Exemplos de formulações co-rotacionais podem ser encontrados nos artigos de CRISFIELD (1990), BEHDINAN et al. (1998) e THE \& CLARKE (1998). Outras formulações não lineares se destacam na literatura, como as formulações termomecânicas, matriciais e cinematicamente exatas. Como exemplo de formulação termomecânica pode-se citar o trabalho de ARGYRIS et al. (1986), capaz de analisar deformações termomecânicas de sólidos com grandes deformações. Como exemplos de formulações matriciais podem ser citados os artigos de PETROLITO \& LEGGE (1996), que utilizam um algoritmo de auto-adaptatividade, e os trabalhos de GOTO et al. (1992) e PAI \& PALAZOTTO (1996), que consideram a curvatura exata de vigas tridimensionais. Como exemplos de formulações cinematicamente exatas podem ser citados os trabalhos de REISSNER (1973), SIMO et al. (1984) e WRIGGERS \& SIMO (1990), baseados na teoria não linear de vigas de Reissner.

Outro trabalho sobre não linearidade geométrica de destaque é o artigo de RIKS (1979) que apresenta formulação incremental para busca de solução em problemas de flambagem passando por pontos $\operatorname{limite}^{1}$ ou pontos de bifurcação ${ }^{2}$ e determinação de carga crítica ${ }^{3}$.

\footnotetext{
${ }^{1} \mathrm{O}$ ponto limite define o fim das configurações estáveis de equilíbrio, onde as soluções são únicas. Até o ponto limite não há ponto de bifurcação na resposta. O ponto limite é único.

${ }^{2} \mathrm{O}$ ponto de bifurcação é definido como o ponto a partir do qual existe mais de uma configuração de equilíbrio possível. Pode existir mais de um ponto de bifurcação, ver BATTINI et al. (2003).

${ }^{3}$ Carga relacionada ao ponto de bifurcação.
} 
O trabalho de CRISFIELD (1981) também merece destaque, pois apresenta um algoritmo baseado na técnica do comprimento de arco (arc-lenght) modificada, apropriado para solução de problemas com salto de deslocamento (snap-through ${ }^{4}$ ) e salto de força (snap-back ${ }^{5}$, nos quais geralmente se utilizam controles de força e de deslocamento respectivamente.

O segundo tipo de não linearidade tratada nesta tese diz respeito ao comportamento do material, quando submetido a níveis elevados de tensão ou deformação, também chamada de não linearidade física, e é de extrema importância para o projetista, pois altera o comportamento local e global da estrutura em seu estado limite último ou mesmo de utilização. De acordo com o modelo constitutivo de cada material utilizado na estrutura e das considerações geométricas, é possível fazer a análise de estabilidade da estrutura. O modelo constitutivo a ser utilizado será elastoplástico com encruamento positivo, conforme descrito na introdução, e será baseado em OWEN \& HINTON (1980) e PROENÇA (1997). Também foram utilizados na tese os trabalhos de YANG \& SAIGAL (1984), SIMO et al. (1986) e SAJE et al. (1998), sendo os dois últimos baseados na cinemática de Reissner ${ }^{6}$ para vigas.

Com o intuito de ampliar a gama das aplicações numéricas da tese buscou-se a implementação de uma técnica de acoplamento nodal que permitisse a consideração de ligações deslocáveis nos nós da estrutura. A técnica de conexão dos graus de liberdade utilizada é semelhante à apresentada em BRASIL (1990) e GRECO \& CODA (2001), e pode ser vista no apêndice 4 . O objetivo da implementação é a aplicação em problemas de multicorpos. Um dos trabalhos pioneiros em multicorpos reticulados foi o artigo de SIMO \& VU-QUOC (1986), que utiliza uma técnica de resíduos ponderados (Galerkin) para modelar o problema. Este trabalho foi um dos mais importantes da literatura e é dividido em duas partes, sendo na segunda parte apresentadas várias aplicações bidimensionais de multicorpos constituídos de estruturas reticuladas. Outros trabalhos mais recentes utilizam a formulação co-rotacional para modelar o problema, como os artigos de RICE \& TING (1993), HSIAO et al. (1994) e ELKARANSHAWY \& DOKAINISH (1995). O artigo de ZYWICZ \& PUSO (1999) apresenta uma técnica baseada nos multiplicadores de Lagrange e conservação de energia aplicada a problemas de multicorpos 3D.

\footnotetext{
${ }^{4}$ Comportamento caracterizado por mais de uma resposta em deslocamento para determinada força.

${ }^{5}$ Comportamento caracterizado por mais de uma resposta em força para determinado deslocamento.

${ }^{6}$ Após as deformações, as seções permanecem planas, mas não necessariamente ortogonais à linha média da viga.
} 
O terceiro tipo de não linearidade tratada nesta tese diz respeito às alterações nas condições iniciais e de contorno do problema, ou seja, contato ou impacto de estruturas. A literatura científica a respeito de problemas de impacto é muito vasta e diversificada, existem várias técnicas e métodos numéricos diferentes para tratar o problema. Nenhuma destas técnicas ou métodos é geral. Devido à complexidade do problema existem muitas alternativas para se tratar o problema e esta área científica ainda está aberta para novas idéias e estratégias, basta observar o grande número de artigos publicados recentemente sobre problemas de contato/impacto.

O trabalho de HUGHES et al. (1976) foi um marco em termos de métodos numéricos aplicados na solução de problemas envolvendo contato/impacto. Este trabalho contribuiu significativamente para o desenvolvimento de aproximações em elementos finitos, utilizando multiplicadores de Lagrange. O trabalho ainda apresenta aplicações que vão desde o impacto entre barras até o impacto de cascas. O trabalho considerou apenas problemas elásticos, sem plastificação ou atrito.

Dois artigos, de mesmos autores, se destacaram na década de 1980. BATHE \& CHAUDHARY (1985) apresentaram uma formulação para tratar problemas bidimensionais de contato com grandes deformações envolvendo atrito, utilizando multiplicadores de Lagrange. No ano seguinte, CHAUDHARY \& BATHE (1986) apresentaram uma formulação tridimensional clássica baseada na técnica do multiplicador de Lagrange para resolver problemas de impacto. Estes dois artigos são considerados referências clássicas sobre problemas de contato/impacto. Porém, o artigo de 1986, que trata especialmente problemas de impacto, apresenta uma formulação baseada no MEF com integração temporal de Newmark que gera problemas de instabilidade numérica em algumas respostas.

Mais recentemente foram publicados artigos importantes que tratam de algoritmos de integração numérica envolvendo problemas de impacto formulados com a técnica do multiplicador de Lagrange. CARPENTER et al. (1991) apresentaram uma formulação quase-explícita para tratar problemas de impacto com atrito. Apesar de apresentarem um algoritmo complexo de integração temporal, baseado num método de Gauss-Seidel modificado, encontra-se neste artigo uma preciosa explicação sobre impacto bidimensional. TAYLOR \& PAPADOPOULOS (1993) apresentaram uma melhoria na integração temporal de problemas de contato/impacto formulados pela técnica do multiplicador de Lagrange, através de multiplicadores de Lagrange expressos em termos de velocidade e aceleração, com o intuito de garantir condições de contato e 
separação entre os corpos envolvidos no impacto. HU (1997) apresentou um novo algoritmo de integração temporal que parte de uma hipótese simples relacionada com as acelerações que se desenvolvem na região de contato durante o impacto. Este último artigo é muito eficiente para tratar problemas de impacto e corrige os problemas de integração temporal existentes na formulação apresentada por CHAUDHARY \& BATHE (1986).

Em relação ao impacto, o primeiro problema que surge é a identificação da ocorrência do mesmo. Existem diversos tipos de algoritmos capazes de identificar o contato/impacto. Os mais simples são baseados em áreas de influência próximas aos elementos do corpo alvo, como o algoritmo baseado no conceito de território (área de influência local de cada elemento alvo) encontrado no artigo de ZHONG \& NILSSON (1996) e os famosos algoritmos do tipo pinball (áreas de influência circulares ou esféricas dos elementos alvo) encontrados nos artigos de BELYTSCHKO \& NEAL (1991) e BELYTSCHKO \& YEH (1993). Apesar de muito utilizados, os algoritmos baseados nas áreas de influência aproximam a posição e o instante do impacto, fornecendo resultados nem sempre confiáveis. Este tipo de algoritmo de contato/impacto é freqüentemente utilizado em conjunto com as funções de penalização. Existem algoritmos de contato/impacto baseados no balanço das forças de superfície na região de contato, como os apresentados nos artigos de LORENZANA \& GARRIDO (1998) e WANG et al. (2001). Dois novos algoritmos de contato/impacto publicados recentemente podem ser encontrados em ULAGA et al. (1999), que utiliza funções splines na modelagem da região do contato, e LI et al. (2001), que apresenta um algoritmo de contato para elementos finitos sem malha.

Uma das conseqüências da natureza não linear de problemas de contato/impacto é que não se conhece a priori qual o instante em que se iniciará o impacto. Geralmente, com intervalos de tempo constantes não se consegue chegar ao instante exato do impacto. Uma das alternativas é a utilização de algoritmos de integração temporal descontínuos. Os trabalhos de HULBERT (1992) e KARAOGLAN \& NOOR (1997) apresentaram técnicas de integração temporal descontínuas baseadas no método de Galerkin, com aplicação da técnica dos mínimos quadrados ${ }^{7}$ para melhorar a estabilidade numérica do algoritmo. Outro artigo, CHO \& KIM (1999), apresenta uma

\footnotetext{
${ }^{7}$ A técnica dos mínimos quadrados é usada para corrigir curvas de dados a partir de pontos conhecidos, de maneira a minimizar o valor quadrático dos erros (visando evitar o cancelamento de erros com sinais opostos).
} 
nova integração descontínua no tempo utilizando a técnica de penalização. Segundo $\mathrm{CHO} \& \mathrm{KIM}$, vários estudos foram feitos sobre o assunto e indicaram que apenas a condição de impenetrabilidade dos corpos não é suficiente para simular numericamente problemas de contato/impacto: “as mudanças repentinas nas variáveis relacionadas com o problema dinâmico, durante o contato, produzem oscilações indesejáveis e o método de integração temporal de Newmark não é suficiente para resolver este tipo de problema". Um artigo mais recente, CZEKANSKI et al. (2001) apresenta um novo algoritmo de integração temporal do tipo Newmark modificado com utilização de multiplicadores de Lagrange na formulação. Para se evitar oscilações adicionais indesejáveis, de acordo com algumas referências consultadas, em especial CHEN et al. (1993) e MAHMOUD et al. (1998), se deveria assumir o contato sem atrito, reduzindose assim a não linearidade do contato apenas ao aspecto geométrico. Porém, a não consideração do atrito no contato restringiria bastante a gama de aplicações de qualquer formulação de impacto. A instabilidade numérica dos algoritmos de impacto e de retorno, com e sem atrito, se confundem na literatura. Continua-se neste capítulo a descrição do conjunto de contribuições gerais sobre o tema da tese, tendo em mente que nos capítulos 5 e 6 serão apresentadas as propostas deste trabalho para as questões da estabilidade, identificação do impacto e algoritmo de retorno (com ou sem atrito). Em relação ao atrito na região de contato, será apresentada no capítulo 5 uma técnica que se baseia na interpretação geométrica do atrito de Coulomb. O apêndice 6 traz um resumo do modelo de atrito de Coulomb clássico.

Alguns trabalhos apresentam modelos de atrito complexos, com comportamento não-linear nas superfícies de contato, como os artigos de WRIGGERS et al. (1990), que apresenta uma lei de atrito baseada em fenômenos micro-mecânicos, ODEN \& PIRES (1983), que apresenta leis de atrito não lineares e não locais, e ODEN \& MARTINS (1985), que apresenta formulações numéricas de modelos de atrito para problemas de impacto. SIMO \& LAURSEN (1992) apresentaram uma formulação baseada no método do multiplicador de Lagrange para problemas de contato com atrito e CHEN et al. (1993) apresentaram formulação baseada no Princípio dos Trabalhos Virtuais (PTV) para problemas de contato/impacto com atrito, utilizando função de relaxação viscoelástica. Recentemente, LIU et al. (2003) apresentaram uma técnica baseada em regiões de influência para a estabilização numérica do contato bidimensional com atrito.

Outros artigos interessantes como os de SOLBERG \& PAPADOPOULOS (1998), baseado na técnica do multiplicador de Lagrange, e LANDENBERGER \& EL- 
ZAFRANY (1999), que utiliza funções de penalização com elementos descontínuos nas superfícies de contato, não consideram a existência de atrito na superfície de contato.

Uma outra abordagem para problemas de impacto pode ser encontrada nas técnicas baseadas nas relações entre quantidade de movimento e impulso, que consideram a conservação da energia total do sistema durante o impacto. Uma ótima referência sobre esta técnica pode ser encontrada em ARMERO \& PETOCZ (1998), que utilizam técnicas de penalização buscando a conservação da energia total do sistema, porém, aplicada apenas em problemas sem atrito. Mais recentemente, HEINSTEIN et al. (2000) apresentaram um trabalho que utiliza a conservação da energia dos corpos separados, cada qual com suas condições de contorno, impondo um conjunto adicional de restrições de contato $^{8}$ no impacto, desta maneira, utiliza-se uma formulação fraca em nível local ${ }^{9}$ e forte no resto do sistema. Outro trabalho de destaque é o apresentado por WASFY \& NOOR (1997), que utiliza conservação de momento e equações de restrição de velocidade nos pontos que sofrem impacto, usadas para calcular as velocidades dos pontos que sofreram impacto após a separação dos corpos. A crítica feita para este tipo de abordagem é relacionada à generalidade das técnicas empregadas, ou seja, em casos que envolvam dissipação de energia, como em problemas de plasticidade, a eficiência da técnica fica comprometida, uma vez que estas formulações são adequadas para sistemas conservativos de energia.

As técnicas baseadas nas funções de penalização são as mais antigas, mas atualmente ainda são utilizadas, como no trabalho de BITTENCOURT \& CREUS (1998) e em pacotes de análise estrutural como ANSYS ${ }^{\circledR}$. Este tipo de técnica considera a existência de uma função de penalização que relaciona a aproximação relativa entre os corpos à intensidade da força de contato. As equações de movimento dos corpos já estão previamente definidas e o problema de contato passa a ser um problema de condições de contorno interdependentes. Segundo WASFY \& NOOR, apesar da simplicidade de implementação computacional, a técnica apresenta duas desvantagens: "não há conservação de energia durante o contato e a função de penalização depende de parâmetros de calibração específicos para cada problema, o que reduz em muito a generalidade esperada". O artigo de HALLQUIST et al. (1985) também apresenta uma estratégia alternativa para a solução de problemas de impacto, usando funções de penalização.

\footnotetext{
${ }^{8}$ Técnica de penalização.

${ }^{9} \mathrm{Na}$ região do contato.
} 
Uma estratégia alternativa para solução de problemas de impacto foi apresentada nos artigos de FARAHANI et al. (2000) e FARAHANI et al. (2001), nos quais os autores apresentam uma técnica baseada em uma forma particular de acoplamento para resolver o problema. Os autores utilizam uma transformação na qual os graus de liberdade normais nas regiões do contato são eliminados e as forças de contato são calculadas após o sistema de equações ser resolvido, através das equações de equilíbrio dos corpos.

Um último trabalho que merece destaque é o artigo de FANCELLO \& FEIJOO (1994), que utiliza a técnica do multiplicador de Lagrange em problemas de otimização de forma durante o contato. Apesar do artigo tratar apenas de contato estático, vale destacar a excelência do trabalho.

Com as informações apresentadas neste capítulo, verifica-se que na ciência o conhecimento científico é fragmentado. O problema da modelagem numérica do impacto, como assunto científico, não apresenta uma referência bibliográfica única capaz de sintetizar todo o assunto estudado. O que existe são diversas referências, com fragmentos de informações, mais ou menos relevantes, sobre o problema. Devido à sua importância, o trabalho de revisão bibliográfica não se restringirá apenas a este capítulo, será ampliado e revisto durante todos os outros capítulos deste trabalho, inclusive com a citação e comentário de artigos não citados aqui. 


\section{FORMULAÇÃO NÃO LINEAR GEOMÉTRICA APLICADA A PROBLEMAS ESTÁTICOS DE ESTRUTURAS RETICULADAS PLANAS}

\subsection{Considerações iniciais}

Neste capítulo descreve-se uma nova formulação não linear geométrica exata para o tratamento de estruturas reticuladas no plano, considerando-se grandes deslocamentos e rotações. É de extrema importância frisar que a descrição aqui apresentada não considera no equacionamento os deslocamentos como variáveis, considera como grandeza real do problema as posições nodais do corpo. Tal abordagem se mostra precisa como demonstrado nos exemplo apresentados no final deste capítulo. Uma das vantagens da formulação é seu fácil entendimento.

Esta nova formulação para problemas não lineares geométricos foi recentemente concebida e desenvolvida em CODA (2003), para o caso de problemas estáticos e elásticos. Neste capítulo será apresentada a formulação original com o acréscimo de termos relacionados com a plastificação, considerando-se o modelo de encruamento misto, combinando-se o encruamento isótropo e cinemático, apresentado no apêndice 3.

\subsection{Equacionamento}

Considera-se inicialmente o princípio da energia potencial total estacionária ${ }^{1}$ para um corpo plano qualquer, ver ilustração da figura 1.

$\Pi=U_{t}-\mathrm{P}$

\footnotetext{
${ }^{1}$ Dentre todas as configurações possíveis num sistema corpo flexível com forças atuantes, àquela correspondente ao valor máximo (ou mínimo) do potencial total (I) é a configuração equilibrada.
} 


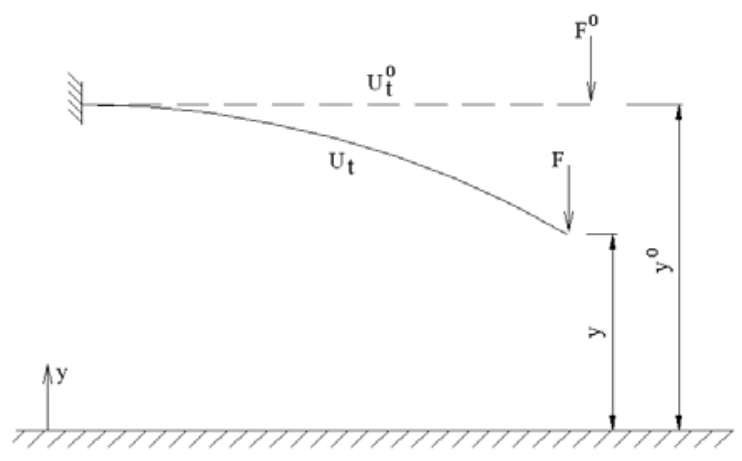

Figura 1 - Energia potencial total escrita para um corpo em duas posições distintas

A energia de deformação total $\left(U_{t}\right)$, incluindo-se a não linearidade física, é dada por:

$U_{t}=\iint_{V \varepsilon} \sigma d \varepsilon d V=\iint_{V}\left(\int_{\varepsilon} E \varepsilon d \varepsilon-\int_{\varepsilon} E \varepsilon_{p} d \varepsilon\right) d V=\iint_{V}\left(\frac{1}{2} E \varepsilon^{2}-E \varepsilon \varepsilon_{p}\right) d V$

Na equação (2), o termo $\varepsilon_{p}$ representa as plastificações que ocorrem no corpo, que são obtidas a partir do modelo constitutivo do material. O termo $V$ representa o volume inicial do corpo analisado, segundo o referencial Lagrangiano.

A energia potencial das forças externas é dada por:

$\mathrm{P}=\sum F X$

Onde X representa o conjunto de coordenadas (posições ou inclinações) independentes que um determinado ponto nodal pode ocupar. A energia potencial das forças externas pode ainda levar em consideração a capacidade de realizar trabalho de momentos fletores aplicados em pontos nodais $(M \theta)$.

O funcional de energia potencial total fica expresso por:

$\Pi=\frac{E}{2} \int_{V}\left(\varepsilon^{2}-2 \varepsilon \varepsilon_{p}\right) d V-\sum F X$

Para se determinar o termo que deve ser integrado na expressão da energia de deformação é necessário entender a geometria do corpo a ser estudado e a relação desta geometria geral com a medida de deformação escolhida, no caso utilizou-se uma medida de deformação chamada de linear pela literatura corrente, e que nesta tese será denominada de deformação não linear de Engenharia. Esta medida de deformação pode ser exemplificada como a leitura de um extensômetro fixado na estrutura, que acompanha as rotações ocorridas durante a mudança de configuração. Conforme CRISFIELD (1991), utilizar esta medida de deformações não significa necessariamente trabalhar em regime de pequenas deformações. Pode-se considerar grandes 
deformações, desde que uma medida de deformações objetiva ${ }^{2}$ possa ser calibrada para o modelo de material considerado. Deve-se ainda observar como fica o termo da energia potencial das forças externas para o corpo a ser analisado. A figura 2 fornece a geometria geral de uma curva no plano (elemento de estrutura reticulada).

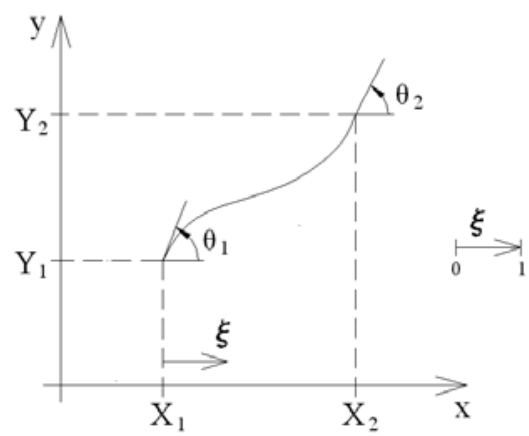

Figura 2 - Curva no espaço bidimensional

Esta curva genérica apresentada na figura 2 é parametrizada, com sua geometria descrita em função da variável adimensional $\xi$ (que varia de zero a um). Deve-se observar que para o caso plano é possível escrever uma relação linear entre $\xi$ e o eixo $X$, e uma relação cúbica entre $\xi$ o eixo $Y$. Deve-se tomar um cuidado adicional (a ser discutido mais adiante) para casos onde a curva deixaria de ser uma função $y$ de $x$.

$x=X_{1}+l_{x} \xi$

$x=X_{1}+\left(X_{2}-X_{1}\right) \xi$

$x=X_{1}(1-\xi)+X_{2} \xi$

$l_{x}=\left(X_{2}-X_{1}\right)$

$l_{y}=\left(Y_{2}-Y_{1}\right)$

$y=c \xi^{3}+d \xi^{2}+e \xi+f$

Deve-se descobrir quais são os parâmetros $c, d, e$ e $f$ da equação (10) de forma a parametrizar $y$ em função dos valores nodais exatos, ou seja: $X_{1}, Y_{1}, X_{2}, Y_{2}, \theta_{1}$ e $\theta_{2}$. Os dois últimos parâmetros não serão obtidos diretamente, pois a expressão ficará escrita em função de $\operatorname{tg}\left(\theta_{1}\right)$ e $\operatorname{tg}\left(\theta_{2}\right)$.

Considerando-se as condições de contorno apresentadas na figura 2, tem-se:

$y_{(\xi=0)}=f=Y_{1}$

\footnotetext{
${ }^{2}$ A medida objetiva de deformação não depende das rotações de corpo rígido.
} 
$\frac{d y}{d \xi} \mid=3 c \xi^{2}+2 d \xi+e$

$\left.\frac{d y}{d \xi}\right|_{\xi=0}=e=\left.\frac{d y}{d x} \frac{d x}{d \xi}\right|_{\xi=0}=\operatorname{tg}\left(\theta_{1}\right) l_{x}$

$\left.\frac{d y}{d \xi}\right|_{\xi=1}=3 c+2 d+\operatorname{tg}\left(\theta_{1}\right) l_{x}=\left.\frac{d y}{d x} \frac{d x}{d \xi}\right|_{\xi=1}=\operatorname{tg}\left(\theta_{2}\right) l_{x}$

$3 c+2 d=\left[\operatorname{tg}\left(\theta_{2}\right)-\operatorname{tg}\left(\theta_{1}\right)\right] l_{x}$

$y_{(\xi=1)}=c+d+\operatorname{tg}\left(\theta_{1}\right) l_{x}+Y_{1}=Y_{2}$

$c+d=l_{y}-\operatorname{tg}\left(\theta_{1}\right) l_{x}$

Considerando-se as equações (15) e (17), tem-se:

$c=\left[\operatorname{tg}\left(\theta_{2}\right)+\operatorname{tg}\left(\theta_{1}\right)\right] l_{x}-2 l_{y}$

$d=3 l_{y}-\left[\operatorname{tg}\left(\theta_{2}\right)+2 \operatorname{tg}\left(\theta_{1}\right)\right] l_{x}$

Conforme o já comentado, será utilizada medida de deformações não linear (de Engenharia) definida em OGDEN (1984).

$\varepsilon=\frac{d s-d s_{0}}{d s_{0}}$

Onde $d s$ representa o comprimento de uma fibra qualquer do corpo (paralela ao eixo médio) em uma posição qualquer e $d s_{0}$ representa o seu comprimento na configuração de referência. Neste caso vamos considerar a configuração de referência como sendo a de um elemento de barra inicialmente reto, ou seja:

$$
\begin{aligned}
& x^{0}=X_{1}^{0}+l_{x}^{0} \xi \\
& y^{0}=Y_{1}^{0}+l_{y}^{0} \xi
\end{aligned}
$$

Para a linha média, passando pelo centro de gravidade do elemento (CG), na configuração inicial tem-se:

$$
\frac{d s_{0}}{d \xi}=\sqrt{\left(\frac{d x^{0}}{d \xi}\right)^{2}+\left(\frac{d y^{0}}{d \xi}\right)^{2}}=\sqrt{\left(l_{x}^{0}\right)^{2}+\left(l_{y}^{0}\right)^{2}}=l_{0}
$$

Ou:

$$
d s_{0}=l_{0} d \xi
$$

Da mesma forma, na configuração final tem-se:

$$
\frac{d s}{d \xi}=\sqrt{\left(\frac{d x}{d \xi}\right)^{2}+\left(\frac{d y}{d \xi}\right)^{2}}=\sqrt{\left(l_{x}\right)^{2}+\left(3 c \xi^{2}+2 d \xi+e\right)^{2}}
$$


Ou:

$d s=\sqrt{\left(l_{x}\right)^{2}+\left(3 c \xi^{2}+2 d \xi+e\right)^{2}} d \xi$

Aplicando-se a medida de deformação dada na equação (20), tem-se a deformação na linha média do elemento.

$\varepsilon^{\text {médio }}=\frac{1}{l_{0}} \sqrt{\left(l_{x}\right)^{2}+\left(3 c \xi^{2}+2 d \xi+e\right)^{2}}-1$

Seguindo-se a coordenada curvilínea $s$ é possível definir uma coordenada ortogonal chamada de $z$, segundo a qual pode-se descrever a deformação no elemento finito, de acordo com a cinemática de Euler/Bernoulli; proporcional à diferença de curvatura entre a configuração final e inicial. Lembrando-se que para a configuração inicial a curvatura é nula tem-se:

$\varepsilon=\varepsilon^{\text {médio }}+\frac{1}{r} z$

A medida exata da curvatura para a configuração deslocada é dada por:

$\frac{1}{r}=\frac{\frac{d x}{d \xi} \frac{d^{2} y}{d \xi^{2}}-\frac{d^{2} x}{d \xi^{2}} \frac{d y}{d \xi}}{\left(\sqrt{\left(\frac{d x}{d \xi}\right)^{2}+\left(\frac{d y}{d \xi}\right)^{2}}\right)^{3}}$

Substituindo-se as expressões (5) a (10) na equação (29), tem-se:

$\frac{1}{r}=\frac{l_{x}(6 c \xi+2 d)}{\left(\sqrt{l_{x}^{2}+\left(3 c \xi^{2}+2 d \xi+e\right)^{2}}\right)^{3}}$

As expressões obtidas acima podem ser descritas de forma mais complexa. As posições dos pontos utilizados na análise do meio contínuo, no caso o elemento de estrutura reticulada, são descritas em função de um mapeamento no espaço auxiliar adimensional, apresentado na figura 3. Todas operações são feitas com base neste sistema auxiliar e descritas em relação à configuração inicial, tornando a descrição da formulação Lagrangiana. 


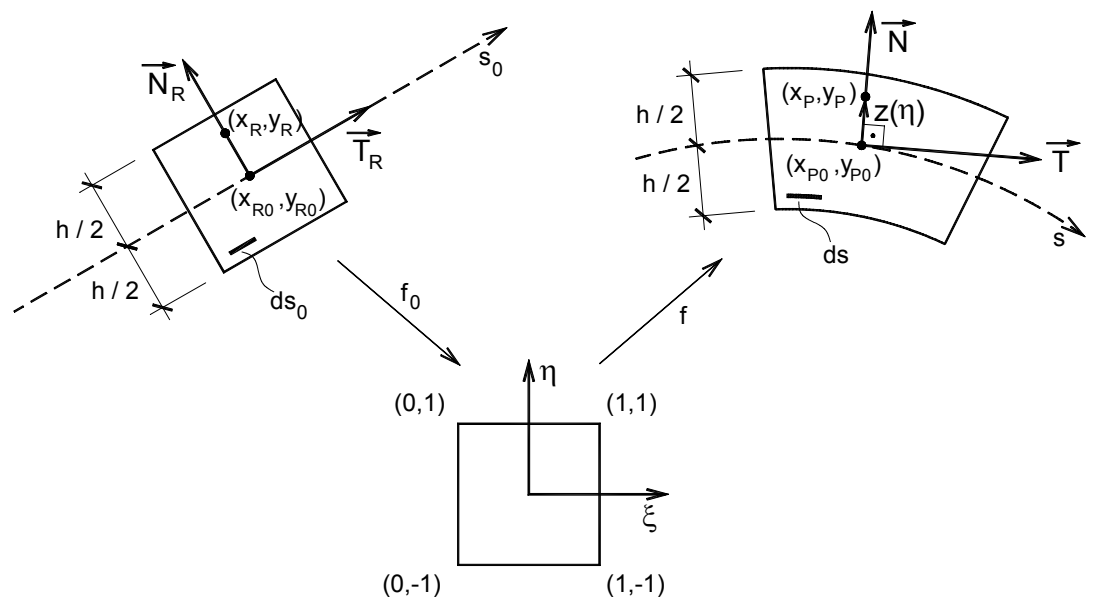

Figura 3 - Mapeamento da deformação utilizando o espaço auxiliar adimensional

O mapeamento mostrado na figura 3 representa a mudança de configuração da estrutura a partir da configuração de referência, à esquerda da figura, até a posição deformada final, à direita da figura, medida com auxilio do espaço auxiliar adimensional.

Na figura 3, $P$ representa um ponto qualquer no meio contínuo e $P_{0}$ um ponto na linha média do elemento. Considerando-se a cinemática de Euler-Bernoulli ${ }^{3}$ para vigas na tese, tem-se:

$$
\begin{aligned}
& X_{p}=X_{p 0}(\xi)-z(\eta) \frac{d Y_{P 0}}{d \xi} \frac{1}{\sqrt{\left(\frac{d Y_{P 0}}{d \xi}\right)^{2}+\left(\frac{d X_{P 0}}{d \xi}\right)^{2}}} \\
& Y_{p}=Y_{p 0}(\xi)+z(\eta) \frac{d X_{P 0}}{d \xi} \frac{1}{\sqrt{\left(\frac{d Y_{P 0}}{d \xi}\right)^{2}+\left(\frac{d X_{P 0}}{d \xi}\right)^{2}}}
\end{aligned}
$$

A partir das equações (31) e (32) encontra-se a expressão (28), via equação (20).

Substituindo-se a equação (28) na equação da energia de deformação total, equação (2), tem-se:

$$
U_{t}=\frac{E}{2} \int_{V} \varepsilon^{2} d V-E \int_{V} \varepsilon \varepsilon_{p} d V=\frac{E}{2} \int_{V}\left(\varepsilon^{m e ́ d i o}+\frac{1}{r} z\right)^{2} d V-E \int_{V} \varepsilon \varepsilon_{p} d V
$$

Considerando-se a hipótese dos elementos serem constituídos de materiais homogêneos e isótropos, têm-se as seguintes integrações nas áreas das seções:

\footnotetext{
${ }^{3}$ Após as deformações, as seções permanecem planas e ortogonais à linha média da viga.
} 


$$
\begin{aligned}
& \int_{A} d A=A \\
& \int_{A} z d A=0 \\
& \int_{A} z^{2} d A=I
\end{aligned}
$$

Substituindo-se o conjunto de equações (34) na equação (31), tem-se:

$U_{t}=\int_{0}^{1} l_{0}\left\{\left[\frac{E A}{2}\left(\varepsilon^{\text {médio }}\right)^{2}+\frac{E I}{2}\left(\frac{1}{r}\right)^{2}\right]-E \int_{A} \varepsilon \varepsilon_{p} d A\right\} d \xi=\int_{0}^{1} l_{0} u_{t} d \xi$

As integrações apresentadas na equação (35) no comprimento dos elementos (função de $\xi$ ) e na área dos elementos (função de $A$ ) são feitas numericamente, tendo em vista que $\varepsilon_{p}$ é variável no problema não linear físico. Buscando-se uma representação da plastificação mais refinada, foi adotada uma malha de 10 pontos de Gauss no comprimento e 10 pontos de Gauss na altura da seção; considerou-se no equacionamento seção retangular.

Deve-se derivar o funcional de energia potencial total em relação aos parâmetros nodais adotados e igualar esta derivada à zero. Para tanto é conveniente reorganizar o problema na seguinte forma:

$\Pi=l_{0} \int_{0}^{1} u_{t} d \xi-F_{X 1} X_{1}-F_{Y 1} Y_{1}-M_{1} \theta_{1}-F_{X 2} X_{2}-F_{Y 2} Y_{2}-M_{2} \theta_{2}$

Como não há nenhuma singularidade na integral devida à energia de deformação pode-se escrever o divergente do funcional de energia em função dos parâmetros nodais.

$$
\begin{aligned}
& \frac{\partial \Pi}{\partial X_{1}}=l_{0} \int_{0}^{1} \frac{\partial u_{t}}{\partial X_{1}} d \xi-F_{X 1}=0 \\
& \frac{\partial \Pi}{\partial Y_{1}}=l_{0} \int_{0}^{1} \frac{\partial u_{t}}{\partial Y_{1}} d \xi-F_{Y 1}=0 \\
& \frac{\partial \Pi}{\partial \theta_{1}}=l_{0} \int_{0}^{l} \frac{\partial u_{t}}{\partial \theta_{1}} d \xi-M_{1}=0 \\
& \frac{\partial \Pi}{\partial X_{2}}=l_{0} \int_{0}^{1} \frac{\partial u_{t}}{\partial X_{2}} d \xi-F_{X 2}=0 \\
& \frac{\partial \Pi}{\partial Y_{2}}=l_{0} \int_{0}^{1} \frac{\partial u_{t}}{\partial Y_{2}} d \xi-F_{Y 2}=0 \\
& \frac{\partial \Pi}{\partial \theta_{2}}=l_{0} \int_{0}^{1} \frac{\partial u_{t}}{\partial \theta_{2}} d \xi-M_{2}=0
\end{aligned}
$$


A estratégia a ser adotada é desenvolver as derivadas presentes no interior do integrando e depois integrar o resultado numericamente de zero a um. Como se pode notar o resultado de tal integral (numérica) não é linear em relação aos parâmetros nodais. Portanto, deve-se escrever o sistema de equações acima na seguinte forma genérica:

$$
\begin{aligned}
& g_{1}\left(X_{1}, Y_{1}, \theta_{1}, X_{2}, Y_{2}, \theta_{2}\right)=f_{1}\left(X_{1}, Y_{1}, \theta_{1}, X_{2}, Y_{2}, \theta_{2}\right)-F_{X 1}=0 \\
& g_{2}\left(X_{1}, Y_{1}, \theta_{1}, X_{2}, Y_{2}, \theta_{2}\right)=f_{2}\left(X_{1}, Y_{1}, \theta_{1}, X_{2}, Y_{2}, \theta_{2}\right)-F_{Y 1}=0 \\
& g_{3}\left(X_{1}, Y_{1}, \theta_{1}, X_{2}, Y_{2}, \theta_{2}\right)=f_{3}\left(X_{1}, Y_{1}, \theta_{1}, X_{2}, Y_{2}, \theta_{2}\right)-M_{1}=0 \\
& g_{4}\left(X_{1}, Y_{1}, \theta_{1}, X_{2}, Y_{2}, \theta_{2}\right)=f_{4}\left(X_{1}, Y_{1}, \theta_{1}, X_{2}, Y_{2}, \theta_{2}\right)-F_{X 2}=0 \\
& g_{5}\left(X_{1}, Y_{1}, \theta_{1}, X_{2}, Y_{2}, \theta_{2}\right)=f_{5}\left(X_{1}, Y_{1}, \theta_{1}, X_{2}, Y_{2}, \theta_{2}\right)-F_{Y 2}=0 \\
& g_{6}\left(X_{1}, Y_{1}, \theta_{1}, X_{2}, Y_{2}, \theta_{2}\right)=f_{6}\left(X_{1}, Y_{1}, \theta_{1}, X_{2}, Y_{2}, \theta_{2}\right)-M_{2}=0
\end{aligned}
$$

Pode-se escrever o conjunto de equações (43) a (48) em notação indicial:

$g_{i}\left(X_{j}, F_{i}\right)=f_{i}\left(X_{j}\right)-F_{i}=0$

Considera-se $\left(X_{1}, Y_{1}, \theta_{1}, X_{2}, Y_{2}, \theta_{2}\right)=(1,2,3,4,5,6)$.

A equação (49) pode ainda ser representada vetorialmente:

$g(X, F)=f-F=0$

As forças externas poderiam ser função da posição, porém aqui as consideraremos independentes da posição. Sendo a função vetorial $g$ não linear em função dos parâmetros de problema, a solução do sistema não-linear expresso em (50) se faz através do método de Newton-Raphson, ou seja:

$$
g(X)=0=g\left(X^{0}\right)+\nabla g\left(X^{0}\right) \Delta X
$$

Ou ainda:

$$
\Delta X=-\left[\nabla g\left(X^{0}\right)\right]^{-1} g\left(X^{0}\right)
$$

A equação (51) é resolvida de acordo com o apresentado no apêndice 2.

A matriz Hessiana $\nabla g\left(X^{0}\right)$ é simétrica e pode ser calculada com base no conjunto de equações (36) a (49).

$$
\nabla g\left(X^{0}\right)=g_{i, k}\left(X^{0}\right)=f_{i, k}\left(X^{0}\right)-F_{i, \ell}
$$

Onde $i=1,6 ; k=1,6$ para os deslocamentos paramétricos e $\ell=7,12$ para as forças externas. Assim obtém-se uma expressão compacta para equação (53).

$$
\nabla g\left(X^{0}\right)=\left.l_{0} \int_{0}^{1} u_{t, i k} d \xi\right|_{X^{0}}-\delta_{i \ell}
$$


Para resolver a equação (52) também é necessário se calcular as forças nodais no início do intervalo em que ocorrem as iterações. É pertinente comentar que o algoritmo desenvolvido não é necessariamente incremental, o valor das forças externas $F_{i}$ é o total acumulado até o intervalo de análise. Através de intervalos de carga é possível acompanhar a evolução da estrutura, mas a consideração de incrementos não é obrigatória, a menos que a posição final esteja muito distante da inicial.

$g\left(X^{0}\right)=\left.l_{0} \int_{0}^{1} u_{t, i} d \xi\right|_{X^{0}}-F_{i}$

Para todos os exemplos numéricos desta tese considerou-se tolerância $(T O L)$ igual a $10^{-8}$, com critério de tolerância $\sqrt{\sum_{i=1}^{\text {coord }} g^{2}\left(X^{0}\right)} \leq T O L$. Com base na equação (55), observa-se que o termo $g\left(X^{0}\right)$ corresponde ao resíduo absoluto da análise.

O processo iterativo fica resumido em:

1) Assume-se inicialmente que $X^{0}$ é a configuração indeslocada. Calcula-se $g\left(X^{0}\right)$ tal como apresentado na expressão (55).

2) Para esse mesmo $X^{0}$ calcula-se a matriz hessiana (ou gradiente do vetor $g$ ) da energia de deformação por unidade de comprimento $\left(\left.u_{t, i k}\right|_{X^{0}}\right)$. Integra-se este como indicado na equação (54) e tem-se o gradiente do vetor $g$ em $X^{0}$.

3) Resolve-se o sistema de equações determinando-se $\Delta X$.

4) Atualiza-se a posição $X^{0}=X^{0}+\Delta X$. Retorna-se ao passo 1 até que $\Delta X$ seja muito pequeno.

Dividir a carga total em pequenos acréscimos cumulativos serve para começar o processo em uma posição mais próxima do equilíbrio final, assim o processo pode ser escrito como:

a) $X^{0}$ posição inicial

b) $X^{0}=X^{0}+\Delta f$ onde $\Delta f$ é um acréscimo de carga ou deslocamento prescrito

c) $\{1,2, \ldots, n\}$ iterações

d) Retorna ao item b

\subsection{Passos algébricos necessários para implementação da formulação}

Para poder executar todo este processo é necessária a determinação explicita das expressões $u_{t, i}$ e $u_{t, i k}$. 
Considerando-se as equações (27), (30) e (35), tem-se:

$l_{0} u_{t}=T\left(\frac{\sqrt{B}}{l_{0}}-1\right)^{2}+F G B^{-3}-l_{0} E \int_{A}\left[\left(\frac{\sqrt{B}}{l_{0}}-1\right)+\sqrt{G} B^{\frac{-3}{2}} z\right] \varepsilon_{p} d A$

Onde:

$$
\begin{aligned}
& T=\frac{E A l_{0}}{2} \\
& F=\frac{E I l_{0}}{2} \\
& B=\left(l_{x}\right)^{2}+S(\xi) \\
& G=\left(l_{x}\right)^{2} N(\xi) \\
& S(\xi)=s^{2}(\xi) \\
& s(\xi)=3 c \xi^{2}+2 d \xi+e \\
& N(\xi)=n^{2}(\xi) \\
& n(\xi)=6 c \xi+2 d
\end{aligned}
$$

A primeira derivada da equação (56) em relação ao parâmetro nodal $i$ fica expressa por:

$$
\begin{aligned}
& l_{0} u_{t, i}=\frac{T}{l_{0}^{2}}\left(1-\frac{l_{0}}{\sqrt{B}}\right) B,_{i}+\frac{F B G,_{i}-3 F B,_{i} G}{B^{4}}-l_{0} E \int_{A} \varepsilon_{,_{i}} \varepsilon_{p} d A \\
& \varepsilon_{,_{i}}=\frac{B,_{i}}{2 l_{0} \sqrt{B}}+\left(\frac{G,_{i}}{2 \sqrt{G}(\sqrt{B})^{3}}-\frac{3 \sqrt{G} B,_{i}}{2(\sqrt{B})^{5}}\right) z
\end{aligned}
$$

De maneira análoga, a derivada da equação (65) em relação ao parâmetro nodal $k$ fica expressa por:

$$
\begin{aligned}
l_{0} u_{t, i k}= & \frac{T}{l_{0}^{2}}\left[\frac{l_{0} B,_{i} B,_{k}}{2(\sqrt{B})^{3}}+\left(1-\frac{l_{0}}{\sqrt{B}}\right) B,_{i k}\right]+ \\
& \frac{F}{B^{5}}\left[G,_{i k} B^{2}-3 B\left(G,_{i} B,_{,}+G,_{k} B,_{i}+G B,,_{i k}\right)+12 G B,_{i} B,_{k}\right]-l_{0} E \int_{A} \varepsilon_{,_{i k}} \varepsilon_{p} d A \\
\varepsilon_{,_{i k}}= & \frac{1}{2 l_{0}}\left(\frac{B,_{i k}}{\sqrt{B}}-\frac{B,_{i} B,_{k}}{2(\sqrt{B})^{3}}\right)+\left[\frac{1}{2 \sqrt{G}}\left(\frac{G,_{i k}}{(\sqrt{B})^{3}}-\frac{3 G,_{i} B,_{k}}{2(\sqrt{B})^{5}}\right)-\frac{G,_{i} G,_{k}}{4(\sqrt{G})^{3}(\sqrt{B})^{3}}-\right. \\
& \left.\frac{3 B,,_{i} G,_{k}}{4 \sqrt{G}(\sqrt{B})^{5}}-\frac{3 \sqrt{G}}{2}\left(\frac{B,_{i k}}{(\sqrt{B})^{5}}-\frac{5 B,_{i} B,_{k}}{2(\sqrt{B})^{7}}\right)\right] z
\end{aligned}
$$


Os termos envolvendo $\varepsilon_{p}$ devem ser calculados apenas quando houver plastificação em algum ponto dos elementos. Deve-se tomar cuidado especial nas equações (66) e (68) quando existir algum elemento na posição horizontal, com $Y_{1}=Y_{2}$ (segundo a figura 2), que sofra plastificação. Nesta situação específica $\sqrt{G}=0$. Uma maneira de contornar este problema é somar um número muito pequeno a $G$, como $10^{-8}$, evitando-se assim singularidades e introduzindo-se um erro desprezível nos resultados.

Deve-se agora calcular os valores de $B,_{i} B,_{k} B,_{i k} G,_{i} G,_{k} G,_{i k}$. Para simplificar os cálculos deve-se observar que de acordo com as equações (8) e (9), tem-se:

$\frac{\partial}{\partial X_{1}}=-\frac{\partial}{\partial l_{x}} ; \frac{\partial}{\partial X_{2}}=\frac{\partial}{\partial l_{x}} ; \frac{\partial}{\partial Y_{1}}=-\frac{\partial}{\partial l_{y}} ; \frac{\partial}{\partial Y_{2}}=\frac{\partial}{\partial l_{y}}$

Considera-se também a seguinte notação:

$$
\begin{aligned}
& \frac{\partial^{2} N}{\partial l_{x} \partial l_{y}}=D 2 N L X L Y ; \frac{\partial^{2} N}{\partial l_{x} \partial \Theta_{l}}=D 2 N L X T 1 \\
& G_{,_{i}}=G i ; G,_{i k}=G i k
\end{aligned}
$$

Assim:

Tabela 1 - Primeiras derivadas segundo parâmetros nodais

\begin{tabular}{|c|c|}
\hline$B 1=-(2 L X+D S L X)$ & $G 1=-\left(2 L X N+(L X)^{2} D N L X\right)$ \\
\hline$B 2=-D S L Y$ & $G 2=-(L X)^{2} D N L Y$ \\
\hline$B 3=D S T 1$ & $G 3=(L X)^{2} D N T 1$ \\
\hline$B 4=2 L X+D S L X$ & $G 4=2 L X N+(L X)^{2} D N L X$ \\
\hline$B 5=D S L Y$ & $G 5=(L X)^{2} D N L Y$ \\
\hline$B 6=D S T 2$ & $G 6=(L X)^{2} D N T 2$ \\
\hline
\end{tabular}

As segundas derivadas são simétricas, portanto apresenta-se apenas a parte superior.

Tabela 2 - Segundas derivadas segundo parâmetros nodais

\begin{tabular}{|c|c|}
\hline$B 11=2+D 2 S L X L X$ & $G 11=2 N+4 L X D N L X+(L X)^{2} D 2 N L X L X$ \\
\hline$B 12=D 2 S L X L Y$ & $G 12=2 L X D N L Y+(L X)^{2} D 2 N L X L Y$ \\
\hline$B 13=-D 2 S L X T 1$ & $G 13=-\left(2 L X D N T 1+(L X)^{2} D 2 N L X T 1\right)$ \\
\hline$B 14=-B 11$ & $G 14=-G 11$ \\
\hline
\end{tabular}




\begin{tabular}{|c|c|}
\hline$B 15=-B 12$ & $G 15=-G 12$ \\
\hline$B 16=-D 2 S L X T 2$ & $G 16=-\left(2 L X D N T 2+(L X)^{2} D 2 N L X T 2\right)$ \\
\hline$B 22=D 2 S L Y L Y$ & $G 22=(L X)^{2} D 2 N L Y L Y$ \\
\hline$B 23=-D 2 S L Y T 1$ & $G 23=-(L X)^{2} D 2 N L Y T 1$ \\
\hline$B 24=-B 21$ & $G 24=-G 21$ \\
\hline$B 25=-B 22$ & $G 25=-G 22$ \\
\hline$B 26=-D 2 S L Y T 2$ & $G 26=-(L X)^{2} D 2 N L Y T 2$ \\
\hline$B 33=D 2 S T 1 T 1$ & $G 33=(L X)^{2} D 2 N T 1 T 1$ \\
\hline$B 34=-B 31$ & $G 34=-G 31$ \\
\hline$B 35=-B 32$ & $G 35=-G 32$ \\
\hline$B 36=D 2 S T 1 T 2$ & $G 36=(L X)^{2} D 2 N T 1 T 2$ \\
\hline$B 44=-B 41$ & $G 44=G 11$ \\
\hline$B 45=-B 42$ & $G 45=-G 42$ \\
\hline$B 46=D 2 S L X T 2=-B 16$ & $G 46=-G 16$ \\
\hline$B 55=B 22$ & $G 55=G 22$ \\
\hline$B 56=D 2 S L Y T 2=-B 26$ & $G 56=(L X)^{2} D 2 N L Y T 2=-G 26$ \\
\hline$B 66=D 2 S T 2 T 2$ & $G 66=(L X)^{2} D 2 N T 2 T 2$ \\
\hline
\end{tabular}

Ainda não se pode determinar numericamente os valores das tabelas um e dois, pois é necessário determinar as grandezas do tipo D2NLXLX, ainda não explicitadas.

Tabela 3 - Primeiras derivadas segundo parâmetros nodais para as funções $S$ e $N$

\begin{tabular}{|c|c|}
\hline$D S L X=2 s D s L X$ & $D N L X=2 n D n L X$ \\
\hline$D S L Y=2 s D s L Y$ & $D N L Y=2 n D n L Y$ \\
\hline$D S T 1=2 s D s T 1$ & $D N T 1=2 n D n T 1$ \\
\hline$D S L X=2 s D S T 2$ & $D N T 2=2 n D n T 2$ \\
\hline
\end{tabular}


Para facilitar a nomenclatura, daqui para frente considerar-se-á os índices $(1,2,3,4)$ no lugar de (LX,LY,T1,T2). Assim, a tabela 3 fica resumida nas seguintes expressões:

$D S(i)=2 s D s(i) ; D N(i)=2 n D n(i)$

Da mesma maneira, seguindo a relação de variáveis descrita acima, as segundas derivadas presentes na tabela 2 podem ser escritas como:

$D 2 S(i, j)=2 D s(i) D s(j)+2 s D s(i, j) ; D 2 N(i, j)=2 D n(i) D n(j)+2 n D n(i, j)$

Faltam serem determinadas as grandezas $D s(i), D s(i, j), D n(i)$ e $D n(i, j)$, que são calculadas a partir das expressões (62) e (64).

$$
\begin{aligned}
& \frac{\partial s(\xi)}{\partial v_{i}}=D s(i)=3 c,,_{i} \xi^{2}+2 d,,_{i} \xi+e,_{i} \\
& \frac{\partial n(\xi)}{\partial v_{i}}=D n(i)=6 c,_{i} \xi+2 d,_{i} \\
& \frac{\partial^{2} s(\xi)}{\partial v_{i} \partial v_{j}}=D 2 s(i, j)=3 c,_{i j} \xi^{2}+2 d,,_{i j} \xi+e,,_{i j} \\
& \frac{\partial^{2} n(\xi)}{\partial v_{i} \partial v_{j}}=D 2 n(i, j)=6 c,,_{i j} \xi+2 d,,_{i j}
\end{aligned}
$$

Onde $v_{i}$ representam as variáveis (LX,LY,T1,T2).

Para completar o procedimento deve-se derivar as constantes da aproximação em função dos parâmetros estabelecidos. Assim, chamando-se $c,{ }_{i}$ de $v c i ; c,{ }_{i j}$ de $d 2 c i j$ e fazendo o mesmo para as variáveis $d$ e $e$, tem-se a tabela 4 .

Tabela 4 - Primeiras derivadas das constantes do polinômio aproximador

\begin{tabular}{|c|c|c|}
\hline$v c 1=\tan g T 1+\tan g T 2$ & $v d 1=-(2 \tan g T 1+\tan g T 2)$ & $v e 1=\tan g T 1$ \\
\hline$v c 2=-2$ & $v d 2=3$ & $v e 2=0$ \\
\hline$v c 3=L X \sec ^{2} T 1$ & $v d 3=-2 L x \sec ^{2} T 1$ & $v e 3=L X \sec ^{2} T 1$ \\
\hline$v c 4=L X \sec ^{2} T 2$ & $v d 4=-L X \sec ^{2} T 2$ & $v e 4=0$ \\
\hline
\end{tabular}

Tabela 5 - Segundas derivadas das constantes do polinômio aproximador

\begin{tabular}{|c|c|c|}
\hline$d 2 c 11=0$ & $d 2 d 11=0$ & $d 2 e 11=0$ \\
\hline$d 2 c 12=0$ & $d 2 d 12=0$ & $d 2 e 12=0$ \\
\hline$d 2 c 13=\sec ^{2} T 1$ & $d 2 d 13=-2 \sec ^{2} T 1$ & $d 2 e 13=\sec ^{2} T 1$ \\
\hline
\end{tabular}




\begin{tabular}{|c|c|c|}
\hline$d 2 c 14=\sec ^{2} T 2$ & $d 2 d 14=-\sec ^{2} T 2$ & $d 2 e 14=0$ \\
\hline$d 2 c 21=0$ & $d 2 d 21=0$ & $d 2 e 21=0$ \\
\hline$d 2 c 22=0$ & $d 2 d 22=0$ & $d 2 e 22=0$ \\
\hline$d 2 c 23=0$ & $d 2 d 23=0$ & $d 2 e 23=0$ \\
\hline$d 2 c 24=0$ & $d 2 d 24=0$ & $d 2 e 24=0$ \\
\hline$d 2 c 31=\sec ^{2} T 1$ & $d 2 d 31=-2 \sec ^{2} T 1$ & $d 2 e 31=\sec ^{2} T 1$ \\
\hline$d 2 c 32=0$ & $d 2 d 32=0$ & $d 2 e 32=0$ \\
\hline$d 2 c 33=2 L x \sec ^{3} T 1 \operatorname{sen} T 1$ & $d 2 d 33=-4 L x \sec ^{3} T 1 \operatorname{sen} T 1$ & $d 2 e 33=2 L x \sec ^{3} T 1 \operatorname{sen} T 1$ \\
\hline$d 2 c 34=0$ & $d 2 d 34=0$ & $d 2 e 34=0$ \\
\hline$d 2 c 41=\sec ^{2} T 2$ & $d 2 d 41=-\sec ^{2} T 2$ & $d 2 e 41=0$ \\
\hline$d 2 c 42=0$ & $d 2 d 42=0$ & $d 2 e 42=0$ \\
\hline$d 2 c 43=0$ & $d 2 d 43=0$ & $d 2 e 43=0$ \\
\hline$d 2 c 44=2 L x \sec ^{3} T 2 \operatorname{sen} T 2$ & $d 2 d 44=-2 L x \sec ^{3} T 2 \operatorname{sen} T 2$ & $d 2 e 44=0$ \\
\hline
\end{tabular}

Agora é possível montar todos os termos necessários para se efetuar a programação, para dada posição $\left(X_{1}, Y_{1}, \theta_{1}, X_{2}, Y_{2}, \theta_{2}\right)$ e determinado ponto de Gauss, calculam-se:

a) Das equações (8), (9), (13), (18) e (19), as constantes: $c, d, e, l x$ e $l y$

b) Da tabela 4, as derivadas: $c,_{i}$

c) Da tabela 5, as segundas derivadas $c,_{i j}$

d) Das equações (61) a (64), as funções $s$ e $n$

e) Da tabela 3 e equação (73), as derivadas primeira e segundas derivadas: $s_{,_{i}}, n,_{i}, s_{, j}$ e $n_{, i j}$

f) Das tabelas 1 e 2 e equações (59) e (60), as funções e derivadas: $B, G, B,_{i}, G,_{i}, B,_{i j}$ e $G,_{i j}$

g) Finalmente tem-se $u_{t, i}$ e $u_{t, i j}$ para cada ponto de Gauss, pelas equações (65) a (68) 
h) Somam-se os resultados (ponderando-se pelos pesos de Gauss) no gradiente da energia de deformação de um elemento finito, monta-se o sistema global de equações (apêndices 1 e 2 ) e procede-se com o processo iterativo descrito anteriormente

\subsection{Comentário final sobre a formulação}

Deve-se observar que caso o elemento tenha valores $l x$ muito próximos de zero ou zero a matriz hessiana perderá a objetividade. Para resolver este problema cria-se o sistema de referência local $\bar{X}$, mostrado na figura abaixo, de forma a evitar $l x$ próximo de zero.

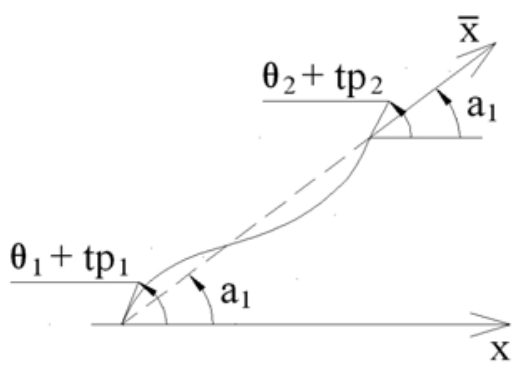

Figura 4 - Sistema de referência local para evitar singularidades

Tem-se assim:

$l_{x}=X_{2}-X_{1}$

$l_{y}=Y_{2}-Y_{1}$

$a_{1}=\operatorname{arctg}\left(\frac{l_{y}}{l_{x}}\right)$

$\bar{x}_{1 l}=\cos \left(a_{1}\right) X_{1}+\operatorname{sen}\left(a_{1}\right) Y_{1}$

$\bar{y}_{1 l}=-\operatorname{sen}\left(a_{1}\right) X_{1}+\cos \left(a_{1}\right) Y_{1}$

$\bar{x}_{2 l}=\cos \left(a_{1}\right) X_{2}+\operatorname{sen}\left(a_{1}\right) Y_{2}$

$\bar{y}_{2 l}=-\operatorname{sen}\left(a_{1}\right) X_{2}+\cos \left(a_{1}\right) Y_{2}$

$l_{\bar{x}}=\left(\bar{x}_{2 l}-\bar{x}_{1 l}\right)$

$l_{\bar{y}}=\left(\bar{y}_{2 l}-\bar{y}_{1 l}\right)$

$\overline{\theta_{1}}=\theta_{1}+t p_{1}-a_{1}$

$\bar{\theta}_{2}=\theta_{2}+t p_{2}-a_{1}$ 
Deve-se notar que $t p_{1}$ e $t p_{2}$ são iguais na presente formulação e representam a inclinação do elemento finito em sua configuração reta de referência. Quando $X_{1}=X_{2}$, não se utiliza a equação (80) para calcular o valor de $a_{l}$, toma-se diretamente o valor $a_{1}=\frac{\pi}{2}$

\subsection{Exemplos numéricos}

\subsubsection{Viga em balanço com carga transversal aplicada na extremidade livre}

A estrutura foi discretizada em 50 elementos finitos e foram utilizados 100 passos de carga de $100 \mathrm{~N}$. Na figura 5 são apresentados os dados do problema. Os resultados numéricos, figuras de números 6,7 e 8, obtidos com a formulação posicional são comparados com as soluções analíticas aproximadas do problema, que podem ser encontradas em MATTIASSON (1981) e FUJII (1983). Na figura 9 são apresentadas as configurações da viga para vários níveis de carregamento.

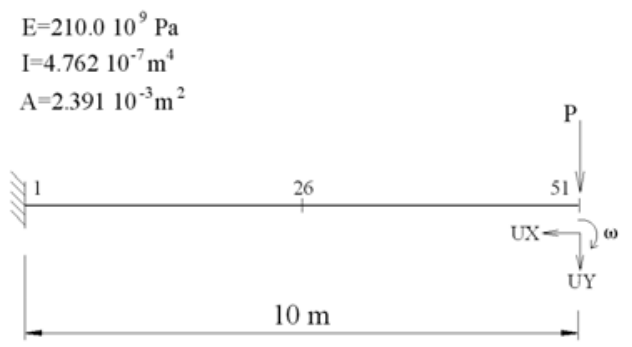

Figura 5 - Dados de entrada do problema

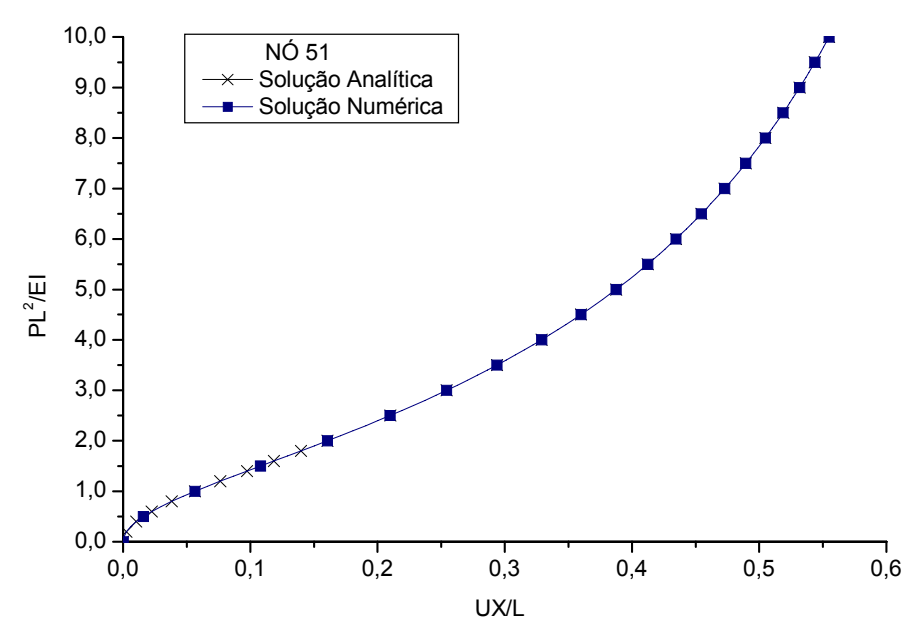

Figura 6 - Deslocamento horizontal adimensional $\times$ carga adimensional aplicada 


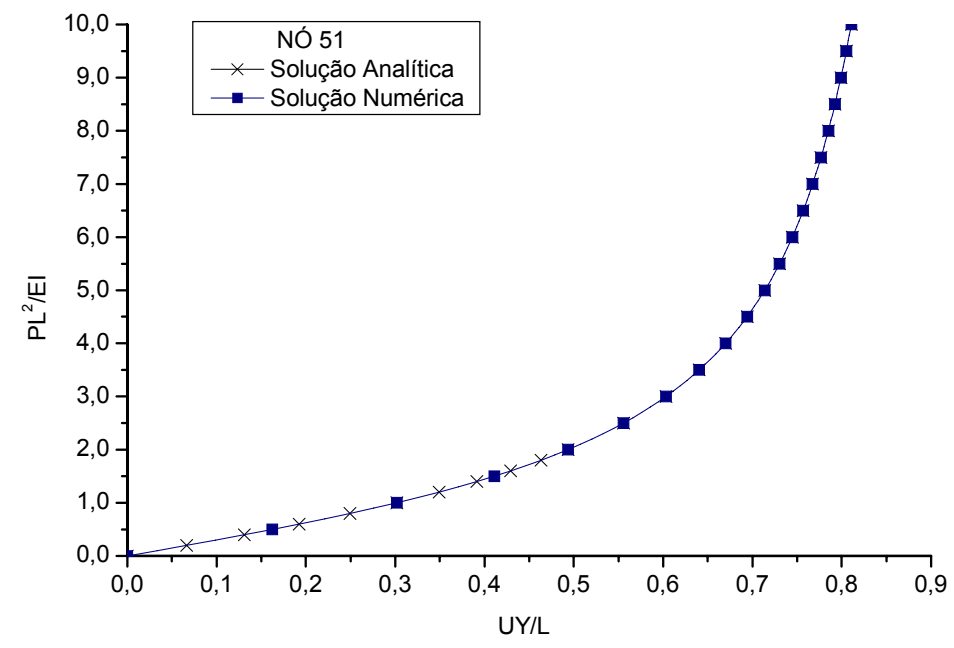

Figura 7 - Deslocamento vertical adimensional $\times$ carga adimensional aplicada

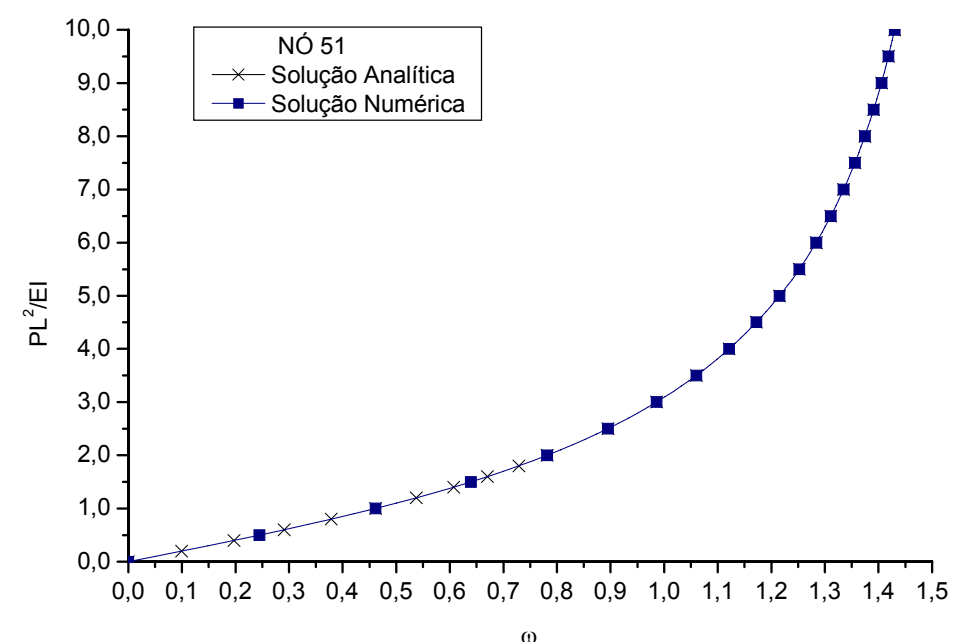

Figura 8 - Rotação $\times$ carga adimensional aplicada

Conforme pode ser observado nos gráficos anteriores, os resultados obtidos com a formulação posicional forneceram ótimos resultados para este exemplo. 


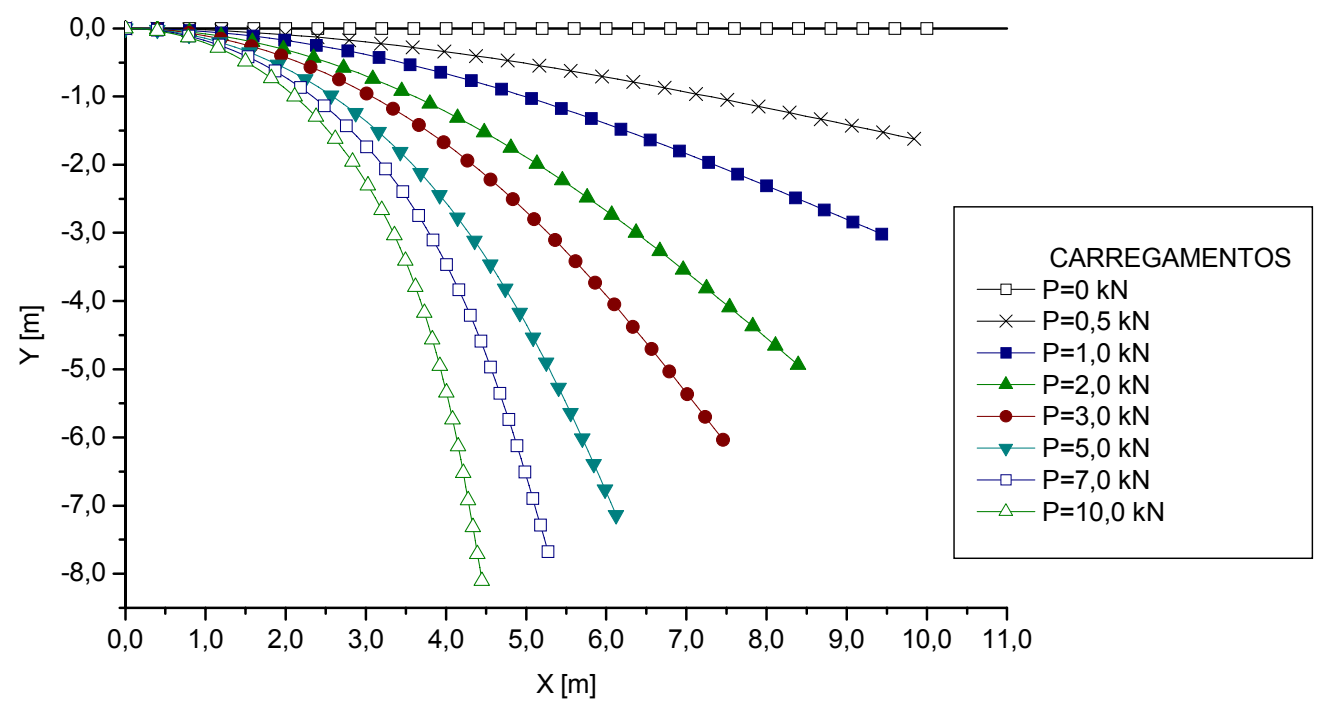

Figura 9 - Configurações da viga para determinados níveis de carregamento

\subsubsection{Viga em balanço com momento aplicado na extremidade livre}

A estrutura foi discretizada em 100 elementos finitos e foram utilizados 100 passos de carga de $502654.8 \mathrm{~kg} \cdot \mathrm{cm}$. Este problema pode ser encontrado em LAVALL (1996), FUJII (1983), SIMO et al. (1984), CHUCHKEEPSAKUL et al. (1995), PAI \& PALAZOTTO (1996) e SCHULZ \& FILIPPOU (2001). Na figura 10 são apresentados os dados do problema. Os resultados numéricos, figura 11, obtidos com a formulação posicional são comparados com a solução analítica do problema.

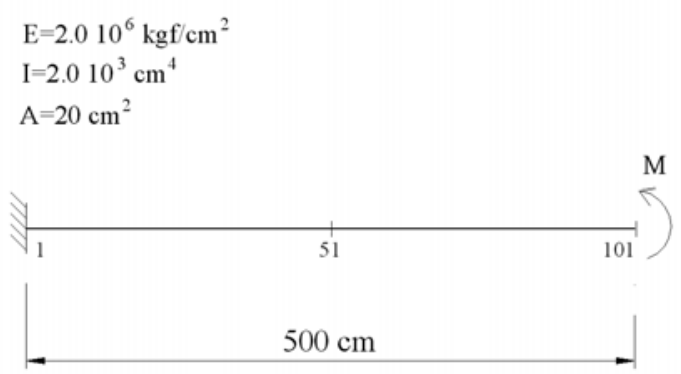

Figura 10 - Dados de entrada do problema 


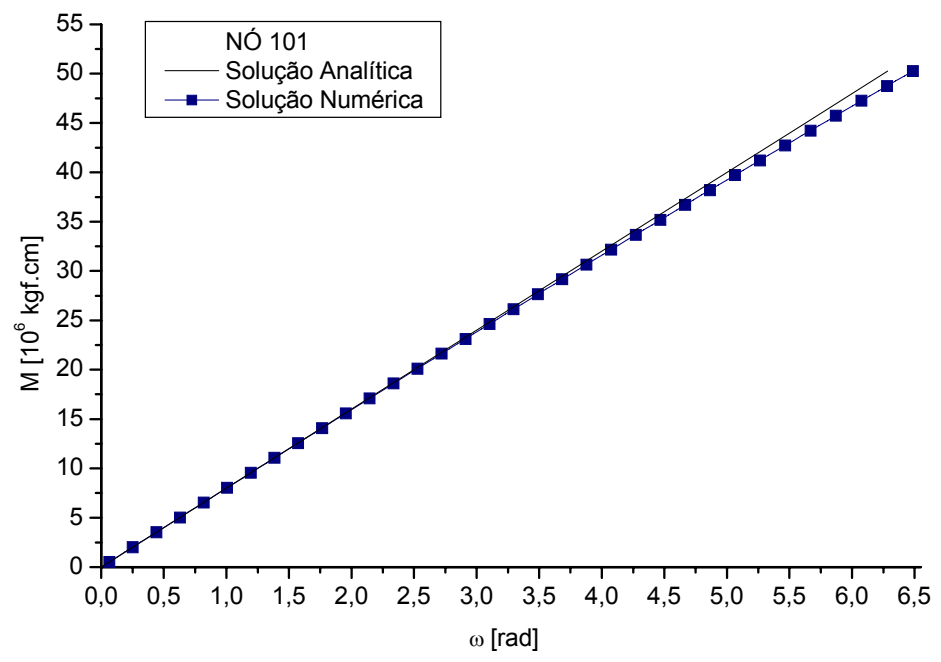

Figura 11 - Rotação $\times$ momento aplicado na extremidade livre da viga

Conforme pode ser observado na figura 11, os resultados obtidos com a formulação posicional forneceram bons resultados para este problema, com pequenas diferenças próximo ao nível de carregamento final. Esta divergência se deve ao fato da aproximação não ser capaz de representar exatamente uma circunferência, o que já era esperado. Melhores resultados podem ser obtidos aumentando-se a discretização. Na figura 12 são apresentadas as configurações da viga para vários níveis de carregamento.

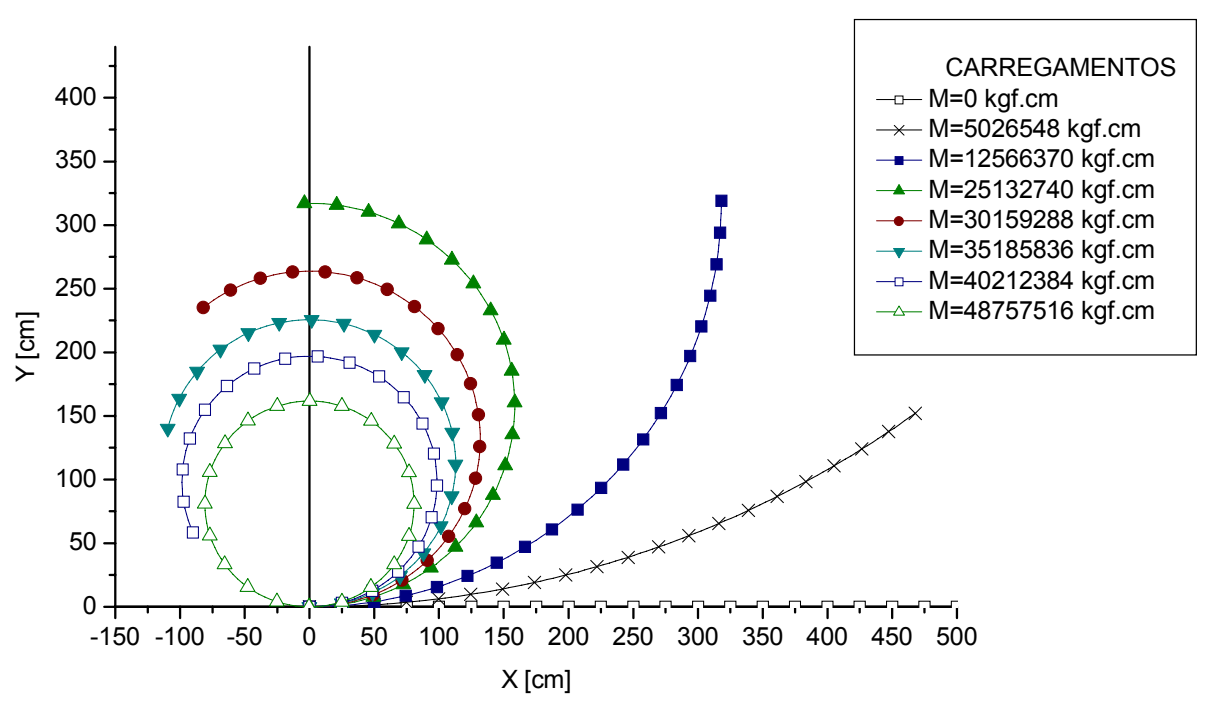

Figura 12 - Configurações da viga para determinados níveis de carregamento 


\subsubsection{Pilar com carga excêntrica}

A estrutura foi discretizada em 10 elementos finitos e foram utilizados 371 passos de carga de $100 \mathrm{kN}$. Na figura 13 são apresentados os dados do problema. São consideradas três situações de excentricidade $(0.1 \%, 1 \%$ e $10 \%$ da altura do pilar) e as respostas são apresentadas na figura 14, juntamente com a carga crítica de flambagem do problema (teoria de $1^{\mathrm{a}}$ ordem). Na figura 15 são apresentadas as configurações do pilar para vários níveis de carregamento. Este problema também é conhecido com linha elástica de Euler e pode ser encontrado nos artigos de FUJI, F. (1983) e SIMO et al. (1984). O eixo de referência $X$ coincide com o eixo vertical que passa pelo nó 1 .

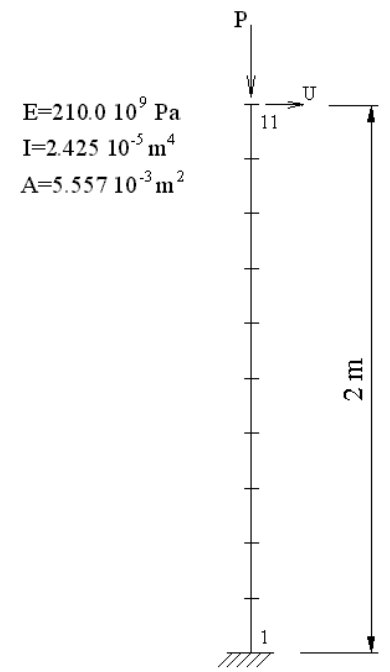

Figura 13 - Dados de entrada do problema

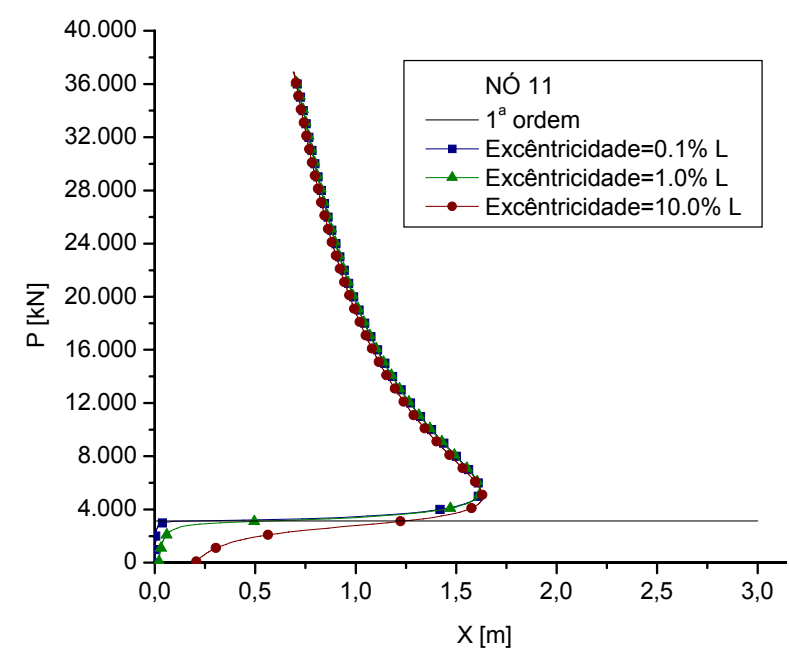

Figura 14 - Deslocamento horizontal $\times$ força aplicada na extremidade livre do pilar 
Observa-se na figura 14 que a formulação posicional permite uma análise de comportamento da estrutura após a carga crítica, quando o problema que antes era de pilar submetido à compressão passa a ser um problema de viga engastada e finalmente quase um problema de barra tracionada. Deve-se destacar a precisão obtida na resposta de excentricidade $0.1 \% L$ na proximidade da posição inicial, quando comparada à carga crítica obtida pela teoria de $1^{\text {a }}$ ordem. As mudanças de comportamento da estrutura e as três fases do problema podem ser observadas na figura 15 .

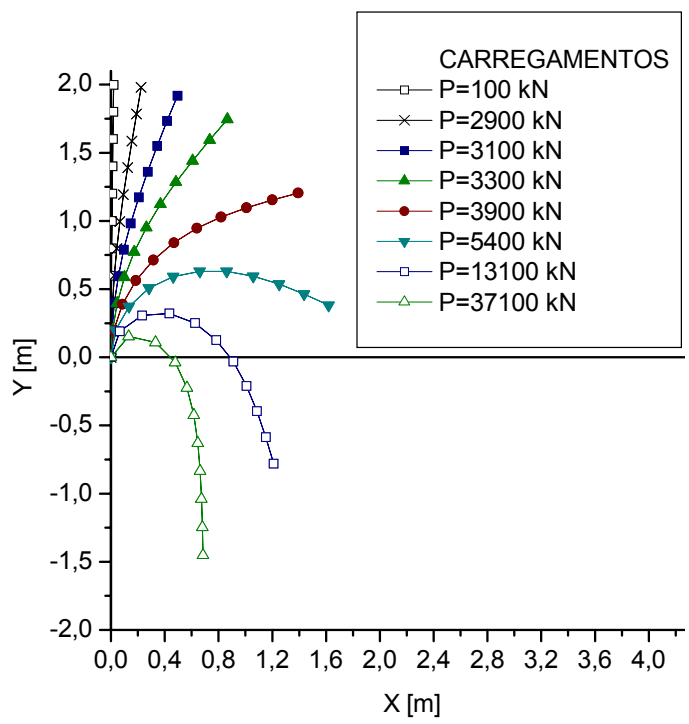

Figura 15 - Configurações do pilar para determinados níveis de carregamento (excentricidade=1\%)

\subsubsection{Viga elastoplástica bi-apoiada com carga no meio do vão}

O material da viga tem comportamento elastoplástico perfeito, com tensão de escoamento igual a $\sigma_{Y}=0.25 \mathrm{kN} / \mathrm{mm}^{2}$. Este problema pode ser encontrado em OWEN \& HINTON (1980). A estrutura foi discretizada em 10 elementos finitos e foram utilizados 95 passos de carga de $12.6 \mathrm{kN}$. Os resultados numéricos obtidos com a formulação posicional são comparados com as soluções de rótula plástica e do modelo não linear físico, baseado no MEF, apresentadas pela referência. 

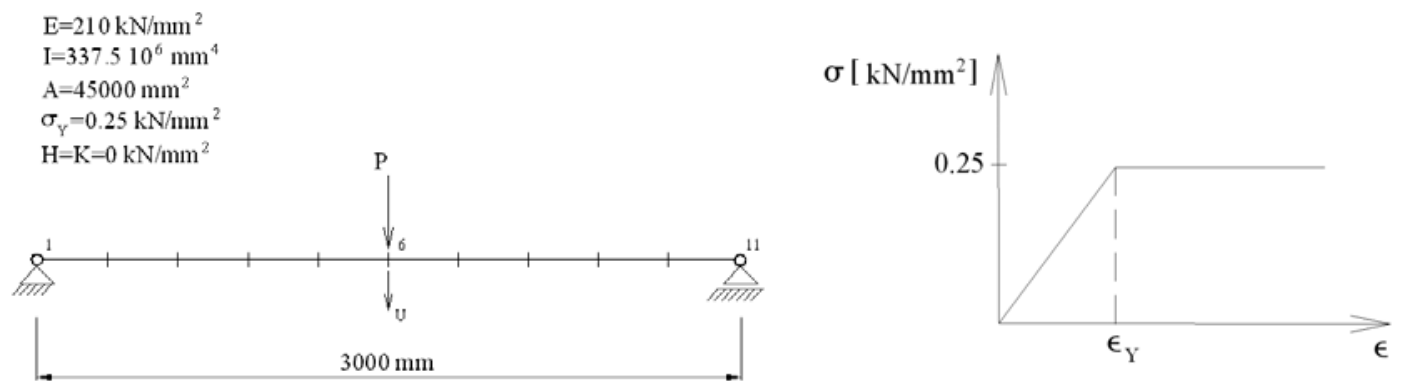

Figura 16 - Dados de entrada do problema

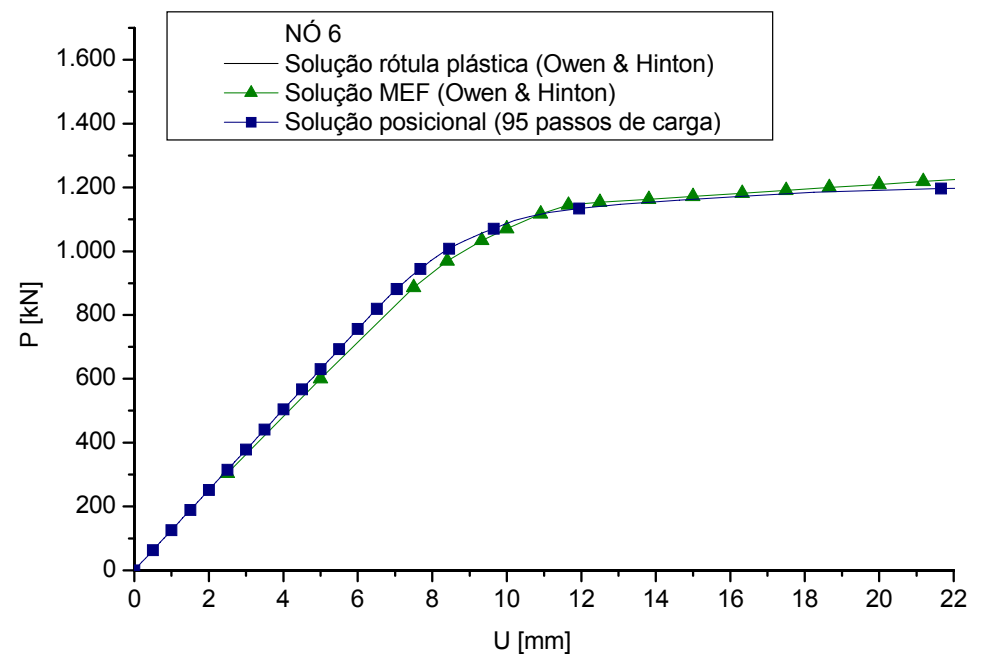

Figura 17 - Deslocamento transversal $\times$ força aplicada no meio do vão da viga

Conforme pode ser observado na figura 17, os resultados obtidos com a formulação posicional forneceram bons resultados para este problema, apresentando solução assintótica em relação à carga crítica de formação da rótula plástica. Vale destacar que o problema proposto na referência não leva em consideração efeitos da não linearidade geométrica, que neste caso não são muito relevantes.

\subsubsection{Viga elastoplástica em balanço com carga transversal aplicada na extremidade livre}

O material da viga tem comportamento elastoplástico, com modelo constitutivo apresentado na figura 18. Este problema pode ser encontrado em YANG \& SAIGAL (1984). A estrutura foi discretizada em 20 elementos finitos e foram utilizados 400 passos de carga de $5.0 \mathrm{lb}$. Os resultados numéricos, figura 19, obtidos com a formulação 
posicional são comparados com a solução apresentada na referência e com a solução não linear geométrica elástica. A primeira plastificação ocorre no quinto passo de carga.
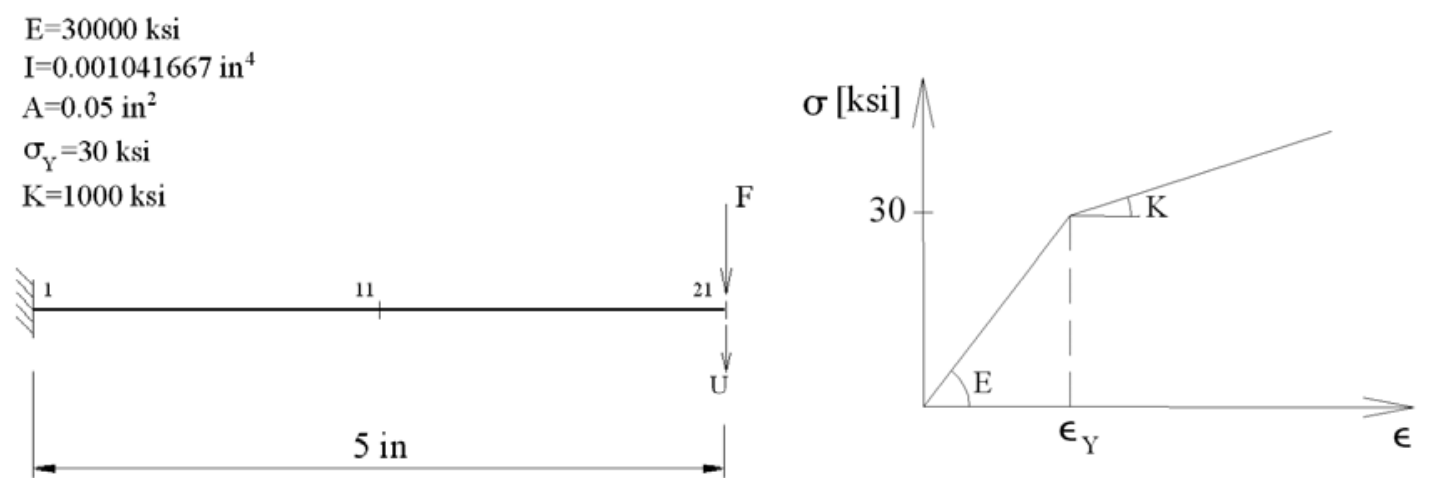

Figura 18 - Dados de entrada do problema

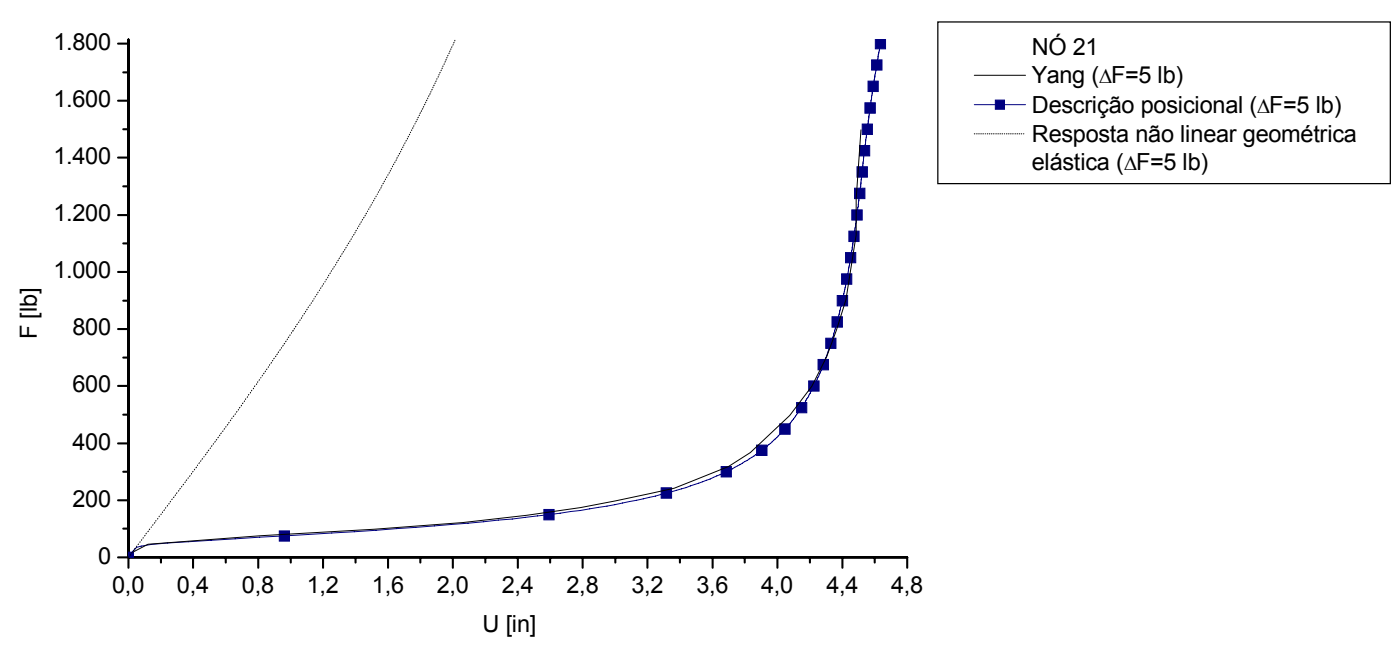

Figura 19 - Deslocamento transversal $\times$ força aplicada na extremidade livre da viga

Conforme pode ser observado na figura 19, os resultados obtidos com a formulação posicional forneceram bons resultados para este problema, com boa convergência com os resultados apresentados na referência. $\mathrm{Na}$ figura 20 são apresentadas as configurações da viga para vários níveis de carregamento. 


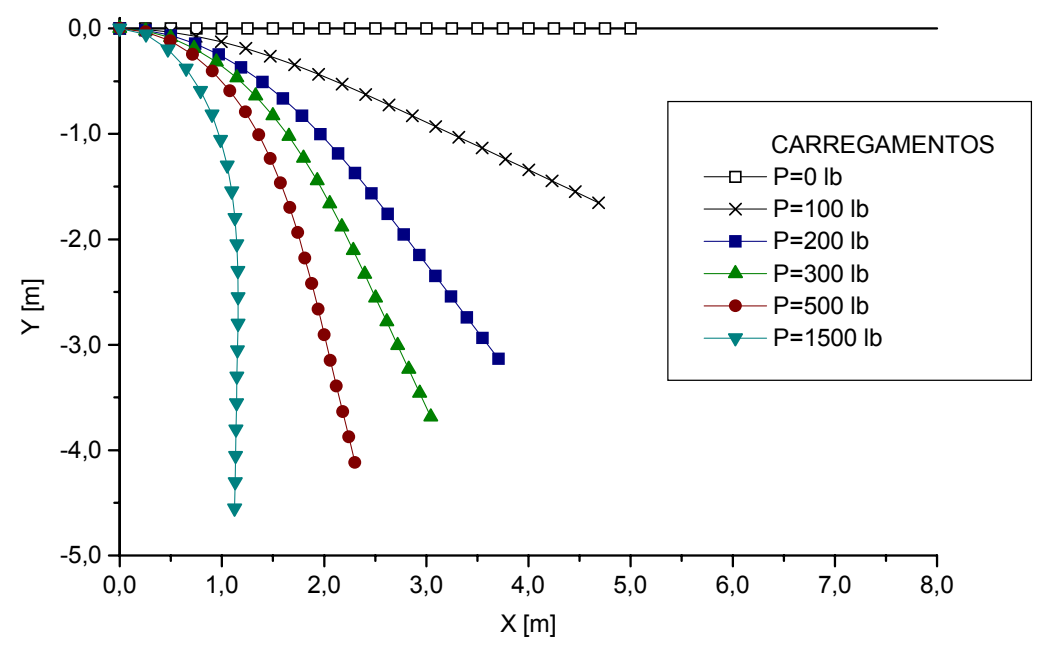

Figura 20 - Configurações da viga para determinados níveis de carregamento

\subsubsection{Quadro elástico articulado em forma de losango submetido a duas cargas aplicadas em sentidos opostos}

O quadro articulado deste exemplo, apresentado nos artigos de MATTIASSON (1981), FUJII (1983), SURANA (1983) e SAJE et al. (1998), é submetido à tração e compressão. Foram utilizados 10 elementos finitos para discretizar a estrutura, fazendose uso da dupla simetria do problema. Os dados do problema são apresentados na figura 21. Foram utilizados 100 passos de carga de 0.1 e os resultados numéricos obtidos com a formulação posicional são comparados com a solução analítica apresentada por MATTIASSON, figuras de números 22 a 24, que apresenta o problema em termos de variáveis adimensionais.
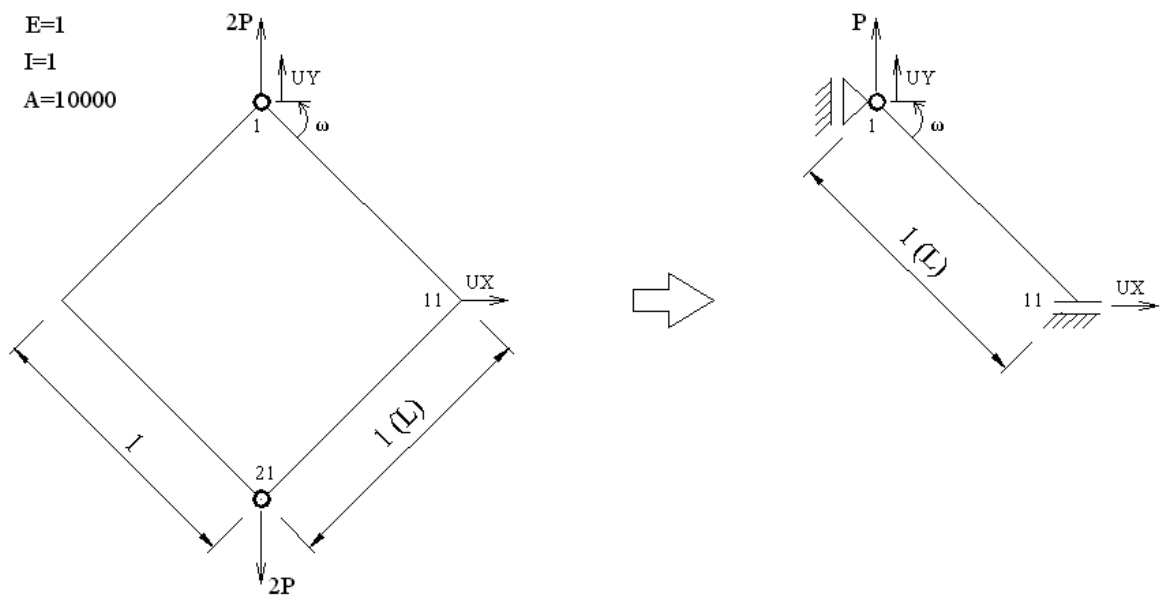

Figura 21 - Dados de entrada do problema 


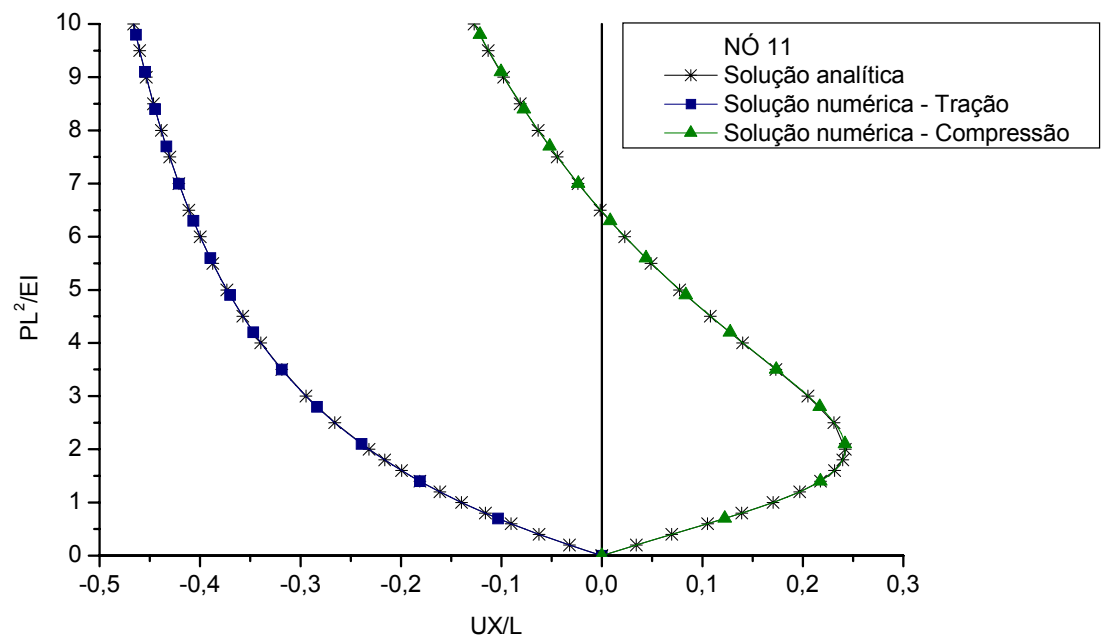

Figura 22 - Deslocamento horizontal adimensional $\times$ carga adimensional aplicada

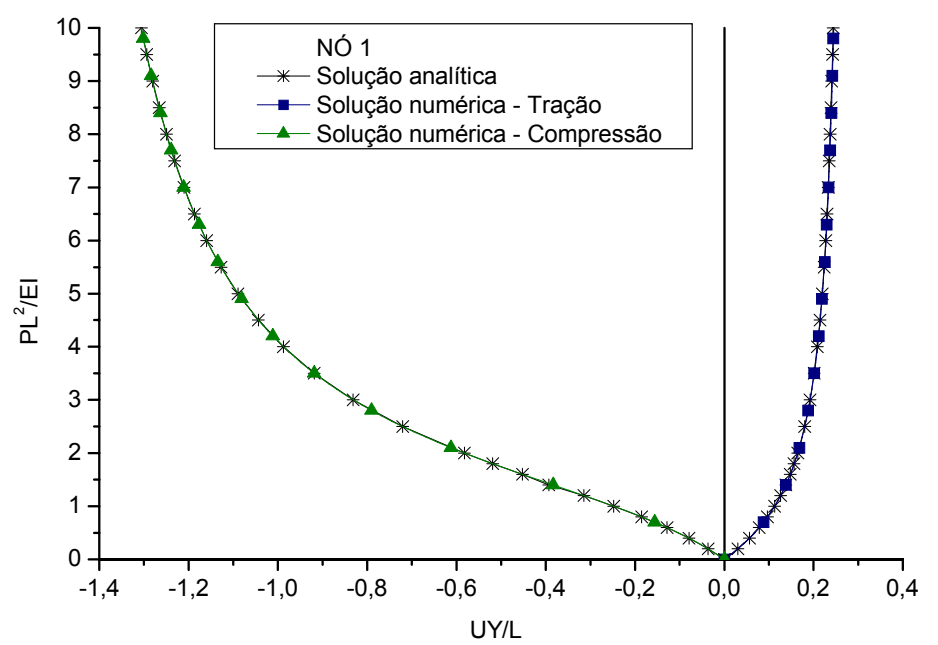

Figura 23 - Deslocamento vertical adimensional $\times$ carga adimensional aplicada

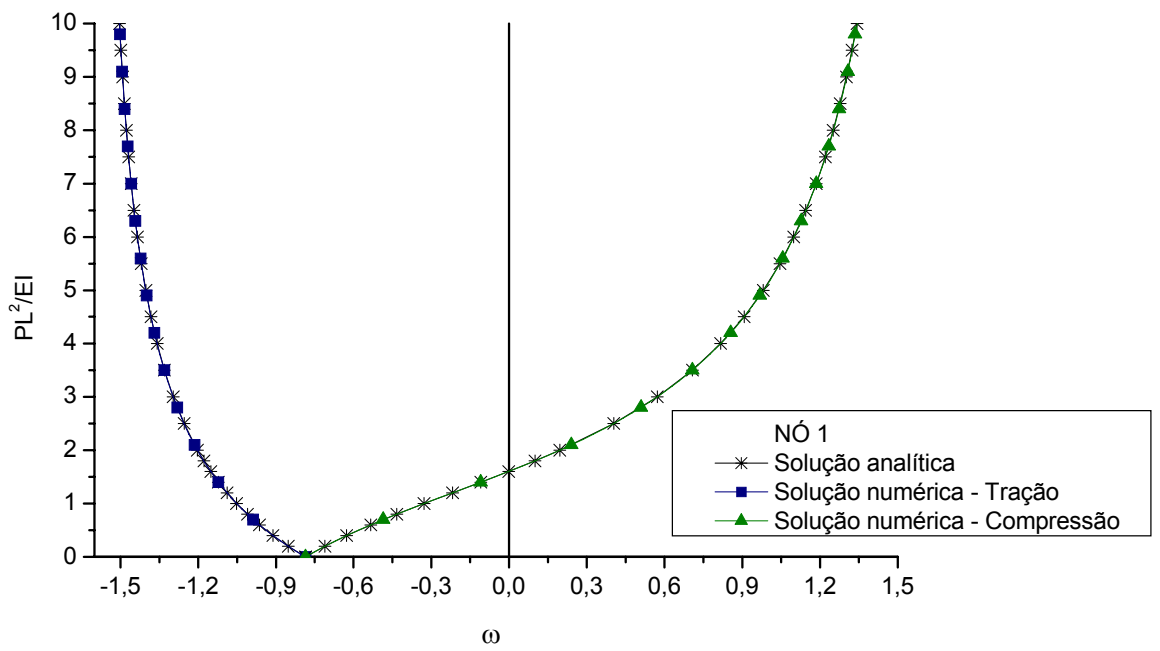

Figura 24 - Rotação $\times$ carga adimensional aplicada 
Conforme pode ser observado nas figuras anteriores, a formulação posicional forneceu ótimos resultados para este problema. Nas figuras 25 e 26 são apresentadas as configurações na estrutura para as situações de tração e compressão.

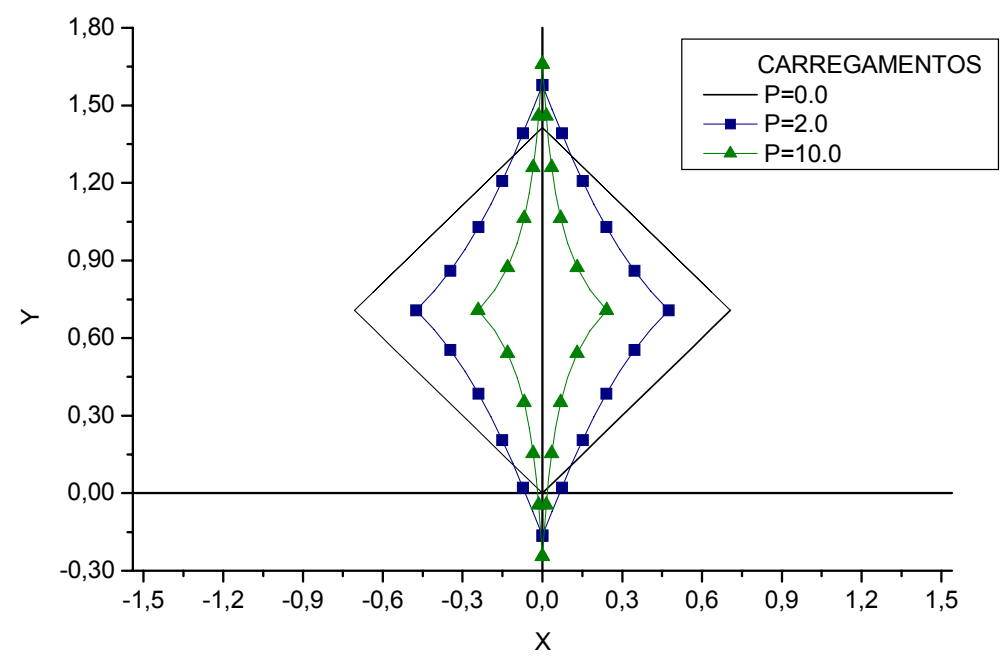

Figura 25 - Configurações na situação de tração para determinados níveis de carregamento

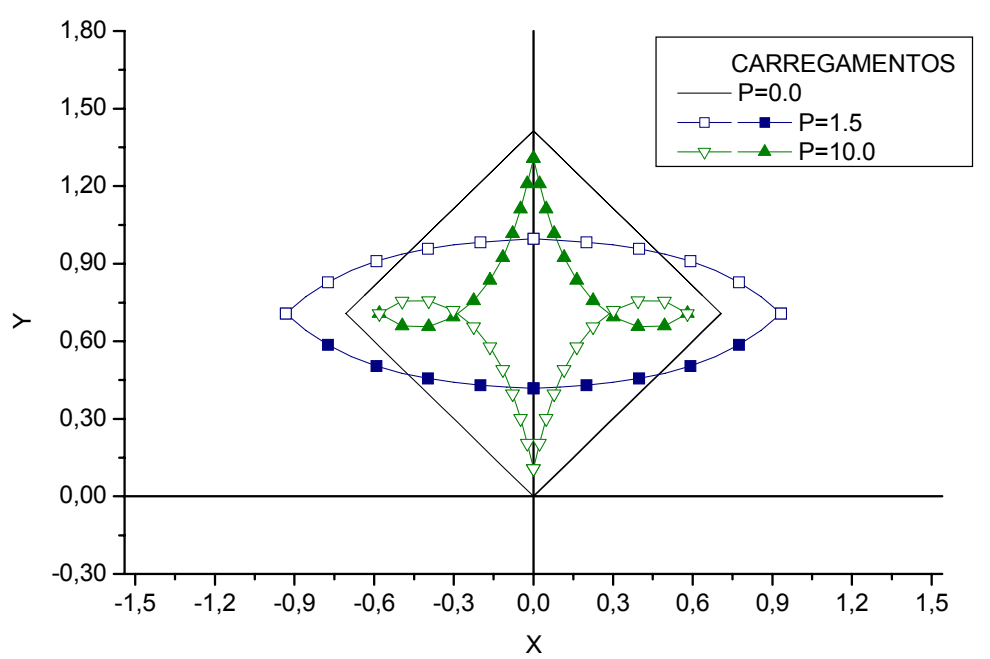

Figura 26 - Configurações na situação de compressão para determinados níveis de carregamento

\subsubsection{Quadro submetido a duas cargas aplicadas em sentidos opostos}

O quadro deste exemplo, apresentado nos artigos de MATTIASSON (1981) e FUJII (1983), é submetido à tração e compressão. Foram utilizados 20 elementos finitos para discretizar a estrutura, fazendo-se uso da dupla simetria do problema. Os dados do problema são apresentados na figura 27. Foram utilizados 100 passos de carga de 0.04 e os resultados numéricos obtidos com a formulação posicional são comparados com a 
solução analítica apresentada por MATTIASSON, figuras de números 28 a 30, que apresenta o problema em termos de variáveis adimensionais.
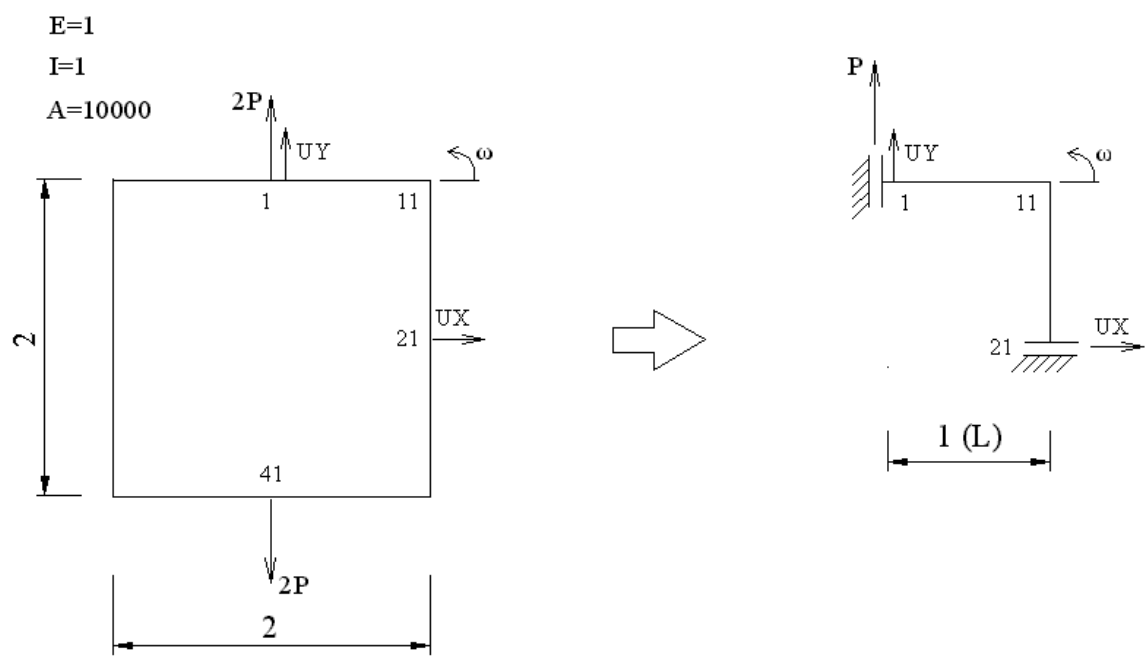

Figura 27 -Dados de entrada do problema

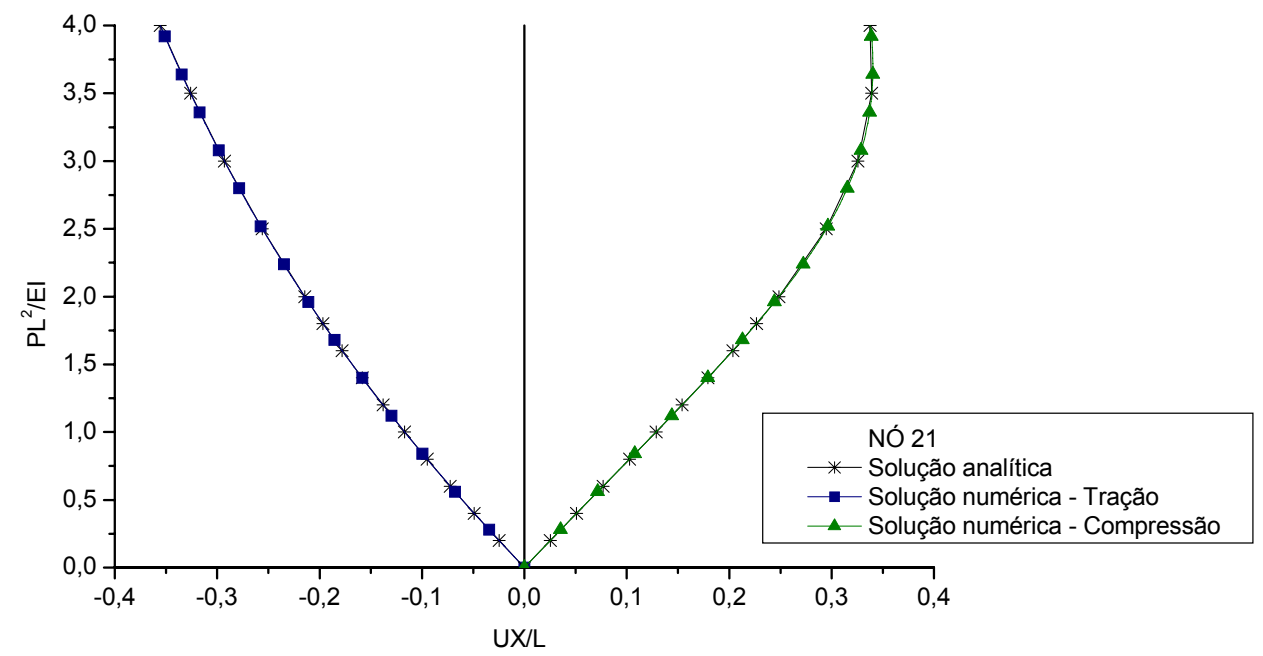

Figura 28 - Deslocamento horizontal adimensional $\times$ carga adimensional aplicada 


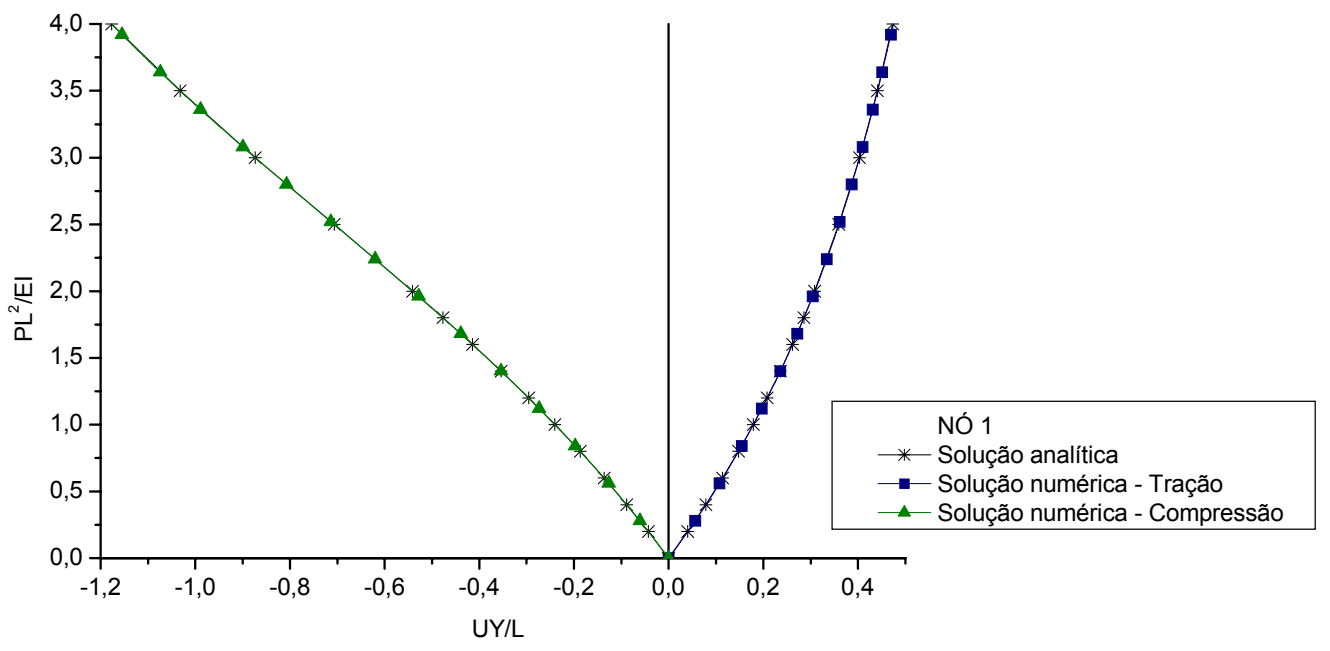

Figura 29 - Deslocamento horizontal adimensional $\times$ carga adimensional aplicada

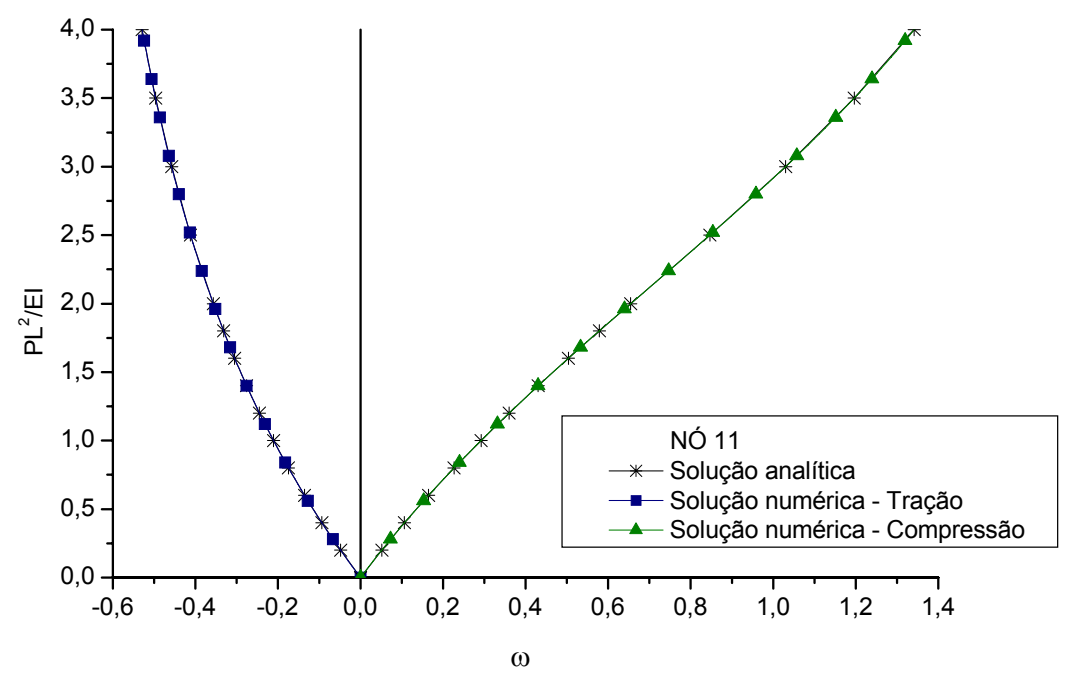

Figura 30 - Rotação $\times$ carga adimensional aplicada

Conforme pode ser observado nas figuras anteriores, a formulação posicional forneceu ótimos resultados para este problema. Nas figuras 31 e 32 são apresentadas as configurações na estrutura para as situações de tração e compressão. 


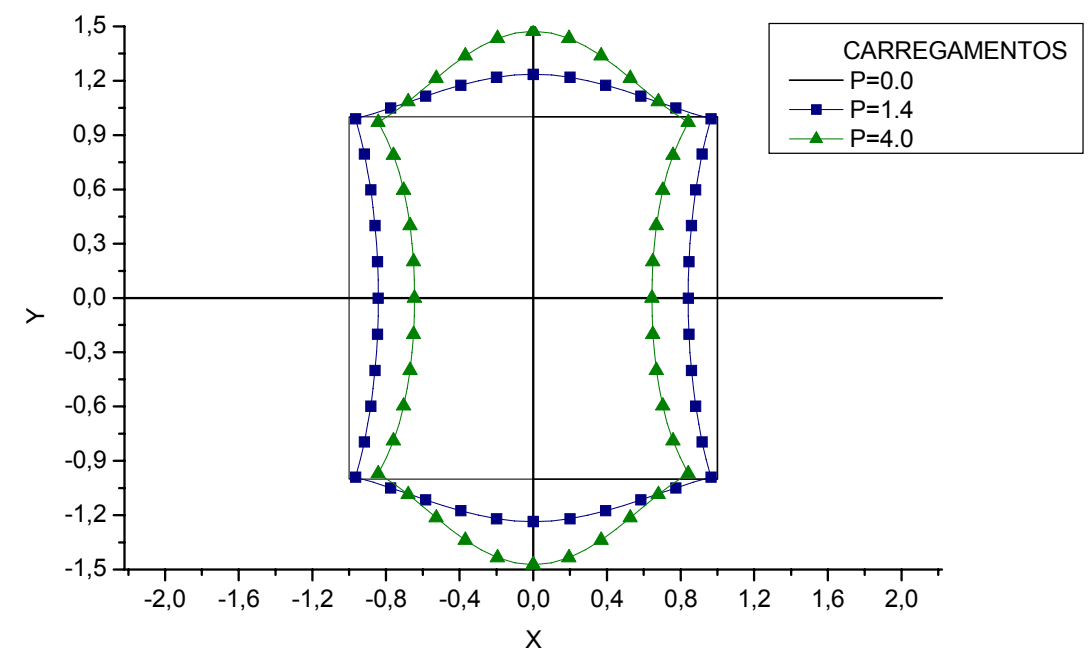

Figura 31 - Configurações na situação de tração para determinados níveis de carregamento

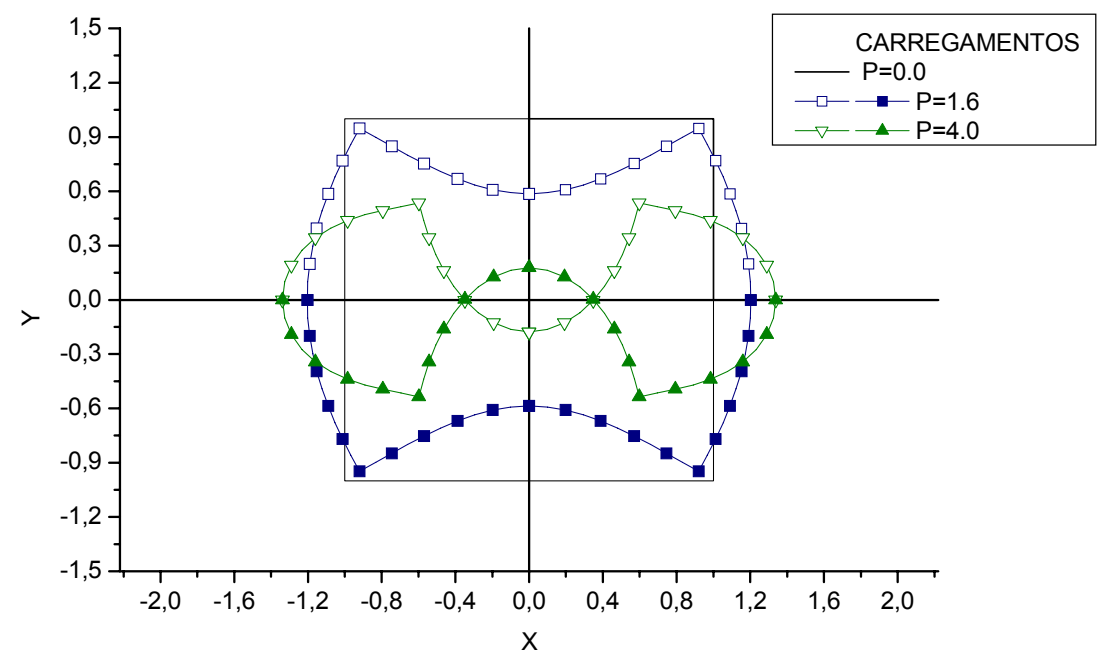

Figura 32 - Configurações na situação de compressão para determinados níveis de carregamento

\subsubsection{Contato entre estrutura anelar e anteparo rígido}

O último exemplo deste capítulo é apresentado no artigo de SIMO et al. (1986) e consiste de uma estrutura reticulada anelar comprimida contra um anteparo rígido. O contato estático será feito de maneira idêntica à proposta no artigo, ou seja, cada nó da estrutura que entrar em contato terá seu grau de liberdade vertical restrito. Foram utilizados 20 elementos finitos para discretizar a estrutura, fazendo-se uso da simetria do problema. Os dados do problema são apresentados na figura 33. Foram utilizados 100 passos de carga de 0.0445 . Na figura 34, os resultados numéricos obtidos com a formulação posicional são comparados com a solução numérica apresentada no artigo, que apresenta o problema em termos de variáveis adimensionais. 

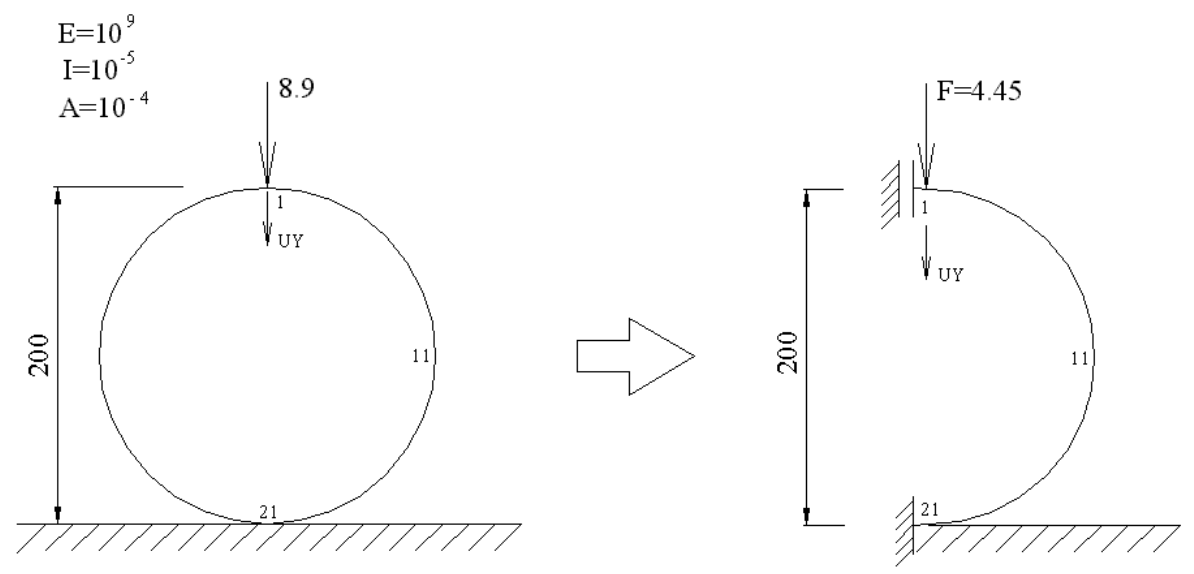

Figura 33 - Dados de entrada do problema

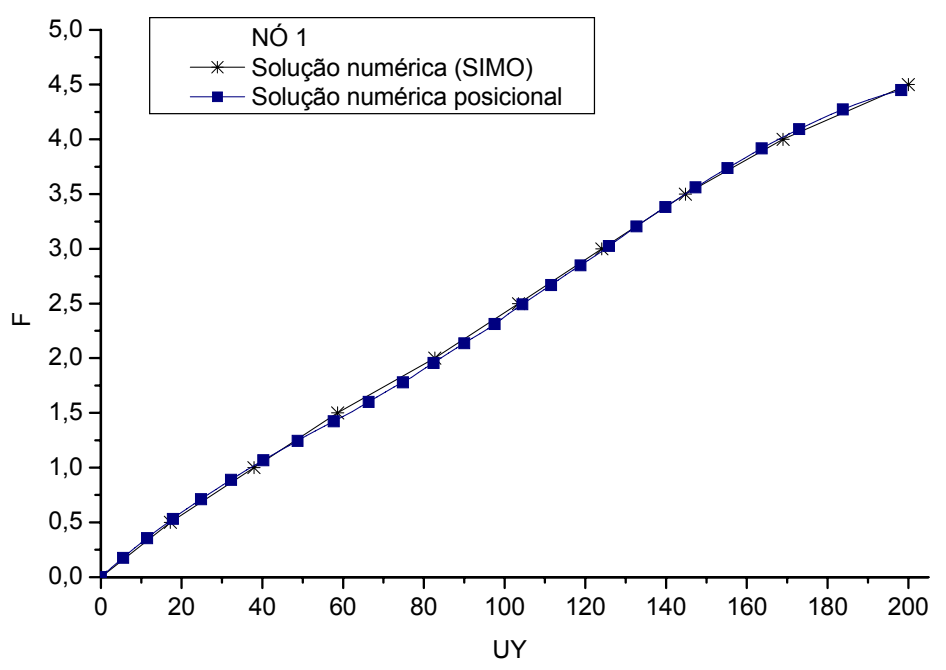

Figura 34 - Deslocamento vertical adimensional $\times$ carga adimensional aplicada

Conforme pode ser observado na figura 34, os resultados obtidos com a formulação posicional estão em boa concordância com os resultados apresentados na referência. Na figura 35 são apresentadas as configurações na estrutura para determinados níveis de carregamento. 


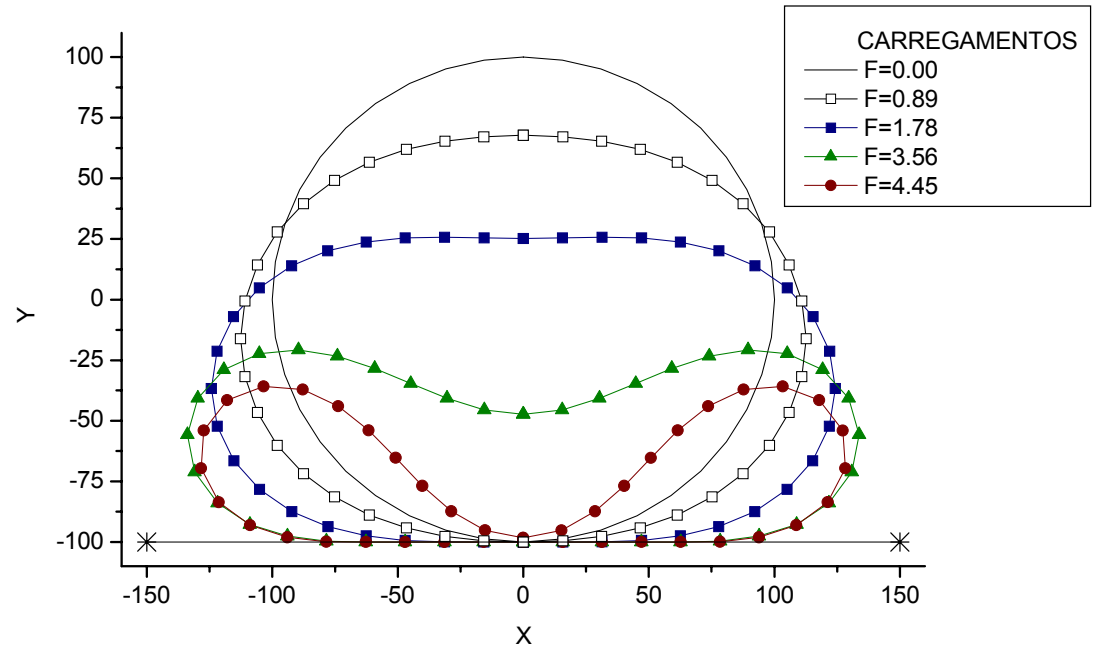

Figura 35 - Configurações anelares para determinados níveis de carregamento 


\section{FORMULAÇÃO NÃO LINEAR GEOMÉTRICA APLICADA A PROBLEMAS DINÂMICOS DE ESTRUTURAS RETICULADAS PLANAS}

\subsection{Considerações iniciais}

O desenvolvimento da formulação dinâmica é baseado na formulação não linear geométrica desenvolvida para problemas estáticos e baseada na descrição de posições, apresentada no capítulo anterior.

$\mathrm{Na}$ formulação dinâmica apresentada neste capítulo considera-se distribuição discreta de massa nas estruturas, amortecimento proporcional apenas à massa e o modelo de plastificação apresentado no apêndice 3 (combinação entre os encruamentos isótropo e cinemático). De acordo com OGDEN (1984), como a formulação proposta é Lagrangiana total, pode-se construir a matriz de massa consistente idêntica à utilizada em análises geometricamente lineares, graças ao princípio da conservação de massa, que também é utilizado neste trabalho.

A consideração do amortecimento viscoso se baseia no livro de LANCZOS (1986), que apresenta uma descrição bastante detalhada sobre a utilização do cálculo variacional em problemas envolvendo energia potencial total com dissipação de energia.

As ligações nodais generalizadas utilizadas nos problemas de multicorpos, como o caso das ligações rotuladas, são modeladas com base no acoplamento nodal apresentado no apêndice 4 .

\subsection{Equacionamento}

No caso do problema dinâmico, consideram-se as parcelas de energia cinética $\left(K_{c}\right)$ e perda de energia devido ao amortecimento $\left(K_{a}\right)$ no funcional de energia potencial total.

$\Pi=U_{t}-F X+K_{c}+K_{a}$ 


$$
\begin{aligned}
& K_{c}=\int_{V} \frac{\rho}{2} \dot{X}^{2} d V \\
& K_{a}=\int_{V} c_{m} \rho X \dot{X} d V-\int_{V} \int_{X_{k}} c_{m} \rho \frac{X \ddot{X}}{\dot{X}} d X_{k} d V
\end{aligned}
$$

O último termo da equação (3) representa a integração nas direções dos parâmetros nodais $\left(X_{k}\right)$. O termo $c_{m}$ representa o coeficiente de amortecimento. $\mathrm{O}$ termo $V$ representa o volume inicial do corpo analisado, segundo o referencial Lagrangiano.

É muito comum encontrar na literatura que o princípio da energia potencial total estacionária não se aplica a problemas dissipativos. Porém, de acordo com LANCZOS (1986), é possível considerar um termo de energia associado ao amortecimento viscoso. No caso da formulação desenvolvida, o termo $K_{a}$ mede a quantidade de energia dissipada no sistema mecânico, e quando somado ao potencial de energia total restitui o caráter estacionário do funcional resultante. Assim, a posição de equilíbrio dinâmico será dada pela minimização do funcional de energia total, dado pela equação (1).

Por simplicidade, considera-se a matriz de massa discreta, ou seja, diagonal e sem termos devido à rotação. Portanto, as equações (2) e (3) podem ser simplificadas.

$$
\begin{aligned}
& K_{c}=M \dot{X}^{2} \\
& K_{a}=C X \dot{X}-C \int_{X_{k}} \frac{X \ddot{X}}{\dot{X}} d X_{k}
\end{aligned}
$$$$
C=2 c_{m} M
$$

Nas equações (5) e (6), o termo $C$ representa a matriz de amortecimento proporcional à massa.

Para cada elemento finito com massa concentrada tem-se uma matriz associada. Por ser uma matriz diagonal, a matriz de massa local é igual à matriz de massa global (ver apêndice 1).

$$
M=m=\frac{\rho A L}{2}\left[\begin{array}{llllll}
1 & 0 & 0 & 0 & 0 & 0 \\
0 & 1 & 0 & 0 & 0 & 0 \\
0 & 0 & 0 & 0 & 0 & 0 \\
0 & 0 & 0 & 1 & 0 & 0 \\
0 & 0 & 0 & 0 & 1 & 0 \\
0 & 0 & 0 & 0 & 0 & 0
\end{array}\right]
$$


O funcional de energia total, equação (1), deve ser minimizado. As parcelas devidas à energia cinética, equações (4) e (5), após serem derivadas em função dos parâmetros nodais podem ser expressas por:

$$
\begin{aligned}
& \frac{\partial K_{c}}{\partial X_{k}}=\sum_{i=1}^{\text {coord }} \frac{m_{i}}{2} 2 \dot{X}_{i} \frac{\partial \dot{X}_{i}}{\partial X_{k}} \delta_{i k} \\
& \frac{\partial K_{a}}{\partial X_{k}}=\sum_{i=1}^{\text {coord }} c_{m_{i}}\left(\frac{\partial X_{i}}{\partial X_{k}} \dot{X}_{i}+X_{i} \frac{\partial \dot{X}_{i}}{\partial X_{k}}-\frac{X_{i} \ddot{X}_{i}}{\dot{X}_{i}}\right) \delta_{i k}
\end{aligned}
$$

Nas equações (8) e (9), leva-se em consideração a ortogonalidade dos parâmetros nodais, representada através da utilização do delta de $\operatorname{Kronecker}\left(\delta_{i k}\right)$.

Pode-se desenvolver a derivada da velocidade em relação à posição utilizando-se a regra da cadeia, com a variável tempo $(t)$ implícita.

$$
\frac{\partial \dot{X}_{i}}{\partial X_{k}}=\frac{\partial \dot{X}_{i}}{\partial t} \frac{\partial t}{\partial X_{k}}=\ddot{X}_{i} \frac{1}{\dot{X}_{k}}
$$

Substituindo-se a equação (10) em nas expressões (8) e (9), tem-se:

$$
\begin{aligned}
& \frac{\partial K_{c}}{\partial X_{k}}=\sum_{i=1}^{\text {coord }} m_{i} \dot{X}_{i} \ddot{X}_{i} \frac{1}{\dot{X}_{k}} \delta_{i k}=\sum_{k=1}^{\text {coord }} m_{k} \ddot{X}_{k} \\
& \frac{\partial K_{a}}{\partial X_{k}}=\sum_{i=1}^{c o o r d} c_{m_{i}}\left(\dot{X}_{i}+X_{i} \ddot{X}_{i} \frac{1}{\dot{X}_{k}}-\frac{X_{i} \ddot{X}_{i}}{\dot{X}_{i}}\right) \delta_{i k}=\sum_{k=1}^{c o o r d} c_{m_{k}} \dot{X}_{k}
\end{aligned}
$$

Considerando-se a minimização de todo o funcional de energia, chega-se a seguinte expressão:

$$
\frac{\partial \Pi}{\partial X}=\frac{\partial U_{t}}{\partial X}-F+M \ddot{X}+C \dot{X}=0
$$

O valor da derivada da energia de deformação $\left(U_{t}\right)$ é o mesmo da formulação estática, apresentada no capítulo anterior.

A equação (13) é diferencial nas variáveis posição $(X)$ e tempo $(t)$. Para integrála no tempo, utilizar-se-á um algoritmo do tipo Newmark, antes de se criar a segunda derivada em relação aos parâmetros nodais. Para isto é necessário se escrever a equação (13) para um instante de tempo, por exemplo, o instante atual $(S+1)$.

$$
\left.\frac{\partial \Pi}{\partial X}\right|_{S+1}=\left.\frac{\partial U_{t}}{\partial X}\right|_{S+1}-F_{S+1}+M \ddot{X}_{S+1}+C \dot{X}_{S+1}=0
$$

A equação (14) representa a equação dinâmica de equilíbrio para o problema não linear geométrico. Os carregamentos nodais $\left(F_{S+1}\right)$ são prescritos para cada passo de tempo, inclusive para $t=0$, através da seguinte expressão:

$$
F_{S+1}=F_{0}\left[c_{1}+c_{2} t+c_{3} t^{2}+c_{4} t^{3}+c_{5} \sin \left(c_{6} t\right)+c_{7} \cos \left(c_{8} t\right)+c_{9} e^{c_{10} t}\right]
$$


As equações de integração temporal de Newmark podem ser descritas em função das posições. A dedução destas equações pode ser encontrada no apêndice 5 .

$$
\begin{aligned}
& X_{S+1}=X_{S}+\Delta t \dot{X}_{S}+\Delta t^{2}\left[\left(\frac{1}{2}-\beta\right) \ddot{X}_{S}+\beta \ddot{X}_{S+1}\right] \\
& \dot{X}_{S+1}=\dot{X}_{S}+\Delta t(1-\gamma) \ddot{X}_{S}+\gamma \Delta t \ddot{X}_{S+1}
\end{aligned}
$$

Vale lembrar que as posições nodais $(X)$ relacionam-se aos deslocamentos $(U)$ através das posições nodais iniciais $\left(X_{0}\right)$.

$X=X_{0}+U$

$\mathrm{Na}$ formulação utilizada, baseada na descrição de posições, não são utilizados deslocamentos em nenhuma etapa da formulação. A equação (18) foi apresentada apenas lembrar a relação entre posição e deslocamento. A velocidade é definida diretamente como a taxa de variação das posições em relação ao tempo.

$\dot{U}=\dot{X}$

Conseqüentemente, a aceleração é definida como a taxa de variação das velocidades em relação ao tempo.

$\ddot{U}=\ddot{X}$

Substituindo-se as equações (18), (19) e (20) nas equações de Newmark, equações (16) e (17), seriam obtidas as equações de integração temporal clássicas de Newmark descritas em função dos deslocamentos, o que não é feito nesta formulação devido a seu caráter posicional.

Desenvolvendo-se a equação (16), pode-se isolar as acelerações do passo de tempo atual.

$$
\ddot{X}_{S+1}=\frac{X_{S+1}}{\beta \Delta t^{2}}-\frac{X_{S}}{\beta \Delta t^{2}}-\frac{\dot{X}_{S}}{\beta \Delta t}-\left(\frac{1}{2 \beta}-1\right) \ddot{X}_{S}
$$

Substituindo-se as equações (17) e (21) em (14), tem-se:

$$
\left.\frac{\partial \Pi}{\partial X}\right|_{S+1}=\left.\frac{\partial U_{t}}{\partial X}\right|_{S+1}-F_{S+1}+\frac{M}{\beta \Delta t^{2}} X_{S+1}-M Q_{S}+C R_{S}+\frac{\gamma C}{\beta \Delta t} X_{S+1}-\gamma \Delta t C Q_{S}=0
$$

Com os vetores $Q_{S}$ e $R_{S}$ representando a contribuição dinâmica das variáveis do passado (passo $S$ ).

$$
\begin{aligned}
& Q_{S}=\frac{X_{S}}{\beta \Delta t^{2}}+\frac{\dot{X}_{S}}{\beta \Delta t}+\left(\frac{1}{2 \beta}-1\right) \ddot{X}_{S} \\
& R_{S}=\dot{X}_{S}+\Delta t(1-\gamma) \ddot{X}_{S}
\end{aligned}
$$


Derivando-se a equação (22) novamente em relação às posições do instante atual, chega-se à matriz Hessiana para o problema dinâmico.

$$
\left.\frac{\partial^{2} \Pi}{\partial X^{2}}\right|_{S+1}=\nabla g\left(X^{0}\right)=\left.\frac{\partial^{2} U_{t}}{\partial X^{2}}\right|_{S+1}+\frac{M}{\beta \Delta t^{2}}+\frac{\gamma C}{\beta \Delta t}
$$

Aplica-se o método de Newton-Raphson na equação (22). Assim, obtém-se a equação (26) para correção das posições durante as iterações, que é resolvida de acordo com o apresentado no apêndice 2.

$g(X)=0=g\left(X^{0}\right)+\nabla g\left(X^{0}\right) \Delta X$

O vetor dos resíduos também é obtido a partir da equação (22).

$g\left(X^{0}\right)=\left.\frac{\partial U_{t}}{\partial X}\right|_{S+1}-F_{S+1}+\frac{M}{\beta \Delta t^{2}} X_{S+1}-M Q_{S}+C R_{S}+\frac{\gamma C}{\beta \Delta t} X_{S+1}-\gamma \Delta t C Q_{S}$

Durante o processo iterativo, devem ser feitas as correções nas posições nodais, de acordo com os valores obtidos na equação (26).

$X_{S+1}=X_{S}+\Delta X$

Em seguida devem ser feitas as correções nas acelerações.

$\ddot{X}_{S+1}=\frac{X_{S+1}}{\beta \Delta t^{2}}-Q_{S}$

Ainda durante o processo iterativo, com os novos valores calculados de posições nodais e acelerações do passo atual $(S+1)$, calculam-se as velocidades, equação (17).

Para verificar se as correções das posições $(\Delta X)$ são suficientemente pequenas dentro de certa tolerância, utiliza-se a equação (30) como critério de parada; quando o critério de tolerância é satisfeito, muda-se para o próximo passo de tempo. Neste próximo passo, os valores que acabaram de ser calculados $(S+1)$, são armazenados como valores do passado $(S)$.

$\sqrt{\sum_{i=1}^{c o o r d} g^{2}\left(X^{0}\right)} \leq T O L$

Vale lembrar que antes de iniciar o primeiro passo deve-se calcular os valores das acelerações nodais iniciais, com base na equação (14).

$\ddot{X}_{0}=M^{-1}\left[F_{0}-C \dot{X}_{0}-\left.\frac{\partial U_{t}}{\partial X}\right|_{0}\right]$

A equação (31) pode ser resolvida facilmente, considerando-se apenas as coordenadas com contribuição na matriz de massa, uma vez que a matriz de massa 
possui termos apenas na diagonal principal. Para as coordenadas de rotação, as acelerações iniciais são nulas.

\subsection{Exemplos numéricos}

\subsubsection{Viga engastada amortecida}

O objetivo do exemplo é testar o termo da formulação relacionado ao amortecimento em uma situação linear. A rigidez da viga é elevada e são obtidos pequenos deslocamentos no grau de liberdade $U$, em relação ao vão da viga. Devido à rigidez elevada da viga, utiliza-se um coeficiente de amortecimento proporcional à massa também elevado. É aplicado um carregamento dinâmico de impacto na extremidade livre da viga, na mesma direção do grau de liberdade medido. A viga foi discretizada em $20 \mathrm{EF}$. Na figura 1 apresentam-se a geometria, carregamento e dados físicos do problema.
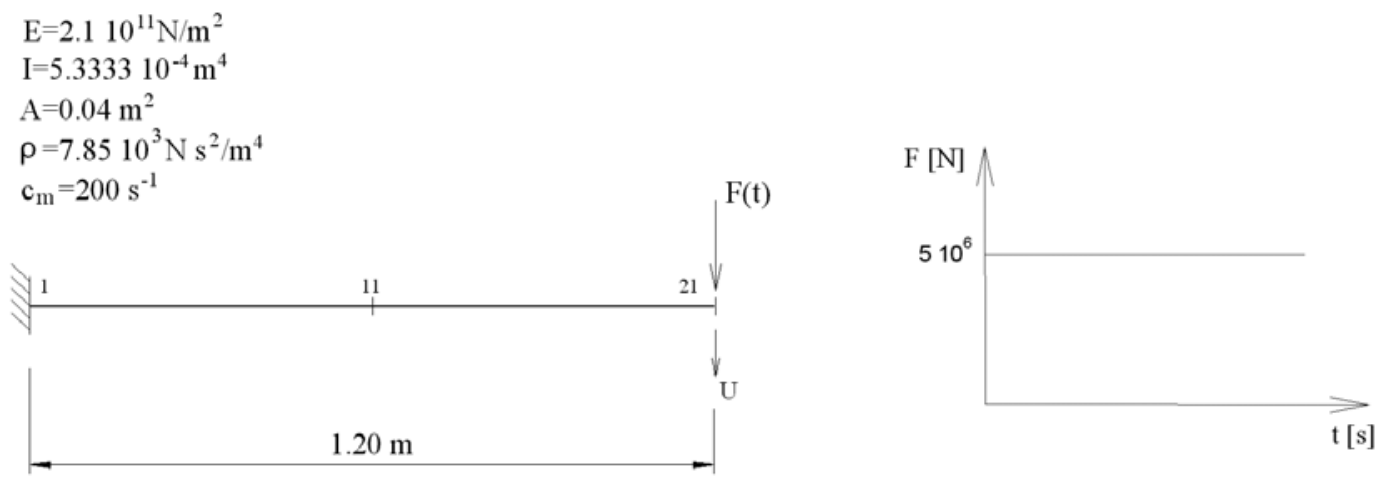

Figura 1 - Dados de entrada do problema

Na figura 2 é apresentada a amplitude do deslocamento medido na extremidade livre, segundo o grau de liberdade $U$ apresentado na figura 1. É apresentada a resposta dinâmica elástica, para as situações sem amortecimento e amortecida. Para efeito de comparação apresenta-se também a resposta estática do problema linear, que conforme era esperado para este exemplo, equivale à metade da amplitude da resposta dinâmica linear. A resposta dinâmica com amortecimento apresentou convergência para a resposta estática, conforme esperado. 


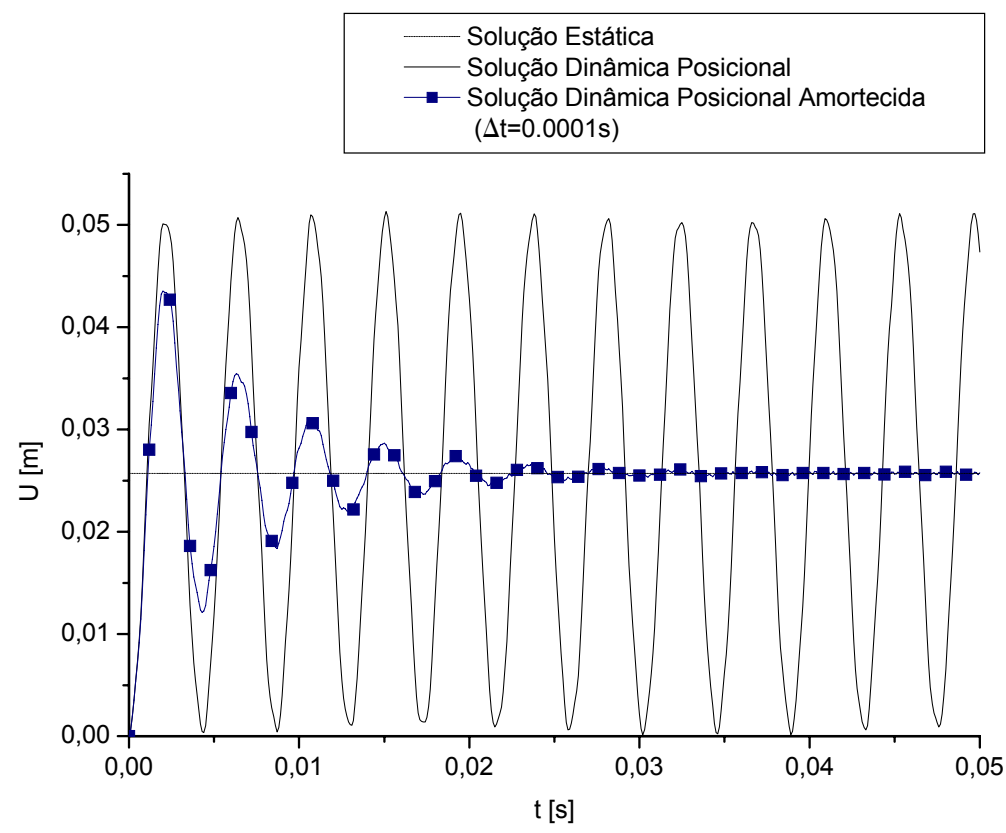

Figura 2 - Tempo $\times$ deslocamento no grau de liberdade analisado

\subsubsection{Sistema massa-mola com plastificação na mola}

Busca-se a resposta dinâmica não linear física de uma barra com massa desprezível (mola), submetida a carregamento axial dinâmico aplicado em uma massa concentrada conectada à extremidade livre da barra. A barra foi discretizada em apenas $1 \mathrm{EF}$, suficiente neste caso para análise do problema. Na figura 3 apresentam-se a geometria, carregamento e dados físicos do problema. O modelo de plastificação da barra é considerado elastoplástico perfeito.
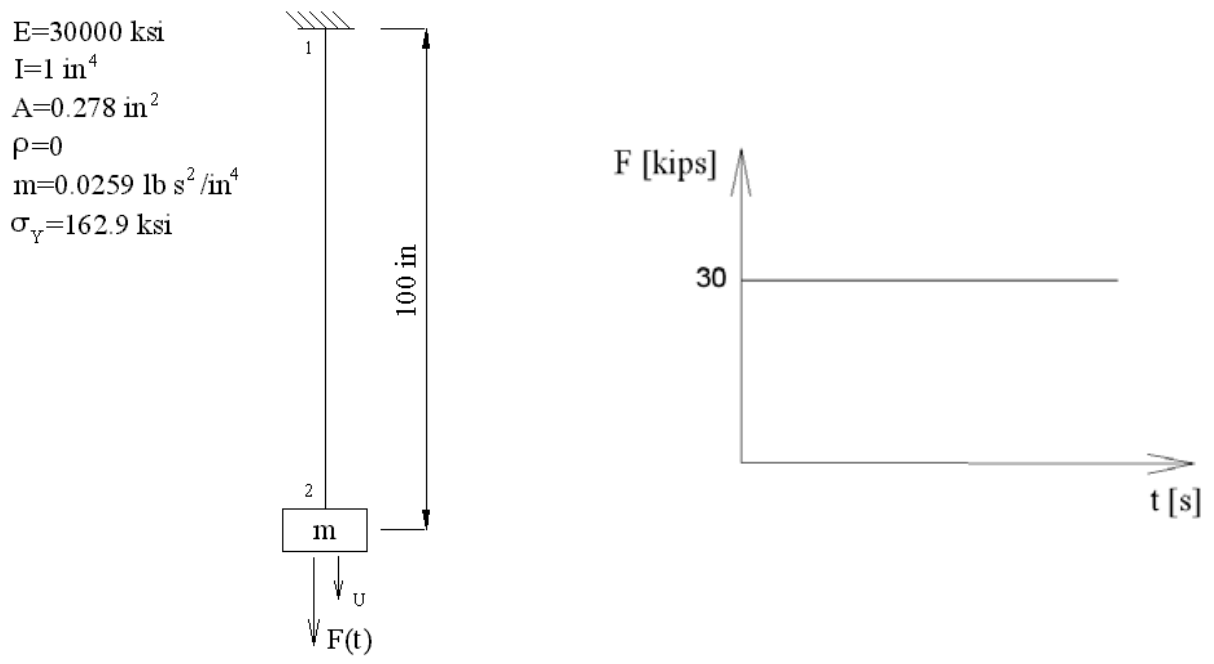

Figura 3 - Dados de entrada do problema 
Este exemplo foi retirado do livro de BIGGS (1964), no qual o autor apresenta a solução analítica para o problema, descrita nas equações (32), (33) e (34). Para este problema específico, tem-se $t_{P}=0.0371 \mathrm{~s}, t_{1 m}=0.0298 \mathrm{~s}$ e $t_{U \max }=0.0669 \mathrm{~s}$.

$U=0.36(1-\cos (56.8 t))$, para $t \leq t_{P}$

$U=-295\left(t-t_{P}\right)^{2}+17.6\left(t-t_{P}\right)+0.543$, para $t_{P} \leq t \leq t_{U \max }$

$U=0.622+0.184 \cos \left(56.8\left(t-t_{1 m}-t_{P}\right)\right)$, para $t \geq t_{U \max }$

Na figura 4 é apresentada a amplitude do deslocamento medido na extremidade livre, segundo o grau de liberdade $U$ apresentado na figura 3. São apresentadas as respostas dinâmicas analítica, linear e não linear física (NLF), baseada na formulação proposta. Para efeito de comparação apresenta-se também a resposta estática do problema linear, que conforme era esperado para este exemplo, equivale à metade da amplitude da resposta dinâmica linear. A resposta NLF apresentou excelentes resultados, quando comparada com a solução analítica do problema.

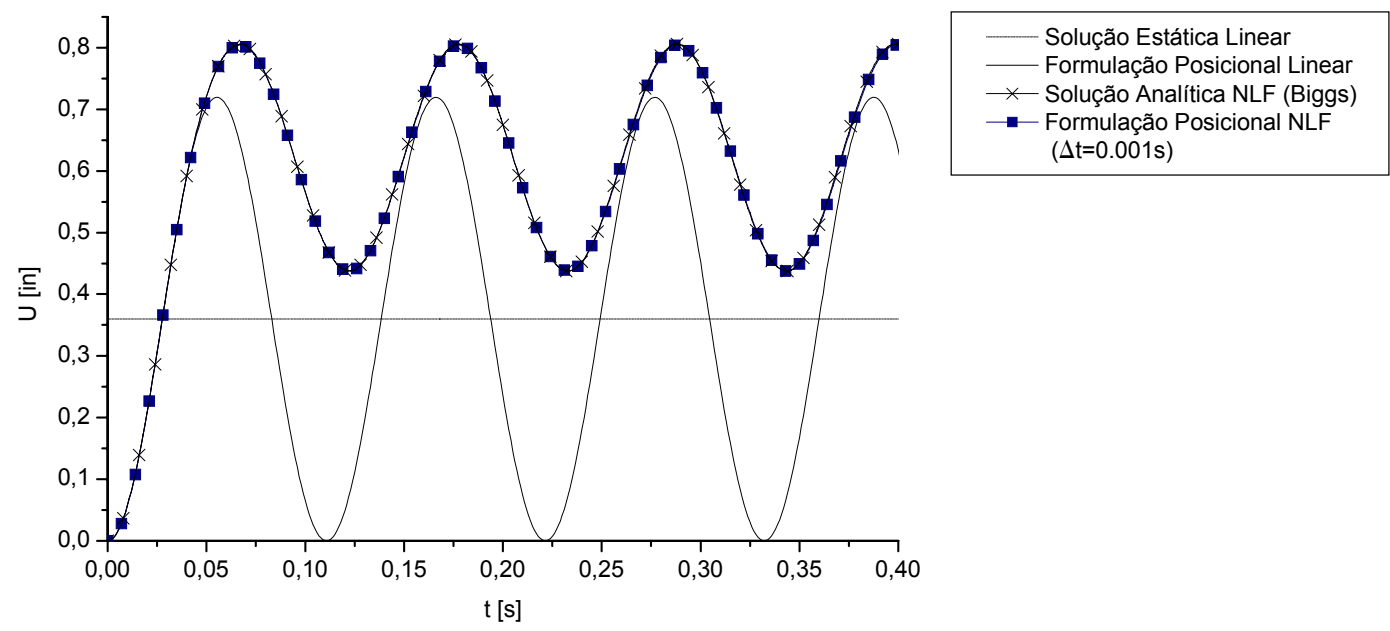

Figura 4 - Tempo $\times$ deslocamento no grau de liberdade analisado

\subsubsection{Não linearidade geométrica em viga bi-engastada}

A viga analisada neste exemplo foi discretizada em apenas 8 elementos finitos e o carregamento é aplicado no meio do vão da viga. Este exemplo foi retirado do artigo de MONDKAR \& POWELL (1977). Na figura 5 apresentam-se a geometria, carregamento e dados físicos do problema. 

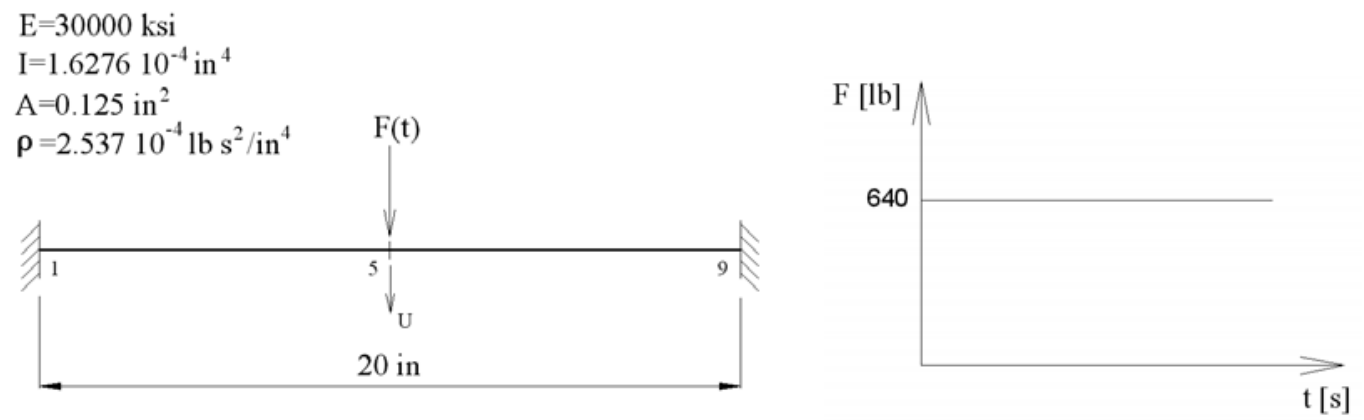

Figura 5 - Dados de entrada do problema

Na figura 6 é apresentada a amplitude do deslocamento medido no meio do vão da viga, segundo o grau de liberdade $U$ apresentado na figura 5. São apresentadas as respostas linear e não linear geométrica (NLG), baseada na formulação proposta, utilizando massa discreta. A resposta linear teve a amplitude dos deslocamentos reduzida para $10 \%$ de seu valor nominal, para efeito de apresentação no mesmo gráfico. $\mathrm{Na}$ figura 7 é apresentada a resposta NLG original do artigo.

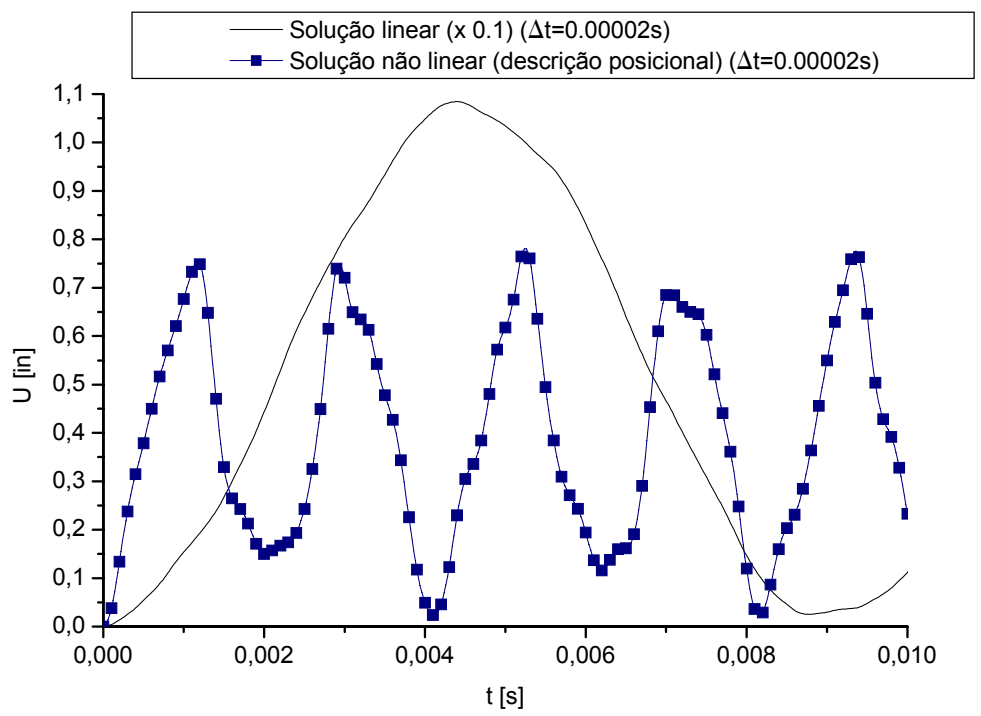

Figura 6 - Tempo $\times$ deslocamento no grau de liberdade analisado

Apesar do reduzido número de elementos, a resposta NLG posicional apresentou bons resultados, quando comparada com a resposta NLG do artigo, tanto em amplitude quanto em período. 


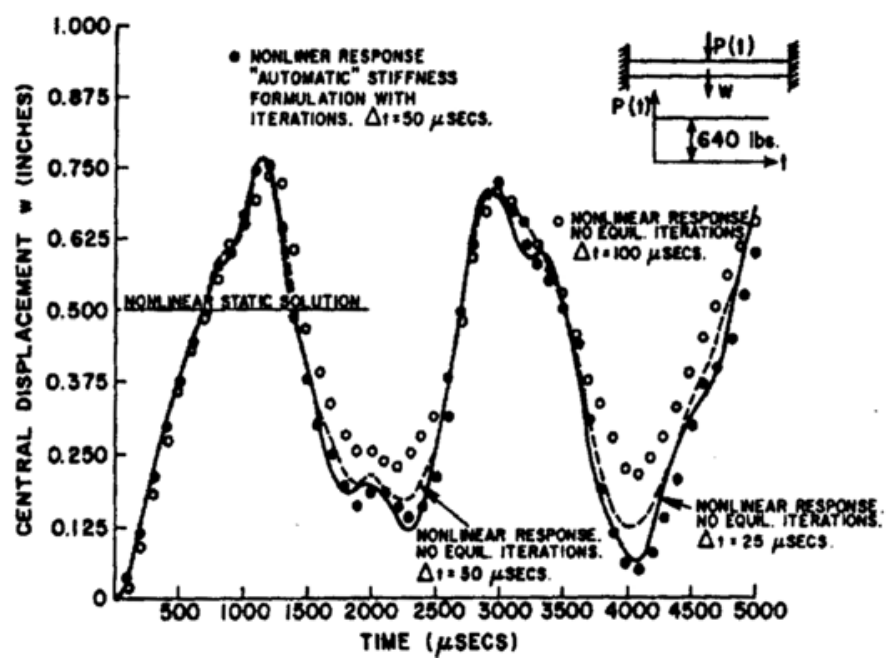

Figura 7 - Resposta original do artigo de MONDKAR \& POWELL (1977)

\subsubsection{Não linearidade geométrica em viga engastada}

A viga é discretizada em 10 elementos finitos e uma carga transversal de impacto é aplicada na extremidade livre. Este exemplo foi retirado do artigo de BEHDINAN et al. (1998). Na figura 8 apresentam-se a geometria, carregamento e dados físicos do problema.
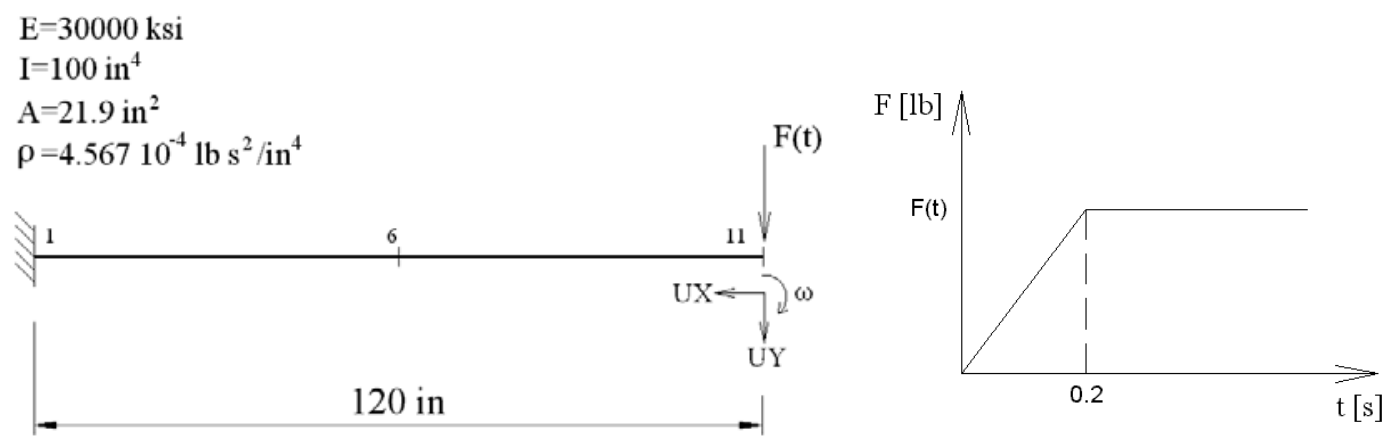

Figura 8 - Dados de entrada do problema

Nas figuras 9, 10 e 11 são apresentadas as amplitudes dos deslocamentos e rotação medidos na extremidade livre da viga, segundo os graus de liberdade $U X, U Y$, e $\omega$ apresentados na figura 8. São apresentadas a resposta linear, utilizando matriz de massa consistente, e a resposta NLG baseada na formulação proposta, utilizando massa discreta. 


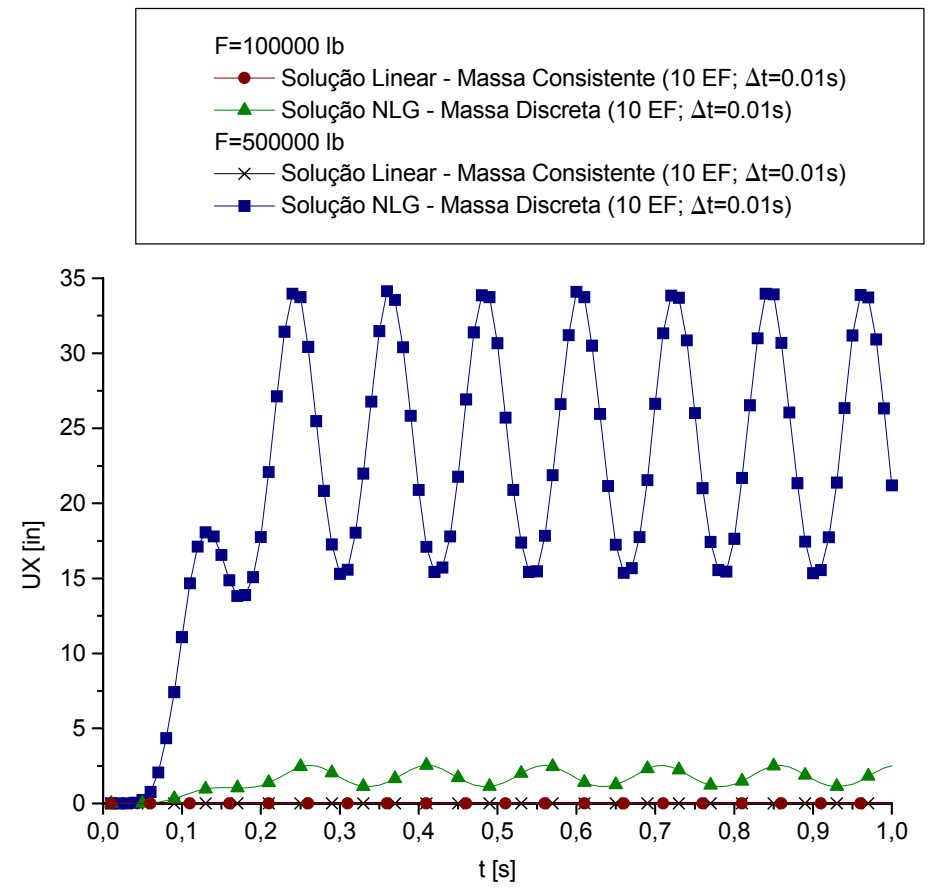

Figura 9 - Tempo $\times$ deslocamento do grau de liberdade UX

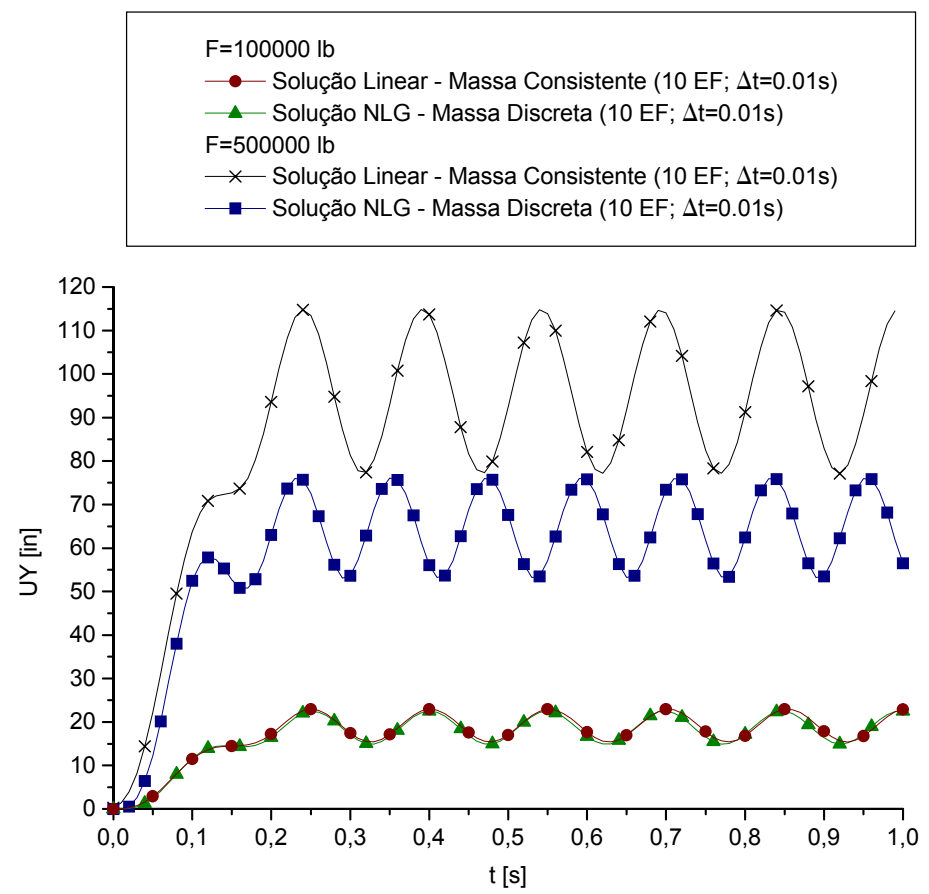

Figura 10 - Tempo $\times$ deslocamento do grau de liberdade UY

$\mathrm{O}$ artigo de referência apresenta apenas o deslocamento do grau de liberdade $U Y$. As respostas obtidas na figura 10 muito foram próximas das encontradas no artigo, que apresenta oscilações após o tempo $t=0.25 \mathrm{~s}$ variando entre $15.0 \mathrm{in}$ e $22.5 \mathrm{in}$. 


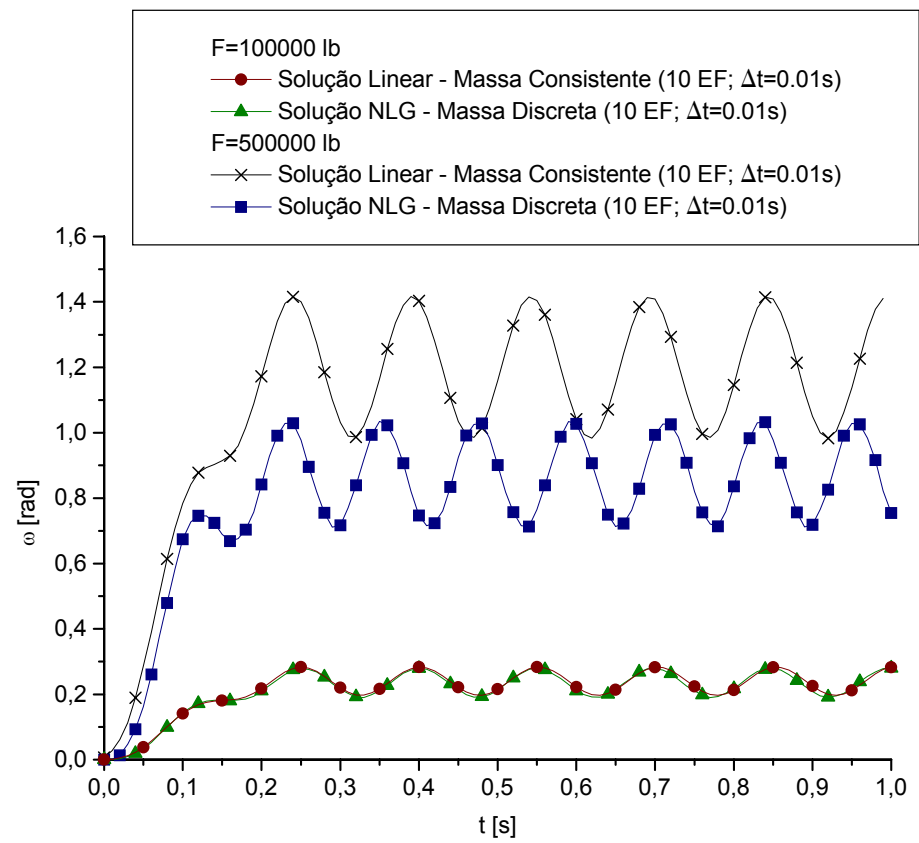

Figura 11 - Tempo $\times$ rotação do grau de liberdade $\omega$

Para o maior nível de carregamento as respostas lineares apresentam maiores amplitudes que as respostas NLG, com exceção do deslocamento na direção $U X$ (que na teoria linear são nulos).

$\mathrm{Na}$ figura 12 são apresentadas as configurações na viga para a formulação linear e NLG, para dois níveis de carregamento $(100000 \mathrm{lb}$ e $500000 \mathrm{lb}$ ). O menor nível de carregamento é o mesmo apresentado no artigo. É interessante observar que para o menor nível de carregamento, as respostas linear e NLG são praticamente iguais, com exceção do deslocamento horizontal. Para o maior nível de carregamento a resposta linear apresentou deformações inaceitáveis, a extremidade livre se desloca verticalmente, gerando uma linha elástica errada na viga. Já o resultado NLG apresentou deformações mais próximas da realidade, com deslocamentos verticais e horizontais da extremidade livre. 


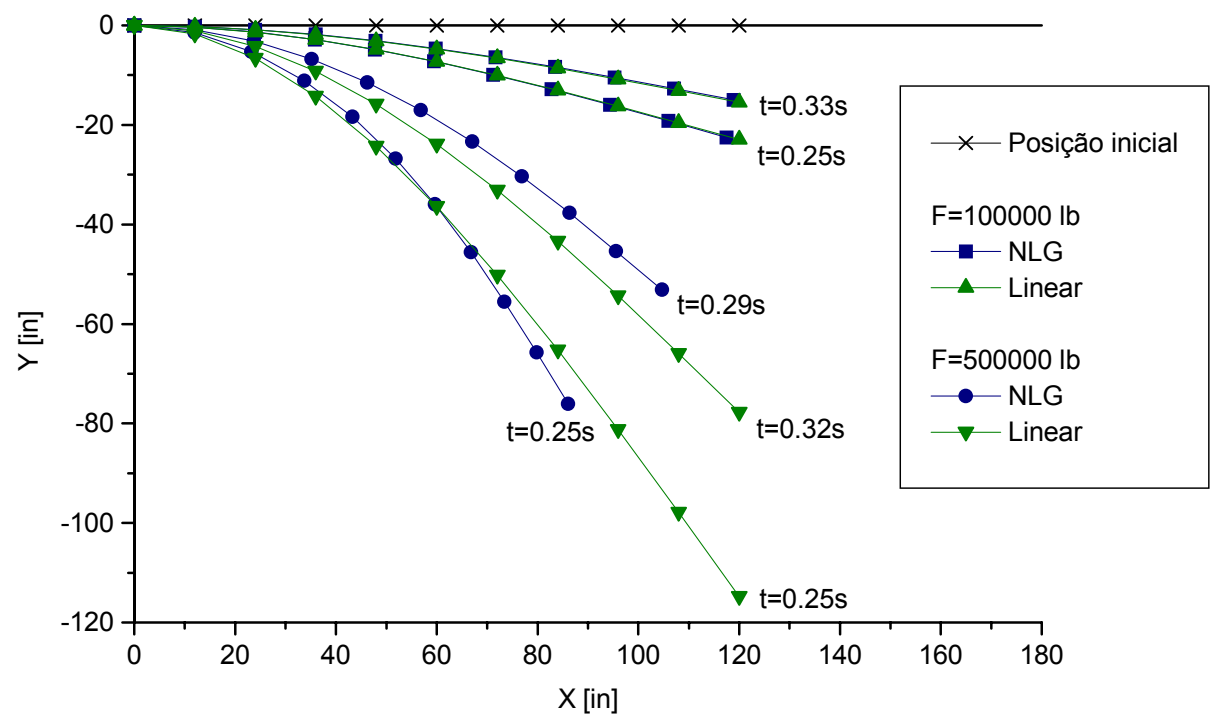

Figura 12 - Configurações da viga para determinados carregamentos e tempos

\subsubsection{Lâmina flexível giratória}

O exemplo trata de uma viga apoiada, com rotação prescrita no apoio. A estrutura foi discretizada em 10 elementos finitos. Na figura 13 apresentam-se a geometria, os dados físicos do problema e o gráfico da rotação prescrita. Este exemplo foi retirado do artigo de SIMO \& VU-QUOC (1986), e também é encontrado nos artigos de CHRISTENSEN \& LEE (1986), WU \& HAUG (1988), HSIAO et al. (1994) e ELKARANSHAWY \& DOKAINISH (1995). A função $\psi_{(t)}$ representa uma rotação típica de lâmina de rotor, como por exemplo, rotor de helicóptero.
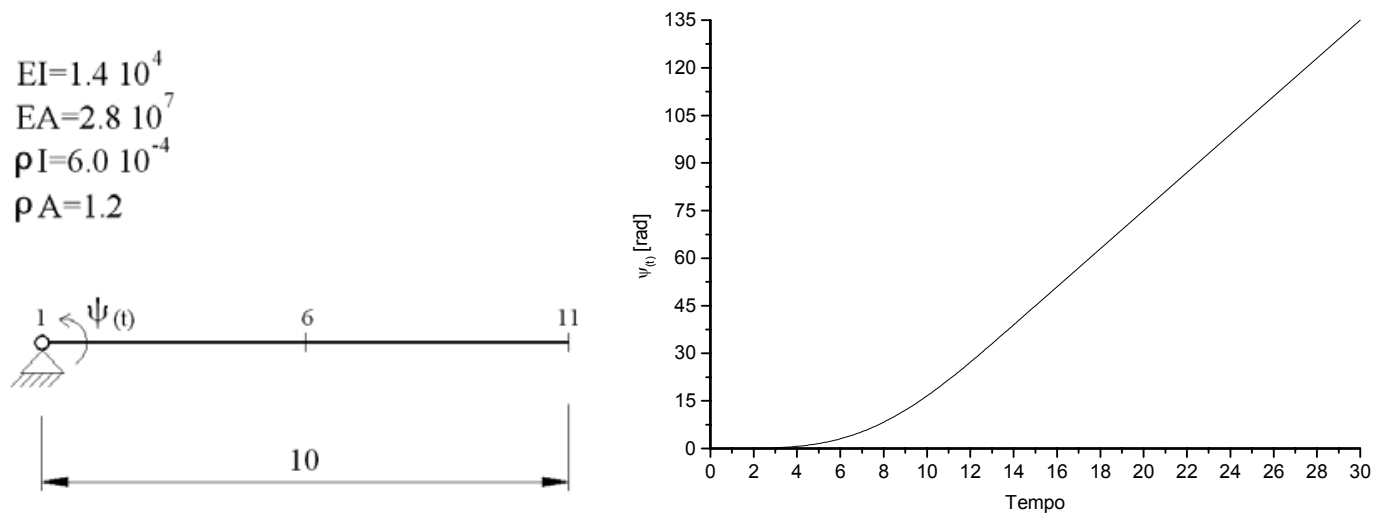

Figura 13 - Dados de entrada do problema 
As expressões para a função de rotação são apresentadas nas equações (35) e (36).

$\psi_{(t)}=\frac{2}{5}\left[\frac{t^{2}}{2}+\left(\frac{15}{2 \pi}\right)^{2}\left(\cos \frac{2 \pi t}{15}-1\right)\right] \mathrm{rad}, \quad$ para $0 \leq t \leq 15$

$\psi_{(t)}=(6 t-45) \mathrm{rad}$, para $t>15$

$\mathrm{Na}$ figura 14 são apresentados o movimento de corpo rígido, as configurações inicial e deformada, e as coordenadas locais $U_{1}$ e $U_{2}$, nas quais são medidos os deslocamentos. Estas coordenadas têm como referência o nó 11 da estrutura submetida a um movimento de corpo rígido em um mesmo instante $t$ em que a estrutura se encontra na configuração deformada.
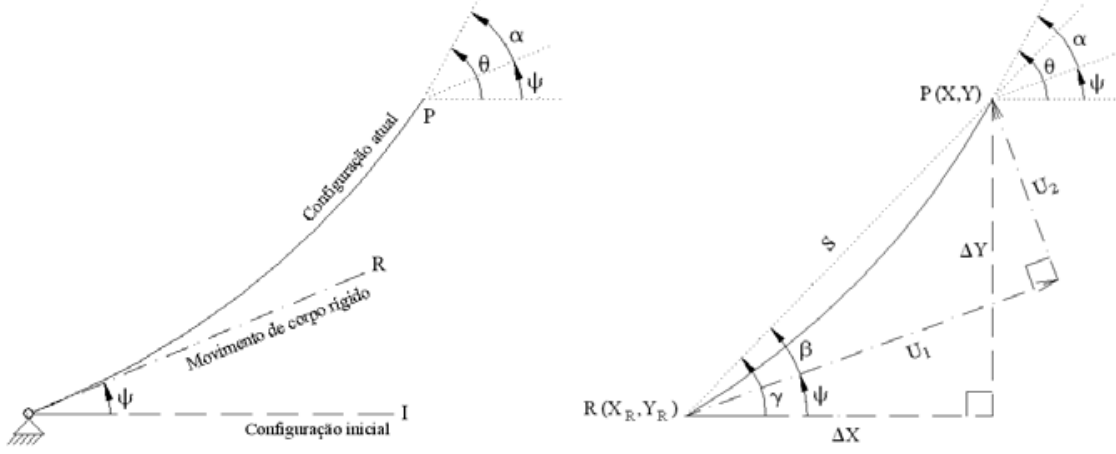

Figura 14 - Configurações de deformação e sistema de coordenadas local

A partir da figura 14, das posições $X$ e $Y$, e da rotação $\theta$ do nó 11 , é possível calcular os deslocamentos $U_{1}$ e $U_{2}$, e a rotação relativa entre a configuração deformada e o movimento de corpo rígido $(\alpha)$.

$S=\sqrt{\Delta X^{2}+\Delta Y^{2}}$

$\beta=\gamma-\psi$

$U_{1}=S \cos \beta$

$U_{2}=S \operatorname{sen} \beta$

$\alpha=\theta-\psi$

Nas figuras 15, 16 e 17 são apresentados os deslocamentos nas direções $U_{l}$ e $U_{2}$, e a rotação relativa $\alpha$, respectivamente. Na figura 18 são apresentadas as posições deformadas NLG e de movimento de corpo rígido para determinados instantes durante o primeiro ciclo de rotação. 


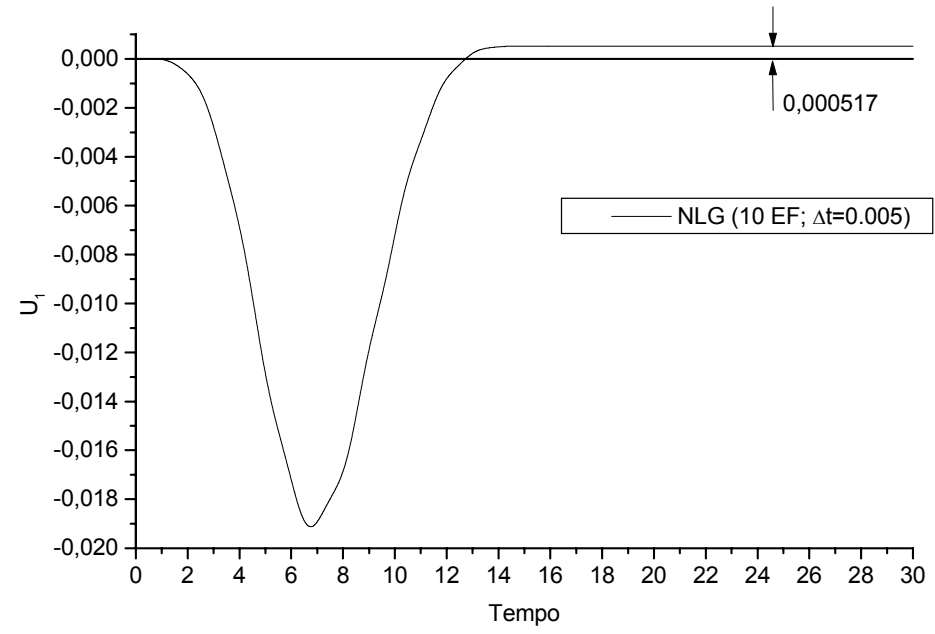

Figura 15 - Tempo $\times$ deslocamento do grau de liberdade $U_{I}$

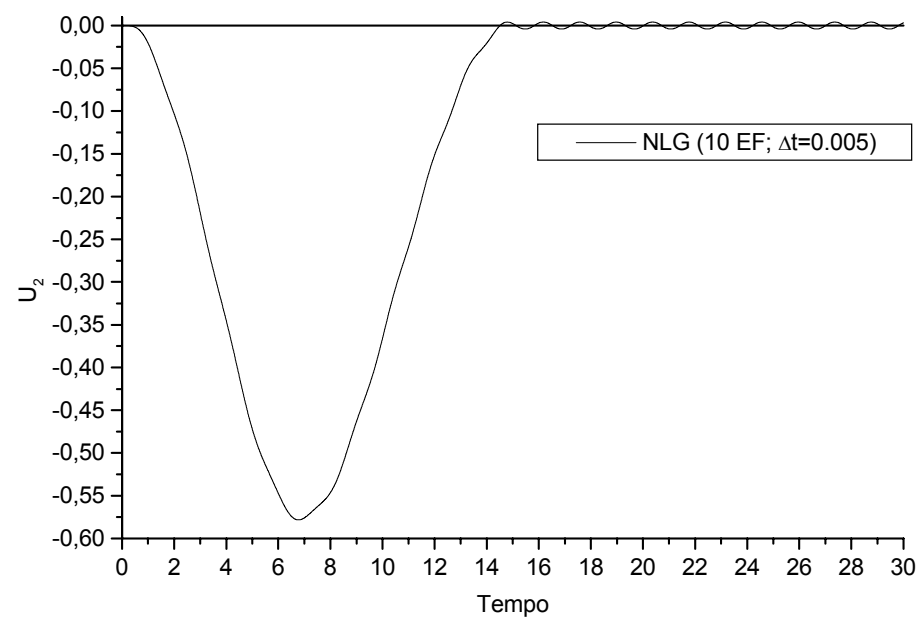

Figura 16 - Tempo $\times$ deslocamento do grau de liberdade $U_{2}$

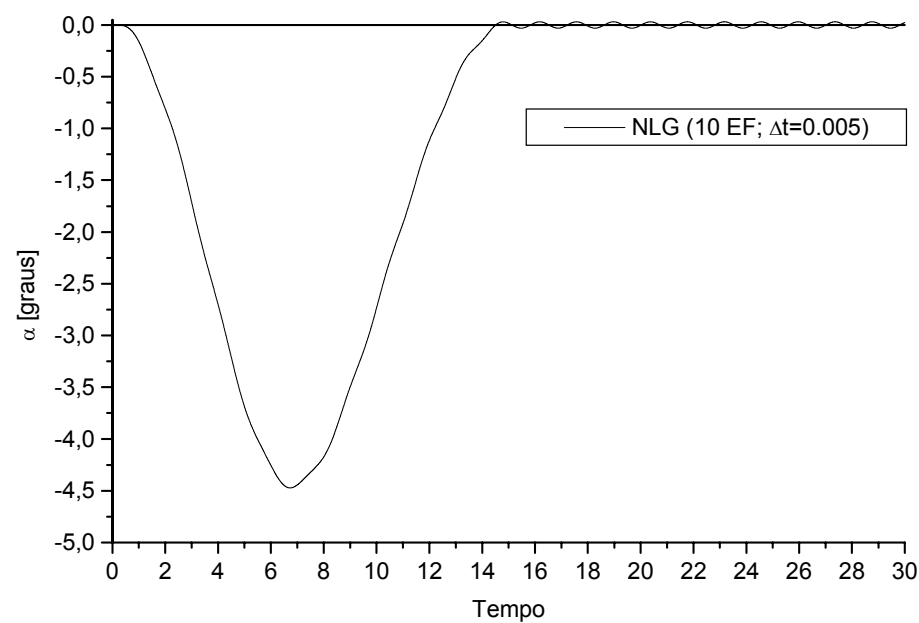

Figura 17 - Tempo $\times$ rotação $\alpha$ 
As respostas obtidas pela formulação proposta foram bem próximas das apresentadas nos artigos que apresentam este exemplo. O tempo de deslocamentos máximos é de $t=6.75$, no qual são obtidos $U_{1}, U_{2}$ e $\alpha$ iguais a $0.019,0.578$ e 4.472 , respectivamente. Na referência são encontrados valores para $U_{1}, U_{2}$ e $\alpha$, para o tempo de deslocamentos máximos, iguais a $0.019,0.578$ e 4.468, respectivamente. Observa-se que ocorrem maiores diferenças entre os deslocamentos elásticos e de corpo rígido no ponto 11 até um tempo próximo de $14.5 \mathrm{~s}$; em seguida o corpo elástico praticamente estabiliza seu movimento, com oscilações muito pequenas. Este efeito é conhecido como protensão inercial e é responsável pela estabilidade de hélices de helicópteros, muito esbeltas e flexíveis, mas quando aceleradas resistem a grandes carregamentos. Para o deslocamento $U_{1}$ tem-se como solução analítica, após a estabilização do movimento, um valor positivo igual a 0.000514 , próximo ao obtido na figura 15 . Com uma discretização de 20 elementos finitos é possível alcançar o valor de 0.000514 para o deslocamento $U_{1}$.

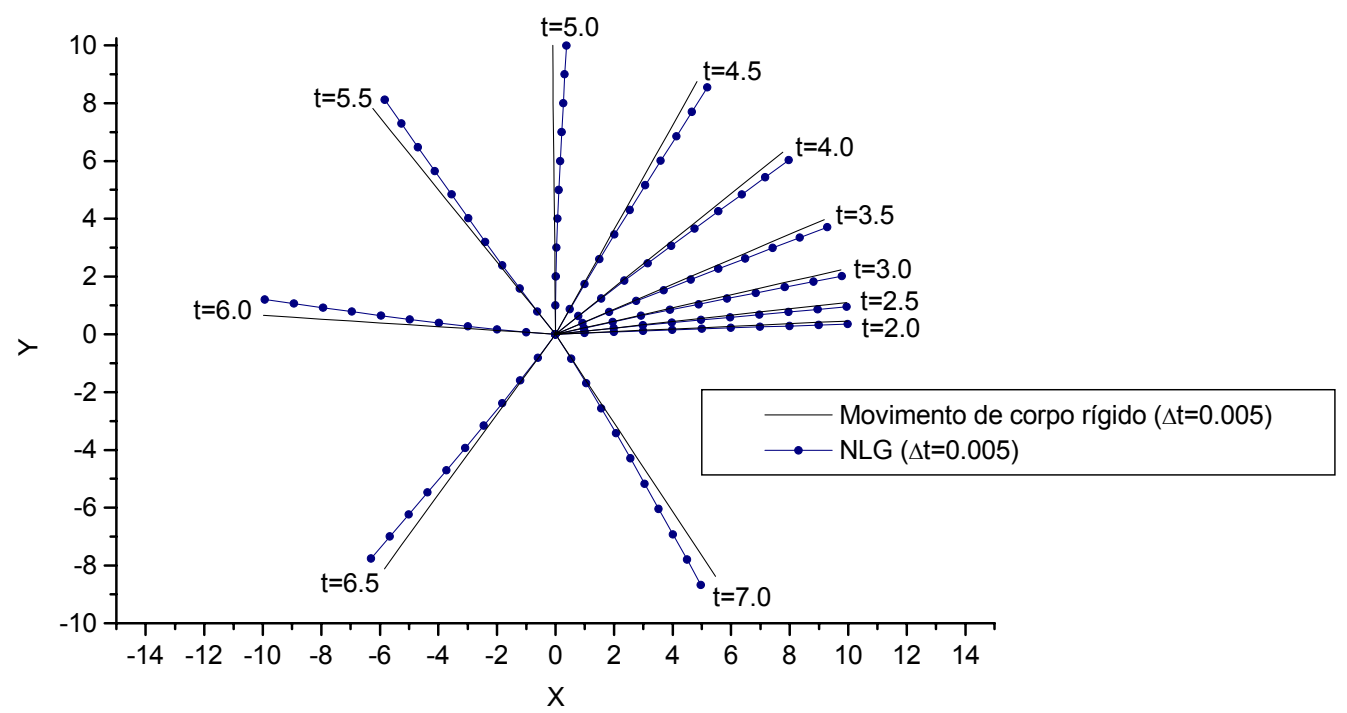

Figura 18 - Configurações da viga para determinados instantes

Observa-se na figura 18 que, para os instantes de tempo apresentados, as configurações deformadas apresentaram defasagens crescentes de movimento em relação às configurações do movimento de corpo rígido. Este fenômeno era esperado, por causa das deformações que sofrem a estrutura elástica quando é aplicada rotação na base. Os efeitos da rotação na base não afetam imediatamente os pontos nodais mais 
afastados, como o nó 11 . Portanto, a estrutura elástica não é rotacionada de maneira uniforme como o corpo rígido. Deste fato, observa-se na figura, que os pontos mais próximos do ponto de aplicação da rotação apresentam respostas elásticas e de corpo rígido próximas, enquanto os pontos mais afastados do ponto de aplicação da rotação apresentam respostas um pouco mais divergentes. Pelas figuras 15, 16 e 17 observa-se que após o tempo $t=7$, as defasagens entre as configurações deformada e rígida diminuem, e após o tempo $t=14.5$ as configurações são praticamente iguais (efeito de protensão).

\subsubsection{Mecanismo flexível articulado}

Trata de um mecanismo composto de um braço mecânico e uma haste articulados, com momento aplicado no apoio do braço mecânico. A haste é menos rígida que o braço mecânico e está conectada, através de uma articulação, a um bloco com massa desprezível que desliza horizontalmente sobre uma superfície sem atrito. $\mathrm{O}$ braço mecânico foi discretizado em 5 elementos finitos e a haste em 10 elementos finitos. $\mathrm{Na}$ figura 19 apresentam-se a geometria, os dados físicos do problema e o gráfico do momento aplicado $\left(M_{(t)}\right)$. São analisadas as respostas para duas situações de carregamento. Este exemplo foi retirado do artigo de ESCALONA et al. (1998) e pode também ser encontrado nos artigos de MEIJAARD (1991) e ELKARANSHAWY \& DOKAINISH (1995) e MAYO \& DOMÍNGUEZ (1996), com carregamentos prescritos diferentes.
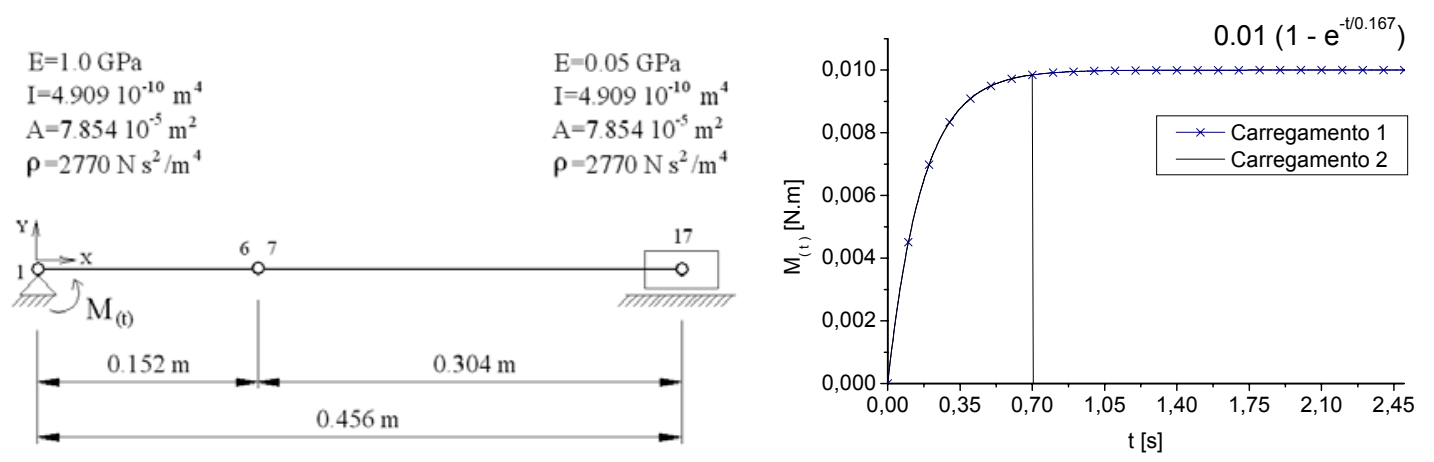

Figura 19 - Dados de entrada do problema

O primeiro carregamento é descrito por uma função exponencial com comportamento assintótico em $M_{(t)}=0.01 \mathrm{~N} \mathrm{~m}$. 
$M_{(t)}=0.01\left(1-e^{\frac{-t}{0.167}}\right) N m$

O segundo carregamento possui duas fases distintas, a primeira igual ao primeiro carregamento e a segunda nula.

$M_{(t)}=0.01\left(1-e^{\frac{-t}{0.167}}\right) N m, \quad$ para $0 s \leq t \leq 7 s$

$M_{(t)}=0 \mathrm{Nm}$, para $t>7 \mathrm{~s}$

Na figura 20 são apresentadas as posições, com origem no apoio do braço mecânico, do centro de gravidade do bloco rotulado com a haste. São apresentadas respostas para os dois carregamentos. $\mathrm{Na}$ figura 21 é apresentada a resposta para o segundo carregamento por um intervalo de tempo maior.

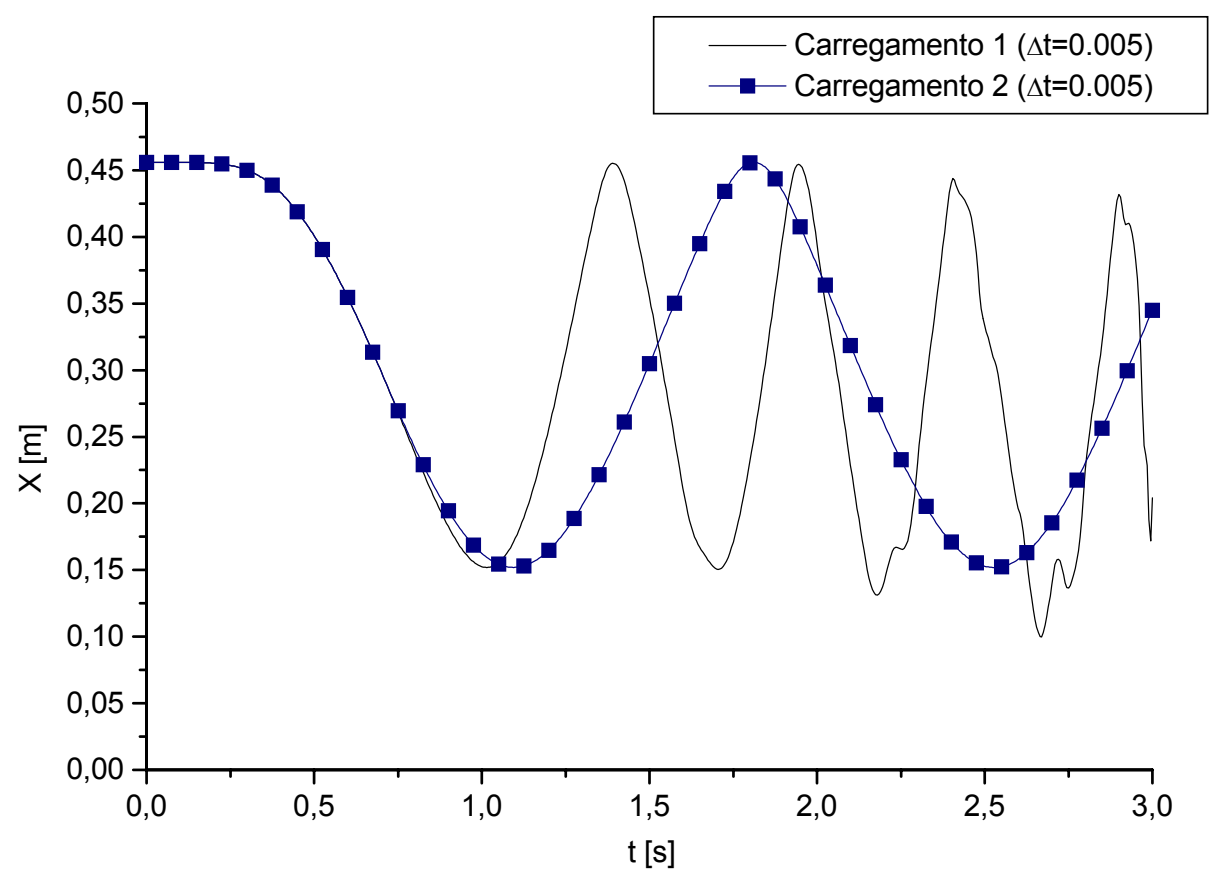

Figura 20 - Tempo $\times$ posição horizontal do bloco para as duas situações de carga 


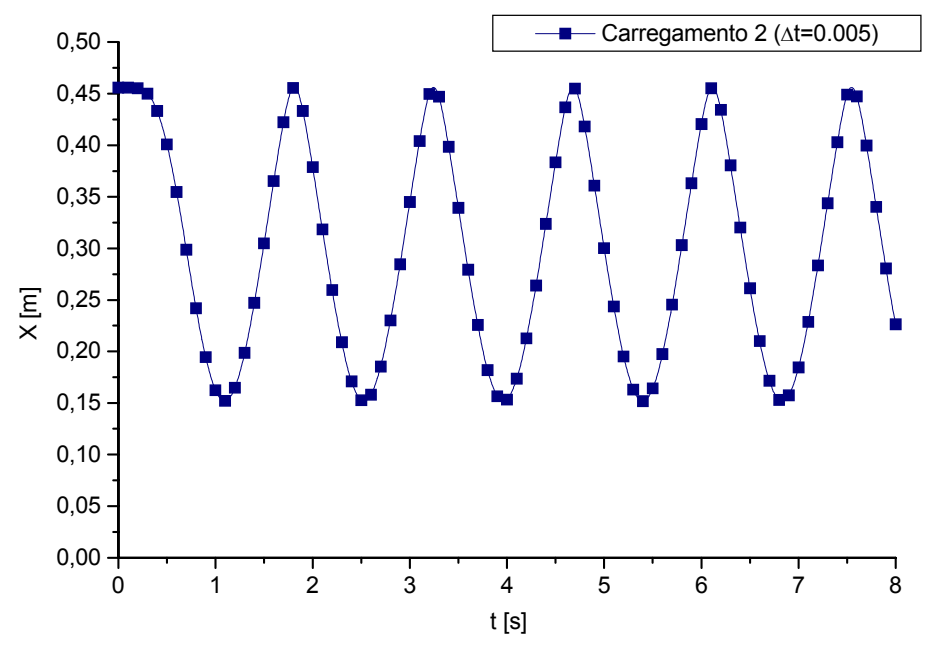

Figura 21 - Tempo $\times$ posição horizontal do bloco para o carregamento 2

As respostas foram muito próximas das apresentadas na referência, que apresenta resultados até $t=1$.6s. Para o carregamento 1 , o tempo de mínima posição $X$ da massa é de $t=1.015 \mathrm{~s}$ (coincidente com o obtido pela formulação proposta) e o tempo de máxima posição ${ }^{1} X$ da massa é de $t=1.395 \mathrm{~s}$ (a formulação proposta forneceu $t=1.390 \mathrm{~s}$ ). Para o carregamento 2, o tempo de mínima posição $X$ da massa apresentada pela referência é $t=1.110 \mathrm{~s}$ (a formulação proposta forneceu $t=1.095 \mathrm{~s}$ ).

Na figura 22 são apresentadas as configurações do mecanismo para o $1^{\circ}$ ciclo de rotação do primeiro carregamento. Na figura 23 são apresentadas as configurações para o $2^{\circ}$ ciclo. Observa-se que as deformações devido à flexão da haste tornam-se mais visíveis no $2^{\circ}$ ciclo de rotação.

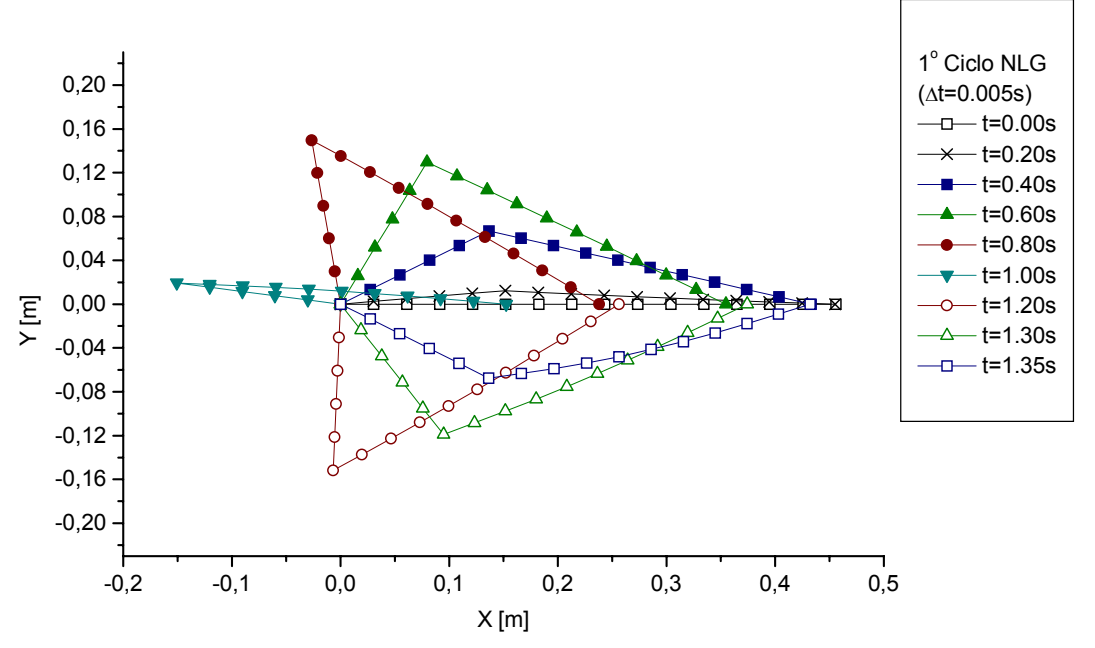

Figura 22 - Configurações do mecanismo para o carregamento 1 ( $1^{\circ}$ ciclo de rotação)

\footnotetext{
${ }^{1}$ Posição inicial da massa.
} 


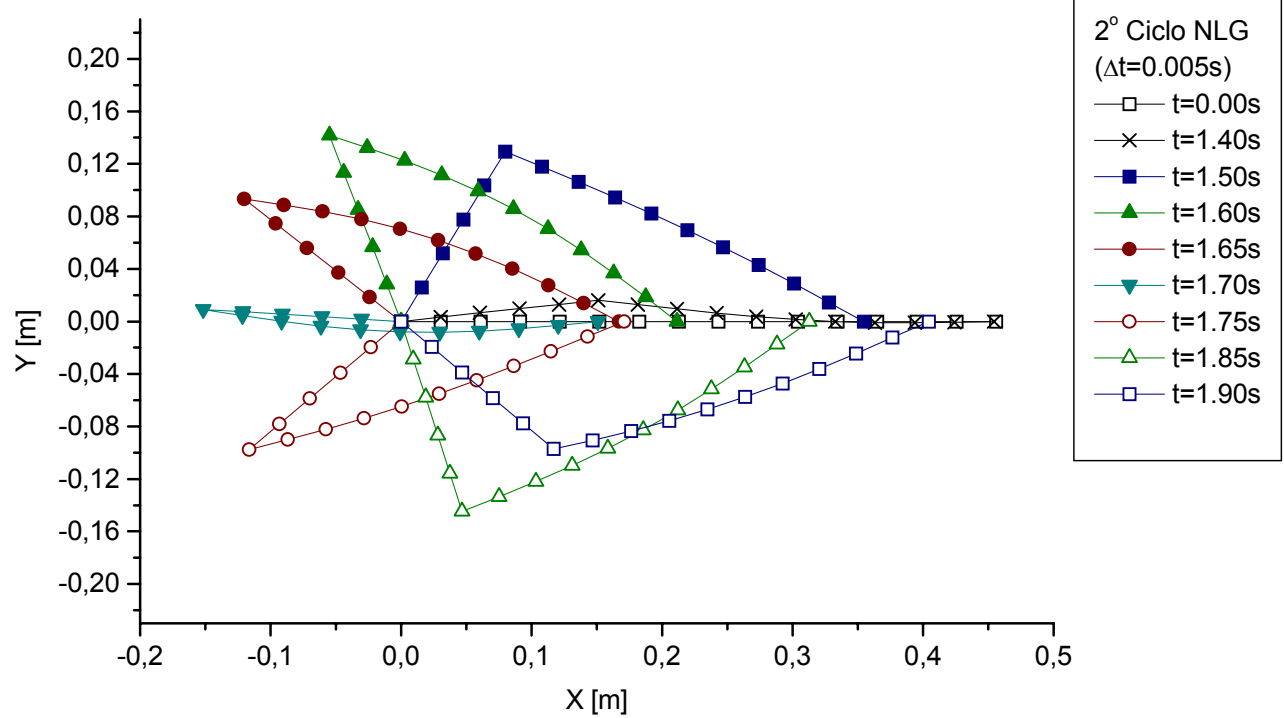

Figura 23 - Configurações do mecanismo para o carregamento 1 ( $2^{\circ}$ ciclo de rotação)

$\mathrm{Na}$ figura 24 são apresentadas as configurações do mecanismo para o $1^{\circ}$ ciclo de rotação do segundo carregamento. Observando-se as figuras 21 e 24, percebe-se que neste caso, o movimento é harmônico, sem oscilações geradas pelas deformações do caso do primeiro carregamento. Vale destacar que este é um exemplo ilustrativo, sem perdas de energia devidas ao atrito ou plastificação.

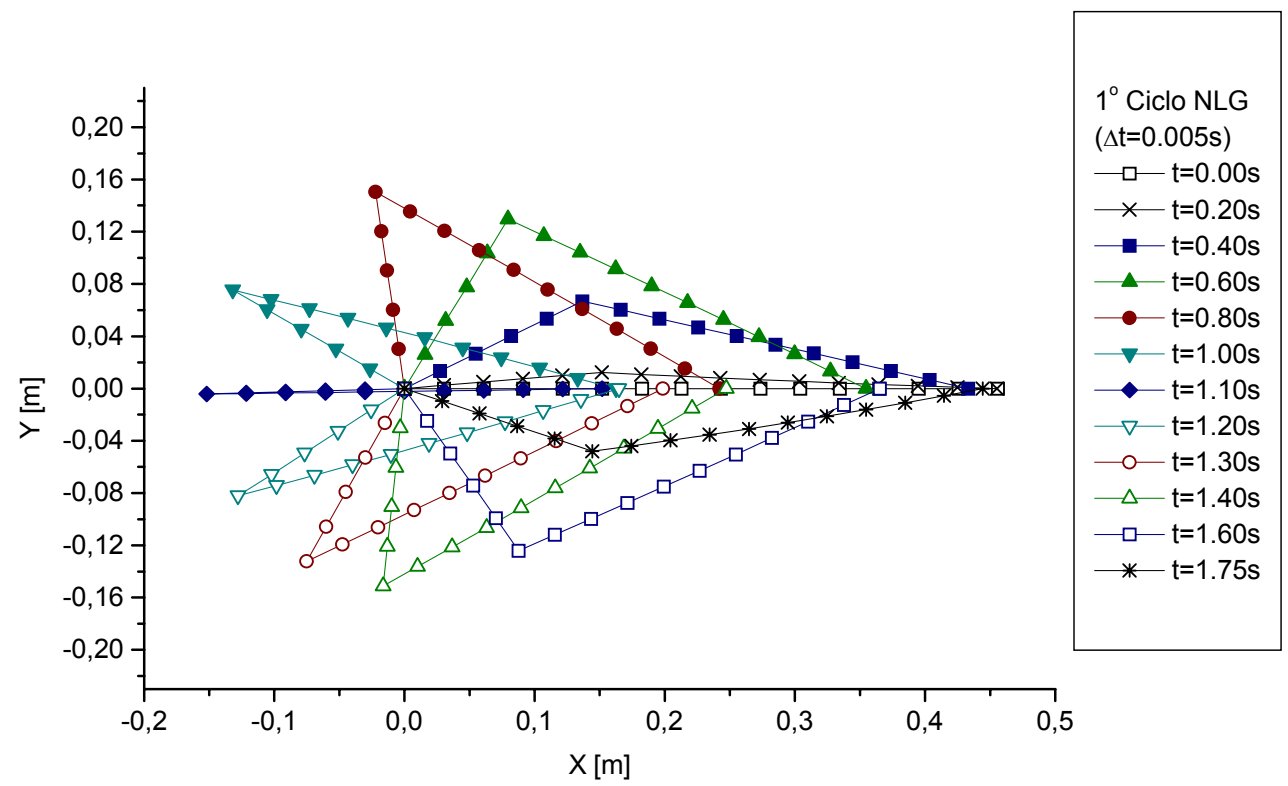

Figura 24 - Configurações do mecanismo para o carregamento 2 ( $1^{0}$ ciclo de rotação) 
Na figura 25 é apresentado um detalhe da re-numeração dos graus de liberdade na rótula entre o braço mecânico e a haste, de acordo com o acoplamento nodal apresentado no apêndice 4 .
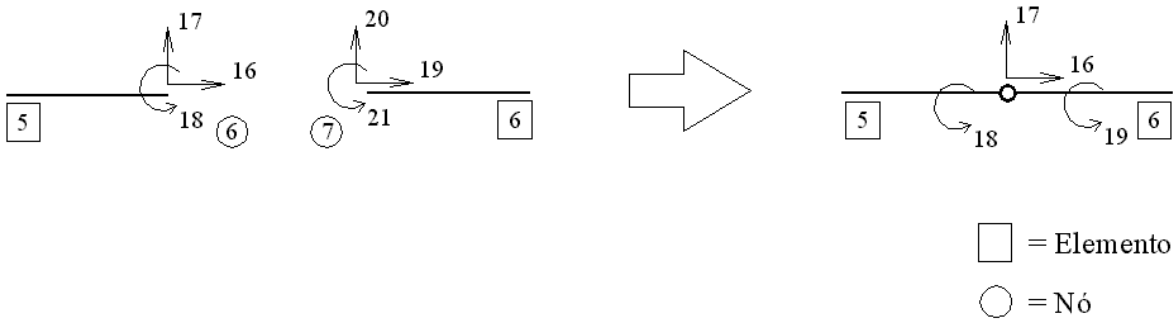

Figura 25 - Re-numeração dos graus de liberdade na rótula

\subsubsection{Mecanismo de Peaucellier flexível}

O exemplo trata da resposta dinâmica de um mecanismo do tipo Peaucellier. Quando considerado rígido, de acordo com SHABANA (1994), este mecanismo é caracterizado por apresentar movimento no nó 20 , ver figura 26 , apenas na direção vertical (segundo o grau de liberdade $U$ ). O objetivo principal deste exemplo é apresentar os desvios de trajetória na direção horizontal do nó 20, quando se considera um mecanismo flexível. A estrutura foi discretizada em 45 elementos finitos, considerando-se nós duplos ou triplos nas posições de rótulas; os graus de liberdade renumerados dos nós que constituem as rótulas são apresentados na figura 27. O carregamento prescrito na base do braço mecânico é apresentado na figura 28 . Escolheu-se um carregamento com mudança no sentido de aplicação, de maneira a amplificar as vibrações nos elementos estruturais.
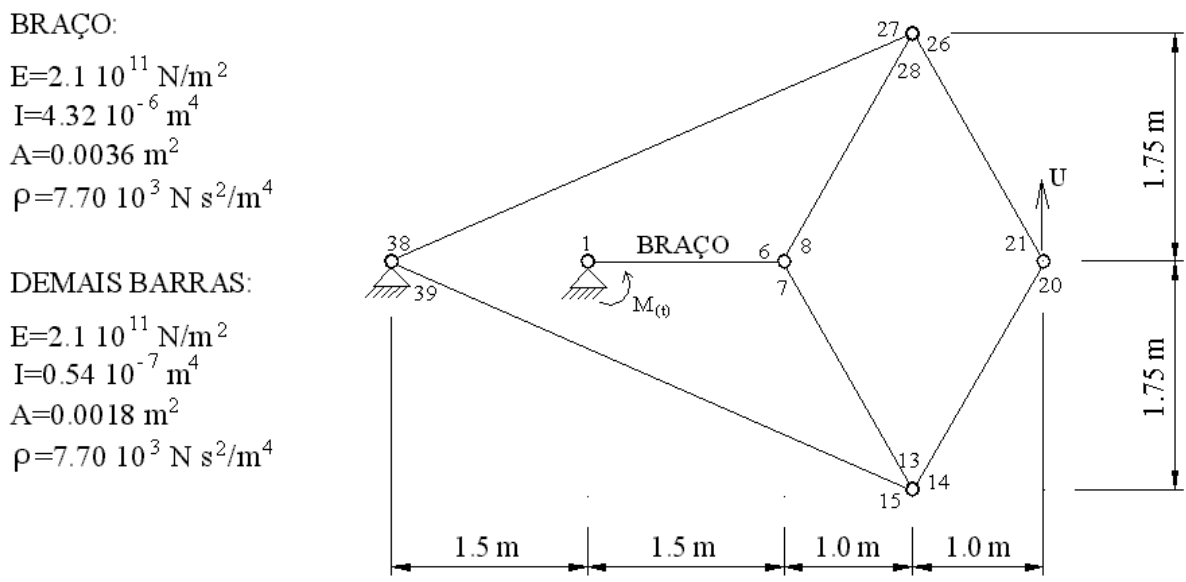

Figura 26 - Dados de entrada do problema 

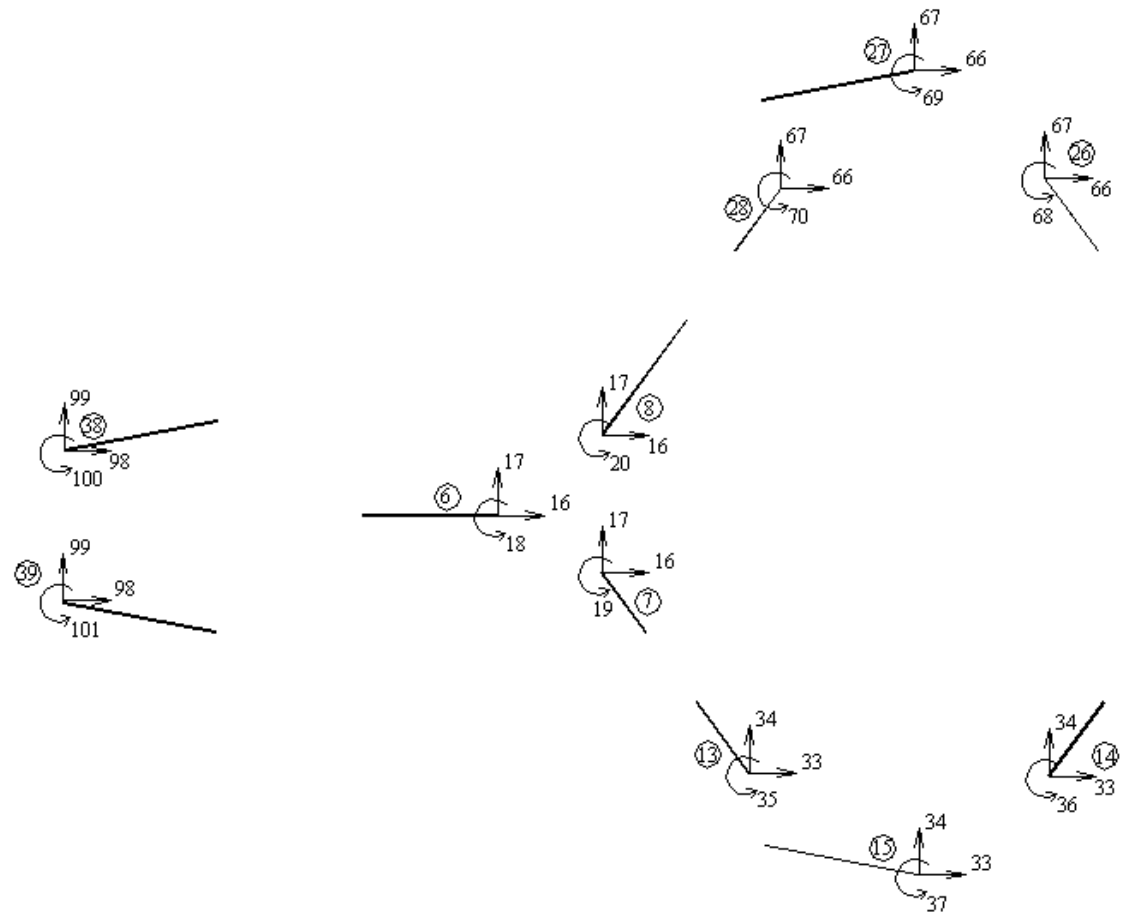

Figura 27 - Re-numeração dos graus de liberdade nas rótulas do mecanismo

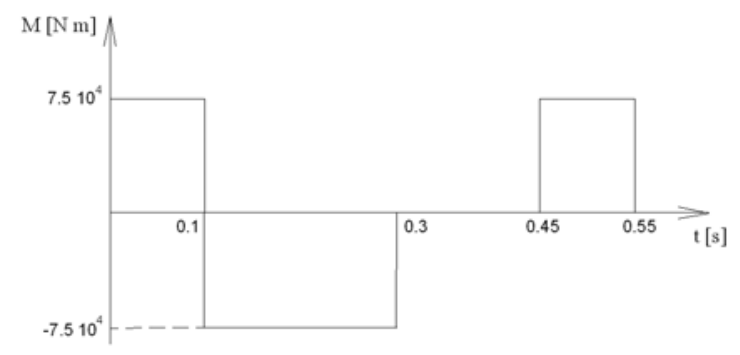

Figura 28 - Carregamento prescrito no apoio do braço mecânico

Na figura 29 é apresentado o desvio na direção horizontal do nó 20 , em $\mathrm{mm}$. Nas figuras de números 30 a 33 são apresentadas as configurações no mecanismo para quatro instantes de tempo. 

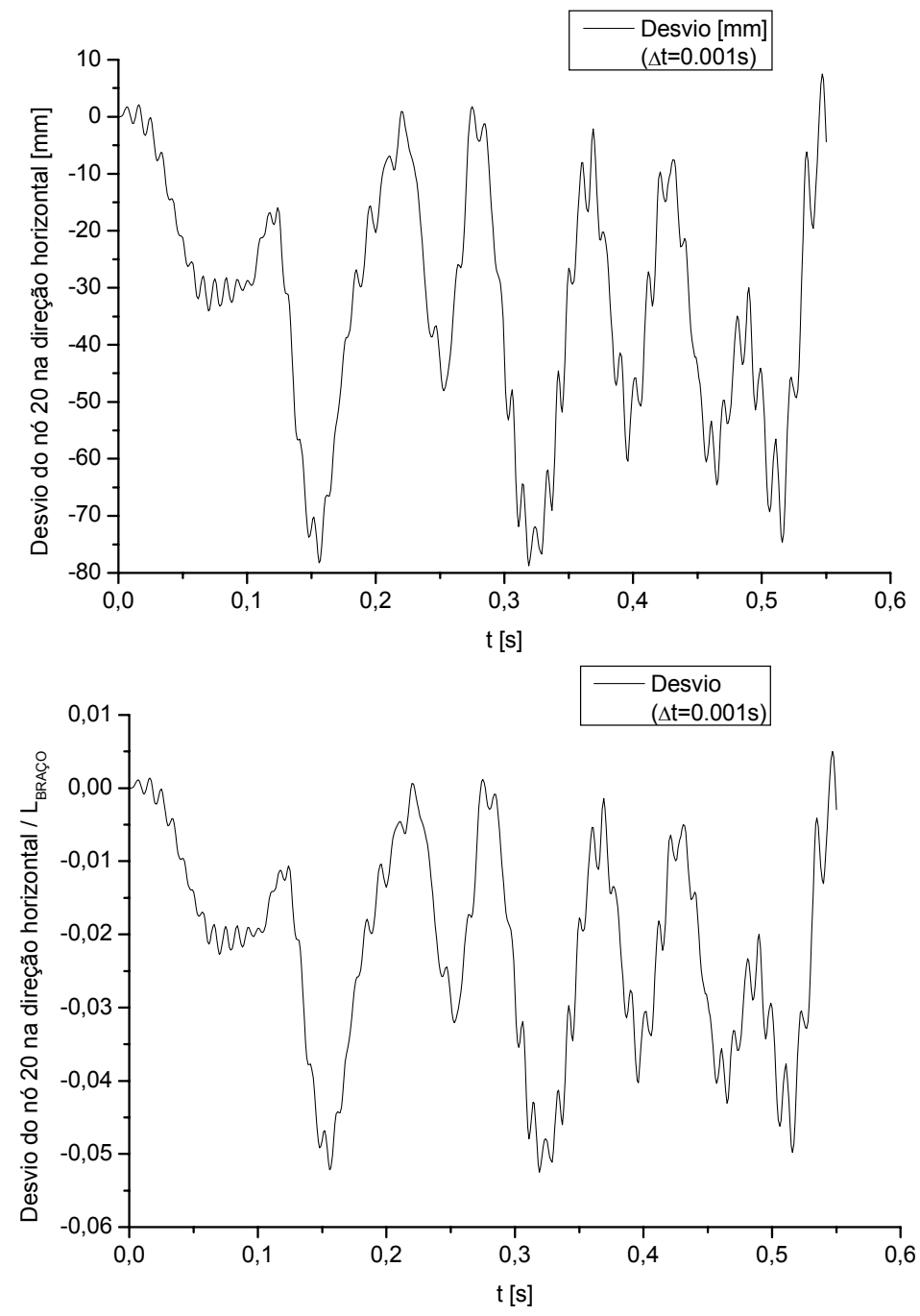

Figura 29 - Tempo $\times$ desvio na direção horizontal $(X)$ do nó 20

Observando-se a figura 29, percebe-se que ocorrem desvios consideráveis. Estes desvios podem ser inaceitáveis em máquinas projetadas para trabalharem em manufatura de alta precisão. 


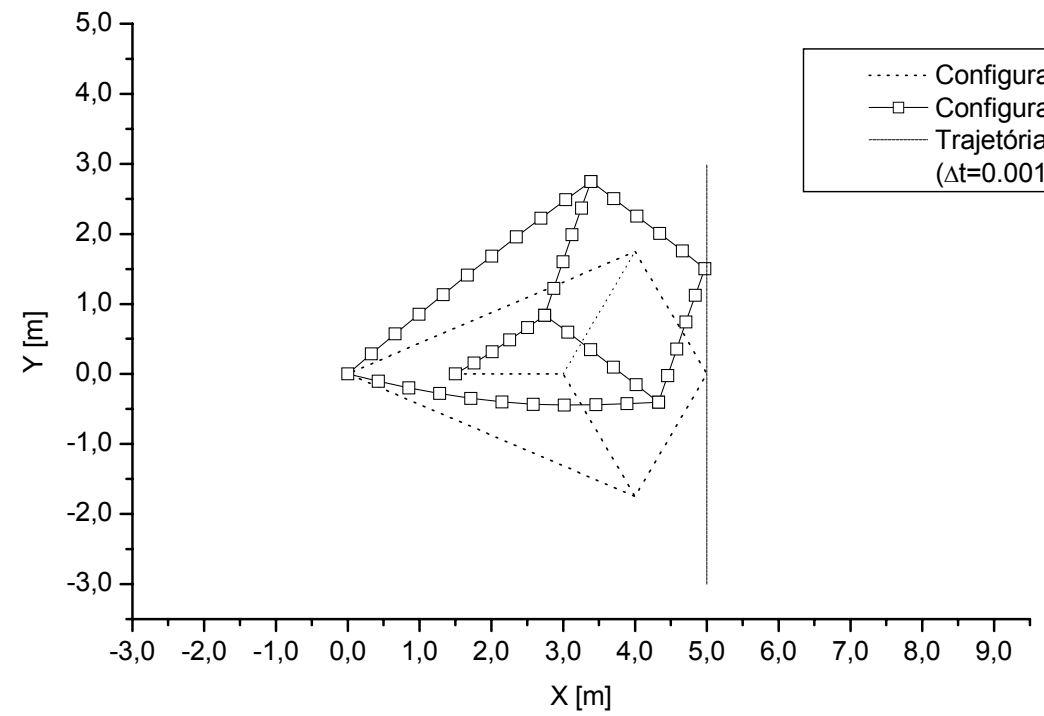

Figura 30 - Configuração do mecanismo para o tempo $t=0.106 \mathrm{~s}$

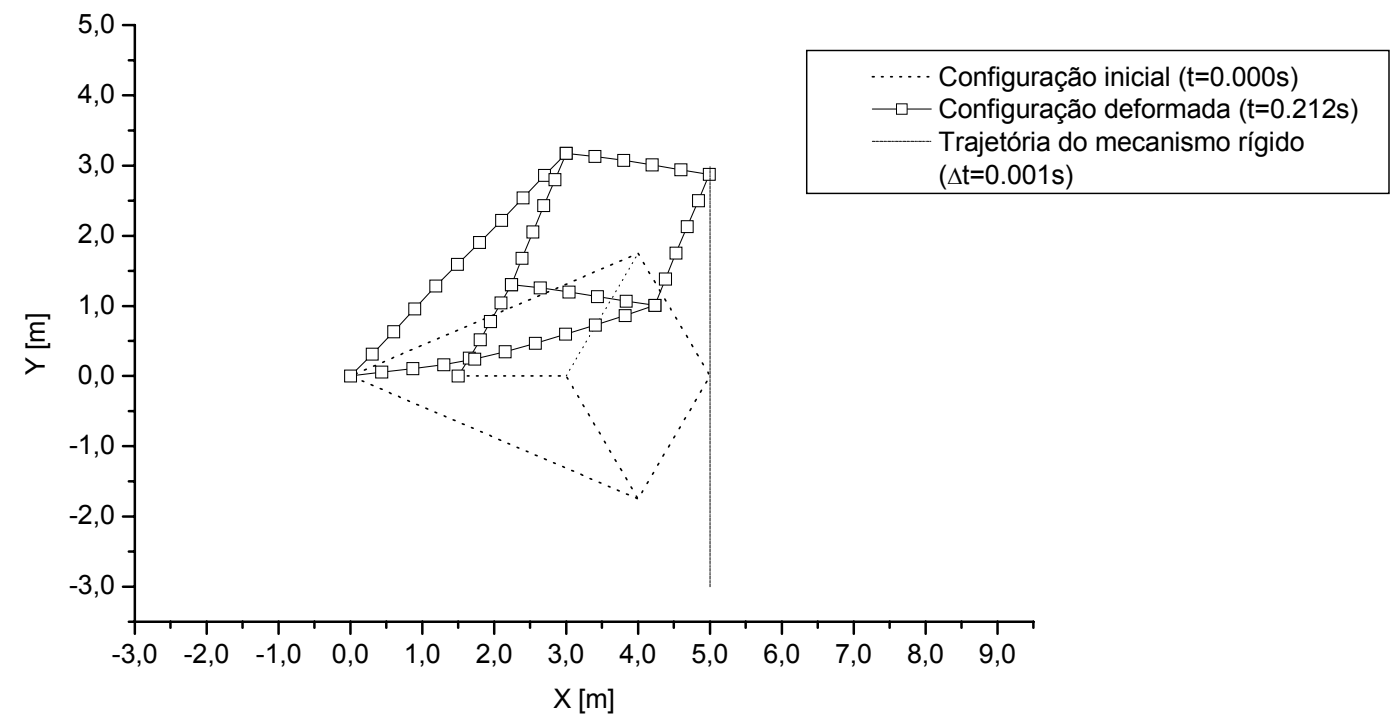

Figura 31 - Configuração do mecanismo para o tempo $t=0.212 \mathrm{~s}$ 


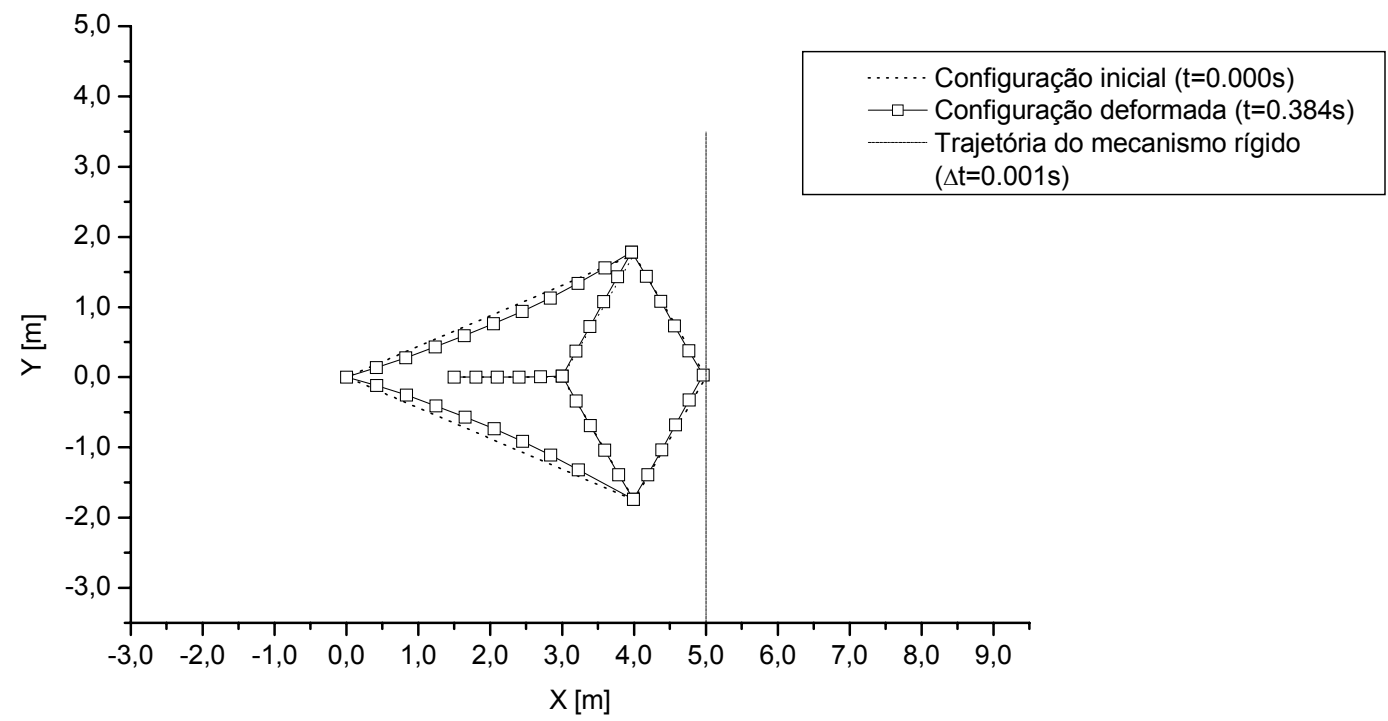

Figura 32 - Configuração do mecanismo para o tempo $t=0.384 \mathrm{~s}$

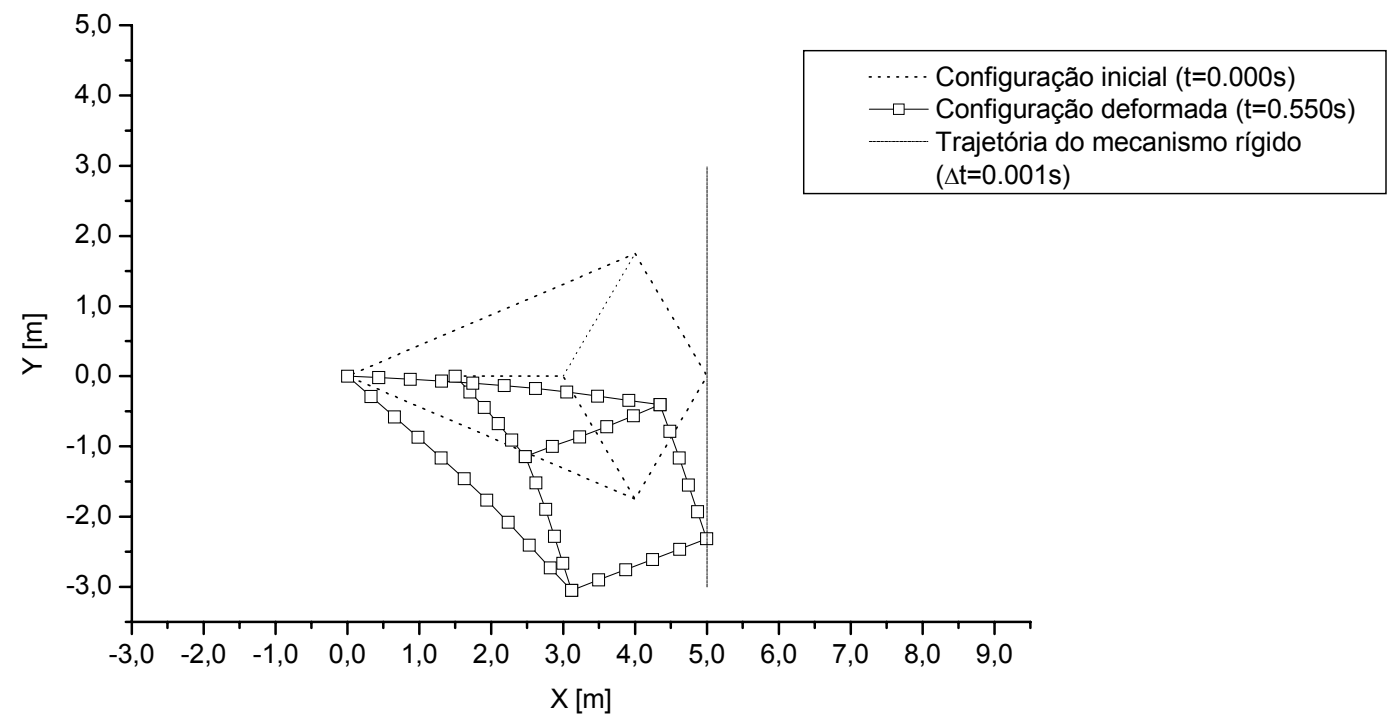

Figura 33 - Configuração do mecanismo para o tempo $t=0.550 \mathrm{~s}$

Pelo apresentado nas configurações do mecanismo, verifica-se que o funcionamento é próximo do esperado. Ocorrem desvios consideráveis do movimento na direção horizontal, e também grandes vibrações nas duas barras de maior comprimento. Para diminuir estes desvios pode-se aumentar a rigidez dos membros estruturais ou, quando possível, diminuir a amplitude dos deslocamentos verticais (através da mudança no carregamento). 


\section{IMPACTO ENTRE ESTRUTURAS RETICULADAS PLANAS E ANTEPARO RÍGIDO}

\subsection{Considerações iniciais}

Este capítulo é dedicado ao estudo de problemas envolvendo impacto entre estrutura reticulada e anteparo rígido. Em algumas partes deste capítulo serão abordados pontos também válidos para o impacto entre estruturas.

A formulação do impacto será feita com base no método do multiplicador de Lagrange em conjunto com um integrador temporal de Newmark adequado ao problema.

Durante o doutorado foi desenvolvido um novo algoritmo de identificação de contato/impacto bidirecional entre estruturas reticuladas. O algoritmo é válido para impacto de pontos nodais de uma estrutura (projétil) em uma outra estrutura, chamada de estrutura alvo. A identificação dos pontos nodais que sofreram impacto nos elementos da estrutura alvo é feita com base na teoria de equações integrais aplicadas a problemas potenciais bidimensionais. Os trabalhos de JASWON (1963) e de SYMM (1963) são referências importantes sobre métodos baseados nas equações integrais aplicados a problemas potenciais. A idéia é fazer uma analogia entre o problema real de impacto, modelado por elementos finitos, e um problema virtual de mesma geometria, modelado por elementos de contorno. Portanto, o problema chamado de virtual não existe de fato, serve apenas para fornecer informações sobre as posições dos pontos nodais da estrutura projétil em relação ao contorno da estrutura alvo. Como a geometria dos elementos finitos é igual à geometria dos elementos de contorno virtuais, na estrutura alvo, é possível utilizar o Método dos Elementos de Contorno (MEC) para analisar as posições relativas entre os pontos de uma estrutura qualquer e os elementos da estrutura alvo. Este processo pode ser estendido para estruturas de chapa, bastando representar os contornos das estruturas envolvidas no impacto através do modelo virtual. $\mathrm{O}$ retorno dos pontos que sofreram impacto também será feito com base nas 
informações fornecidas pelo problema virtual modelado pelo MEC. É importante observar que existem algoritmos de impacto (ou contato) desenvolvidos utilizando-se o MEC, sendo que os algoritmos de previsão de contato e retorno são totalmente similares àqueles empregados pelo $\mathrm{MEF}^{1}$, ou seja, a técnica aqui proposta é original tanto em aplicações com o MEF quanto com o MEC.

No algoritmo de retorno considerou-se a possibilidade da existência de atrito na superfície de contato da estrutura alvo, através de uma interpretação geométrica do modelo de atrito de Coulomb.

Com a nova formulação não linear geométrica é possível resolver problemas de contato/impacto com grandes deslocamentos e rotações, e também problemas envolvendo comportamento pós-crítico nas estruturas, como os apresentados nos artigos de WRIGGERS et al. (1990) e SIMO et al. (1986).

\subsection{Algoritmo de identificação do impacto}

O algoritmo de identificação do impacto é baseado nas equações integrais de um problema potencial relacionado ao contorno da estrutura alvo. Conforme ilustrado na figura 1, existem três tipos principais de domínios de integração, o finito, o infinito e os corpos finitos com cavidades internas. O que define o tipo de contorno, externo ou interno, é sentido de integração, horário para o domínio infinito e anti-horário para o domínio finito. Assim, o algoritmo aqui desenvolvido não se limita à análise de corpos sem orifícios que colidem entre si, mas possibilita também a análise de impacto de corpos no interior de domínios finitos com cavidade.

Na figura 1, as letras gregas $\eta$ e $\Gamma$ representam, respectivamente, a direção normal e a direção tangencial em relação ao contorno integrado. Após a definição do tipo de domínio a ser integrado é feita a discretização do corpo alvo em elementos de contorno; no caso são utilizados elementos de contorno lineares e coincidentes com os elementos finitos da estrutura alvo, conforme a figura 2.

\footnotetext{
${ }^{1}$ BELYTSCHO \& NEAL (1991); ZHONG \& NILSSON (1996); LORENZANA \& GARRIDO (1998); ULAGA et al. (1999); LANDENBERGER \& EL-ZAFRANY (1999); LI et al. (2001).
} 


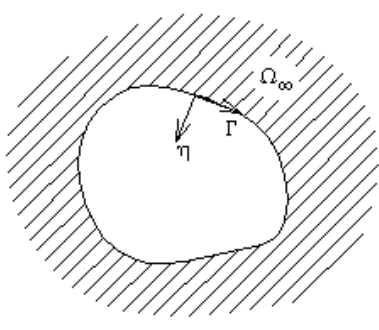

Domínio infinito

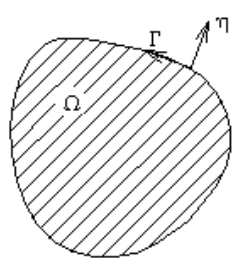

Domínio finito

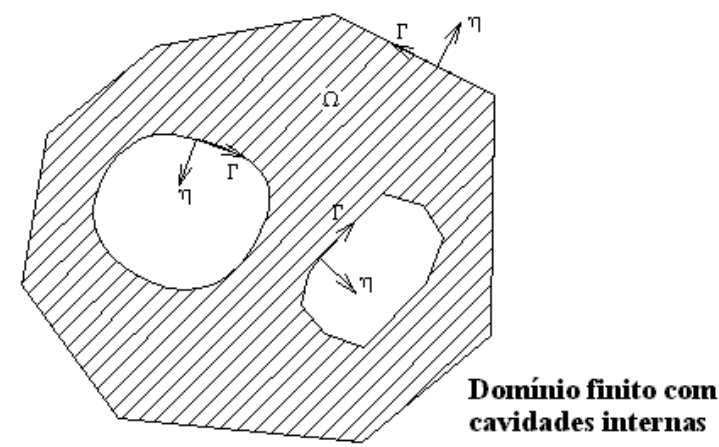

Figura 1 - Tipos de domínio

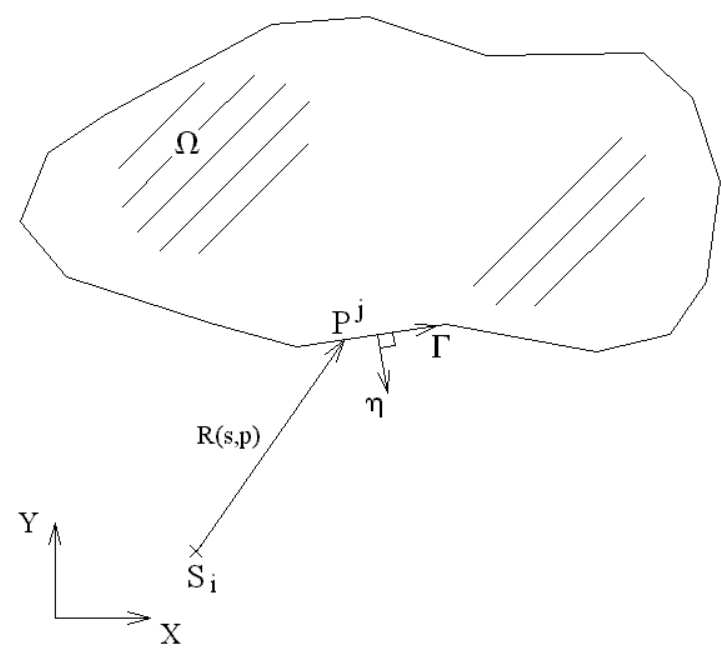

Figura 2 - Integração de um corpo finito discretizado em elementos de contorno lineares

Considera-se que cada ponto nodal da estrutura que se colidirá com a estrutura alvo seja um ponto de integração, chamado de ponto fonte ${ }^{2}(S)$, de todos os elementos de contorno da estrutura alvo. Portanto, cada ponto fonte gerará uma equação integral para problema potencial. No caso, optou-se pela distribuição constante de variáveis nos

\footnotetext{
2 Também chamado de ponto de colocação.
} 
elementos de contorno lineares. A variável $R_{(s, p)}$ representa a distância do ponto fonte $(S)$ da estrutura projétil ao ponto de integração ${ }^{3}(P)$ da estrutura alvo.

Para um problema potencial usual, as principais variáveis envolvidas no problema são o potencial $(p)$ e o fluxo $(q)$. O fluxo é relacionado ao potencial pela seguinte expressão:

$q=\frac{\partial p}{\partial \eta}$

Através de um equacionamento clássico do MEC, que pode ser encontrado em KANE (1994), obtém-se a equação integral de contorno para o problema potencial.

$$
c_{(S)} p_{(S)}+\int_{\Gamma} q^{*} p d_{\Gamma}=\int_{\Gamma} p^{*} \frac{\partial p}{\partial \eta} d_{\Gamma}
$$

Onde as variáveis com um asterisco sobrescrito representam as soluções fundamentais do problema.

$$
\begin{aligned}
& p^{*}=\frac{-1}{2 \pi} \ln R \\
& q^{*}=\frac{-1}{2 \pi R} \frac{\partial R}{\partial \eta}
\end{aligned}
$$

O valor do parâmetro livre $\left(c_{(S)}\right)$ da equação integral (2) depende da posição do ponto fonte. A variável $p_{(S)}$ representa o potencial no ponto de colocação.

Onde:

- $c_{(S)}=0$ para pontos $S$ externos ao domínio.

- $c_{(S)}=\frac{\alpha}{2 \pi}$ para pontos $S$ no contorno ( $\alpha$ é o ângulo no contorno).

- $c_{(S)}=\frac{\pi}{2 \pi}=0.5$ para pontos $S$ no contorno (contorno suave).

- $c_{(S)}=1$ para pontos $S$ internos ao domínio.

Para distribuição constante de potenciais nos $N$ elementos de contorno, com um nó no centro de cada elemento, tem-se a seguinte equação para cada ponto fonte:

$$
c_{(S)} p_{(S)}+\sum_{j=I}^{N}\left(\int_{\Gamma} q^{*} d_{\Gamma}\right) p_{j}=\sum_{j=I}^{N}\left(\int_{\Gamma} p^{*} d_{\Gamma}\right) q_{j}
$$

Pode-se escrever a equação (6) na forma algébrica.

\footnotetext{
${ }^{3}$ Também chamado de ponto campo.
} 
$c_{(S)} p_{(S)}+\sum_{j=1}^{N} \hat{H}_{j} p_{j}=\sum_{j=1}^{N} G_{j} q_{j}$

Deve-se determinar o valor de $c_{(S)}$ para os pontos nodais da estrutura projétil. Para um problema particular, mas possível, de potencial constante em toda estrutura alvo e, portanto, fluxo nulo no contorno, tem-se:

$c_{(S)}=-\sum_{j=1}^{N} \hat{H}_{j}$

A partir da equação (8) pode-se calcular o parâmetro livre $c_{(S)}$. Com este parâmetro é possível saber se algum nó da estrutura projétil penetrou na estrutura alvo, com base nas afirmações apresentadas no conjunto de equações (5).

Imaginando-se que não se conhece a posição do ponto fonte em relação à estrutura alvo, utiliza-se desta propriedade para calcular o parâmetro livre da equação integral. Com o valor calculado do parâmetro livre é possível saber se o ponto fonte está fora do domínio da estrutura alvo ${ }^{4}(\Sigma \hat{H}=0)$, no contorno da estrutura alvo ${ }^{5}(\Sigma \hat{H}$ $=-0.5)$ ou dentro da estrutura alvo ${ }^{5}(\Sigma \hat{H}=-1)$. No caso de ter ocorrido impacto, ainda é possível identificar para qual elemento finito da estrutura alvo o ponto nodal deverá retornar, ou seja, para o elemento de contorno $j$ cuja integração $\left(\hat{H}_{j}\right)$ forneça valor mais próximo de 0.5 (contorno suave).

$\Sigma \hat{H}=\sum_{j=1}^{N} \hat{H}_{j}=\sum_{j=I}^{N}\left(\int_{\Gamma} q^{*} d_{\Gamma}\right)$

Deve-se agora calcular os valores do coeficientes $\hat{H}_{j}$. Existem muitas maneiras de calcular estes valores, várias delas podem ser encontradas em BANERJEE (1994). Uma alternativa é calcular numericamente os valores, através de pontos de Gauss, com o cuidado de calcular as integrais através do Valor Principal de Cauchy (VPC) quando o ponto fonte estiver localizado em algum elemento de contorno. Esta integração singular usando-se o VPC é necessária devido à singularidade do núcleo integral de $q^{*}$, equação (4). Este procedimento é usual no MEC, porém utilizar-se-á um procedimento analítico, matematicamente mais simples e elegante para o cálculo dos componentes $\hat{H}_{j}$. O procedimento de cálculo, independentemente da posição do ponto fonte, segue o esquema apresentado na figura 3 , onde há um sistema de coordenadas global $(X Y)$ e outro sistema de coordenadas local $(\bar{X} \bar{Y})$.

\footnotetext{
${ }^{4}$ Não ocorreu impacto no ponto nodal.

${ }^{5}$ Ocorreu impacto no ponto nodal.
} 


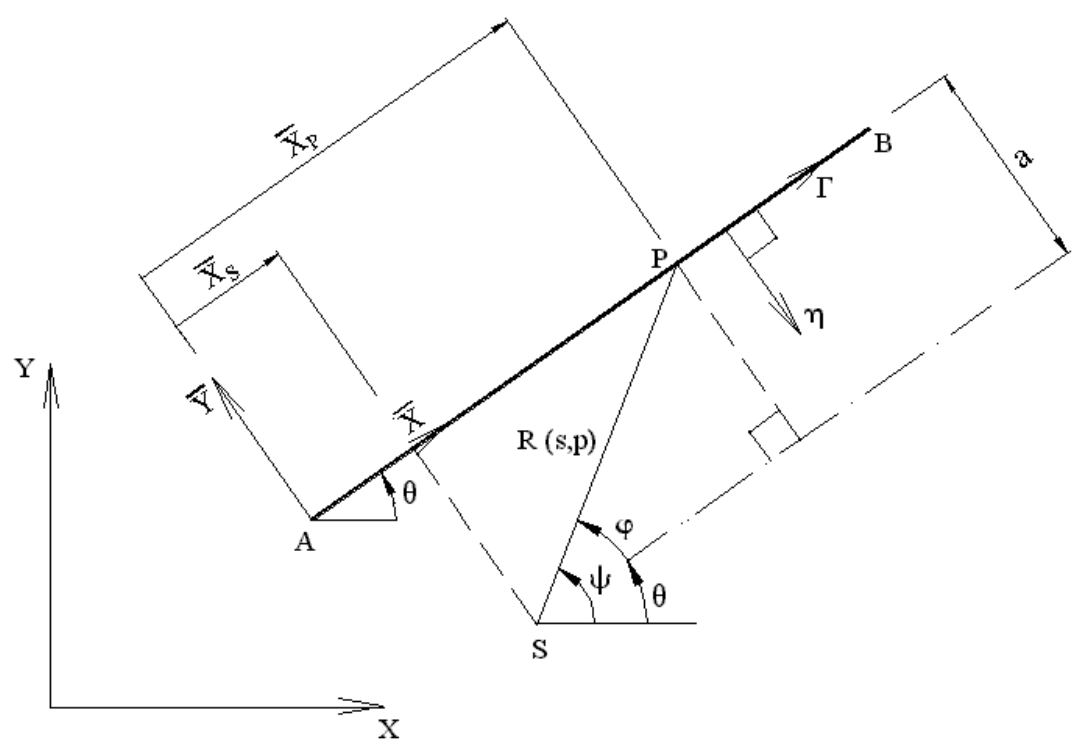

Figura 3 - Integração de um elemento de contorno

A integral $\hat{H}_{j}$ é calculada para cada elemento de contorno $j$.

$\hat{H}_{j}=\int_{\Gamma} \frac{-1}{2 \pi R} \frac{\partial R}{\partial \eta} d_{\Gamma}=\int_{\Gamma} \frac{-1}{2 \pi R}\left(\frac{\partial R}{\partial X} \eta_{X}+\frac{\partial R}{\partial Y} \eta_{Y}\right) d_{\Gamma}$

Observando-se a figura 3, pode-se reescrever a equação (10) de forma mais conveniente.

$\hat{H}_{j}=\int_{\Gamma} \frac{-1}{2 \pi R}\left(\frac{\partial R}{\partial X} \eta_{X}+\frac{\partial R}{\partial Y} \eta_{Y}\right) d_{\Gamma}=\int_{\Gamma} \frac{-1}{2 \pi R}(\cos \psi \operatorname{sen} \theta-\operatorname{sen} \psi \cos \theta) d_{\Gamma}$

Pelo sistema local de eixos, escreve-se:

$R=\frac{-a}{\operatorname{sen} \varphi}$

Onde o termo $a$ mede a distância entre o ponto fonte e o elemento de contorno virtual. É possível obter uma equação em coordenadas locais para a posição do ponto de integração $(P)$.

$\bar{X}_{P}=\bar{X}_{S}-a \frac{\cos \varphi}{\operatorname{sen} \varphi}$

Pode-se estabelecer uma relação diferencial em coordenadas locais no contorno.

$d \bar{X}_{P}=d \Gamma$

Derivando-se a equação (13) em relação ao ângulo $\varphi$, tem-se: 
$\frac{d \bar{X}_{P}}{d \varphi}=\frac{a}{\operatorname{sen}^{2} \varphi}$

Considerando-se as equações (14) e (15), escrever-se:

$d \Gamma=\frac{a}{\operatorname{sen}^{2} \varphi} d \varphi$

Substituindo-se as equações (12) e (16) em (11) obtém-se a integral escrita em função de $\varphi$, para cada elemento de contorno, independentemente da posição do ponto fonte e seu resultado analítico em forma fechada pode ser facilmente encontrado.

$\hat{H}_{j}=\int_{\Gamma} \frac{1}{2 \pi \operatorname{sen} \varphi}(-\operatorname{sen}(\psi-\theta)) d \varphi=\int_{\Gamma} \frac{1}{2 \pi \operatorname{sen} \varphi}(-\operatorname{sen} \varphi) d \varphi=\int_{\varphi_{A}}^{\varphi_{B}} \frac{-1}{2 \pi} d \varphi=\frac{\varphi_{A}-\varphi_{B}}{2 \pi}$

Na equação (17), $\varphi_{A}$ é o ângulo $\varphi$ medido em relação ao nó inicial do elemento de contorno (nó $A$ ) e $\varphi_{B}$ é o ângulo $\varphi$ medido em relação ao nó final do elemento de contorno (nó $B$ ). A equação (17) é extremamente simples, mas se deve tomar o cuidado para que $-\pi \leq \varphi_{A}-\varphi_{B} \leq \pi$. Quando não for atendido este critério, deve-se seguir a regra abaixo:

- Se $\Delta \varphi=\varphi_{A}-\varphi_{B}>\pi$, então: $\Delta \varphi=\Delta \varphi-2 \pi$.

- Se $\Delta \varphi<-\pi$, então: $\Delta \varphi=\Delta \varphi+2 \pi$.

Portanto, a equação (8) pode ser resumida na seguinte expressão:

$c_{(S)}=\frac{-1}{2 \pi} \sum_{j=1}^{N} \Delta \varphi_{j}$

Deve-se comentar que este procedimento também pode ser utilizado em problemas tridimensionais, fazendo-se uso das respectivas expressões apropriadas. No caso de estruturas alvo ou anteparos rígidos abertos, conforme ilustrado nas figuras $4 \mathrm{e}$ 5, pode-se utilizar o artifício do elemento mudo para delimitar as regiões de contato/impacto do alvo. 


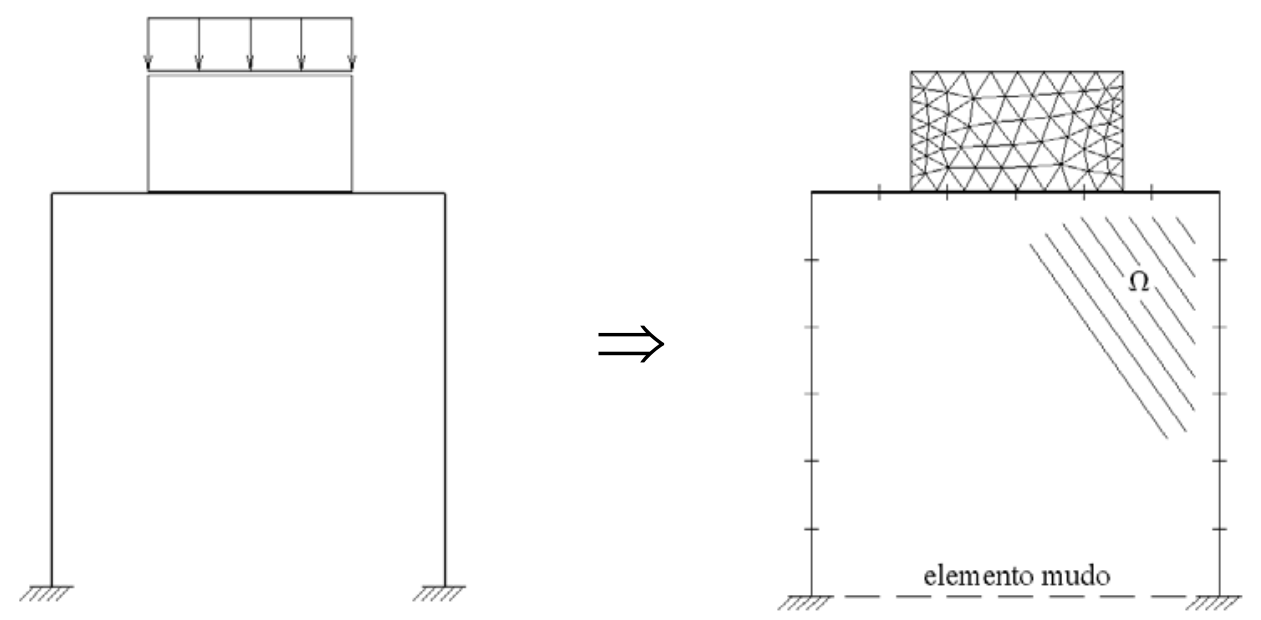

Figura 4 - Utilização de elementos mudos na modelagem de estrutura alvo

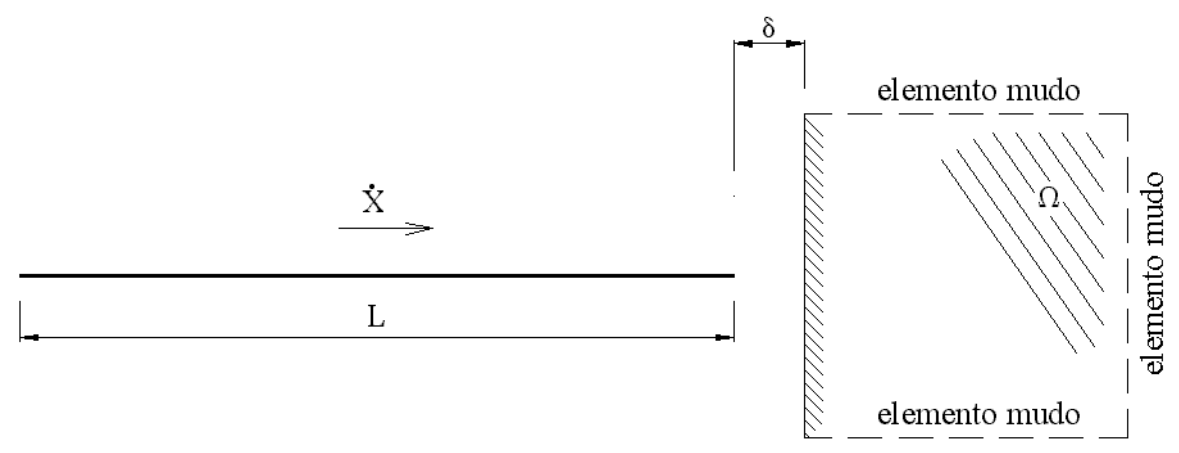

Figura 5 - Utilização de elementos mudos na modelagem de anteparo rígido

Durante o contato/impacto, o modelo de atrito utilizado é baseado na interpretação geométrica do modelo de atrito de Coulomb, onde dependendo de um coeficiente de retorno $R$, que varia de 0 a 1 , um ponto impactante com trajetória $C D$ pode retornar dentro de um intervalo na posição sem atrito até a posição de aderência total. Na figura 6 são apresentados os principais ângulos envolvidos em uma análise de contato bidimensional. Todos os ângulos são medidos no sentido anti-horário, portanto o ângulo $\omega$ ilustrado na figura possui sinal negativo. 


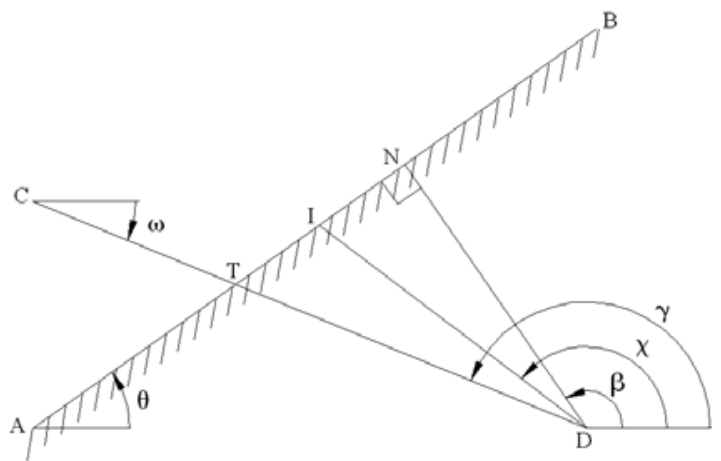

Figura 6 - Ângulos envolvidos na análise do contato bidimensional

$\mathrm{O}$ ângulo $\beta$ indica a direção normal ao anteparo $A B$, a partir do ponto $\mathrm{D}$, e é calculado pela seguinte expressão:

$\beta=90^{\circ}+\theta$

Com o ângulo $\beta$ calcula-se o coeficiente de inclinação de reta do segmento $D N$ $\left(m_{D N}\right)$.

$m_{D N}=\operatorname{tg} \beta$

O ângulo $\gamma$ indica a direção do ponto $D$ ao ponto $C$.

$\gamma=180^{\circ}+\omega$

O ângulo $\omega$ pode ser calculado considerando-se o coeficiente de inclinação de reta do segmento $C D\left(m_{C D}\right)$, quando $X_{D} \neq X_{C}$.

$\omega=\operatorname{arctg}\left(m_{C D}\right)=\operatorname{arctg}\left(\frac{Y_{D}-Y_{C}}{X_{D}-X_{C}}\right)$

Com o ângulo do elemento alvo de retorno $(\theta)$ calcula-se o coeficiente de inclinação de reta do segmento $A B\left(m_{A B}\right)$.

$m_{A B}=\frac{Y_{B}-Y_{A}}{X_{B}-X_{A}}=\operatorname{tg} \theta$

Considerando-se as expressões (20) e (23), pode-se calcular a posição do ponto $N$.

$X_{N}=\frac{Y_{D}-Y_{A}+m_{A B} X_{A}-m_{D N} X_{D}}{m_{A B}-m_{D N}}$

$Y_{N}=Y_{A}+\frac{m_{A B}}{m_{A B}-m_{D N}}\left[Y_{D}-Y_{A}+m_{D N}\left(X_{A}-X_{D}\right)\right]$

$\mathrm{O}$ ponto $N$ pode ser associado à posição de retorno tentativa, referente à condição de atrito nulo. 


\subsection{Atrito no contato}

O modelo de atrito de Coulomb, ver apêndice 6, estabelece uma proporção direta entre as forças normais $\left(F_{\eta}\right)$ que ocorrem na região de contato e forças tangenciais $\left(F_{\tau}\right)$ que são geradas devido ao atrito entre a superfície de contato e o corpo que sofre colisão.

$$
F_{\tau}=\mu F_{\eta}
$$

O coeficiente de proporcionalidade $\mu$ é chamado de coeficiente de atrito e pode ser classificado em estático $\left(\mu_{S}\right)$ ou dinâmico $\left(\mu_{K}\right)$. O coeficiente de atrito estático é maior que o dinâmico, experimentalmente verifica-se que a força necessária para atingir a força tangencial de atrito é maior quando o corpo está em repouso e menor quando este mesmo corpo já se encontra em movimento. Nesta tese utilizar-se-á o coeficiente $\mu$ para se referir a $\mu_{K}$, uma vez que o objetivo do trabalho é analisar problemas de contato dinâmico.

O modelo de atrito de Coulomb é vastamente empregado em problemas de contato/impacto. Neste trabalho, propõe-se um modelo alternativo para a consideração de atrito em problemas de impacto. Este modelo é baseado no ângulo de retorno $(\chi)$ que posiciona o nó que sofreu impacto numa posição do anteparo (ponto $I$ ) intermediária entre a posição de atrito nulo (ponto $N$ ) e a posição de atrito máximo (ponto $T$ ), ou condição de aderência, de acordo com a figura 6 . O ângulo de retorno está associado a um coeficiente de retorno $(R)$, que varia de 0 (sem atrito) a 1 (atrito máximo). As vantagens desta interpretação geométrica do atrito são a possibilidade de retorno do ponto apenas entre os pontos $N$ e $T$, e a facilidade de implementação computacional. Porém uma desvantagem é a falta de valores experimentais do coeficiente de retorno $R \mathrm{e}$ como conseqüência, a necessidade de associar estes coeficientes de retorno a outros coeficientes de atrito conhecidos.

$$
\chi=90^{\circ}+\theta+R\left(90^{\circ}-\theta+\omega\right)
$$

Desta maneira, pode-se encontrar a posição do ponto $I$ no anteparo.

$$
\begin{aligned}
& m_{D I}=\operatorname{tg} \chi \\
& X_{I}=\frac{Y_{D}-Y_{A}+m_{A B} X_{A}-m_{D I} X_{D}}{m_{A B}-m_{D I}} \\
& Y_{I}=Y_{A}+\frac{m_{A B}}{m_{A B}-m_{D I}}\left[Y_{D}-Y_{A}+m_{D I}\left(X_{A}-X_{D}\right)\right]
\end{aligned}
$$


As equações (28), (29) e (30) não são válidas nos casos $X_{D}=X_{C}$ e $X_{A}=X_{B}$. Para estas duas situações, devem ser obtidas outras equações semelhantes que possibilitem o cálculo da posição do ponto $N$. A primeira situação particular pode ser observada na figura 7 , neste caso $X_{D}=X_{C}$.
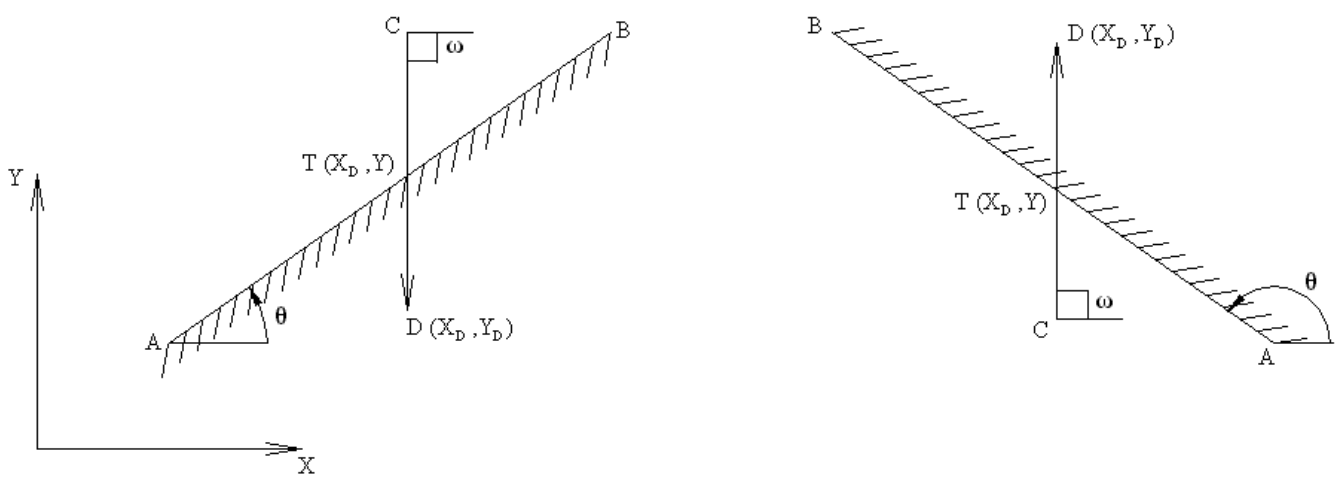

Figura 7 - Caso de trajetória vertical (paralela ao eixo Y)

Ocorrerá um problema no cálculo do coeficiente $m_{D I}$ quando $R=1$. Nesta situação, as equações (29) e (30) podem ser substituídas pelas seguintes expressões:

$X_{I}=X_{D}$

$Y_{I}=Y_{A}+m_{A B}\left(X_{D}-X_{A}\right)$

No caso em que $X_{A}=X_{B}$, ilustrado na figura 8 , também não são válidas as equações (24) e (25).

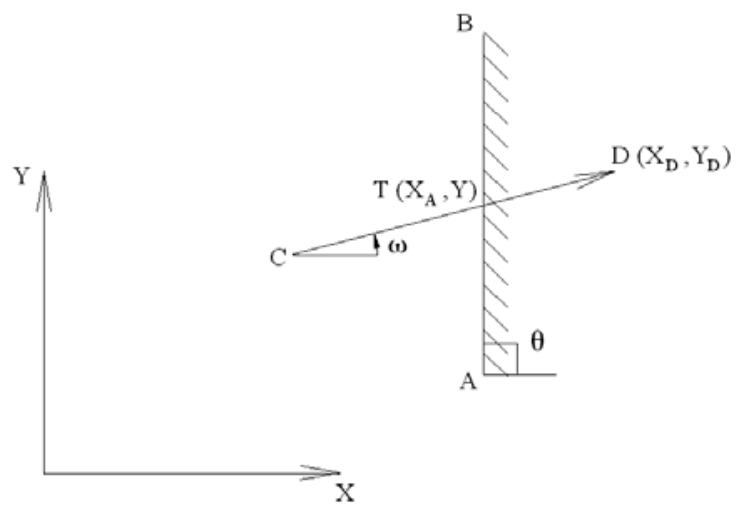

Figura 8 - Caso de anteparo vertical (paralelo ao eixo Y)

Nesta situação, as equações (24), (25), (29) e (30) podem ser substituídas pelas seguintes expressões:

$X_{N}=X_{A}=X_{B}=X_{I}$ 
$Y_{N}=Y_{D}$

$Y_{I}=Y_{D}+m_{D I}\left(X_{A}-X_{D}\right)$

\subsection{O multiplicador de Lagrange}

Consiste em uma técnica de cálculo destinada a incorporar uma restrição em uma função objetiva. Em problemas de impacto a variável a ser otimizada é a posição $(X)$, descrita pela equação dinâmica de equilíbrio, e a restrição é obtida pela condição de penetração nula (CPN) entre os corpos que colidem. Neste caso, o multiplicador de Lagrange $(\lambda)$ representa as forças de contato que atuam nas superfícies, comuns aos corpos no instante do impacto.

Na figura 9 é apresentado um problema unidirecional ${ }^{6}$ de impacto de uma barra com um anteparo rígido, onde para que ocorra o impacto, fisicamente, é necessário que $X-\delta \geqslant 0$.

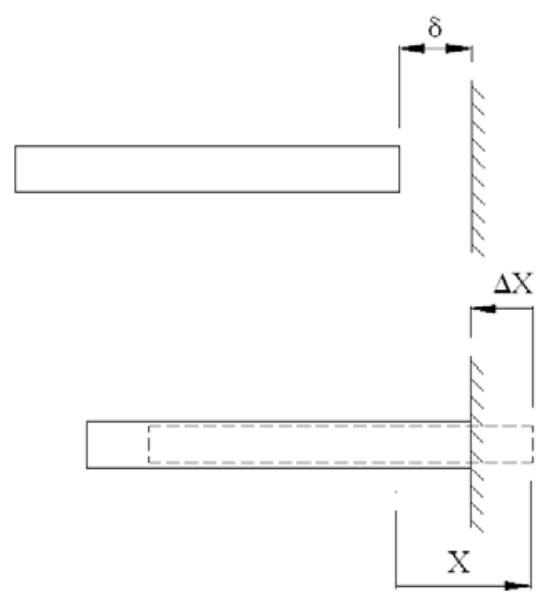

Figura 9 - Impacto unidirecional de uma barra com um anteparo rígido

Sendo $\delta$ é a distância inicial entre pontos que poderão entrar em contato ${ }^{7}$ e $\Delta X$ a correção na posição do nó impactante necessária para que seja atendida a CPN. O multiplicador de Lagrange pode ser entendido como a força necessária para restituir a posição de penetração nula, impedindo que ocorra $\Delta X$ entre o anteparo e a estrutura; em uma situação limite, na qual a penetração não ocorre nem como previsão numérica, $\lambda$ se confunde com a força de contato entre os corpos.

\footnotetext{
${ }^{6}$ Com possibilidade de correções em posições nodais apenas em uma direção.

${ }^{7}$ No caso, nó de extremidade da barra e ponto de retorno no anteparo rígido.
} 
Para uma situação mais genérica, as posições dos nós submetidos ao contato/impacto podem estar associadas a uma matriz de restrição de contato $\left(R_{C}\right)$, onde o impacto em uma direção pode afetar o movimento em outras direções. O impacto em anteparo rígido mostrado na figura 9 é relevante apenas na direção horizontal, portanto $R_{C}=1$.

A equação (36) indica a restrição imposta ao problema (CPN).

$R_{C} X-\delta \leq 0$

\subsection{Formulação de impacto baseada no multiplicador de Lagrange}

Para um caso mais geral de impacto entre estruturas, considera-se o impacto entre dois corpos elásticos, apresentado na figura 10 . Tem-se $\Gamma_{1}$ representado as regiões no contorno dos corpos com forças prescritas, $\Gamma_{2}$ representando as regiões no contorno com deslocamentos prescritos e $\Gamma_{\mathrm{C}}$ representado a região de contato entre os dois corpos.

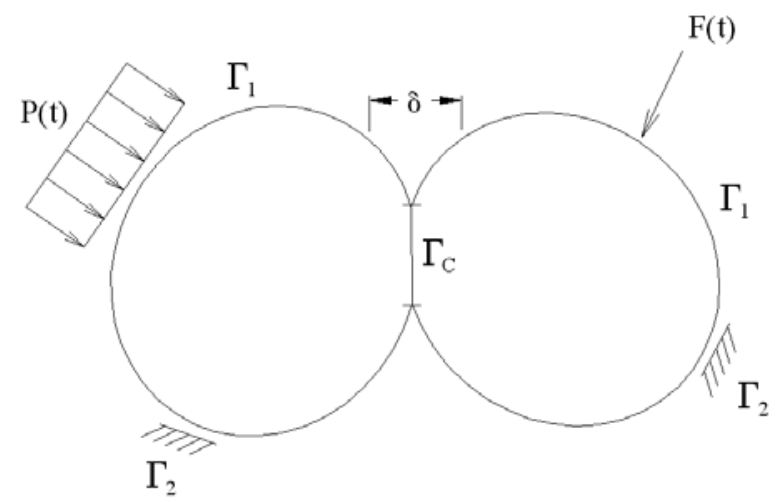

Figura 10 - Impacto entre dois corpos elásticos

Para garantir que não haja superposição dos domínios dos corpos (CPN), na região de contato tem-se a seguinte equação:

$$
R_{C} X_{S+1}=X^{E} \quad \delta=0
$$

Onde $X^{E}$ é a posição do alvo, $X_{S_{+}} l$ é o vetor posição do corpo projétil e $R_{C}$ é a matriz de restrição de contato (usada apenas para representar os efeitos do atrito).

Na região de contato a equação dinâmica de equilíbrio pode ser representada por: 
$\left.\frac{\partial U_{t}}{\partial X}\right|_{S+1}+M \ddot{X}_{S+1}+C \dot{X}_{S+1}=F_{S+1}^{E X T}+R_{C} \lambda_{S+1} \quad X_{S+1} \in \Gamma_{C}$

Sendo $C$ a matriz de amortecimento proporcional à massa $(M)$ e $\lambda_{S+1}$ os multiplicadores de Lagrange, ou forças externas $(F)$ aplicadas nas estruturas de maneira a garantir a CPN. Lembrando que $U_{t}$ é a energia total de deformação do sistema

O algoritmo de integração temporal é do tipo Newmark, com constantes de integração $\gamma$ e $\beta$.

$$
\begin{aligned}
& X_{S+1}=X_{S}+\Delta t \dot{X}_{S}+\Delta t^{2}\left[\left(\frac{1}{2}-\beta\right) \ddot{X}_{S}+\beta \ddot{X}_{S+1}\right] \\
& \dot{X}_{S+1}=\dot{X}_{S}+\Delta t(1-\gamma) \ddot{X}_{S}+\gamma \Delta t \ddot{X}_{S+1}
\end{aligned}
$$

Substituindo-se as equações (39) e (40) em (37) e (38) pode-se obter expressões escritas em função da aceleração.

$$
\begin{aligned}
& \beta \Delta t^{2} R_{C} \ddot{X}_{S+1}=X^{E}-R_{C} b_{0} \\
& (M+\gamma \Delta t C) \ddot{X}_{S+1}=F_{S+1}^{E X T}+R_{C} \lambda_{S+1}-\left.\frac{\partial U_{t}}{\partial X}\right|_{S+1}-C b_{1}
\end{aligned}
$$

Com:

$$
\begin{aligned}
& b_{0}=X_{S}+\Delta t \dot{X}_{S}+\Delta t^{2}\left(\frac{1}{2}-\beta\right) \ddot{X}_{S} \\
& b_{1}=\dot{X}_{S}-\Delta t(1-\gamma) \ddot{X}_{S}
\end{aligned}
$$

As equações (41) e (42) podem ser representadas na forma matricial.

$$
\left[\begin{array}{cc}
(M+\gamma \Delta t C) & -R_{C} \\
\beta \Delta t^{2} R_{C} & 0
\end{array}\right]\left\{\begin{array}{c}
\ddot{X}_{S+1} \\
\lambda_{S+1}
\end{array}\right\}-\left\{\begin{array}{c}
F_{S+1}^{E X T}-\left.\frac{\partial U_{t}}{\partial X}\right|_{S+1}-C b_{1} \\
X^{E}-R_{C} b_{0}
\end{array}\right\}=\left\{\begin{array}{l}
0 \\
0
\end{array}\right\}=g\left(X^{0}\right)
$$

Considerando-se o comportamento não linear da equação (45), pode-se utilizar uma expansão de Taylor em primeira ordem (ou método de Newton-Raphson) a fim de encontrar um algoritmo iterativo de solução.

$$
\begin{aligned}
& g(X)=0=g\left(X^{0}\right)+\nabla g\left(X^{0}\right) \Delta X \\
& \nabla g\left(X^{0}\right)=\frac{\partial g\left(X^{0}\right)}{\partial \ddot{X}_{S+1}} \frac{\partial \ddot{X}_{S+1}}{\partial X_{S+1}}=\left[\begin{array}{cc}
(M+\gamma \Delta t C) & 0 \\
\beta \Delta t^{2} R_{C} & 0
\end{array}\right] \frac{1}{\beta \Delta t^{2}}+\left\{\begin{array}{c}
\left.\frac{\partial^{2} U_{t}}{\partial X^{2}}\right|_{S+1} \\
0
\end{array}\right\}
\end{aligned}
$$

Considera-se o mesmo critério de convergência utilizado nos capítulos anteriores da tese, com tolerância igual a $10^{-8}$.

Considerando-se as equações (45), (46) e (47), tem-se: 


$$
\left.\left[\left(\frac{M}{\beta \Delta t^{2}}+\frac{\gamma C}{\beta \Delta t}+\left.\frac{\partial^{2} U_{t}}{\partial X^{2}}\right|_{S+1}\right)-R_{C}\right]\left\{\begin{array}{c}
\Delta X \\
\lambda_{S+1}
\end{array}\right\}=\left\{\begin{array}{c}
F_{S+1}^{E X T}-\left(\left.\frac{\partial U_{t}}{\partial X}\right|_{S+1}+M \ddot{X}_{S+1}+C \dot{X}_{S+1}\right) \\
X^{E}-R_{C} X_{S+1}
\end{array}\right)\right\}
$$

Durante o processo iterativo são feitas correções nas posições $(X)$, velocidades $(\dot{X})$ e acelerações $(\ddot{X})$.

$$
X_{S+1}=X_{S+1}+\Delta X
$$

$$
\dot{X}_{S+1}=\dot{X}_{S+1}+\Delta \dot{X}=\dot{X}_{S+1}+\frac{\partial \dot{X}_{S+1}}{\partial X_{S+1}} \Delta X=\dot{X}_{S+1}+\frac{\gamma}{\beta \Delta t} \Delta X
$$

$$
\ddot{X}_{S+1}=\ddot{X}_{S+1}+\Delta \ddot{X}=\ddot{X}_{S+1}+\frac{\partial \ddot{X}_{S+1}}{\partial X_{S+1}} \Delta X=\ddot{X}_{S+1}+\frac{1}{\beta \Delta t^{2}} \Delta X
$$

As forças de contato podem ser calculadas a partir da equação (38).

$$
F_{S+1}^{C O N}=F_{S+1}^{E X T}-\left(\left.\frac{\partial U_{t}}{\partial X}\right|_{S+1}+M \ddot{X}_{S+1}+C \dot{X}_{S+1}\right) \quad X_{S+1} \in \Gamma_{C}
$$

\subsection{O problema da integração temporal no impacto}

A integração temporal de Newmark, utilizada na formulação clássica do multiplicador de Lagrange $(\gamma=0.5$ e $\beta=0.25)$ é eficiente na solução dinâmica de estruturas convencionais. No entanto, de acordo com os trabalhos de CARPENTER et al. (1991), TAYLOR \& PAPADOPOULOS (1993) e SOLBERG \& PAPADOPOULOS (1998), em problemas de impacto, especialmente envolvendo altas freqüências, a técnica é ineficiente. Estes três artigos apresentam diferentes soluções para melhorar a integração temporal em problemas de impacto.

Uma solução alternativa para melhorar a formulação baseada no método do multiplicador de Lagrange é simplesmente utilizar os parâmetros de integração temporal propostos por HU (1997). Segundo o autor, o multiplicador de Lagrange $\left(\lambda_{\mathrm{S}+1}\right)$ influência os campos de aceleração, velocidade e deslocamento apenas no passo atual de tempo $(S+1)$, quando seria desejável que a influência fosse estendida para as variáveis do próximo passo. A aproximação utilizada para a aceleração do próximo passo de tempo $(S+2)$ é linear. Assim, pode-se utilizar as equações de integração temporal de Newmark com os seguintes parâmetros $\gamma=1.5$ e $\beta=1.0$. Esta constatação tem implicações práticas importantes, pois programas comerciais baseados no integrador temporal de Newmark, usualmente instáveis para problemas de impacto, tornam-se estáveis a partir de uma simples interferência do usuário. No artigo original 
de HU, e também na formulação clássica, não são considerados os efeitos do amortecimento.

As hipóteses utilizadas por HU implicam nas seguintes equações:

$$
\begin{aligned}
& \ddot{X}_{S+2}=2 \ddot{X}_{S+1}-\ddot{X}_{S} \\
& X_{S+1}=X_{S}+\Delta t \dot{X}_{S}+\Delta t^{2}\left[-\frac{1}{2} \ddot{X}_{S}+\ddot{X}_{S+1}\right] \\
& \dot{X}_{S+1}=\dot{X}_{S}+\Delta t\left[-\frac{1}{2} \ddot{X}_{S}+\frac{3}{2} \ddot{X}_{S+1}\right]
\end{aligned}
$$

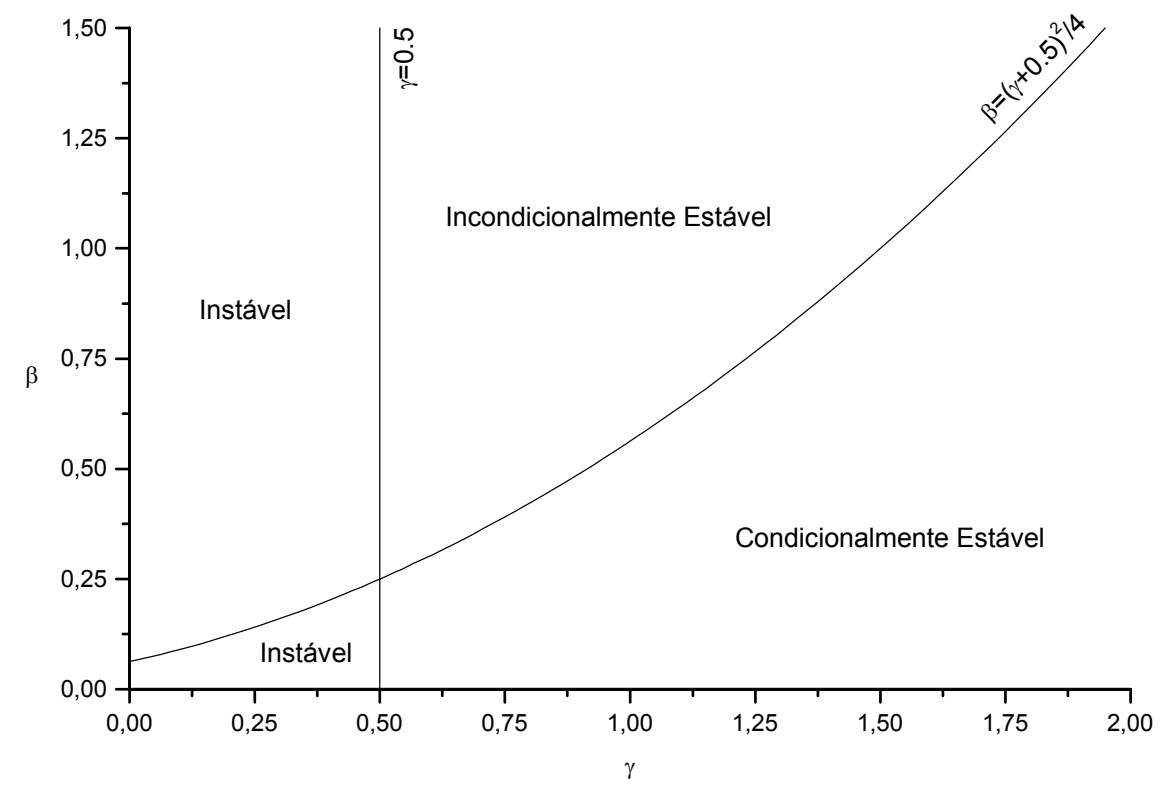

Figura 11 - Regiões de estabilidade para os parâmetros de Newmark $\gamma$ e $\beta$

$\mathrm{Na}$ figura 11 são apresentadas as regiões de estabilidade dos integradores temporais da família de Newmark em função dos parâmetros $\gamma$ e $\beta$. Segundo ARGYRIS \& MLEJNEK (1991), a curva de $\beta$ representa o limite da estabilidade do algoritmo onde ocorre o máximo amortecimento numérico das freqüências mais altas de vibração, que em problemas de impacto geralmente geram erros numéricos na resposta. Conforme pode ser observado na figura, os parâmetros propostos por $\mathrm{HU}(\gamma=1.5 ; \beta=1.0)$ estão no limite da região de estabilidade sobre a curva $\beta$. Os parâmetros propostos no artigo de CHAUDHARY \& BATHE $(\gamma=0.5 ; \beta=0.5)$ estão no limite da região de estabilidade sobre a curva $\gamma$ e, portanto, também geram um algoritmo estável para problemas usuais. 
Parâmetros usuais de integração temporal utilizados em problemas dinâmicos comuns ${ }^{8}$ $(\gamma=0.5 ; \beta=0.25)$ estão no limite da região de estabilidade na interseção da reta $\gamma$ e da curva $\beta$, também gerando um algoritmo estável. Discussões mais detalhadas sobre a estabilidade de algoritmos de integração temporal podem ser encontradas em ARGYRIS \& MLEJNEK (1991).

O termo estabilidade do algoritmo de integração temporal se refere apenas à característica do algoritmo em apresentar solução para qualquer discretização temporal, ou seja, um algoritmo estável apresenta resposta para qualquer intervalo de tempo $(\Delta t)$. Porém, a estabilidade não garante a qualidade da resposta numérica obtida. $\mathrm{Na}$ formulação de impacto $(\gamma=0.5 ; \beta=0.5$ ou $\gamma=0.5 ; \beta=0.25)$, pequenos valores de $\Delta t$ podem gerar respostas oscilatórias para o campo das forças de contato. Na formulação modificada $(\gamma=1.5 ; \beta=1.0)$ é desejável que $\Delta t$ seja pequeno, pois a formulação cria um pequeno amortecimento numérico que pode resultar em um pequeno erro na fase. $\mathrm{O}$ autor da formulação modificada, descrita em termos de deslocamentos, limita o erro na energia do sistema, para um período, em $1 \%$ se $\omega_{n} \Delta t<0.1$. Onde $\omega_{n}$ são as freqüências naturais; em problemas usuais utiliza-se o maior valor de $\omega_{n}$ disponível (que depende da discretização do problema). O algoritmo de integração temporal modificado obtido é incondicionalmente estável, para qualquer $\Delta t$ existe resposta, e convergente, quanto menor $\Delta t$, a resposta converge para determinado valor.

Depois de resolvido o problema da estabilidade do algoritmo de integração temporal deve-se observar a convergência do algoritmo, que também depende da discretização espacial. A discretização espacial deve ser suficientemente refinada a ponto de poder captar as freqüências de vibração mais relevantes no problema (quanto maior a discretização mais freqüências de vibração são captadas). Por exemplo, se a maior freqüência de vibração (calculada) de uma estrutura for igual a $100 \mathrm{~Hz}$, o intervalo de tempo deve ser menor que $0.01 \mathrm{~s}$, que seria o menor período de vibração da estrutura. No entanto, este período deve ainda ser subdividido. Então, deve-se escolher um intervalo de tempo pequeno o suficiente para descrever a vibração da estrutura na maior freqüência captada (por exemplo: $\Delta t=0.002 \mathrm{~s}$ ou $\Delta t=0.001 \mathrm{~s}$ ). No trabalho de TAYLOR \& PAPADOPOULOS (1993), os autores recomendam intervalos de tempo baseados na velocidade de propagação de ondas $\left(c=\sqrt{\frac{E}{\rho}}\right)$. O intervalo de tempo

\footnotetext{
${ }^{8}$ Sem ocorrência de impacto.
} 
recomendado deve ser próximo à razão do comprimento característico médio dos elementos finitos pela velocidade de propagação de ondas $\left(\Delta t=\frac{\bar{L}}{c}\right)$. No caso de estruturas reticuladas, o comprimento característico é o próprio comprimento do elemento finito e no caso de elementos bidimensionais, corresponde ao diâmetro de uma circunferência onde o elemento possa ser circunscrito.

\subsection{Exemplos numéricos}

\subsubsection{Impacto unidirecional entre duas barras}

Este exemplo, encontrado em CARPENTER et al. (1991), trata do impacto entre duas barras iguais, com mesma velocidade inicial, se movimentando em sentidos opostos. As características físicas, geométricas e cinemáticas do problema original são apresentadas na figura 12 .

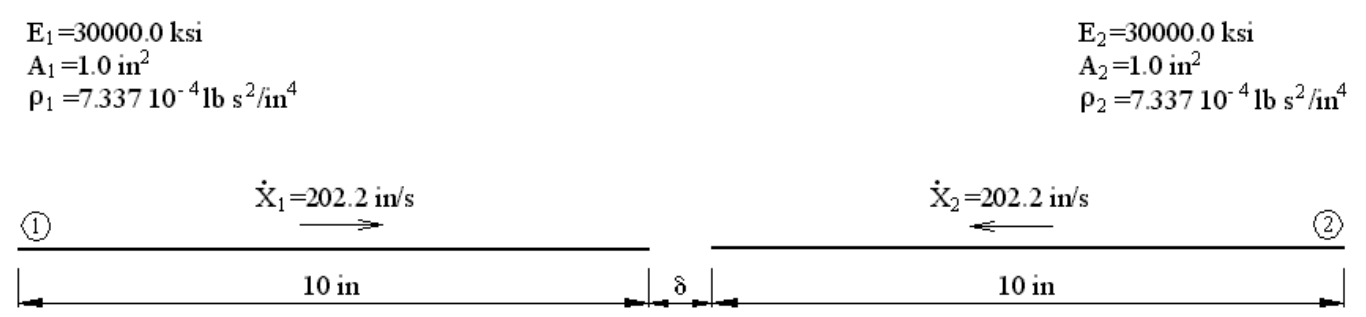

Figura 12 - Dados de entrada do problema originais

Para usar a formulação bidirecional proposta neste capítulo aproveitou-se a simetria do problema, conforme o apresentado na figura 13. Neste problema, o impacto ocorre no meio do espaço inicial entre as barras. No lugar da barra 2 definiu-se uma região quadrada finita como anteparo rígido na posição de impacto do problema original. As respostas foram obtidas para dois intervalos de tempo $\left(\Delta t=2.010^{-6} \mathrm{~s}\right.$ e $\Delta t=0.510^{-6} \mathrm{~s}$ ). A barra foi discretizada em 20 elementos finitos e o espaço inicial entre as barras do problema original é $\delta=0.02 \mathrm{in}$. 


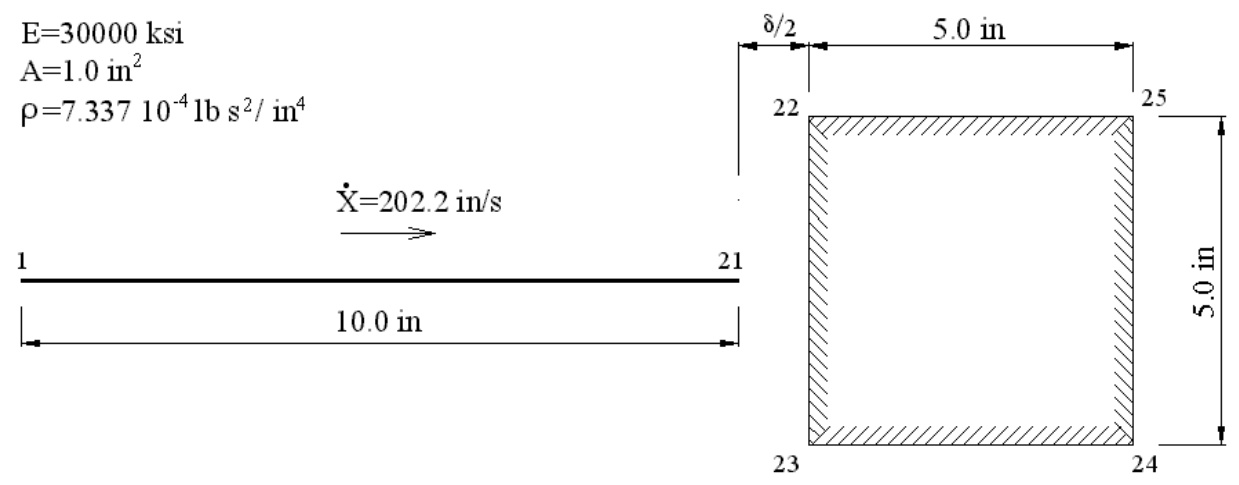

Figura 13 - Dados de entrada do problema modificados

São apresentados como respostas numéricas os gráficos de posição, velocidade e força de contato do ponto que sofre impacto na barra 1, ao longo do tempo. A origem do sistema de referência está no nó 1 . Nas figuras 14, 15 e 16 são apresentadas também as soluções analíticas do problema de corpo rígido, que para este tipo de problema podem ser encontradas em CARPENTER et al. (1991).

- Para $t \leq t_{\text {impacto }}$

$U_{1}=\dot{U}_{0} t$

$\dot{U}_{1}=\dot{U}_{0}$

$\lambda_{l}=0$

- Para $t_{\text {impacto }}<t<t_{\text {separação }}$

$U_{1}=0$

$\dot{U}_{1}=0$

$\lambda_{1}=-\dot{U}_{0} \sqrt{E \rho}$

- Para $t \geq t_{\text {separação }}$

$U_{l}=2 \dot{U}_{0}\left(\frac{\delta}{\dot{U}_{0}}+L \sqrt{\frac{\rho}{E}}-\frac{t}{2}\right)$

$\dot{U}_{1}=-\dot{U}_{0}$

$\lambda_{1}=0$

Onde:

$t_{\text {impacto }}=\frac{\delta}{\dot{U}_{0}}$

$t_{\text {separação }}=\frac{g}{\dot{U}_{0}}+2 L \sqrt{\frac{\rho}{E}}$ 
$L$ - comprimento das barras

$\delta$ - espaço inicial entre as barras

$U_{1}$ - deslocamento do nó que sofreu impacto na barra 1

$\lambda_{1}$ - multiplicador de Lagrange do nó que sofreu impacto na barra 1

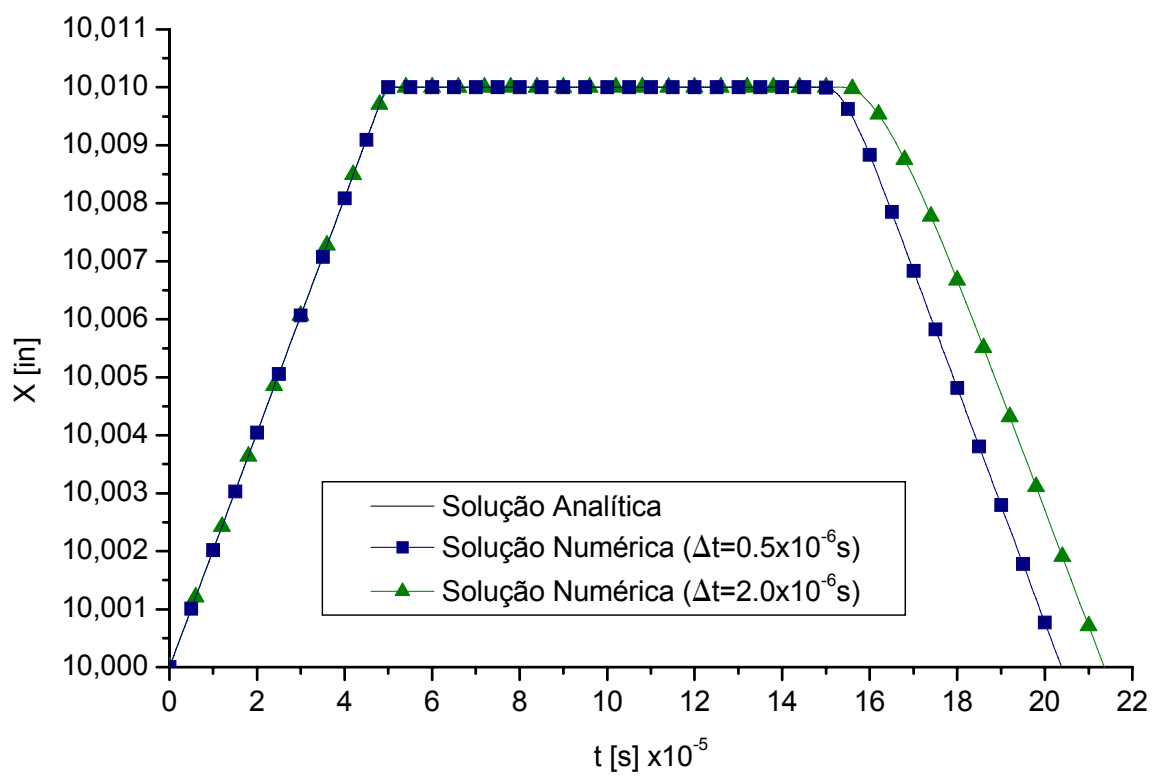

Figura 14 - Tempo $\times$ posição horizontal do ponto que sofre impacto na barra 1

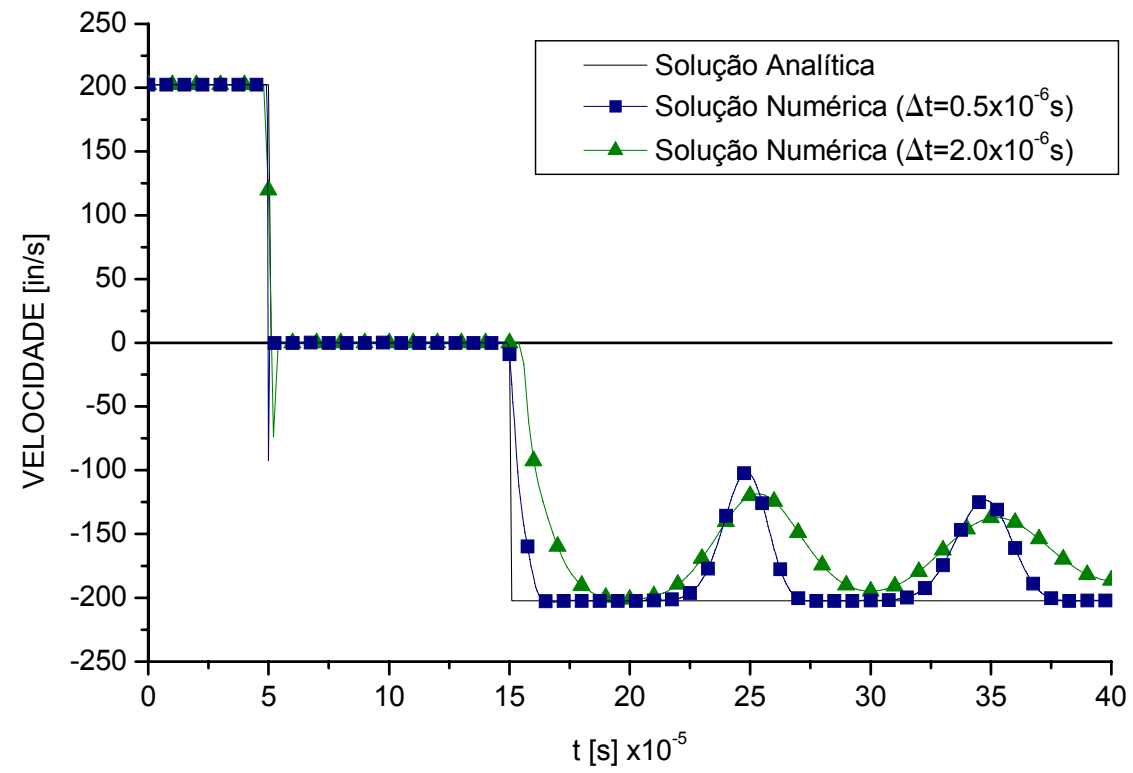

Figura 15 - Tempo $\times$ velocidade horizontal do ponto que sofre impacto na barra 1 


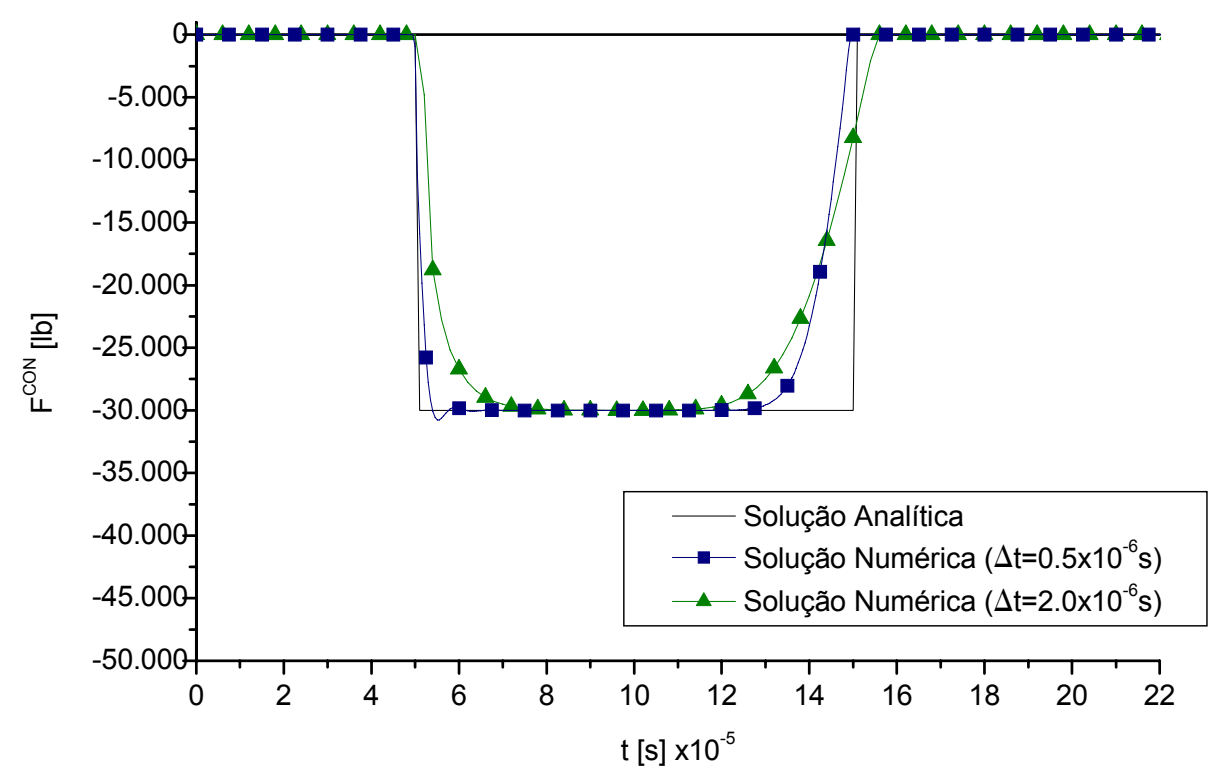

Figura 16 - Tempo $\times$ força de contato horizontal do ponto que sofre impacto na barra 1

Para os dois intervalos de tempo utilizados, as respostas se aproximaram das soluções analíticas. Sendo que para o menor intervalo de tempo $\left(\Delta t=0.510^{-6} \mathrm{~s}\right) \mathrm{a}$ resposta foi melhor em relação às soluções analíticas, conforme era esperado. Na figura 15, a velocidade do ponto analisado, para os dois intervalos de tempo, oscila em relação à velocidade de $-202.2 \mathrm{in} / \mathrm{s}$ após a separação das barras. Este fenômeno ocorre devido ao movimento oscilatório apresentado pela barra elástica após o impacto e não é representado pela solução analítica simplificada.

A seguir, introduziu-se plasticidade à análise. Definiu-se um limite de escoamento para as barras $\left(\sigma_{y}=10 \mathrm{ksi}\right)$ e utilizou-se um modelo de encruamento isótropo $(H=0 ; K=1000 k s i)$. As demais características físicas, geométricas e cinemáticas são as mesmas descritas na figura 13. São apresentados como respostas numéricas, obtidas com a formulação proposta, os gráficos de posição, velocidade e força de contato do ponto que sofre impacto na barra 1, ao longo do tempo. Nas figuras 17, 18 e 19 são apresentadas também as soluções analíticas lineares do problema e numéricas obtidas com o programa comercial ANSYS ${ }^{\circledR}$, utilizando-se os parâmetros modificados de integração temporal $(\gamma=1.5 ; \beta=1.0)$. 


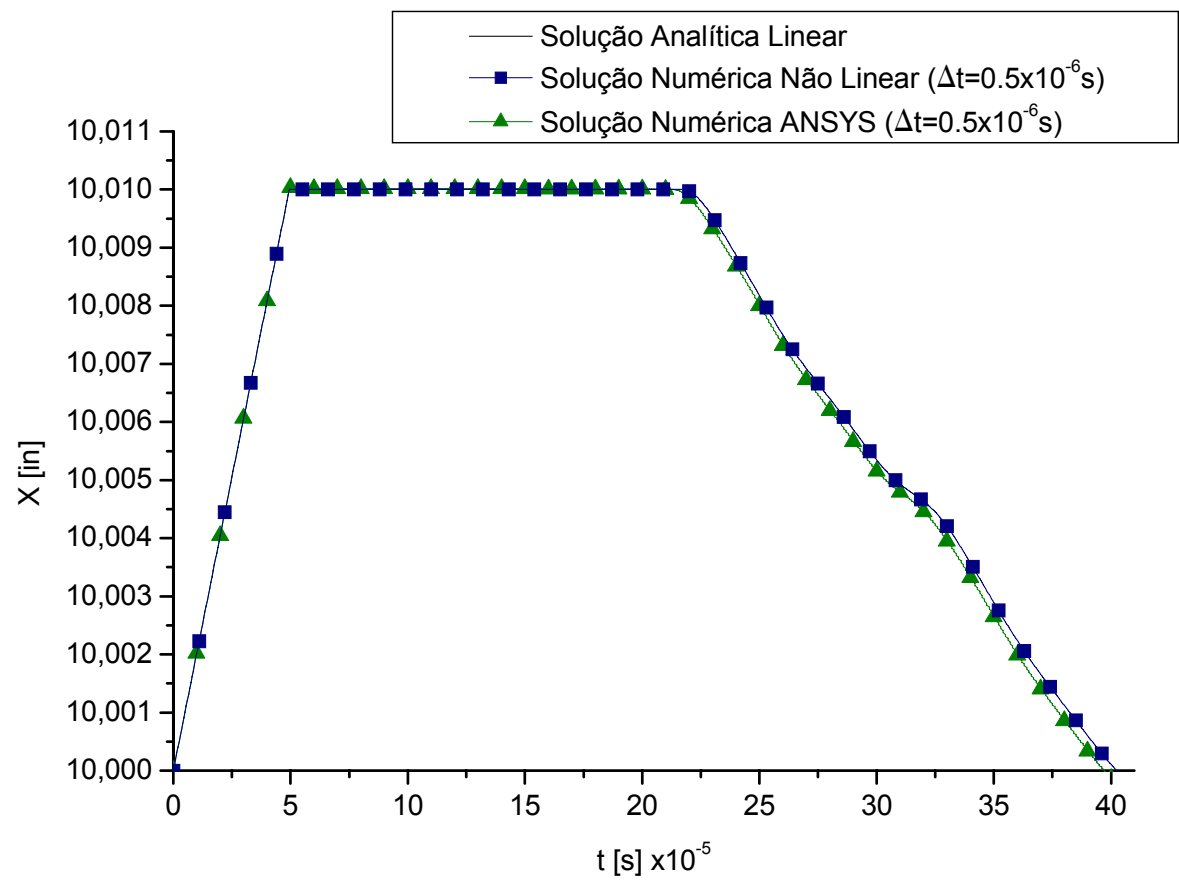

Figura 17 - Tempo $\times$ posição horizontal NLF do ponto que sofre impacto na barra 1

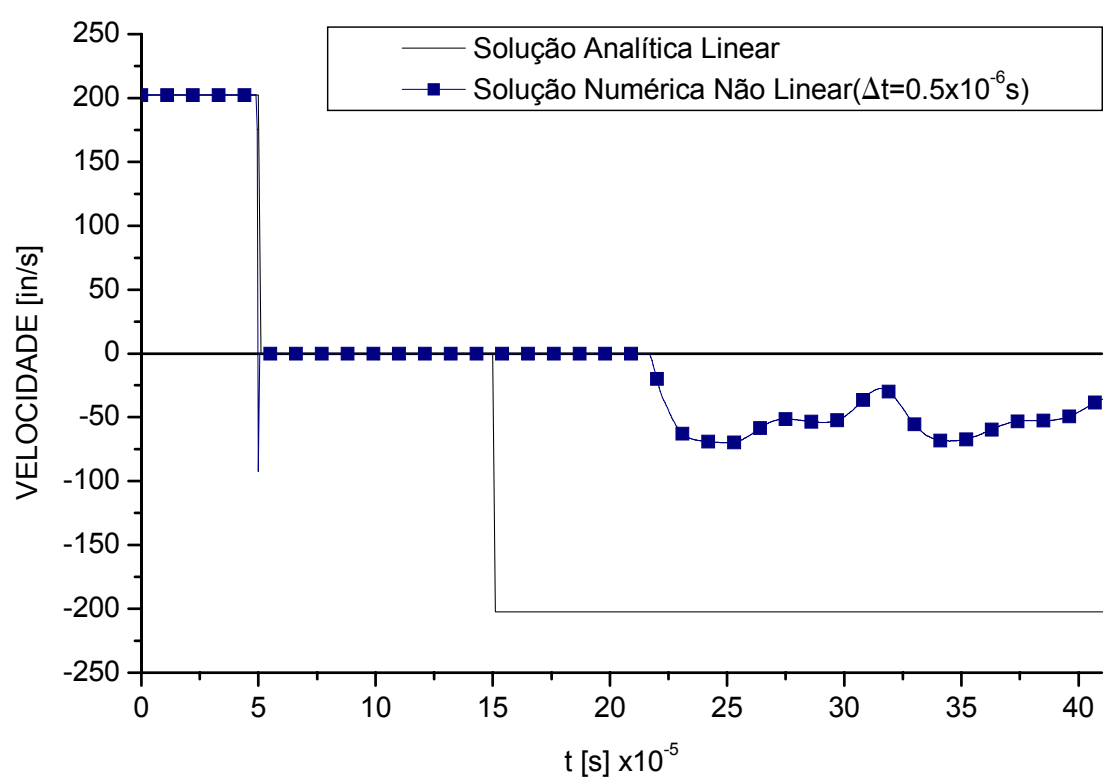

Figura 18 - Tempo $\times$ velocidade horizontal NLF do ponto que sofre impacto na barra 1 


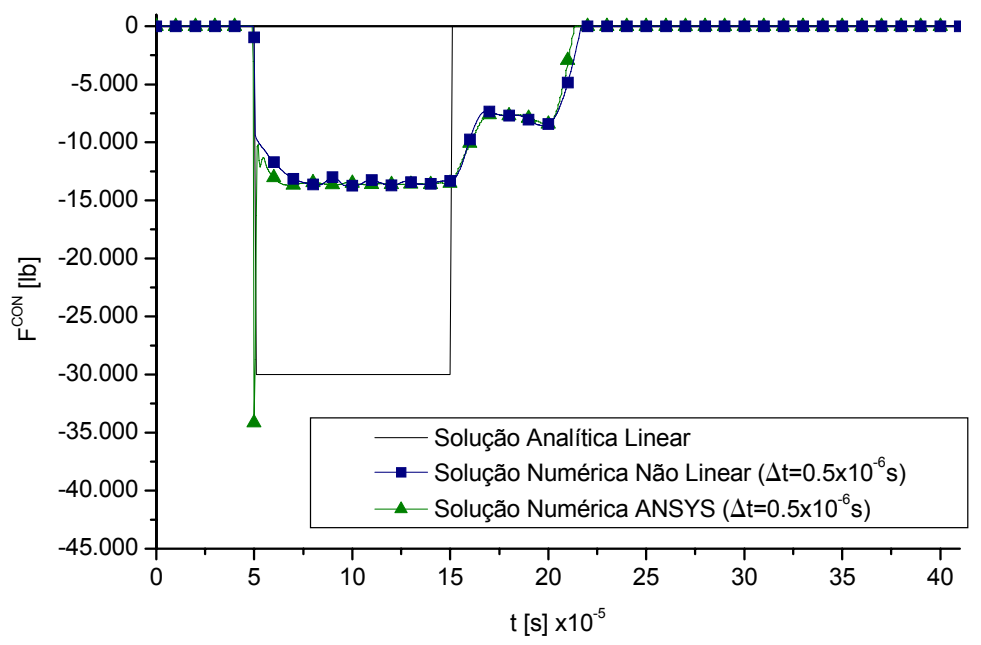

Figura 19 - Tempo $\times$ força de contato horizontal NLF do ponto que sofre impacto na barra 1

A primeira plastificação ocorre logo no inicio do impacto $\left(t=5.010^{-5} \mathrm{~s}\right)$ e se desenvolve nas barras até o momento da separação $\left(t=21.010^{-5} \mathrm{~s}\right)$. Percebe-se que no caso NLF, as barras ficam em contato por mais tempo ${ }^{9}$ e ao se separarem as velocidades de retorno são menores que as velocidades de retorno do caso elástico $(-202.2 \mathrm{in} / \mathrm{s})$. A diminuição da velocidade de afastamento do ponto analisado, em valor absoluto, era esperada, pois há perda de energia durante a plastificação. Ainda em relação às velocidades, após a separação as barras se movimentam em sentidos opostos aos seus movimentos iniciais, com oscilações nas amplitudes das velocidades.

Quanto às forças de contato desenvolvidas durante o impacto, são menores que às do caso linear e estão compreendidas em dois intervalos de tempo, um de mesma

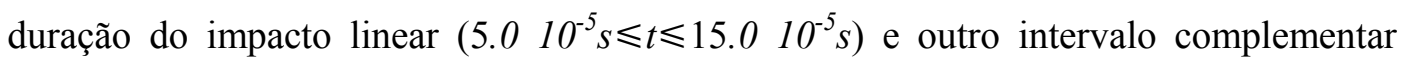
$\left(15.010^{-5} \mathrm{~s} \leqslant t \leqslant 21.010^{-5} \mathrm{~s}\right)$, sendo a força de contato do último intervalo ainda menor que a do primeiro intervalo. Nos instantes iniciais do impacto, as forças de contato sofrem oscilações devido a plastificação.

A plastificação neste exemplo traz informações importantes para o projeto de estruturas submetidas ao impacto. Observa-se que para a barra elastoplástica as forças de contato são menores que as forças de contato do caso elástico. Portanto, os níveis de aceleração também serão menores e no projeto estrutural isto significa que as condições de segurança serão maiores. É claro que a barra não é um veículo de transporte, mas os conceitos válidos para este exemplo também são válidos para problemas mais complexos, como o impacto em veículos de transporte tripulados.

\footnotetext{
${ }^{9}$ No caso linear, o tempo de contato é $t=10.010^{-5} \mathrm{~s}$.
} 
As respostas obtidas com o programa ANSYS para posições e forças de contato foram próximas às obtidas com a formulação proposta. O programa ANSYS não possibilita a listagem direta das velocidades.

Nas figuras de número 20 a 23 são apresentadas as respostas obtidas com o programa de análise estrutural ANSYS para duas combinações de parâmetros $\gamma$ e $\beta$. São apresentadas as respostas em deslocamento e força de contato, utilizando-se o mesmo intervalo de integração temporal do exemplo $\left(\Delta t=0.510^{-6} \mathrm{~s}\right)$. Foram utilizados no programa ANSYS os elementos BEAM3 e CONTAC26 (2D point-to-ground contact).

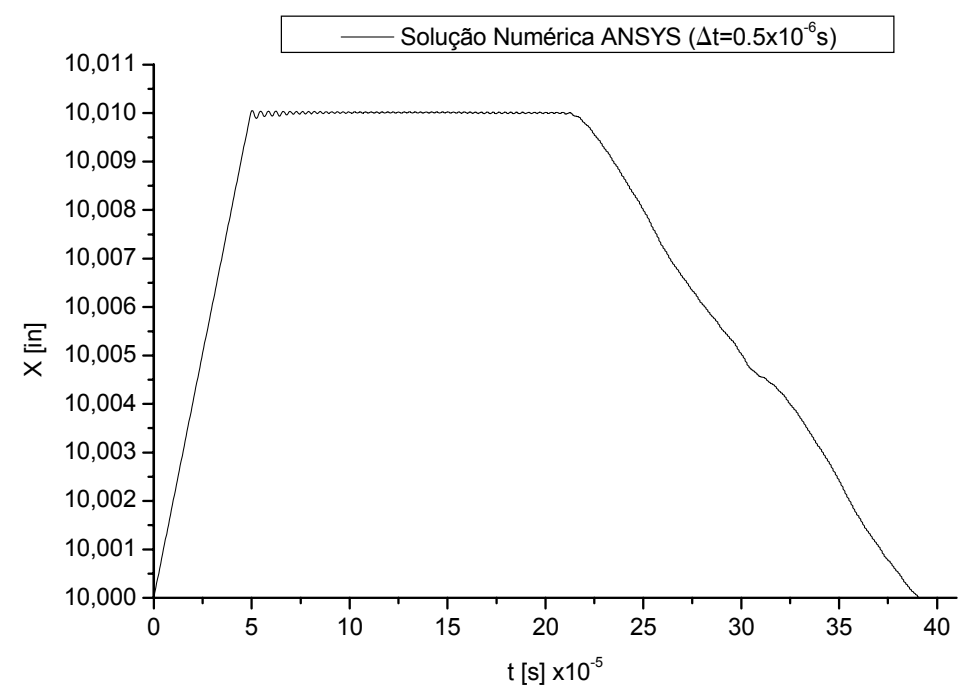

Figura 20 - Tempo $\times$ posição horizontal NLF do ponto que sofre impacto na barra 1 obtida com o programa ANSYS $(\gamma=0.5 ; \beta=0.5)$

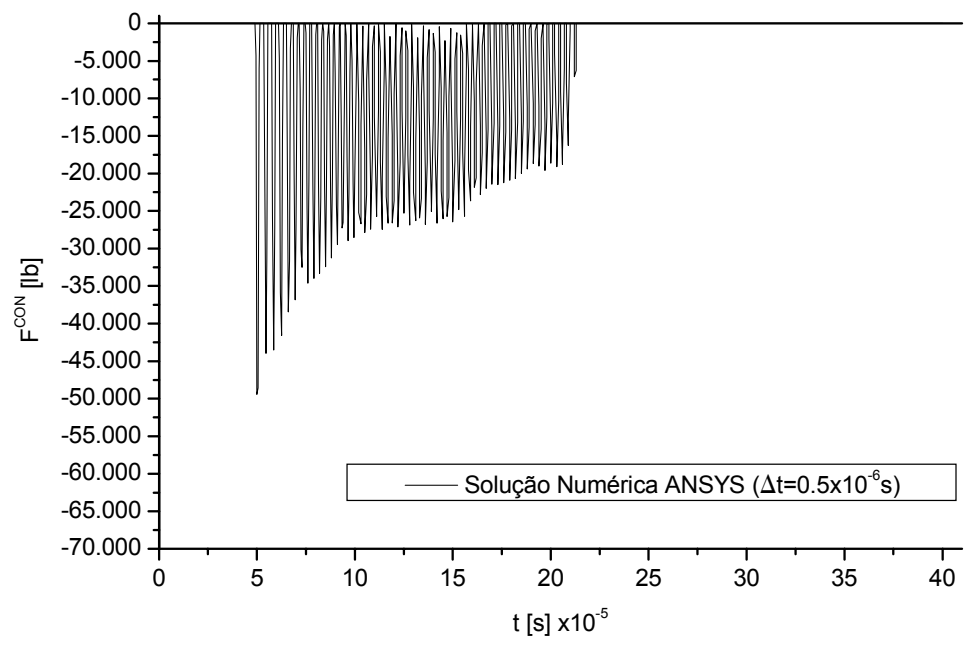

Figura 21 - Tempo $\times$ força de contato horizontal NLF do ponto que sofre impacto na barra 1 obtida com o programa ANSYS $(\gamma=0.5 ; \beta=0.5)$ 


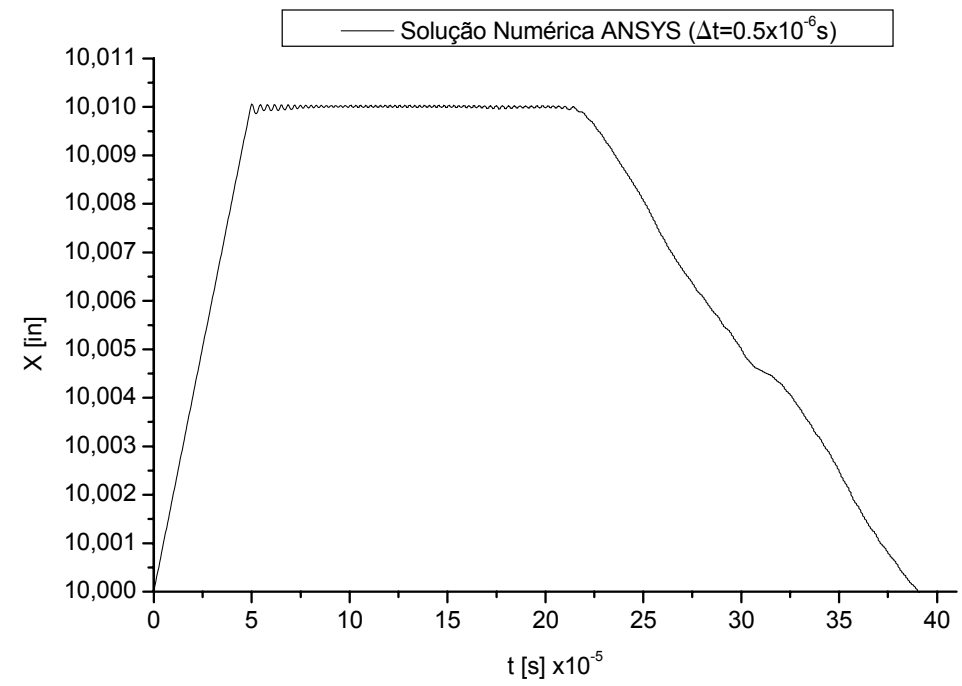

Figura 22 - Tempo $\times$ posição horizontal NLF do ponto que sofre impacto na barra 1 obtida com o programa ANSYS $(\gamma=0.5 ; \beta=0.25)$

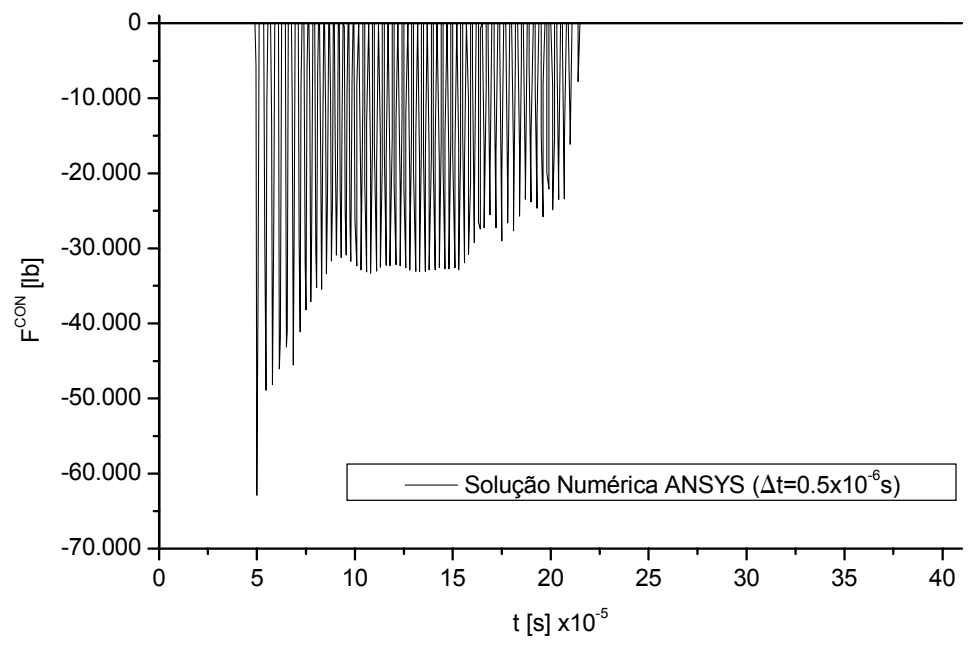

Figura 23 - Tempo $\times$ força de contato horizontal NLF do ponto que sofre impacto na barra 1 obtida com o programa ANSYS $(\gamma=0.5 ; \beta=0.25)$

Conforme pode ser observado nos gráficos anteriores, as respostas do ANSYS que utilizaram a integração de Newmark modificada, com parâmetros $\gamma=1.5$ e $\beta=1.0$, apresentaram resultados próximos das obtidas com a formulação proposta, figuras $17 \mathrm{e}$ 19, tanto para o deslocamento do ponto que sofreu impacto da barra 1 como para a força de contato. Já as respostas que utilizaram os parâmetros propostos por CHAUDHARY \& BATHE (1986), $\gamma=\beta=0.5$, e parâmetros de integração usuais em problemas dinâmicos, $\gamma=0.5$ e $\beta=0.25$, apresentaram um resultado razoável para a posição horizontal, figuras 20 e 22, e um péssimo resultado para a força de contato, com muitas 
oscilações, conforme apresentado nas figuras 21 e 23. Isto mostra como a atividade de pesquisa relacionada às técnicas numéricas é de grande importância mesmo para definir caminhos para o uso de programas comerciais existentes.

\subsubsection{Impacto bidirecional de anel em anteparo rígido inclinado}

O exemplo trata do impacto de uma estrutura de malha anelar em um anteparo rígido inclinado. A estrutura foi discretizada em 32 elementos finitos e se movimenta com velocidade constante. Considera-se o problema sem atrito. As características físicas, geométricas e cinemáticas do problema são apresentadas na figura 24. As respostas obtidas são comparadas com o programa comercial ANSYS, utilizando-se os parâmetros modificados de integração temporal $(\gamma=1.5 ; \beta=1.0)$.
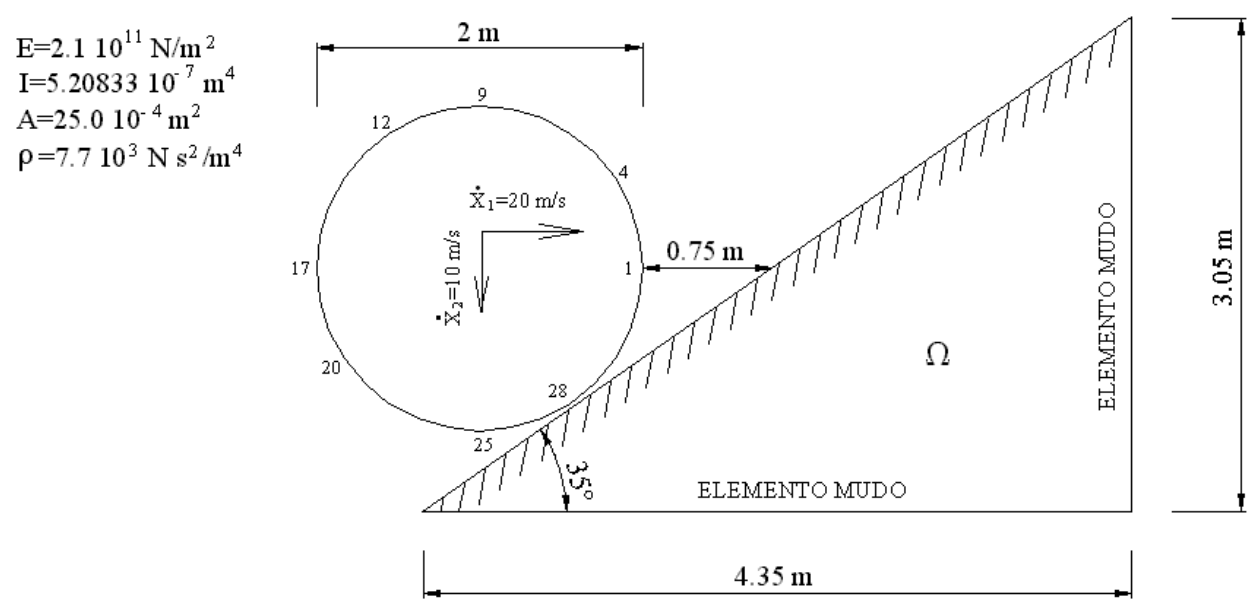

Figura 24 - Dados de entrada do problema

Adotou-se na análise um intervalo de integração temporal igual a $\Delta t=0.00015 \mathrm{~s}$. Nas figuras 25 e 26 são apresentadas as posições horizontal $(X)$ e vertical $(Y)$ do nó número 28. Nas figuras 27 e 28 são apresentadas as forças de contato e multiplicadores de Lagrange para este mesmo nó, nas direções $X$ e $Y$. A origem do sistema de coordenadas $X Y$ se encontra no centro da estrutura indeformada inicial. 


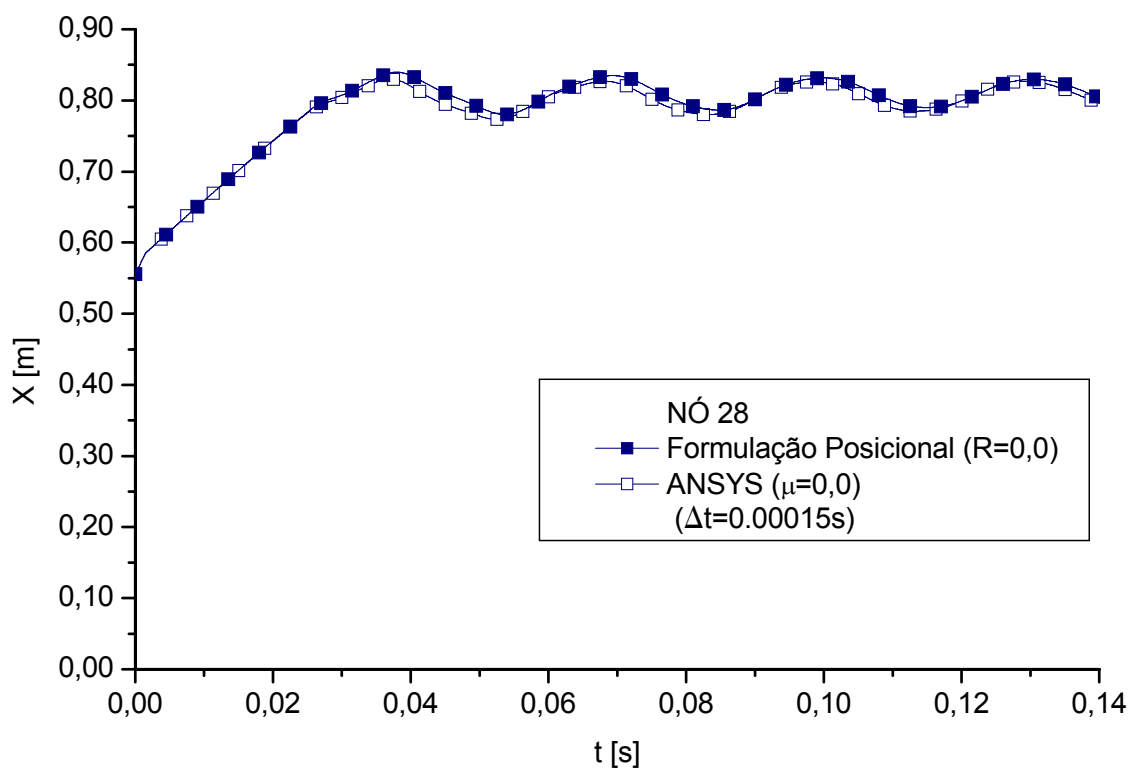

Figura 25 - Tempo $\times$ posição horizontal $(X)$ do nó 28

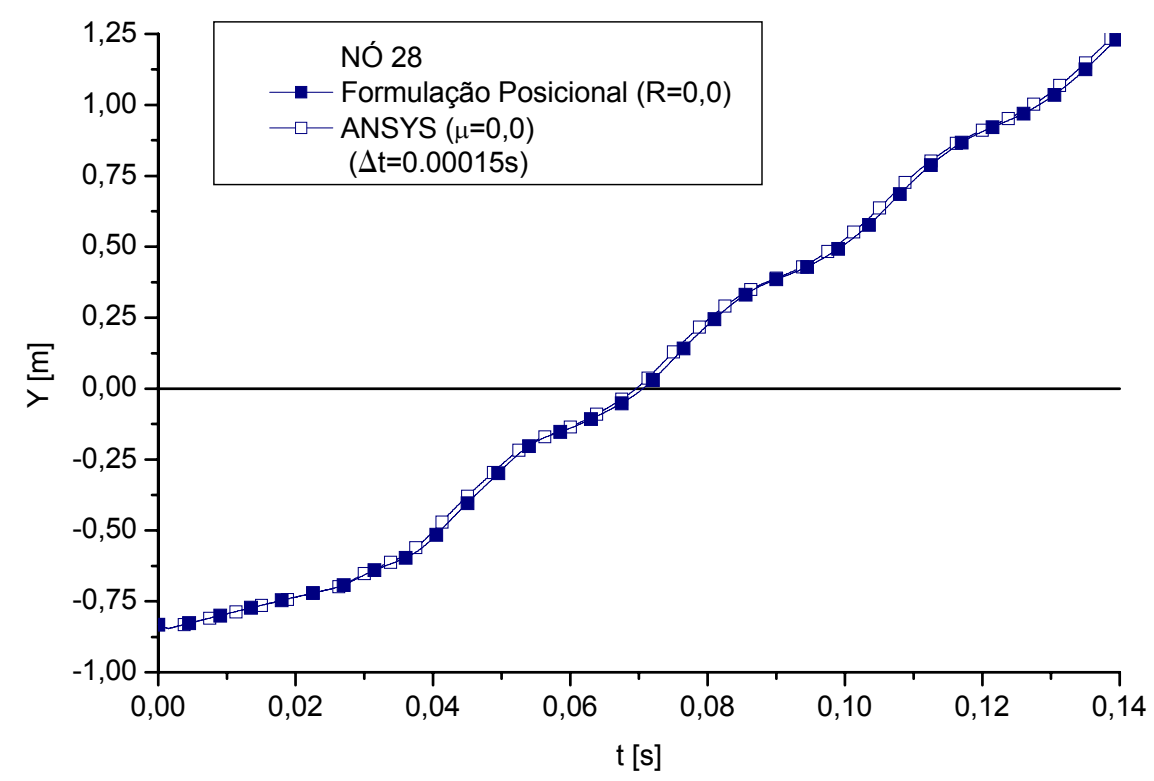

Figura 26 - Tempo $\times$ posição vertical $(Y)$ do nó 28 


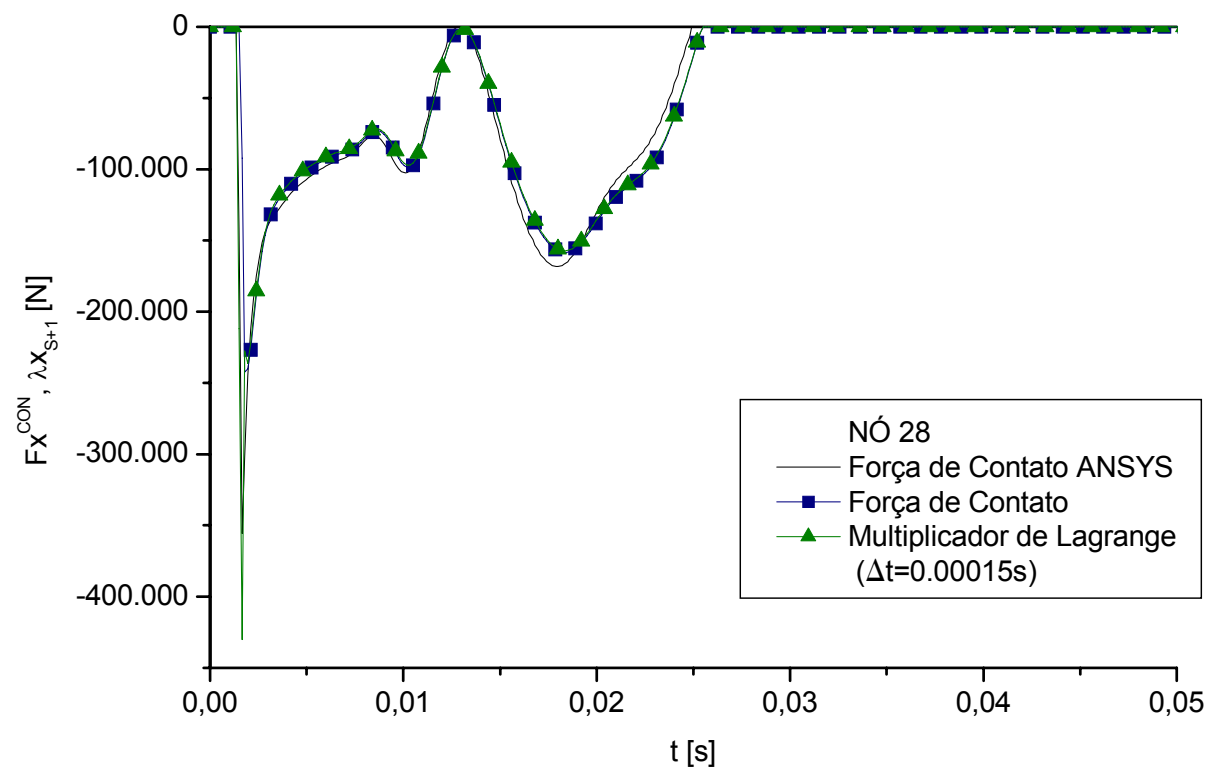

Figura 27 - Tempo $\times$ força de contato (e multiplicador de Lagrange) na direção horizontal do nó

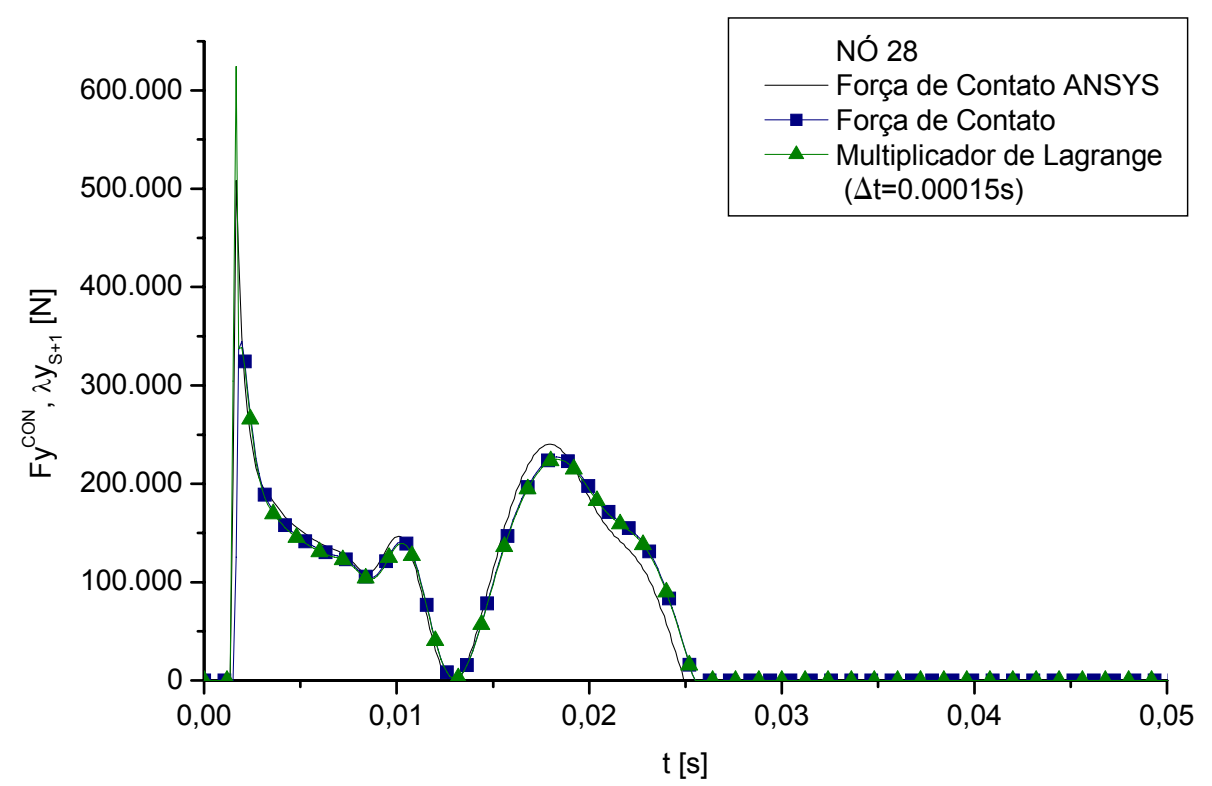

Figura 28 - Tempo $\times$ força de contato (e multiplicador de Lagrange) na direção vertical do nó 28

As respostas em posições e forças de contato, obtidas com a formulação posicional, foram muito próximas das encontradas com o programa ANSYS. Observase nas figuras 27 e 28 que as forças de contato e os multiplicadores de Lagrange, 
calculados a partir da equação (48), são praticamente iguais, a menos dos saltos nos instantes iniciais do impacto que apresentam os multiplicadores de Lagrange. Na figura 29 são apresentadas posições deformadas da estrutura em determinados instantes de tempo.

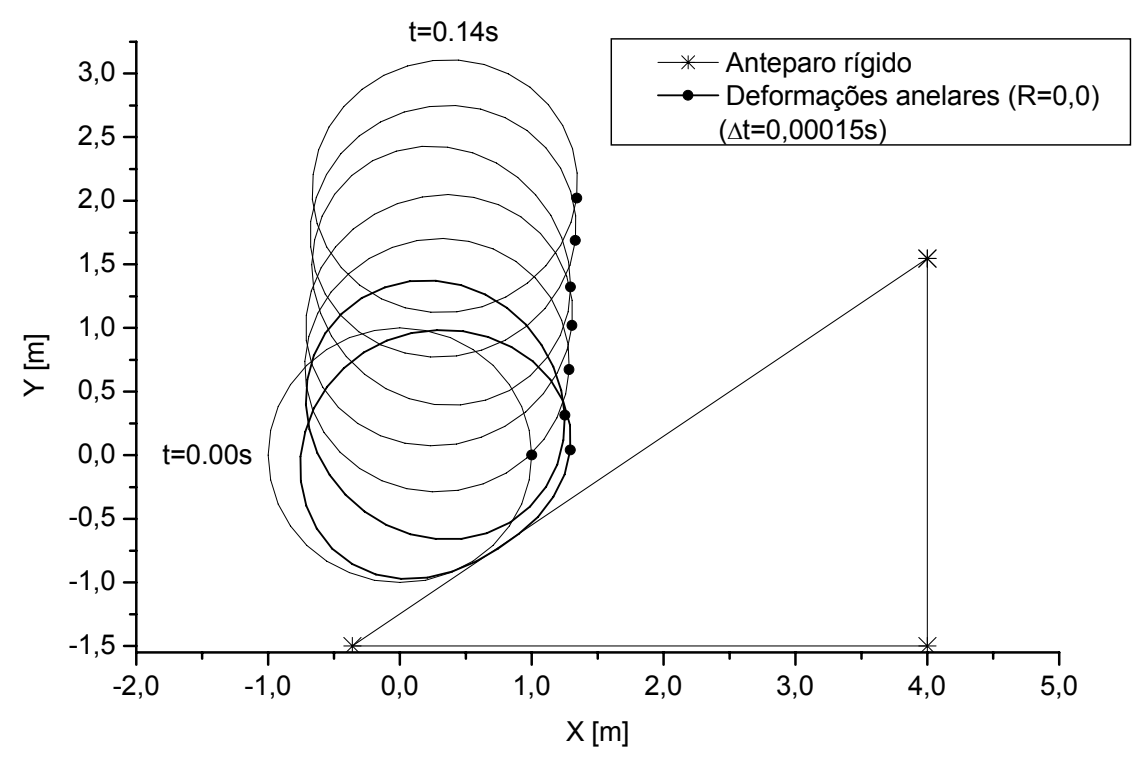

Figura 29 - Configurações da estrutura

\subsubsection{Impacto bidirecional de anel em anteparo rígido}

O exemplo trata do impacto de uma malha anelar em um anteparo rígido horizontal. A estrutura se movimenta com velocidade constante, seguindo uma trajetória inclinada em relação ao anteparo. Foram utilizados 16 elementos finitos na discretização da estrutura anelar e os dados do problema podem ser vistos na figura 30. Considera-se na análise do problema as situações sem atrito e com atrito. Este exemplo pode ser encontrado em WRIGGERS et al. (1990). Os autores consideram as variáveis adimensionais. Adotou-se um intervalo de integração temporal igual a $\Delta t=0.05$. 


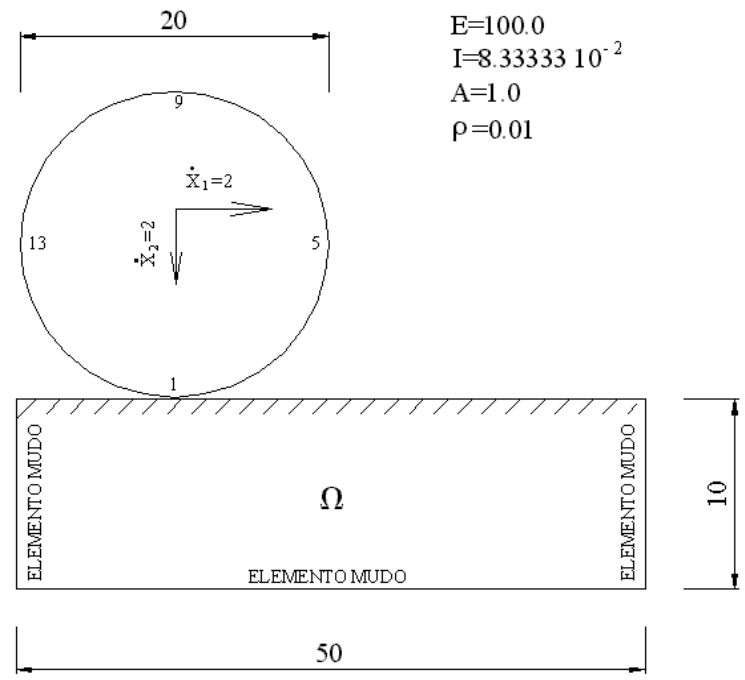

Figura 30 - Dados de entrada do problema

Na figura 31 são apresentadas as configurações deformadas da estrutura para vários instantes de tempo, segundo a referência. Na figura 32 são apresentadas as respostas obtidas com a formulação não linear geométrica posicional para as duas situações analisadas. Para a situação sem atrito o ângulo de reflexão obtido foi de $49.83^{\circ}$ e para a situação com atrito (considerando coeficiente de atrito equivalente ao da referência, $R=0.10$ ) o ângulo de reflexão foi de $34.86^{\circ}$. Na referência, figura 31 , os ângulos de atrito são respectivamente $50^{\circ}$ e $35^{\circ}$. Os resultados dos ângulos de reflexão estão resumidos na tabela 1.

Tabela 1 - Ângulos de reflexão

\begin{tabular}{|c|c|c|c|}
\hline \multicolumn{2}{|c|}{ Referência } & \multicolumn{2}{c|}{ Formulação posicional } \\
\hline Impacto sem atrito & Impacto com atrito & Impacto sem atrito & Impacto com atrito \\
\hline $50^{\circ}$ & $35^{\circ}$ & $49.83^{0}$ & $34.86^{0}$ \\
\hline
\end{tabular}



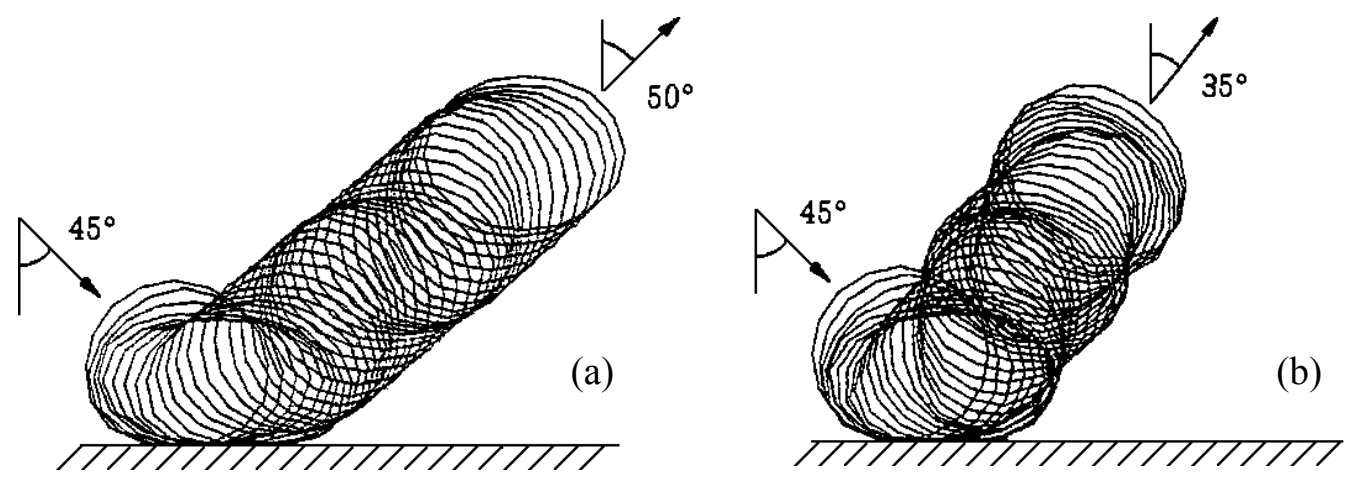

Figura 31 - Respostas da referência para os casos: (a) sem atrito (b) com atrito
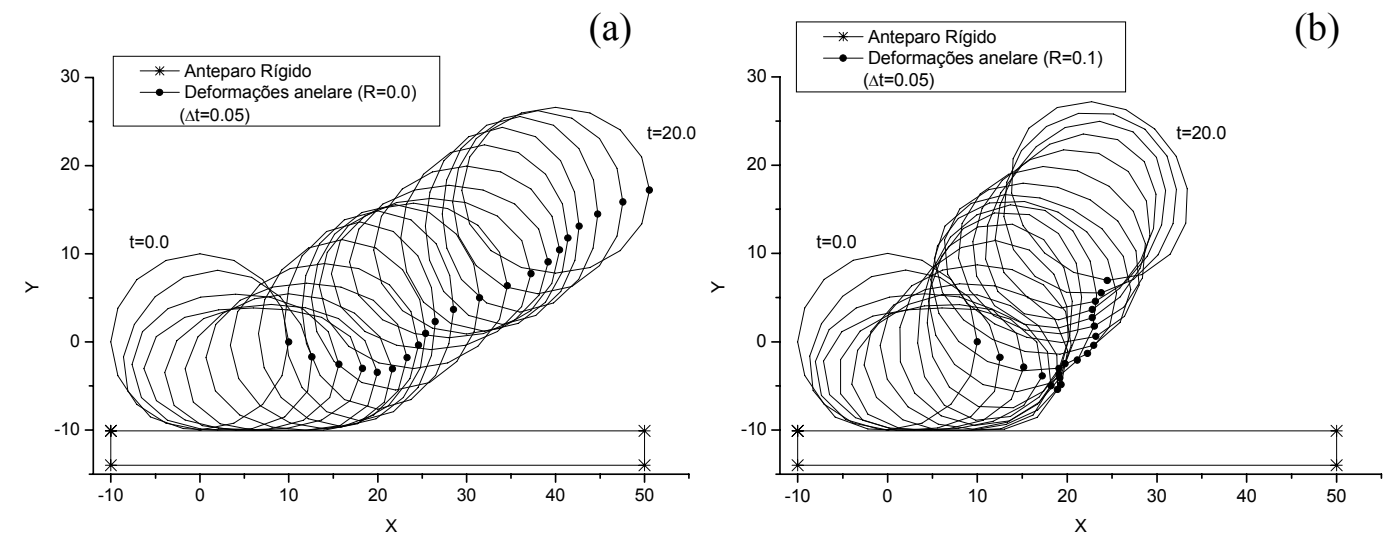

Figura 32 - Configurações anelares obtidas para os casos: (a) sem atrito (b) com atrito

Considerou-se ainda uma nova situação de impacto com atrito, apresentada na figura 33. No caso, os dados da estrutura são os mesmos apresentados na figura 30, porém, agora o anteparo considerado é dentado. Esta situação não é apresentada na referência e utilizou-se o mesmo coeficiente de retorno do caso (b) apresentado na figura 32. Observa-se pela figura 33 que o novo anteparo introduz um efeito geométrico que aumenta o atrito no impacto, pois o ângulo de reflexão aumenta. 


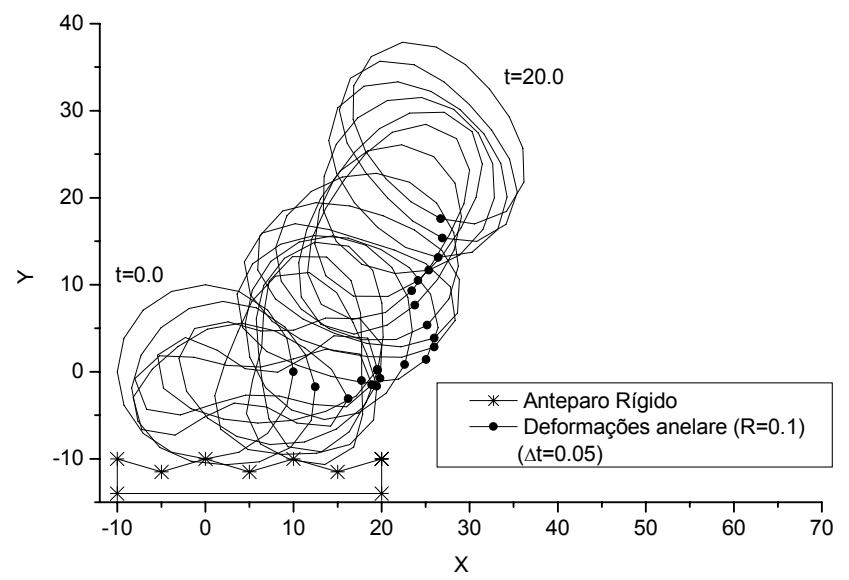

Figura 33 - Configurações anelares obtidas para o impacto com atrito em anteparo dentado

\subsubsection{Impacto bidirecional de anel em anteparo rígido em forma de $\mathrm{V}$}

O último exemplo deste capítulo trata do impacto de uma estrutura reticulada anelar em um anteparo rígido em forma de $\mathrm{V}$, também encontrado no artigo de WRIGGERS et al. (1990). A estrutura se movimenta com velocidade constante em direção ao anteparo. Devido à simetria, metade da estrutura foi discretizada em 30 elementos finitos e os dados do problema podem ser vistos na figura 34 . O anteparo foi discretizado por 3 elementos (sendo dois mudos), definindo um domínio finito na forma de triângulo. Os autores consideram as variáveis adimensionais. Utilizou-se uma discretização temporal constante igual $\Delta t=0.05$.
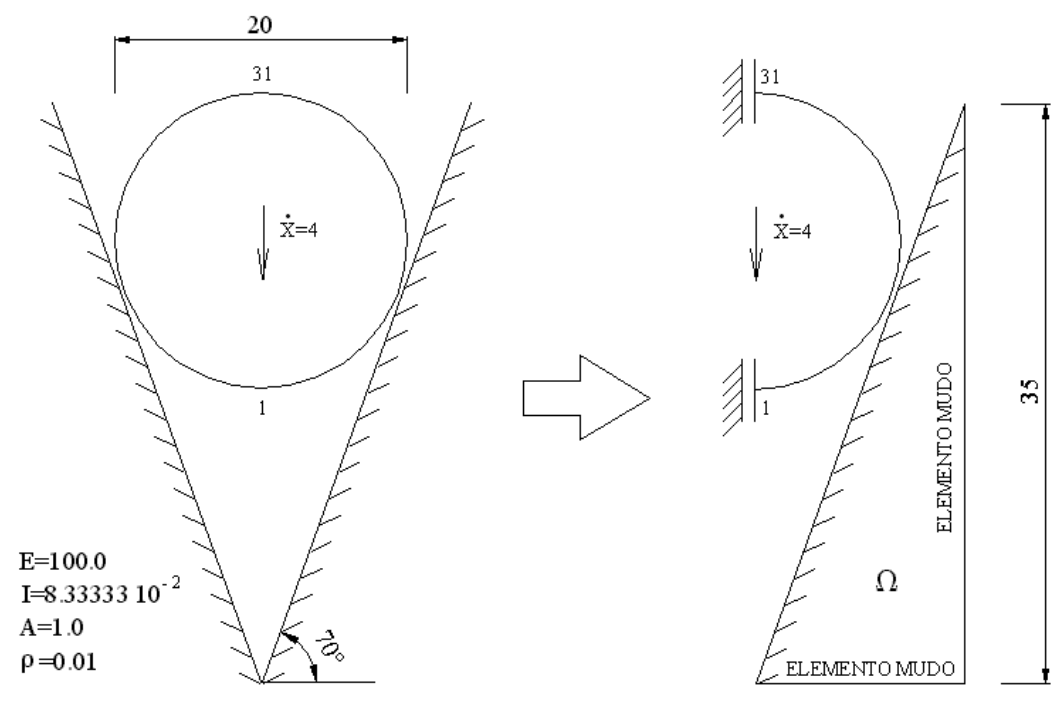

Figura 34 - Dados de entrada do problema 
$\mathrm{Na}$ figura 35 são apresentadas as configurações deformadas da estrutura para vários instantes de tempo, segundo a referência. Nas figuras 36 e 37 são apresentadas as respostas obtidas com a formulação não linear geométrica posicional para a situação sem atrito e com atrito, respectivamente. A referência apresenta apenas as configurações em alguns instantes, sem maiores detalhes. No entanto, os gráficos das posições deformadas encontrados foram bem semelhantes aos da referência, o que leva a crer que os resultados são de boa qualidade.

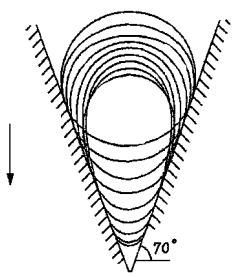

(a)
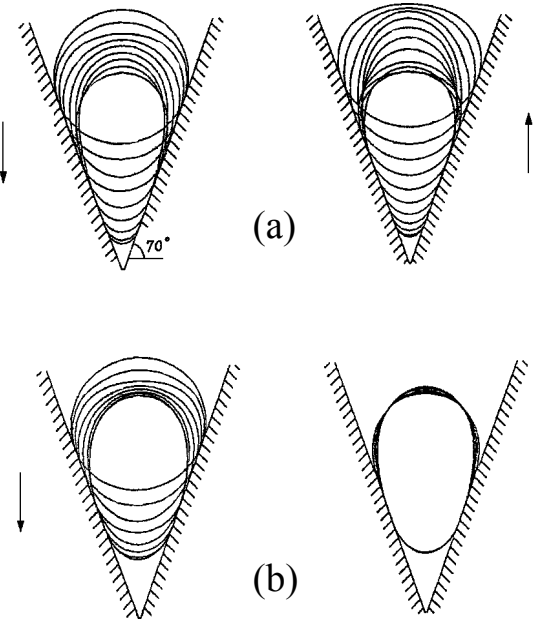

Figura 35 - Respostas da referência para os casos: (a) sem atrito (b) com atrito
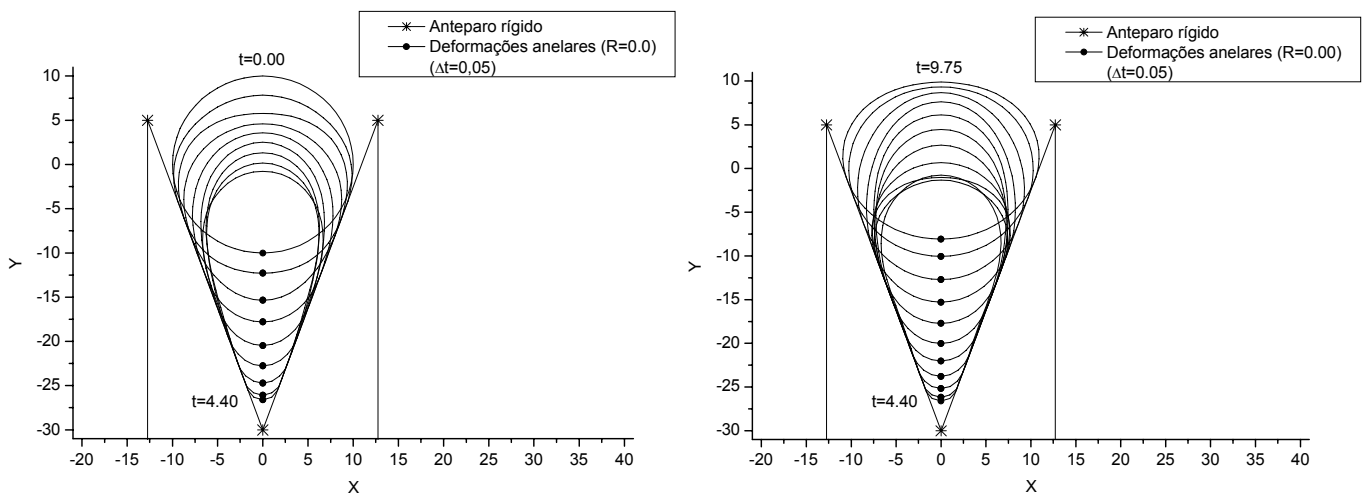

Figura 36 - Configurações anelares obtidas para o caso sem atrito 


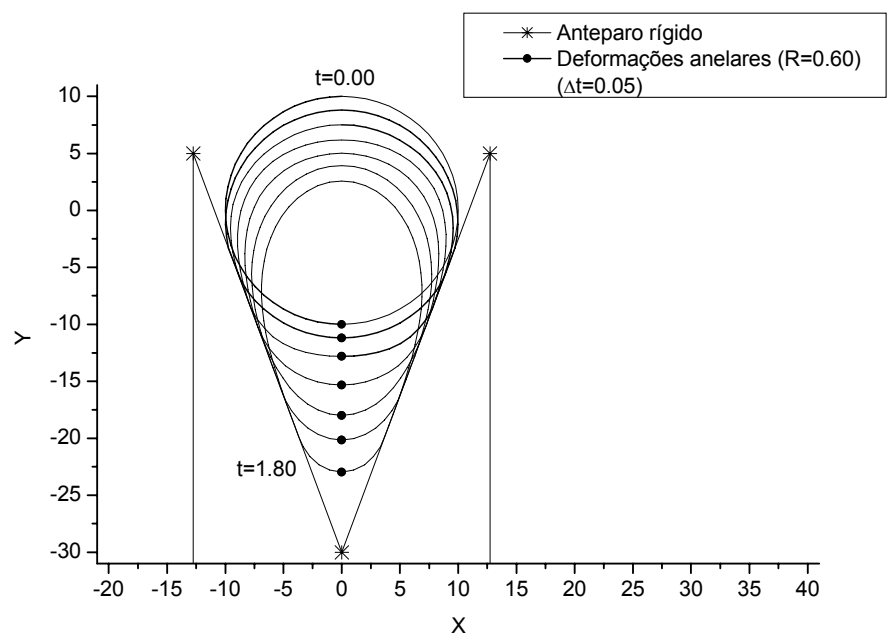

Figura 37 - Configurações anelares obtidas para o caso com atrito

Com o intuito de extrair maiores informações do exemplo e testar o programa desenvolvido, efetuou-se um corte na metade da altura do anteparo, figura 38 , de maneira a permitir que a estrutura continuasse seu movimento. Os dados do problema são os mesmos apresentados na figura 34 , com exceção da forma do anteparo. Considerou-se um coeficiente de atrito $R=0.25$.

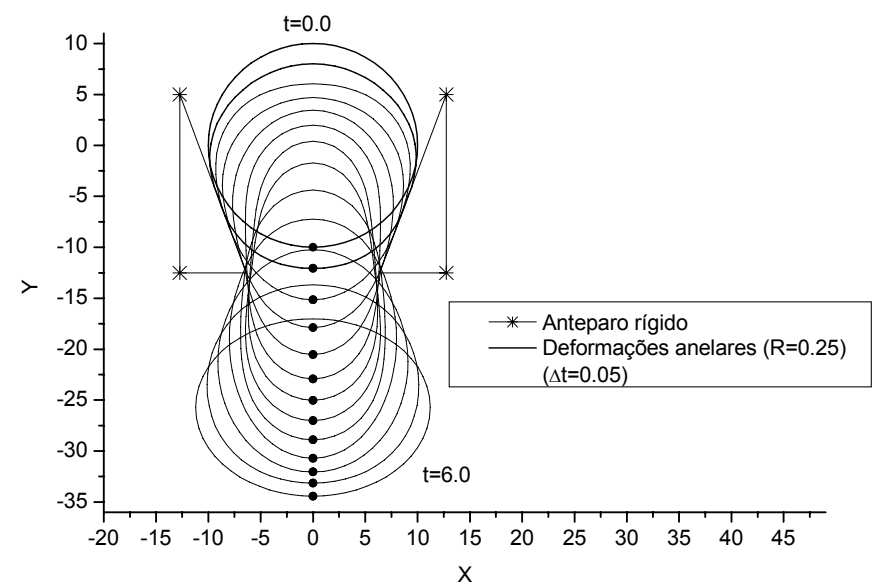

Figura 38 - Configurações anelares obtidas para o caso do anteparo secionado na metade da altura (com atrito)

Na figura 39 alterou-se novamente a forma do anteparo, de maneira que a metade superior do anteparo fosse igual ao anteparo original e a metade inferior do anteparo fosse vertical. Os dados do problema são os mesmos apresentados na figura 
34, com exceção da forma do anteparo. Considerou-se neste caso um coeficiente de atrito $R=0.10$. Tanto no caso apresentado na figura $38 \mathrm{com}$ no caso apresentado na figura 39 fez-se uso das condições de simetria do problema.

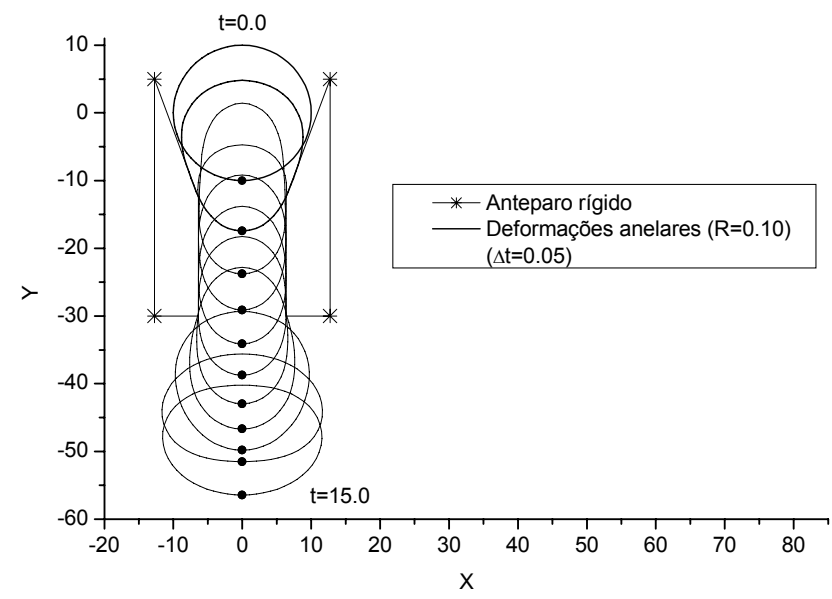

Figura 39 - Configurações anelares obtidas para o caso do anteparo secionado na metade superior e com geometria vertical na metade inferior (com atrito)

$\mathrm{Na}$ figura 40 considerou-se uma forma dentada para o anteparo. Os dados do problema são os mesmos apresentados na figura 34, com exceção da forma do anteparo. Considerou-se neste caso um coeficiente de atrito $R=0.10$ e fez-se uso das condições de simetria do problema.

Por fim, na figura 41 apresenta-se um gráfico com posições verticais dos nós inferiores das estruturas anelares analisadas nas figuras 36 a 40.

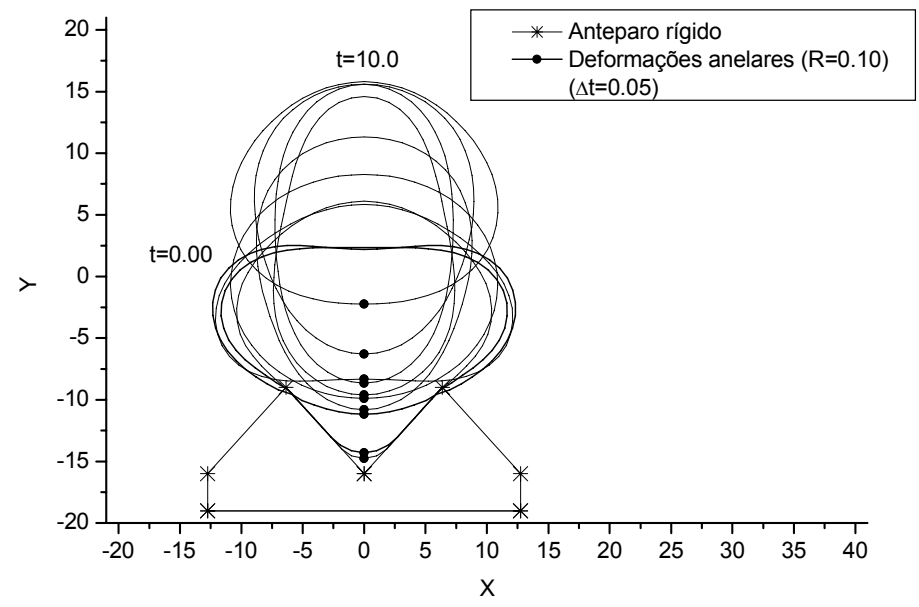

Figura 40 - Configurações anelares obtidas para o caso do anteparo dentado (com atrito) 


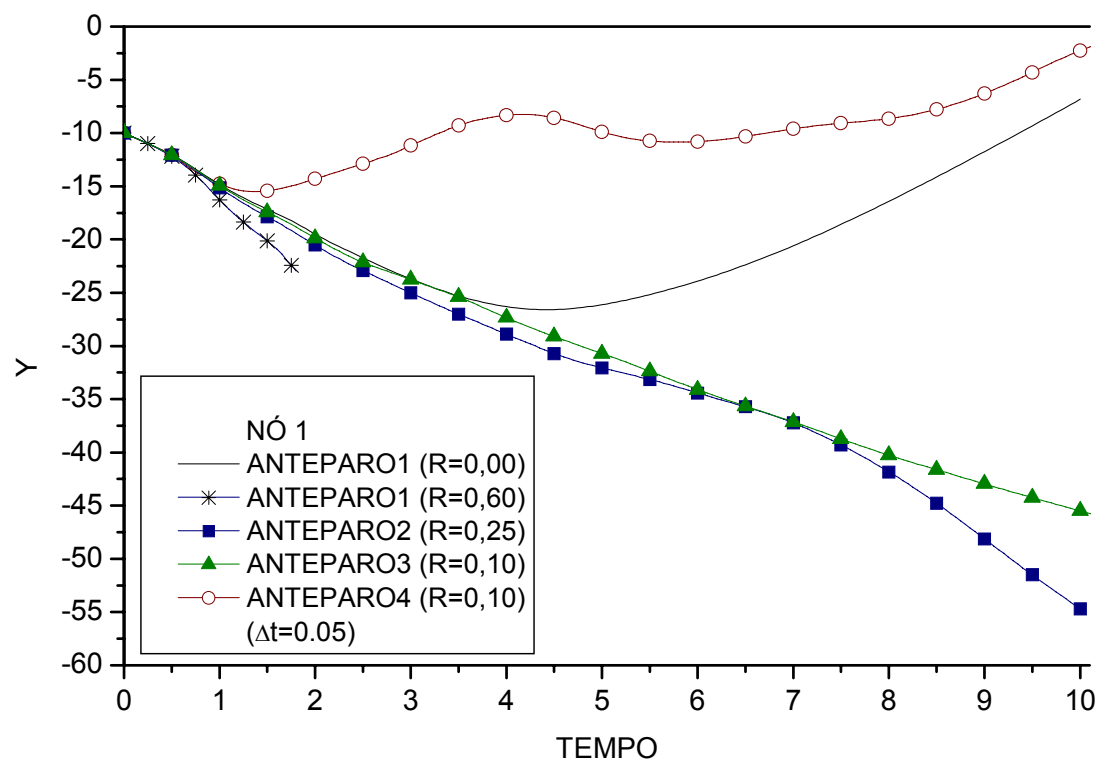

Figura 41 - Tempo $\times$ posição vertical $(Y)$ do nó 1

Deve-se comentar que no caso do anteparo 1 com atrito $(R=0.60)$ o nó 1 pára de se movimentar.

Os resultados obtidos neste capítulo demonstram a qualidade e o potencial da formulação desenvolvida. Os exemplos analisados apresentam estruturas sujeitas a grandes deflexões e rotações. Em alguns casos é possível ter comportamento pós-crítico e os programas computacionais desenvolvidos são capazes de encontrar as posições de equilíbrio mesmo nesta situação. 


\section{IMPACTO ENTRE ESTRUTURAS RETICULADAS PLANAS}

\subsection{Considerações iniciais}

Neste capítulo o algoritmo de contato/impacto é aplicado em problemas de colisão bidirecional entre estruturas reticuladas planas. No impacto entre estruturas é necessário avaliar tanto as correções de posição e forças de contato desenvolvidas nas estruturas impactantes como os efeitos gerados por estas forças nas estruturas alvo. Para as estruturas impactantes utiliza-se o algoritmo de impacto baseado em equações integrais, apresentado no capítulo anterior, e aplica-se o algoritmo de retorno, que será descrito neste capítulo. Para as estruturas alvo é necessário considerar a distribuição das forças de contato, a situação particular de impacto nodal e a determinação das condições iniciais.

Serão apresentadas apenas as modificações que deverão ser feitas para o caso de impacto entre estruturas, sendo válidos os modelos de atrito e plasticidade utilizados nos capítulos anteriores.

\subsection{Algoritmo de retorno e distribuição das forças de contato}

O retorno dos pontos nodais impactantes em elementos das estruturas alvo é feito conforme o modelo de atrito apresentado no capítulo anterior. As novas posições, velocidades e acelerações de cada ponto que sofreu impacto devem ser consideradas no cálculo das forças de contato, conforme a equação (1).

$$
F_{S+1}^{C O N}=F_{S+1}^{E X T}-\left(\left.\frac{\partial U_{T}}{\partial X}\right|_{S+1}+M \ddot{X}_{S+1}+C \dot{X}_{S+1}\right) \quad X_{S+1} \in \Gamma_{C}
$$

Estas forças de contato geradas nos pontos das estruturas impactante que entraram em contato devem ser distribuídas nos elementos que sofreram impacto da estrutura alvo. São estas forças de contato aplicadas nos pontos de retorno $I$, de cada elemento que sofreu impacto, que ocasionarão movimento na estrutura alvo. $\mathrm{Na}$ 
figura 1 está ilustrado o impacto de um ponto nodal com trajetória $C D$ em um elemento $A B$ da estrutura alvo.

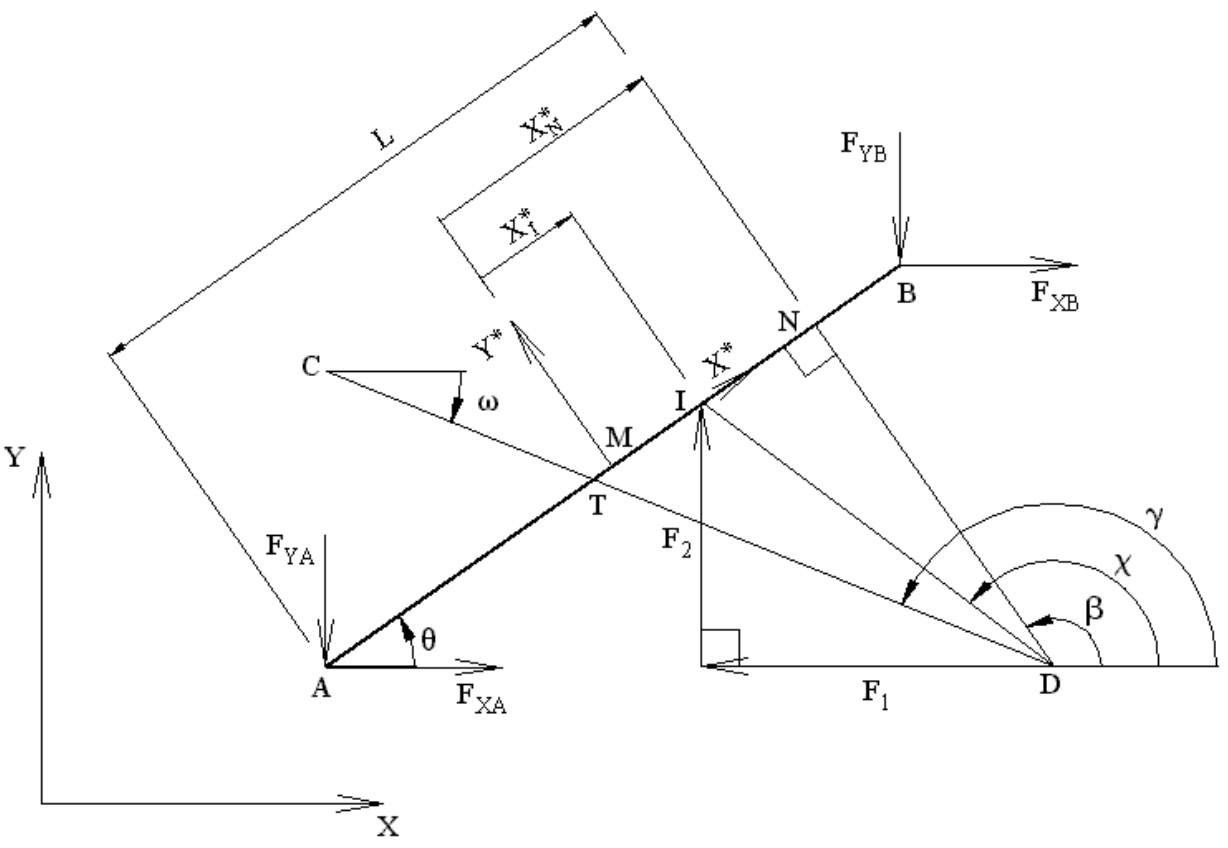

Figura 1 - Distribuição da força de contato aplicada no ponto $I$ de um elemento da estrutura alvo

Nas condições apresentadas na figura 1, as forças de contato $F_{1}$ e $F_{2}$ geram componentes de forças nos nós $A$ e $B$. Estas componentes dependem da posição de retorno no elemento $A B$. Para calcular a posição de retorno toma-se o sistema de referências local $X^{*} Y^{*}$, com origem no ponto médio do elemento. $\mathrm{O}$ ponto de retorno será $X_{I}^{*}$. É importante salientar que referências como ANSYS 5.5 (1998) e WRIGGERS et al. (1990) adotam o ponto $X_{N}^{*}$ como ponto de retorno, independentemente da existência de atrito. Também vale lembrar que pelo novo modelo de atrito proposto, quando $R=0$ tem-se $X_{N}^{*}=X_{I}^{*}$. As funções de distribuição dos carregamentos são consideradas lineares.

As forças aplicadas nos nós do elemento da estrutura alvo $\left(F_{X A}, F_{Y A}, F_{X B}\right.$ e $\left.F_{Y B}\right)$ são calculadas a partir de uma distribuição linear das forças de contato nas direções horizontal e vertical $\left(F_{1}\right.$ e $\left.F_{2}\right)$, conforme proposto por WRIGGERS et al. (1990).

$\left\{\begin{array}{l}F_{X A} \\ F_{Y A}\end{array}\right\}=-\left(\frac{1}{2}-\frac{X_{I}^{*}}{L}\right)\left\{\begin{array}{l}F_{1} \\ F_{2}\end{array}\right\}$ 


$$
\left\{\begin{array}{l}
F_{X B} \\
F_{Y B}
\end{array}\right\}=-\left(\frac{1}{2}+\frac{X_{I}^{*}}{L}\right)\left\{\begin{array}{l}
F_{1} \\
F_{2}
\end{array}\right\}
$$

De acordo com a figura 2, o valor de $X_{I}^{*}$ (sistema $\left.X^{*} Y^{*}\right)$ pode ser calculado com base no sistema de coordenadas local $\bar{X} \bar{Y}$.

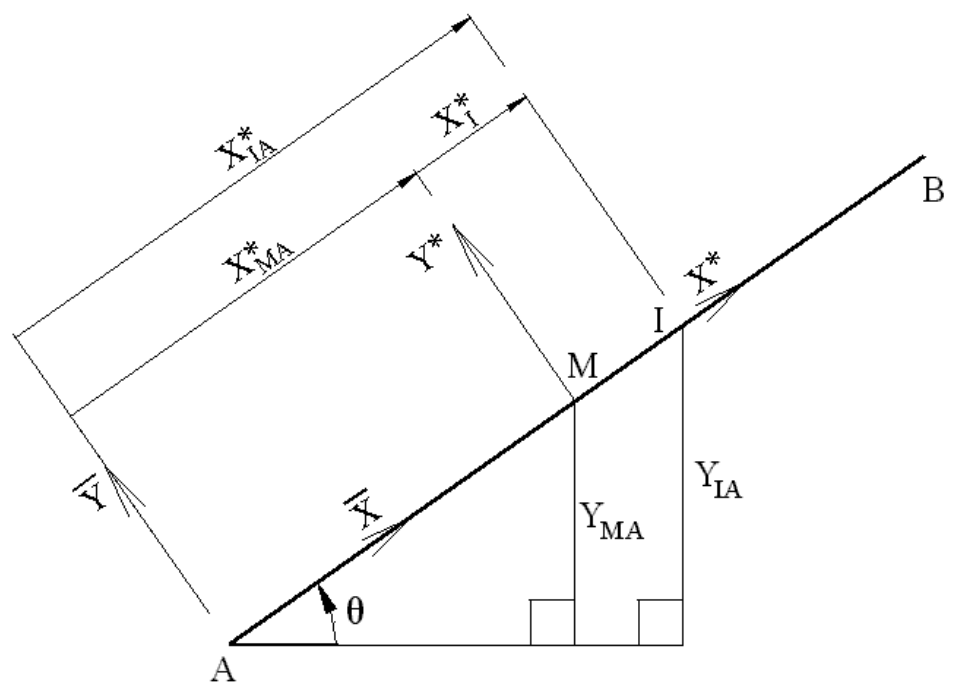

Figura 2 - Coordenadas locais em um elemento da estrutura alvo que sofreu impacto

Onde $M$ representa o ponto médio do segmento $A B$. Tomando-se com base o sistema $\bar{X} \bar{Y}$, tem-se:

$X_{I}^{*}=X_{I A}^{*}-X_{M A}^{*}$

$\mathrm{Na}$ figura 2, as cotas verticais em coordenadas globais (sistema $X Y$ ) podem ser calculadas pelas seguintes expressões:

$Y_{I A}=Y_{I}-Y_{A}$

$Y_{M}=\frac{Y_{A}+Y_{B}}{2}$

$Y_{M A}=Y_{M}-Y_{A}$

Pode-se utilizar o seguinte procedimento para o cálculo das variáveis necessárias na solução da equação (4):

- Se $Y_{A} \neq Y_{B}$ então:

$X_{I A}^{*}=\frac{Y_{I A}}{\operatorname{sen} \theta}$ 
$X_{M A}^{*}=\frac{Y_{M A}}{\operatorname{sen} \theta}$

- Senão $\left(Y_{A}=Y_{B}\right)$ :

$X_{I A}^{*}=X_{I}$

$X_{M A}^{*}=\frac{X_{A}+X_{B}}{2}$

No caso de impacto entre uma estrutura e um anteparo rígido, não há distribuição de forças de contato para os nós dos elementos do anteparo aonde ocorreram os impactos.

\subsection{Impacto nodal}

O impacto nodal pode ocorrer caso um nó da estrutura alvo esteja colinear com a trajetória de impacto de um nó da estrutura impactante. No caso, a colinearidade é admitida dentro de certa tolerância. Na figura 3, ilustra-se uma trajetória definida pelo segmento de reta $C D$ com um ponto $A$ aproximadamente colinear ao segmento. Ao invés do retorno ser feito para o elemento cujo valor da integral $\hat{H}_{j}$ for mais próximo de 0.5 , para o ponto $N$ apresentado na figura 3 , o retorno será feito para o ponto nodal $A$ da estrutura alvo.

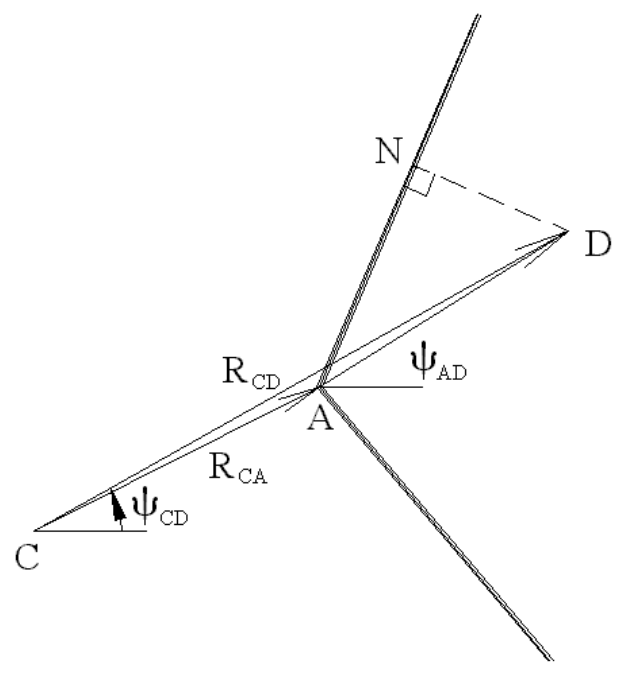

Figura 3 - Situação de impacto nodal

Para testar colinearidade do ponto $A$ com o segmento de reta $C D$ utilizam-se os coeficientes de reta $m_{C D}$ e $m_{A D}$, além das distâncias $R_{C D}$ e $R_{C A}$. O ponto $A$ será 
considerado como pertencente ao segmento $C D$ quando forem verificadas duas condições:

$$
\begin{aligned}
& \left|m_{A D}-m_{C D}\right| \leq T O L \\
& R_{C A} \leq R_{C D}
\end{aligned}
$$

Os coeficientes $m_{C D}$ e $m_{A D}$ são calculados a partir das tangentes $\psi_{C D}$ e $\psi_{A D}$, conforme apresentado no capítulo 5. Caso o segmento $C D$ e o segmento $A D$ sejam, dentro da tolerância especificada, aproximadamente verticais, considera-se apenas a equação (13) na verificação da colinearidade.

$\mathrm{O}$ algoritmo de impacto proposto calcula inicialmente o retorno para o elemento com valor da integral $\hat{H}_{j}$ mais próximo de 0.5 , em seguida verifica se para cada trajetória de ponto nodal da estrutura impactante se existe algum nó da estrutura alvo que seja colinear a cada trajetória analisada. Se houver, então o impacto passa a ser do tipo nodal e as forças de contato serão calculadas para as novas correções de deslocamento e serão transferidas diretamente como forças de contato, com sentidos opostos, para o respectivo nó da estrutura alvo.

\subsection{Condições iniciais}

Em problemas usuais de dinâmica das estruturas, que não envolvem não linearidade devido ao contato, as variáveis podem ser prescritas de duas maneiras, através das condições de contorno e das condições iniciais. A partir das condições de contorno em força e das condições iniciais calculam-se as acelerações iniciais $\left(\ddot{X}_{0}\right)$ nos pontos nodais.

$$
\ddot{X}_{0}=M^{-1}\left[F_{0}-C \dot{X}_{0}-\left.\frac{\partial U_{t}}{\partial X}\right|_{0}\right]
$$

Para os problemas dinâmicos chamados de usuais, após o cálculo de $\ddot{X}_{0}$ iniciase a solução do primeiro passo de tempo e sucessivamente dos próximos passos, de acordo com o algoritmo de integração temporal utilizado. No caso do impacto entre duas ou mais estruturas, é necessário efetuar o cálculo das acelerações iniciais nas estruturas alvo quando os impactos ocorrerem pela primeira vez. Esta necessidade existe porque no instante inicial da análise pode ser que não tenha ocorrido ainda nenhum impacto. Caso a estrutura alvo esteja em repouso e sem nenhum carregamento externo aplicado, então não haverá aceleração inicial na estrutura alvo. No instante inicial do 
impacto são aplicadas forças externas, geradas pelas forças de contato, na estrutura alvo. Este novo carregamento externo aplicado provoca uma aceleração inicial na estrutura alvo e que não existia previamente, pois no cálculo de $\ddot{X}_{0}(t=0 \mathrm{~s})$ não havia esta condição de contorno em força externa aplicada na estrutura alvo. Portanto, para cada novo impacto que ocorre é necessário que se calcule as acelerações iniciais da estrutura alvo que sofreu impacto $\left(\ddot{X}_{(t)}^{E}\right)$.

$$
\ddot{X}_{(t)}^{E}=M^{E^{-1}}\left[F_{(t)}^{E}-C \dot{X}_{(t)}^{E}-\left.\frac{\partial U_{t}^{E}}{\partial X}\right|_{(t)}\right]
$$

Onde o índice sobrescrito $E$ indica estrutura alvo que sofreu impacto e o índice subscrito $(t)$ indica o tempo no qual ocorreu o respectivo impacto. A equação (15) deve sempre ser aplicada quando uma estrutura alvo sofrer impacto, nos respectivos instantes iniciais de cada impacto.

\subsection{Exemplos numéricos}

\subsubsection{Impacto entre duas estruturas anelares}

$\mathrm{O}$ exemplo trata do impacto entre duas malhas anelares iguais. A estrutura à esquerda se movimenta com velocidade constante em direção à estrutura alvo, à direita. Cada estrutura foi discretizada com 32 elementos finitos e o espaço inicial entre as estruturas é de $\delta=0.01 \mathrm{~m}$. As características físicas, geométricas e cinemáticas são apresentadas na figura 4. Considera-se neste exemplo o problema sem atrito. À direita da figura, observa-se o detalhe do ponto nodal 1 e o elemento 33-34 da estrutura alvo, aonde ocorrerá o impacto. Nota-se ainda que os nós 33 e 34 foram definidos estrategicamente com mesmo valor de coordenada global $X$, com o intuito destes nós apresentarem o mesmo deslocamento horizontal. As respostas obtidas com a formulação proposta, baseada no método do multiplicador de Lagrange, são comparadas com as respostas obtidas pelo programa ANSYS (1998), que utiliza funções de penalização para resolver problemas de impacto. 

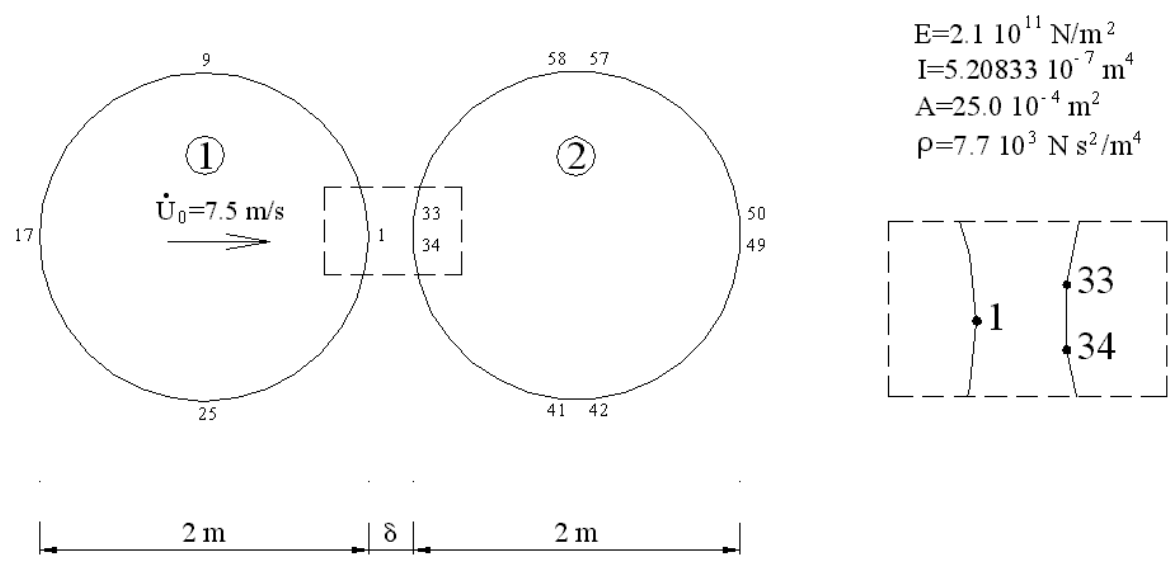

Figura 4 - Dados de entrada do problema

Foram considerados três valores para calibrar o coeficiente de rigidez $K N$ utilizado pelo programa ANSYS. Na figura 5 são apresentadas as posições na direção $X$ para os pontos 1 (da estrutura impactante) e o ponto 33 (da estrutura alvo) para os três valores de $K N$ considerados.

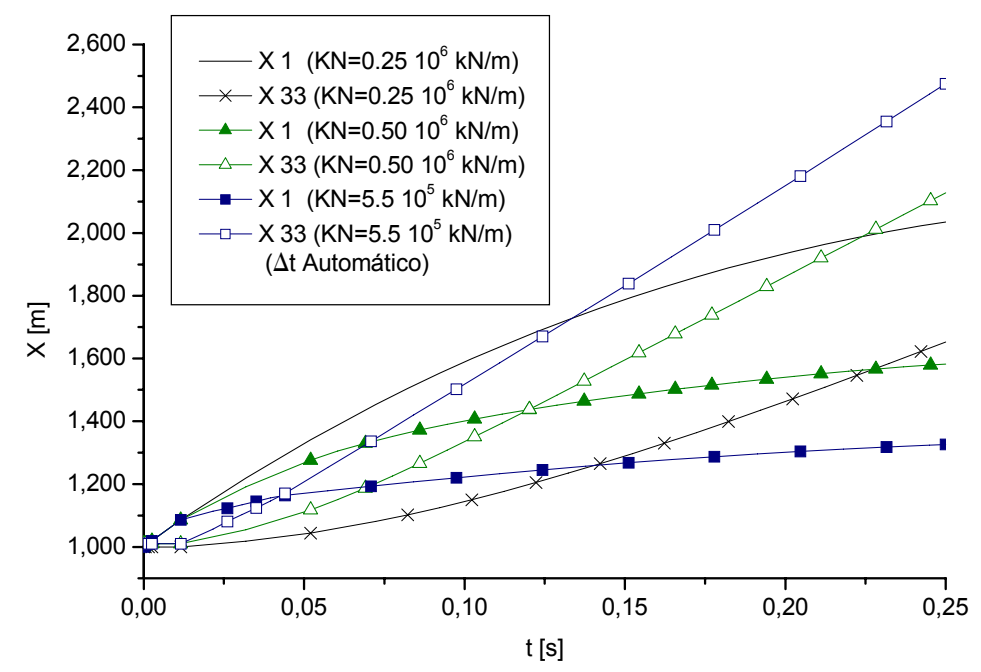

Figura 5 - Tempo $\times$ posição na direção X dos nós 1 e 33 (ANSYS)

Observa-se na figura 5 que a variação de $K N$ gerou respostas muito diferentes. Para o menor valor de $K N$ o deslocamento do ponto 1 quase não influencia o movimento do ponto 33, é como se o nó 1 se movimentasse dentro da estrutura alvo sem haver grande influência no comportamento da estrutura alvo. Valores menores de 
$K N$ geram respostas ainda mais independentes para os deslocamentos dos nós 1 e 33, enquanto o nó 1 se movimenta de maneira quase livre, o nó 33 quase não se movimenta. Para o valor intermediário de $K N$ ainda há a sobreposição do nó 1 sobre a estrutura alvo até o tempo $t \cong 0.12 \mathrm{~s}$. Para o maior valor de $K N$ a sobreposição do nó 1 na estrutura alvo é menor e durante o tempo de impacto, $t \cong 0.04 \mathrm{~s}$, a diferença entre o deslocamento do nó 1 e do nó 33 é pequena. Para valores maiores de $K N$ é gerado um impacto rígido, a estrutura 2 passa a se comportar como se fosse um anteparo rígido e não se movimenta. É interessante observar que as diferenças dos valores adotados de $K N$ não são muito grandes entre si, mas geram resultados completamente diferentes.

Na figura 6 são ilustradas as posições dos pontos 1 e 33 na direção $X$, utilizandose a formulação proposta e a melhor resposta obtida pela técnica de penalização do ANSYS (para o maior valor de $K N$ apresentado na figura 5).

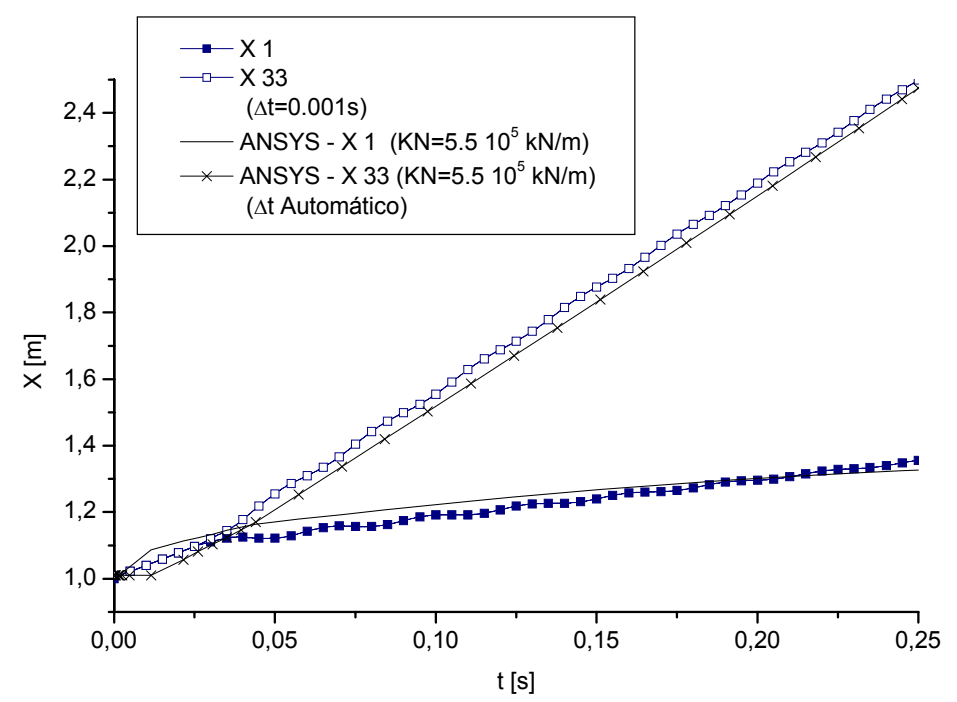

Figura 6 - Tempo $\times$ posição na direção $X$ dos nós 1 e 33

Observa-se na figura 6 que a formulação proposta fornece respostas mais coerentes do que as obtidas com as funções de penalização. O período de impacto passa a ser igual a $t \cong 0.025 \mathrm{~s}$. Durante este período os nós 1 e 33 se movimentam juntos, até a separação das estruturas. Após a separação o nó 33 da estrutura alvo, que inicialmente estava em repouso, passa a ter deslocamentos maiores que o nó 1 da estrutura impactante, que continua a se movimentar, porém com velocidade menor que a inicial. Observa-se ainda que devido ao fato da função de penalização ser mais flexível, 
permitindo a sobreposição das estruturas, a transferência de forças é feita de forma mais suave, gerando assim movimentos pós-impacto praticamente sem vibrações. Já a formulação proposta permite observar que os corpos, além de sofrerem alterações em suas velocidades de conjunto, também vibram após a separação.

Na figura 7 são apresentadas as forças de contato e multiplicadores de Lagrange obtidos usando a formulação proposta e as forças de contato obtidas pelo programa ANSYS.

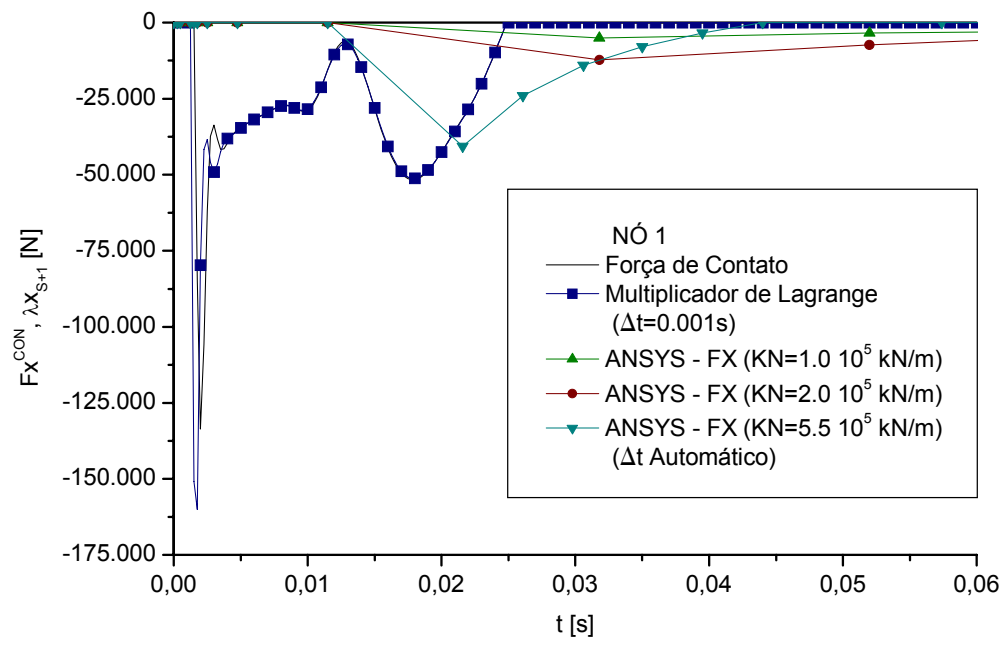

Figura 7 - Tempo $\times$ força de contato (e multiplicador de Lagrange) na direção X do nó 1

Os multiplicadores de Lagrange foram um pouco maiores do que as forças de contato obtidas com a formulação proposta nos instantes iniciais do impacto e a partir do tempo $t \cong 0.004 \mathrm{~s}$ forneceram praticamente os mesmo resultados. Já as forças de contato obtidas usando funções de penalização (ANSYS) apresentaram comportamentos diferentes. Somente a partir do tempo $t \cong 0.01 \mathrm{~s}$ começam a existir forças de contato. Neste tempo, o nó 1 já teria se deslocado dentro da estrutura alvo. De maneira geral, observou-se para as funções de penalização que quanto maiores os valores de $K N$, maiores serão os valores das forças de contato. Porém, convém salientar que os valores das forças de contato obtidos pela formulação proposta e pelas funções de penalização são completamente diferentes. A formulação proposta forneceu resultados mais coerentes para este problema que as funções de penalização.

Na figura 8 são apresentadas as configurações das estruturas durante o impacto e após a separação, em determinados instantes. 

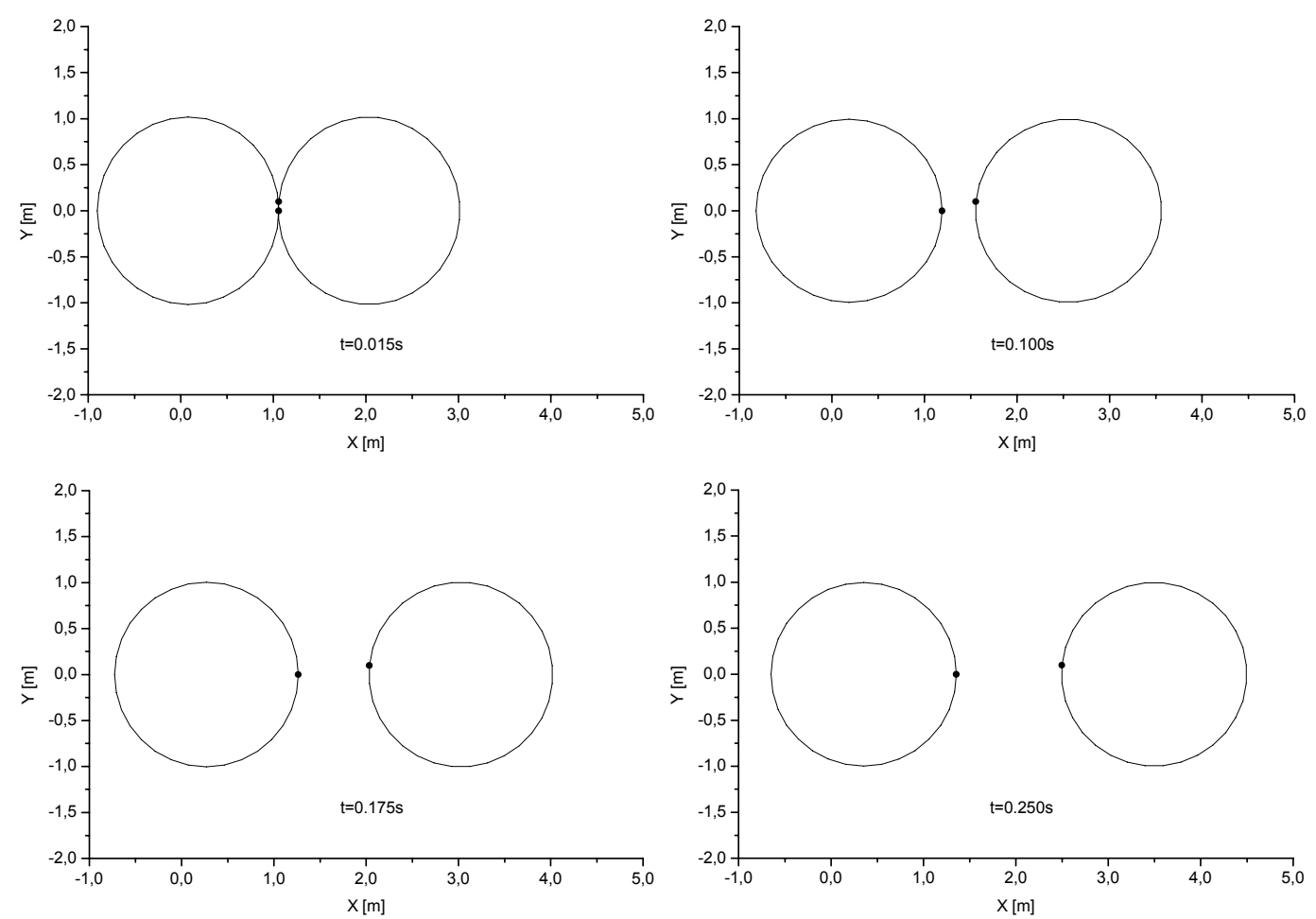

Figura 8 - Configurações dos anéis para determinados instantes de tempo

\subsubsection{Impacto entre três estruturas anelares}

$\mathrm{O}$ exemplo trata do impacto entre três malhas anelares iguais. A estrutura à esquerda se movimenta com velocidade constante em direção às estruturas alvos, que inicialmente se encontram em repouso. Cada estrutura foi discretizada com 32 elementos finitos e o espaço inicial entre a estrutura em movimento e as estruturas-alvo é de $\delta=0.01 \mathrm{~m}$. Não existe separação entre as duas estruturas em repouso. As características físicas, geométricas e cinemáticas são apresentadas na figura 9 . Considera-se o problema sem atrito. À direita da figura, observa-se o detalhe dos pontos nodais 1 e 33, além do detalhe do ponto nodal 49 e do o elemento 65-66, da segunda estrutura alvo à direita. Nesta situação ocorrem dois impactos, envolvendo três estruturas. Considerando-se uma numeração crescente das estruturas, da esquerda para direita, define-se para o algoritmo de previsão de impacto que a estrutura 2 é alvo da estrutura 1 e a estrutura 3 é alvo da estrutura 2. A coordenada $X$ é definida com o intuito didático de marcar o ponto de origem do primeiro impacto. 

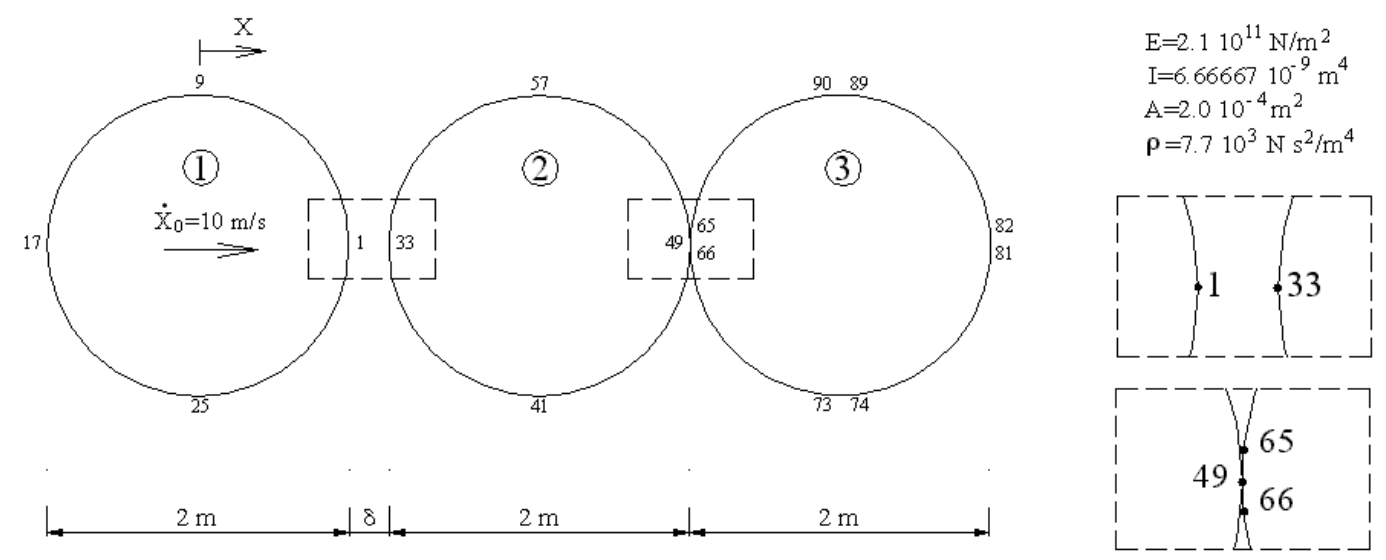

Figura 9 - Dados de entrada do problema

Na figura 10 são apresentados os deslocamentos, com origem na direção $X$, dos pontos nodais $1,33,49$ e 65 . Estes pontos foram definidos de maneira a ilustrar como é feita a transferência de quantidade de movimento ${ }^{1}$ entre as três estruturas. Na figura 11 são apresentas forças de contato e multiplicadores de Lagrange para os nós 1 e 49.

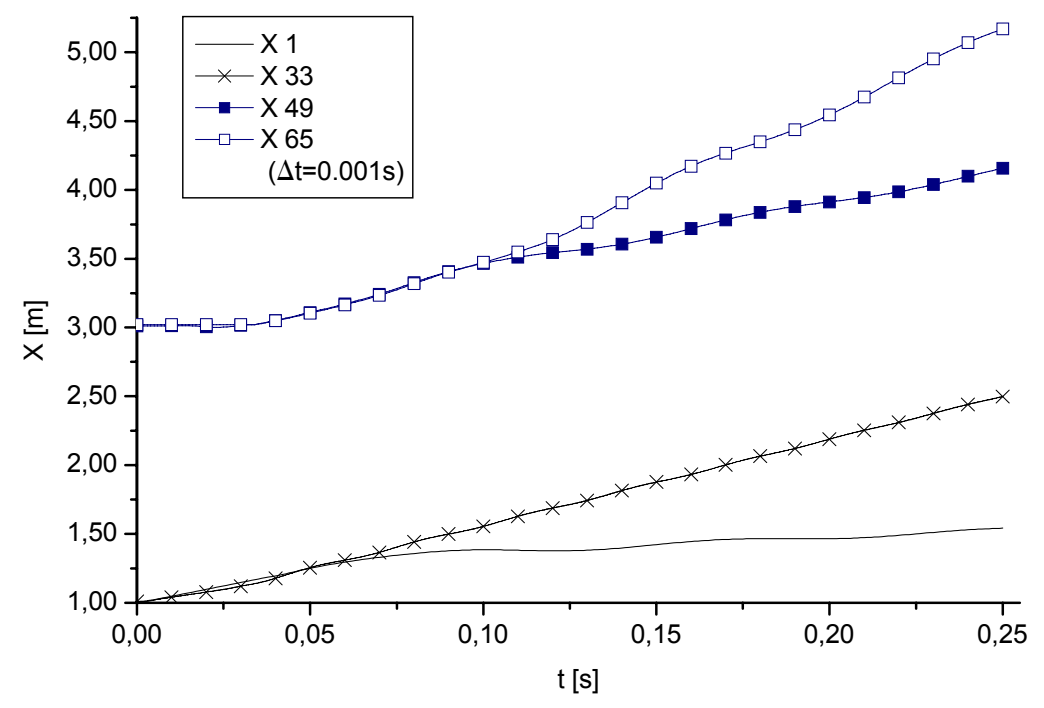

Figura 10 - Tempo $\times$ posição na direção X dos nós 1, 33, 49 e 65

\footnotetext{
${ }^{1}$ As forças externas também podem ser definidas como variações nas quantidades de movimento dos corpos.
} 


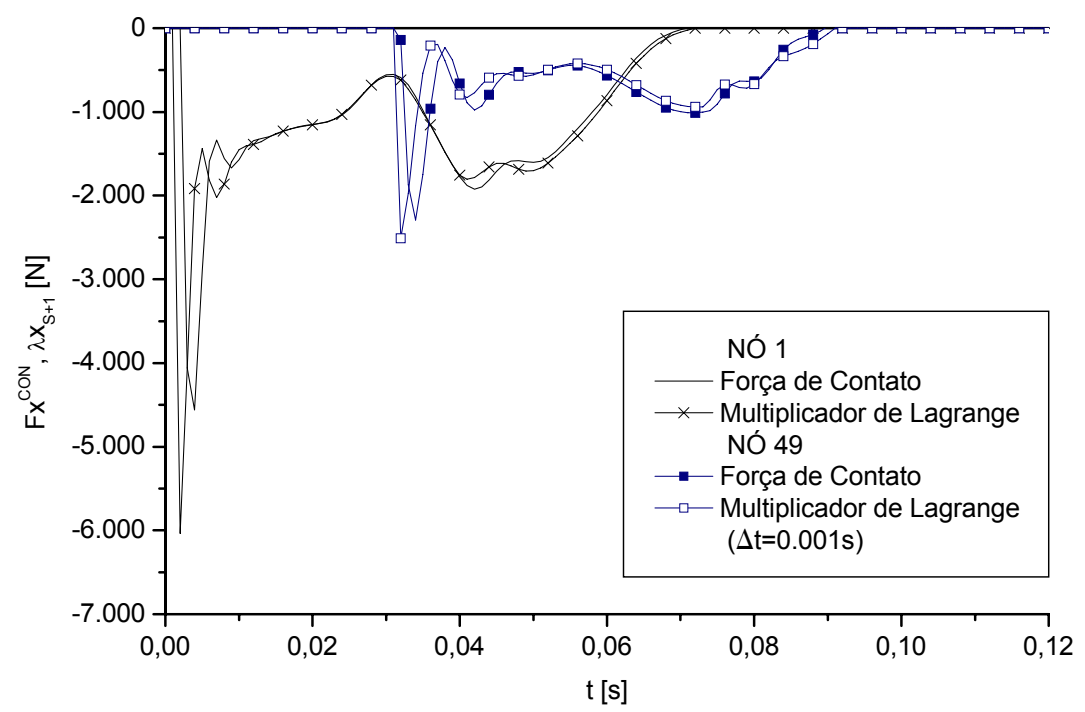

Figura 11 - Tempo $\times$ força de contato (e multiplicador de Lagrange) na direção X dos nós 1 e 49

Na figura 10, nota-se que após a separação entre as estruturas os nós envolvidos no impacto continuam seus movimentos de forma oscilatória. Seguindo-se a numeração da esquerda para direita, o período de impacto entre a estrutura 1 e 2 termina em $t \cong 0.07 \mathrm{~s}$. O impacto entre as estruturas 2 e 3 tem uma duração menor $t \cong 0.06 \mathrm{~s}$ e termina em $t \cong 0.09 \mathrm{~s}$. Com base na figura 11 , observa-se que até o tempo de $t \cong 0.06 \mathrm{~s}$ o impacto entre as estruturas 1 e 2 é mais relevante, em termos da amplitude das forças de contato. Durante o intervalo de tempo que varia de $t \cong 0.06 \mathrm{~s}$ a $t \cong 0.09 \mathrm{~s}$ o impacto entre as estruturas 2 e 3 passa a ter maior importância. No instante inicial do impacto entre as estruturas 1 e 2 , e no segundo impacto entre as estruturas 2 e $3(t \cong 0.035 s)$, ocorrem saltos nas forças de contato e multiplicadores de Lagrange.

Na figura 12 são mostradas as configurações das estruturas em colisão para determinados instantes. 

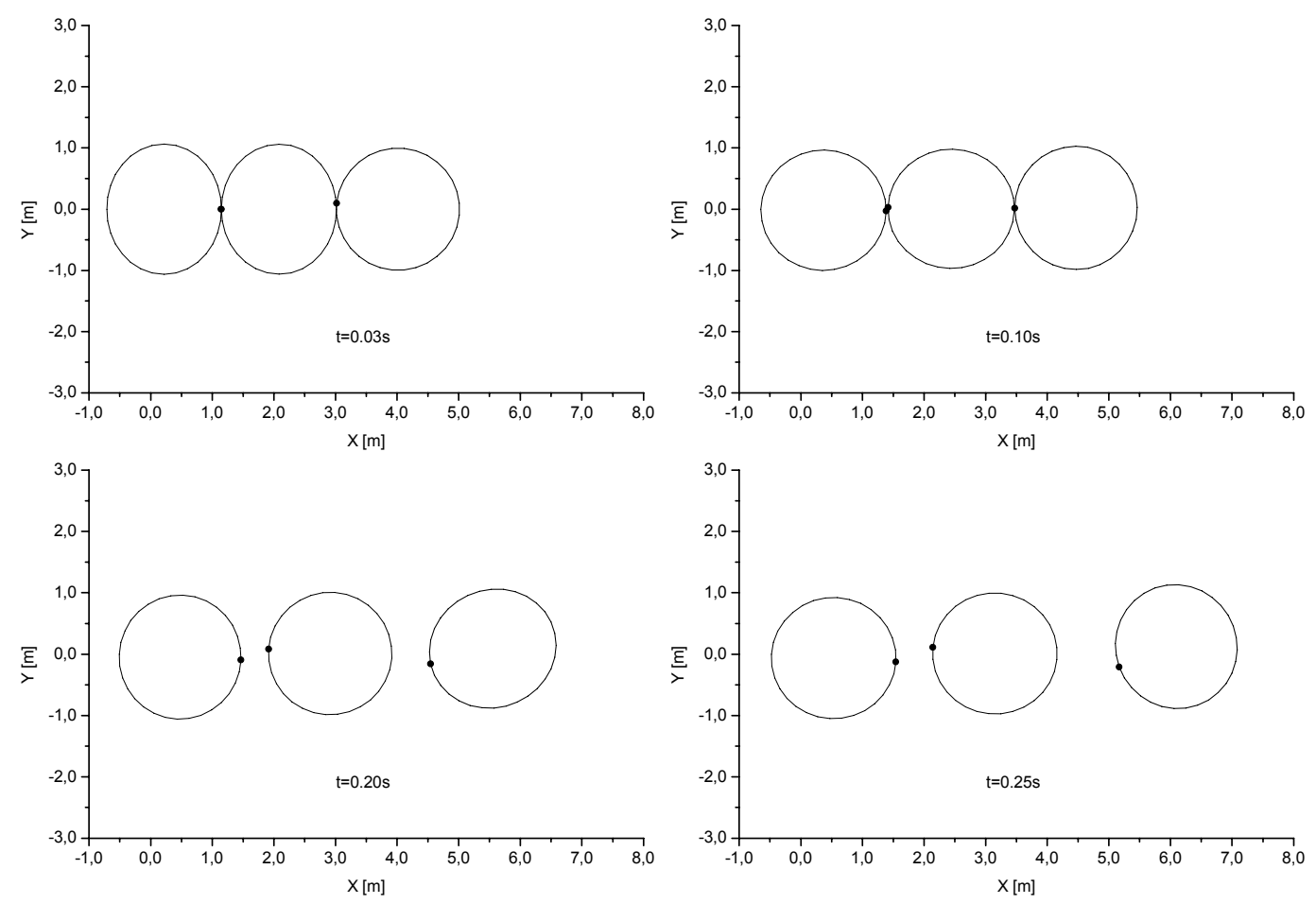

Figura 12 - Configurações dos anéis para determinados instantes de tempo

\subsubsection{Estrutura anelar confinada em quadro flexível}

O exemplo trata do impacto entre uma malha anelar e um quadro flexível. A estrutura anelar está confinada no quadro, conforme ilustrado na figura 13. Considera-se neste exemplo o problema sem atrito. Neste problema a malha é definida como uma região virtual infinita para efeitos de identificação do impacto. A estrutura anelar foi discretizada em 32 elementos finitos e o quadro em 40 elementos finitos. Inicialmente o quadro se encontra em repouso, enquanto a estrutura anelar se movimenta com velocidade constante em uma trajetória inclinada em direção ao contorno da malha. $\mathrm{Na}$ figura 14 são apresentadas as posições dos nós 1 e 33 nas direções horizontal $(X)$ e vertical $(Y)$. O espaço inicial entre as estruturas é de $\delta=0.05 \mathrm{~m}$. 


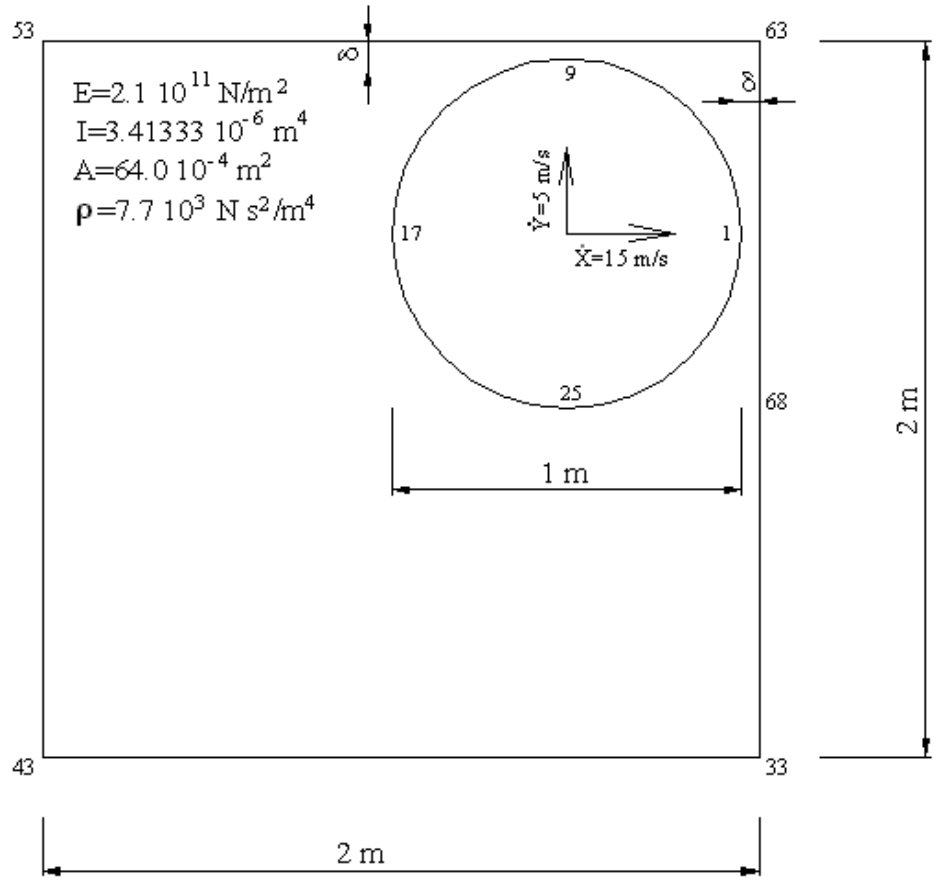

Figura 13 - Dados de entrada do problema

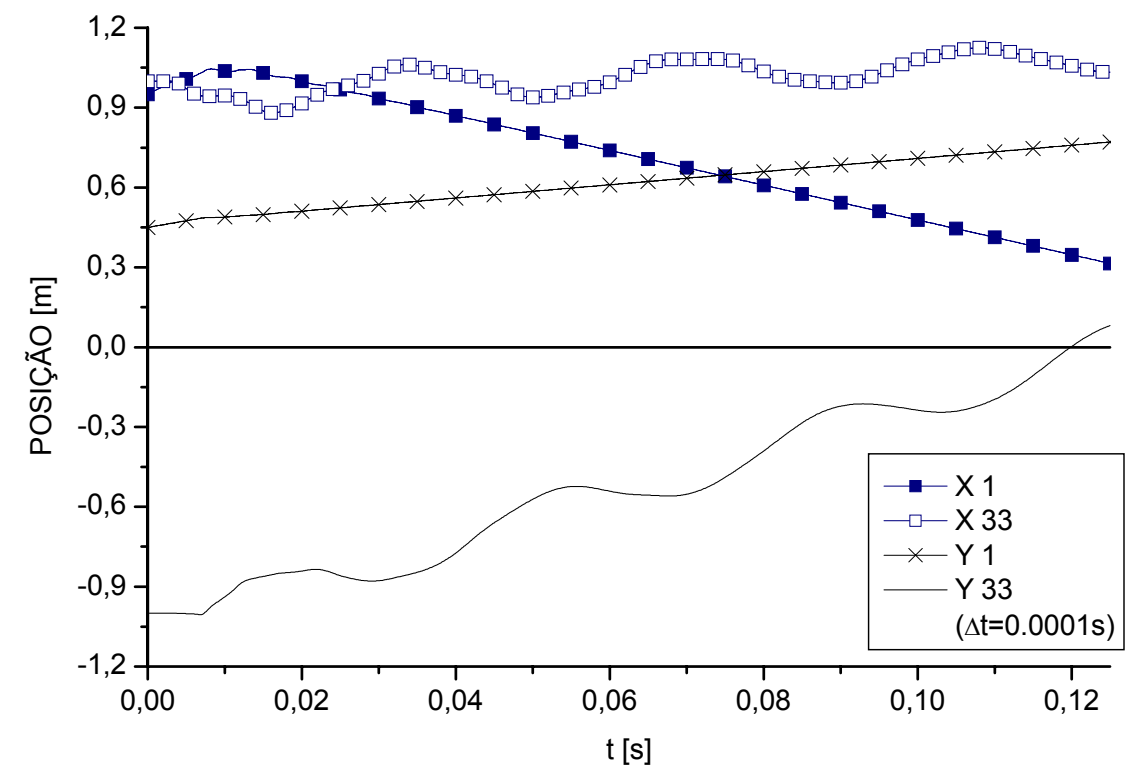

Figura 14 - Tempo $\times$ posições horizontal (X) e vertical (Y) dos nós 1 e 33

$\mathrm{Na}$ figura 15 são mostradas as configurações das estruturas em colisão para vários instantes. 

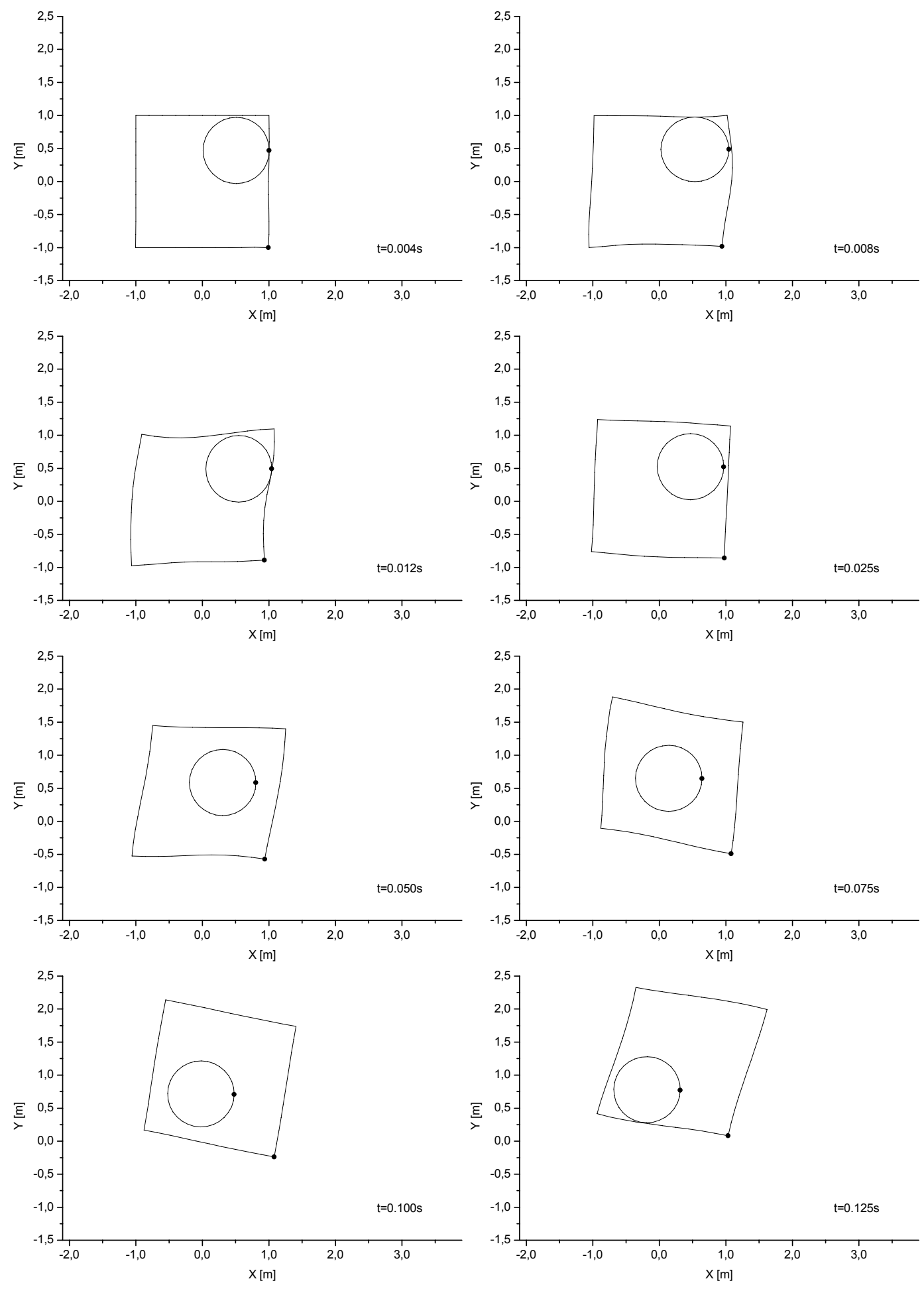

Figura 15 - Configurações estruturais em determinados instantes de tempo 


\section{CONCLUSÕES E CONSIDERAÇÕES FINAIS}

\subsection{Conclusões}

Como conclusão da tese serão feitas as considerações finais sobre os resultados obtidos e em seguida serão apresentadas algumas sugestões para trabalhos futuros, para a seqüência do trabalho desenvolvido na tese.

Durante o doutorado foram apresentadas formulações, baseadas no MEF, para a solução de problemas de impacto bidirecional entre estruturas reticuladas planas e foram desenvolvidos códigos computacionais adequados para implementação das formulações desenvolvidas. Os exemplos apresentados nos quatro últimos capítulos da tese comprovam a precisão das formulações e dos programas desenvolvidos, sendo plenamente atingido o objetivo do trabalho.

A primeira contribuição relevante da tese está na extensão para os casos elastoplástico e dinâmico da formulação posicional não linear geométrica estática desenvolvida em CODA (2003) e CODA \& GRECO (2003). Com a técnica de conexão nodal apresentada no apêndice 4, o programa dinâmico pôde ampliar o campo de aplicações da formulação para além dos problemas convencionais da Engenharia Civil, se destacando a aplicação a problemas de multicorpos. Em relação ao tema da tese propriamente dito as contribuições estão principalmente nos algoritmos de impacto e retorno para problemas bidirecionais de impacto. A confirmação da originalidade e relevância das contribuições pode ser verificada através da aceitação para publicação de dois artigos científicos em revistas indexadas de alto coeficiente de impacto na área de Engenharia, ver CODA \& GRECO (2003) e GRECO, CODA \& VENTURINI (2003).

Apesar de tratar apenas de um tipo de elemento finito, um dos mais simples, a tese aborda um vasto conteúdo, com três tipos de não linearidades encontradas em estruturas (física, geométrica e de contato). Outro ponto de destaque é a utilização dos multiplicadores de Lagrange e de um algoritmo de integração temporal eficiente na 
solução dos problemas de impacto, constituindo uma alternativa interessante para tratar o problema.

Nas referências bibliográficas é apresentado um número razoável de trabalhos. Consultaram-se diversas outras referências; que não foram apresentadas devido à falta de relação direta com o tema da tese. Outro comentário que se deve fazer é a respeito da bibliografia complementar, constituída por algumas teses de excelente qualidade defendidas no Departamento de Estruturas da Escola de Engenharia de São Carlos nos últimos anos, e que buscaram um enfoque mais voltado para aplicações em Engenharia Civil.

Para os problemas analisados nesta tese, considerados de dinâmica não linear, os resultados obtidos são considerados de excelente qualidade. Os algoritmos numéricos utilizados nas formulações apresentaram as características desejáveis de consistência, convergência e estabilidade, definidas no apêndice 2, para os exemplos numéricos apresentados.

\subsection{Considerações finais e desenvolvimentos futuros}

Existem outros tipos de problemas, mais complexos, e que ainda não foram testados com os algoritmos desenvolvidos. Estes problemas são considerados de dinâmica não linear e não ideal ${ }^{1}$. A estabilidade dos sistemas não lineares gerados nestes problemas, também truncados por séries de Taylor, pode ser verificada através do método de Liapunov ${ }^{2}$. Este tipo de verificação de estabilidade é estudada através dos auto-valores do sistema.

Após serem feitas as considerações finais serão apresentadas algumas sugestões para trabalhos e projetos futuros que o doutorando pretende desenvolver.

Atualmente, a ferramenta numérica mais utilizada na solução de problemas não lineares geométricos é o MEF e recomenda-se que seja utilizada em futuras formulações desenvolvidas.

Uma futura aplicação é o estudo de comportamento pós-crítico, com o cálculo dos pontos de bifurcação. O artigo de BATTINI et al. (2003) utiliza a equação diferencial não linear geométrica para o cálculo dos pontos de bifurcação. No caso, o sistema não linear de equações seria composto por três equações:

\footnotetext{
${ }^{1}$ A dinâmica não ideal estuda a influência do movimento de um sistema em sua fonte excitadora.

${ }^{2}$ As funções de Liapunov definem a região de estabilidade do algoritmo.
} 
$l_{0} \int_{0}^{l} \frac{\partial u_{t}}{\partial X} d \xi-\lambda F=0$

$\nabla g\left(X^{0}\right) \phi=0$

$\|\phi\|-1=0$

Onde $\lambda$ é o vetor dos fatores de carga e $\phi$ o auto-vetor crítico no ponto de bifurcação. Assim, o sistema de equações (1) pode ser resolvido pelo algoritmo de Newton-Raphson, conforme descrito no artigo de WRIGGERS et al. (1988).

$\left[\begin{array}{ccc}\nabla g\left(X^{0}\right) & -F & 0 \\ \frac{\partial}{\partial X}\left[\nabla g\left(X^{0}\right) \phi\right] & \frac{\partial}{\partial \lambda}\left[\nabla g\left(X^{0}\right) \phi\right] & \nabla g\left(X^{0}\right) \\ 0 & 0 & \frac{\phi^{T}}{\|\phi\|}\end{array}\right]\left\{\begin{array}{l}\Delta X \\ \Delta \lambda \\ \Delta \phi\end{array}\right\}=-\left\{\begin{array}{c}l_{0} \int_{0}^{1} \frac{\partial u_{t}}{\partial X} d \xi-\lambda F \\ \nabla g\left(X^{0}\right) \phi \\ \|\phi\|-1\end{array}\right\}=0$

A identificação dos pontos de bifurcação em problemas estáticos deve ser feita utilizando-se um algoritmo do tipo arc-lenght, como os apresentados por RIKS (1979) e CRISFIELD (1981).

Outro tópico possível de ser considerado, com certa facilidade, é o efeito da variação de temperatura nas deformações dos membros estruturais, através da variável de deformações térmicas $\left(\varepsilon_{T}\right)$, dependentes de um coeficiente de dilatação térmica $(\alpha)$ e da variação da temperatura $(\Delta T)$. No caso, são utilizados pontos de Gauss para mapear a estrutura, da mesma maneira que foi feito no caso da plasticidade.

$\varepsilon_{T}=\alpha \Delta T$

Poderão ainda ser considerados o atrito nas rótulas e a inércia de rotação nos elementos estruturais.

A partir das formulações e programas computacionais desenvolvidos no doutorado pretende-se dedicar a pesquisa principalmente aos problemas de multicorpos. A mecânica racional utilizada em projetos de máquinas, devido às pequenas deformações previstas em projeto, considera os membros estruturais como corpos rígidos ligados entre si através de ligações rígidas, livres ou semi-rígidas. Na realidade, mesmo em condições ideais de trabalho os membros estruturais sofrem vibrações e deformações. As vibrações geradas nos membros estruturais podem causar problemas de utilização das estruturas e muitas vezes podem levar a baixas condições de segurança. As deformações geradas nos mecanismos, mesmo quando pequenas, podem 
trazer problemas de tolerância geométrica no funcionamento, conforme o mecanismo de Peaucellier flexível apresentado no capítulo 4.

$\mathrm{Na}$ última década foram publicados vários artigos que tratam de problemas de multicorpos envolvendo estruturas compostas por dois ou três membros estruturais flexíveis, como os artigos de CHOURA \& YIGIT (2001), KARKOUB \& YIGIT (1999), SHIGANG et al. (1997), LEE (1996), BAUCHAU \& THERON (1996) e ELKARANSHAWY \& DOKAINISH (1995).

A formulação desenvolvida nesta tese também deve ser capaz de analisar problemas de impacto envolvendo multicorpos, como os apresentados nos trabalhos de STOENESCU \& MARGHITU (2003) e YIGIT (1994), mas ainda não foram testados.

Outro tipo de mecanismo de torque interessante é o chamado mecanismo de retorno rápido, apresentado na figura 1. Este tipo de mecanismo é caracterizado por produzir uma fase de movimento rápido e outra fase de movimento lento.

$\mathrm{O}$ mecanismo de retorno rápido acoplado à estrutura flexível, ilustrado na figura 2, é muito utilizado em plainas. Pode-se considerar o mecanismo como totalmente rígido acoplado a outros elementos flexíveis da estrutura, parcialmente rígido ou totalmente flexível, como o apresentado no artigo de BAUCHAU (2000). A idéia mais interessante é adaptar o algoritmo de impacto desenvolvido na tese para a modelagem do mecanismo de retorno rápido totalmente flexível.

(a)

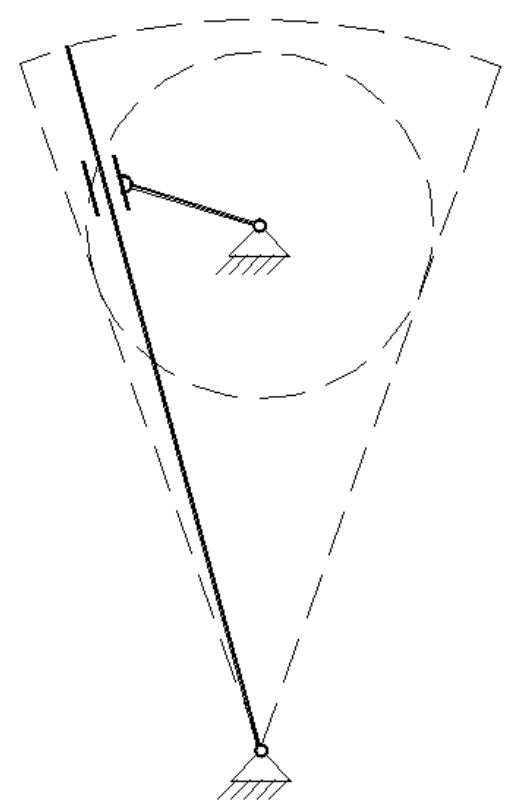

(b)

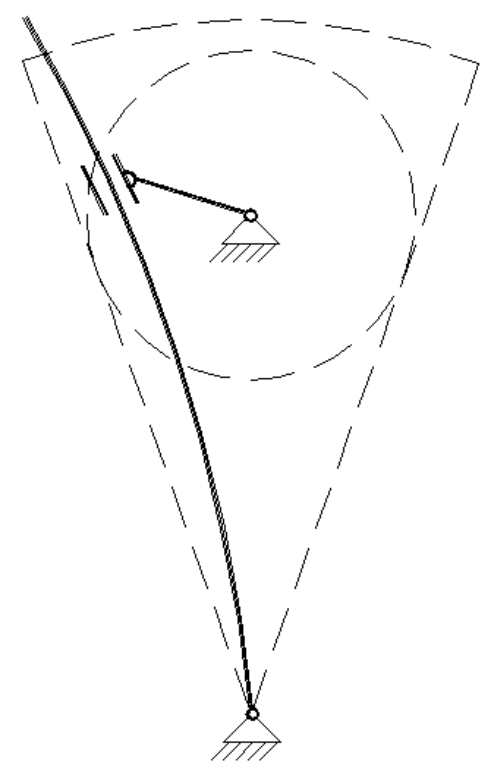

Figura 1 - Mecanismos de retorno rápido (a) rígido e (b) flexível 


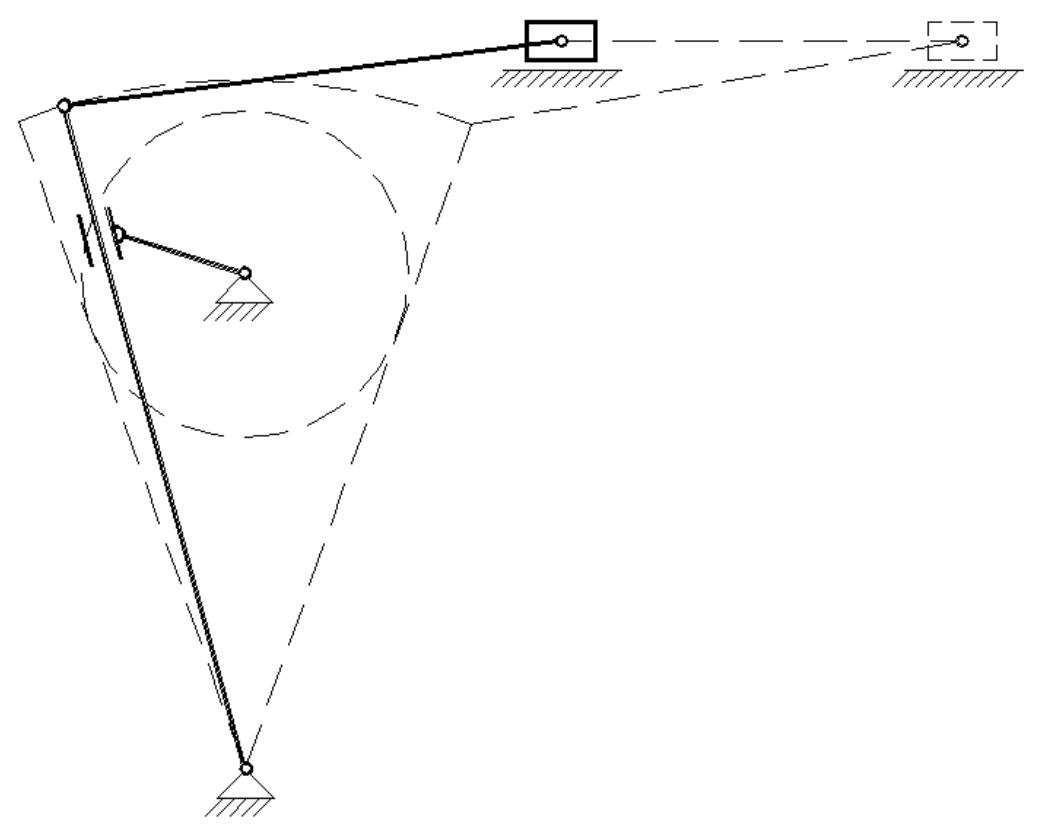

Figura 2 - Mecanismo de retorno acoplado a um elemento estrutural flexível (posição indeformada)

Outra possibilidade para trabalhos futuros é a extensão das formulações não lineares (física, geométrica e de contato) desenvolvidas para outros tipos de elementos finitos, como chapa, placa e de estrutura reticulada tridimensional e também melhorar a aproximação espacial do EF utilizado nesta tese. O trabalho de MITSUGI et al. (2000) apresenta uma estrutura retrátil para antena de satélite simulada por elementos de treliça espacial, que pode ser modelada com a formulação dinâmica apresentada no capítulo 4. Outro possível campo de aplicação da tese é no ensino de Engenharia, através da elaboração de pós-processador gráfico para fazer animações dos problemas estruturais apresentados. Modelos de atrito mais complexos devem ainda ser estudados e incorporados à formulação de impacto desenvolvida. Como última sugestão para futuros trabalhos pode-se aplicar as formulações desenvolvidas no estudo de cabos, utilizandose novos modelos de plasticidade para os materiais constituintes das estruturas.

O doutorando espera poder dar continuidade aos assuntos abordados nesta tese, com a idéia de que todo fim também pode representar um novo começo. 


\section{REFERÊNCIAS BIBLIOGRÁFICAS}

ABRAMOWITZ, M.; STEGUN, I.A. (1972). Handbook of mathematical functions. New York, Dover Publications.

ARGYRIS, J.; MLEJNEK, H.P (1991). Dynamics of structures. Texts on computational mechanics, Vol.5, Amsterdam, North-Holland, 606 p.

ARGYRIS, J.H.; STDOLTSINIS, J.; PIMENTA, P.M.; WUSTENBERG, H. (1986). Termomechanical response of solids at high strains - natural approach. Numerical methods in coupled systems, p.59-117, ed. Lewis R.W., John Wiley \& Sons.

ARMERO, F.; PETOCZ, E. (1998). Formulation and analysis of conserving algorithms for frictionless dynamic contact/impact problems. Computer methods in applied mechanics and engineering, v.158, p.269-300.

BANERJEE, P.K. (1994). The boundary element methods in engineering. 2.ed. London, McGraw-Hill.

BATHE, K.J.; CHAUDHARY, A.B. (1985). A solution method for planar and axisymmetric contact problems. International journal for numerical methods in engineering, v.21, p.65-88.

BATTINI, J.M.; PACOSTE, C.; ERIKSSON, A. (2003). Improved minimal augmentation procedure for the direct computation of critical points. Computer methods in applied mechanics and engineering, v.192, p.2169-2185.

BAUCHAU, O.A.; THERON, N.J. (1996). Energy decaying scheme for nonlinear elastic multi-body systems. Computers \& structures, v.59, p.317-331.

BAUCHAU, O.A. (2000). On the modeling of prismatic joints in flexible multi-body systems. Computer methods in applied mechanics and engineering, v.181, p.87-105.

BEHDINAN, K.; STYLIANOU, M.C.; TABARROK, B. (1998). Co-rotational dynamic analysis of flexible beams. Computer methods in applied mechanics and engineering, v.154, p.151-161.

BELYTSCHO, T.; NEAL, M.O. (1991). Contact-impact by the pinball algorithm with penalty and Lagrangian methods. International journal for numerical methods in engineering, v.31, p.547-572. 
BELYTSCHKO, T.; YEH, I.S. (1993). The splitting pinball method for contact-impact problems. Computer methods in applied mechanics and engineering, v.105, p.375-393.

BIGGS, J.M. (1964). Introduction to structural dynamics. New York, McGraw-Hill.

BITTENCOURT, E.; CREUS, G.J. (1998). Finite element analysis of three-dimensional contact and impact in large deformation problems. Computer \& structures, v.69, p.219234.

BISSHOPP, K.E.; DRUCKER, D.C. (1945). On the deflection of a cantilever beam. Quarterly of applied mathematics, v.3, p.272-275.

BRASIL, R.M.L.R.F. (1990). Não-linearidade geométrica na dinâmica de estruturas aporticadas planas: um tratamento pelo método dos elementos finitos. São Paulo. 211p. Tese (Doutorado) - Escola Politécnica, Universidade de São Paulo.

CARPENTER, N.J.; TAYLOR, R.L.; KATONA, M.G. (1991). Lagrange constrains for transient finite element surface contact. International journal for numerical methods in engineering, v.32, p.103-128.

CHAUDHARY, A.B.; BATHE, K.J. (1986). A solution method for static and dynamic analysis of three-dimensional contact problems with friction. Computer \& structures, v.24, p.855-873.

CHEN, W.H.; CHANG, C.M.; YEH, J.T. (1993). An incremental relaxation finite element analysis of viscoelastic problems with contact and friction. Computer methods in applied mechanics and engineering, v.109, p.315-329.

CHO, J.Y.; KIM, S.J. (1999). Discontinuous time-integration method for dynamic contact/impact problems. AIAA journal, v.37, n.7, p.874-880.

CHOURA, S.; YIGIT, A.S. (2001). Control of a two-link rigid-flexible manipulator with a moving payload mass. Journal of sound and vibration, v.243, p.883-897.

CHUCHKEEPSAKUL S.; BUCHAROEN S.; HUANG T. (1995). Elastica of simple variable-arc-length beam subjected to end moment. Journal of engineering mechanics$A S C E$, v.121, p.767-772.

CHRISTENSEN, E.R.; LEE, S.W. (1986). Nonlinear finite element modeling of the dynamics of unrestrained flexible structures. Computer \& structures, v.23, p.819-829.

CODA, H.B. (2000). Contribuição à análise dinâmica transiente de meios contínuos pelo método dos elementos de contorno. São Carlos. 381p. Tese (Livre-Docência) Escola de Engenharia de São Carlos, Universidade de São Paulo.

CODA, H.B. (2003). An exact FEM geometric non-linear analysis of frames based on position description. In: XVIII CONGRESSO BRASILEIRO DE ENGENHARIA MECÂNICA, São Paulo. 
CODA, H.B.; GRECO, M. (2003). A simple FEM formulation for large deflection 2D frame analysis based on position description. Computer methods in applied mechanics and engineering. (aceito para publicação).

CRISFIELD, M.A. (1981). A fast incremental-iterative solution procedure that handles snap-through. Computer \& structures, v.13, p.55-62.

CRISFIELD, M.A. (1990). A consistent corotational formulation for nonlinear threedimensional beam-elements. Computer methods in applied mechanics and engineering, v.81, p.131-150.

CRISFIELD, M.A. (1991). Non-Linear finite element analysis of solids and structures. v.1. England, John Wiley \& Sons.

CZEKANSKI, A.; MEGUID, S.A.; EL-ABBASI, N.; REFAAT, M.H. (2001). On the elastodynamic solution of frictional contact problems using variational inequalities. International journal for numerical methods in engineering, v.50, p.611-627.

ELKARANSHAWY, H.A.; DOKAINISH, M.A. (1995). Corotational finite element analysis of planar flexible multibody systems. Computer \& structures, v.54, p.881-890.

ESCALONA, J.L.; HUSSIEN, H.A.; SHABANA, A.A. (1998). Application of the absolute nodal co-ordinate formulation to multibody system dynamics. Journal of sound and vibration, v.214, p.833-851.

FANCELLO, E.A.; FEIJOO, R.A. (1994). Shape optimization in frictionless contact problems. International journal for numerical methods in engineering, v.37, p.23112335 .

FARAHANI, K.; MOFID, M.; VAFAI, A. (2000). A solution method for general contact-impact problems. Computer methods in applied mechanics and engineering, v.187, p.69-77.

FARAHANI, K.; MOFID, M.; VAFAI, A. (2001). United elements method for general contact-impact problems. Computer methods in applied mechanics and engineering, v.191, p.843-860.

FUJII, F. (1983). A simple mixed formulation for elastica problems. Computer \& structures, v.17, p.79-88.

GADALA, M.S.; DOKAINISH, M.A.; ORAVAS, G. A. (1984). Formulation methods of geometric and material nonlinearity problems. International journal for numerical methods in engineering, v.20, p.887-914.

GATTASS, M., ABEL, J.F. (1987). Equilibrium considerations of the updated Lagrangian formulation of beam-columns with natural concepts. International journal for numerical methods in engineering, v.24, p.2119-2141. 
GOTO, Y.; WATANABE, Y.; KASUGAI, T.; OBATA, M. (1992). Elastic buckling phenomenon applicable to deployable rings. International journal of solids and structures, v.29, p.893-909.

GRECO, M. (2000). Análise do problema harmônico de radiação e dispersão acústica, usando o método dos elementos de contorno. São Carlos. 90p. Dissertação (Mestrado) Escola de Engenharia de São Carlos, Universidade de São Paulo.

GRECO, M.; CODA, H.B. (2001). Uma forma simples de se introduzir vínculos internos generalizados em estruturas modeladas pelo MEF. In: XXII CONGRESSO IBERO LATINO-AMERICANO DE MÉTODOS COMPUTACIONAIS EM ENGENHARIA, Campinas.

GRECO, M.; CODA, H.B.; VENTURINI, W.S. (2003). An alternative contact/impact identification algorithm for general structural problems. Computational mechanics. (aceito para publicação).

HALLQUIST, J.O.; GOUDREAU, G.L.; BENSON, D.J. (1985). Sliding interfaces with contact-impact in large-scale Lagrangian computations. Computer methods in applied mechanics and engineering, v.51, p.107-137.

HEINSTEIN, M.W.; MELlO, F.J.; ATTAWAY, S.W.; LAURSEN, T.A. (2000). Contact-impact modeling in explicit transient dynamics. Computer methods in applied mechanics and engineering, v.187, p.621-640.

HSIAO, K.M.; YANG, R.T.; LEE, A.C. (1994). A consistent finite element formulation for non-linear dynamic analysis of planar beam. International journal for numerical methods in engineering, v.37, p.75-89.

HU, N. (1997). A solution method for dynamic contact problems. Computer \& structures, v.63, p.1053-1063.

HULBERT, G.M. (1992). Time finite element methods for structural dynamics. International journal for numerical methods in engineering, v.33, p.307-331.

HUGHES, T.J.R.; TAYLOR, R.L.; SACKMAN, J.L.; CURNIER, A.; KANOKNUKULCHAI, W. (1976). A finite element method for a class of contactimpact problems. Computer methods in applied mechanics and engineering, v.8, p.249276.

IBRAHIMBEGOVIC, A.; MAMOURI, S. (2000). On rigid components and joint constraints in nonlinear dynamics of flexible multibody systems employing 3D geometrically exact beam model. Computer methods in applied mechanics and engineering, v.188, p.805-831.

KLEIBER, M. (1989). Incremental finite element modeling in non-linear solid mechanics. England, Ellis Horwood. 
IZZUDDIN B.A., ELNASHAI A.S. (1993). Eulerian formulation for largedisplacement analysis of space frames. Journal of engineering mechanics-ASCE, v.119, p.549-569.

JASWON, M.A. (1963). Integral equation methods in potential theory I. Proceedings of the royal society of London, Series A - mathematical and physical sciences, v.275, p.23-32.

KANE, J.H. (1994). Boundary element analysis in engineering continuum mechanics. New Jersey, Prentice Hall.

KARAOGLAN, L.; NOOR, A.K. (1997). Space-time finite element methods for the sensitivity analysis of contact/impact response of axisymmetric composite structures. Computer methods in applied mechanics and engineering, v.144, p.371-389.

KARKOUB, M.; YIGIT, A.S. (1999). Vibration control of a four-bar mechanism with a flexible coupler link. Journal of sound and vibration, v.222, p.171-189.

LANCZOS, C. (1986), The variational principles of mechanics. 4.ed. New York, Dover Publications.

LANDENBERGER, A.; EL-ZAFRANY, A. (1999). Boundary element analysis of elastic contact problems using gap finite elements. Computer \& structures, v.71, p.651661.

LAVALL, A.C.C. (1996). Uma formulação consistente para análise não-linear de pórticos planos de aço considerando imperfeições iniciais e tensões residuais. São Carlos. 265p. Tese (Doutorado) - Escola de Engenharia de São Carlos, Universidade de São Paulo.

LEE, J.H. (1996). On the application of the modal integration method to flexible multibody systems. Computers \& structures, v.59, p.553-559.

LI, S.; QIAN, D.; LIU, W.K.; BELYTSCHKO, T. (2001). A meshfree contact-detection algorithm. Computer methods in applied mechanics and engineering, v.190, p.32713292.

LIU, W.N.; MESCHKE, G.; MANG, H.A. (2003). Algorithmic stabilization of FE analyses of 2D frictional contact problems with large slip. Computer methods in applied mechanics and engineering, v.192, p.2099-2124.

LORENZANA, A.; GARRIDO, J.A. (1998). A boundary element approach for contact problems involving large displacements. Computer \& structures, v.68, p.315-324.

MAHMOUD, F.F.; ALI-ELDIN, S.S.; HASSAN, M.M.; EMAM, S.A. (1998). An incremental mathematical programming model for solving multi-phase frictional contact problems. Computer \& structures, v.68, p.567-581. 
MATTIASSON, K. (1981). Numerical results from large deflection beam and frame problems analysed by means of elliptic integrals. International journal for numerical methods in engineering, v.17, p.145-153.

MAYO, J.; DOMÍNGUEZ, J. (1996). Geometrically non-linear formulation of flexible multibody systems in terms of beam elements: geometric stiffness. Computer \& structures, v.59, p.1039-1050.

MEEK, J.L.; TAN, H.S. (1984). Geometrically nonlinear-analysis of space frames by an incremental iterative technique. Computer methods in applied mechanics and engineering, v.47, p.261-282.

MEIJAARD, J.P. (1991). Direct determination of periodic-solutions of the dynamic equations of flexible mechanisms and manipulators. International journal for numerical methods in engineering, v.32, p.1691-1710.

MITSUGI, J.; ANDO, K.; SENBOKUYA, Y.; MEGURO, A. (2000). Deployment analysis of large space antenna using flexible multibody dynamics simulation. Acta astronautica, v.47, p.19-26.

MONDKAR, D.P.; POWELL, G.H. (1977). Finite element analysis of non-linear static and dynamic response. International journal for numerical methods in engineering, v.11, p.499-520.

ODEN, J.T.; PIRES, E.B. (1983). Nonlocal and nonlinear friction laws and variational principles for contact problems in elasticity. Journal of applied mechanics, ASME, v.50, p.67-76.

ODEN, J.T.; MARTINS, J.A.C. (1985). Models and computational methods for dynamic friction phenomena. Computer methods in applied mechanics and engineering, v.52, p.527-634.

OGDEN, R.W. (1984), Non-linear Elastic deformation. Chichester, Ellis Horwood.

ORAN, C.; KASSIMALI, A. (1976). Large deformations of framed structures under static and dynamic loads. Computer \& structures, v.6, p.539-547.

OWEN, D.R.J.; HINTON, E. (1980). Finite elements in plasticity: theory and practice. Swansea, Pineridge Press.

PAI, P.F.; PALAZOTTO, A.N. (1996). Large-deformation analysis of flexible beams. International journal of solids and structures, v.33, p.1335-1353.

PETERSON A.; PETERSSON H. (1985). On finite-element analysis of geometrically nonlinear problems. Computer methods in applied mechanics and engineering, v.51, p.277-286.

PETROLITO, J.; LEGGE, K.A. (1996). Unified nonlinear elastic frame analysis. Computer \& structures, v.60, p.21-30. 
PROENÇA, S.P.B. (1997). Análise não-linear de estruturas. São Carlos. /Notas de aula EESC-USP/

REISSNER, E. (1973). One-dimensional large displacement finite-strain beam theory. Studies in applied mathematics, v.52, p. 87-95.

RICE, D.L.; TING, E.C. (1993). Large displacement transient analysis of flexible structures. International journal for numerical methods in engineering, v.36, p.15411562 .

RIKS, E. (1979). Incremental approach to the solution of snapping and buckling problems. International journal of solids and structures, v.15, p.529-551.

SAJE, M.; TURK, G., KALAGASIDU, A.; VRATANAR, B. (1998). A kinematically exact finite element formulation of elastic-plastic curved beams. Computer \& structures, v.67, p.197-214.

SCHULZ, M.; FILIPPOU, F.C (2001). Non-linear spatial Timoshenko beam element with curvature interpolation. International journal for numerical methods in engineering, v.50, p.761-785.

SHIGANG, Y.; YUEQING, Y.; SHIXIAN, B. (1997). Flexible rotor beam element for the manipulator with joint and link flexibility. Mechanism and machine theory, v.32, p.209-219.

SIMO, J.; C.; HJELMSTAD, K.D.; TAYLOR, R.L. (1984). Numerical formulations of elasto-viscoplastic response of beams accounting for the effect of shear. Computer methods in applied mechanics and engineering, v.42, p.301-330.

SIMO, J.C.; VU-QUOC, L. (1986). On the dynamics of flexible beams under large overall motions - the plane case: part 1. Journal of applied mechanics, ASME, v.53, p.849-854.

SIMO, J.C.; VU-QUOC, L. (1986). On the dynamics of flexible beams under large overall motions - the plane case: part 2. Journal of applied mechanics, ASME, v.53, p.855-863.

SIMO, J.C.; WRIGGERS, K.H.; SCHWEIZERHOF, H.; TAYLOR, R.L (1986). Finite deformation post-buckling analysis involving inelasticity and contact constrains. International journal for numerical methods in engineering, v.23, p.779-800.

SIMO, J.C.; LAURSEN, T.A. (1992). An augmented Lagrangian treatment of contact problems involving friction. Computers \& structures, v.42, p.97-116.

SOLBERG, J.M.; PAPADOPOULOS, P. (1998). A finite element method for contact/impact. Finite elements in analysis and design, v.30, p.297-311.

STOENESCU, E.D.; MARGHITU, D.B. (2003). Dynamic analysis of a planar rigidlink mechanism with rotating slider joint and clearance. Journal of sound and vibration, v.266, p.394-404. 
SURANA, K.S. (1983). Geometrically non-linear formulation for 2 dimensional curved beam elements. Computer \& structures, v.17, p.105-114.

SYMM, G.T. (1963). Integral equation methods in potential theory II. Proceedings of the royal society of London, Series A - mathematical and physical sciences, v.275, p.33-46.

TAYLOR, R.L.; PAPADOPOULOS, P. (1993). On a finite element method for dynamic contact/impact problems. International journal for numerical methods in engineering, v.36, p.2123-2140.

THE, L.H., CLARKE, M.J. (1998). Co-rotational and Lagrangian formulations for elastic three-dimensional beam finite elements. Journal of constructional steel research, v.48, p.123-144.

ULAGA, S.; ULBIN, M., FLASKER, J. (1999). Contact problems of gears using Overhauser splines. International journal of mechanical sciences, v.41, p.385-395.

VENTURINI, W.S. (1988). Um estudo sobre o método dos elementos de contorno e suas aplicações em problemas de engenharia. São Carlos. 348p. Tese (Livre-Docência) - Escola de Engenharia de São Carlos, Universidade de São Paulo.

WANG, B.; LU, G.; YU, T.X. (1995). A numerical-analysis of the large deflection of an elastoplastic cantilever. Structural engineering and mechanics, v.3, p.163-172.

WASFY, T.M.; NOOR, A.K. (1997). Computational procedure for simulating the contact/impact response in flexible multibody systems. Computer methods in applied mechanics and engineering, v.147, p.153-166.

WONG M.B.; TINLOI F. (1990). Geometrically nonlinear analysis of elastic framed structures. Computers \& structures, v.34, p.633-640.

WRIGGERS, P.; VAGNER, W.; MIEHE, C. (1988). A quadratically convergent procedure for the calculation of stability points in finite element analysis. Computer methods in applied mechanics and engineering, v.88, p.329-347.

WRIGGERS, P.; VAN, T.V.; STEIN, E. (1990). Finite element formulation of large deformation impact-contact problems with friction. Computer \& structures, v.37, p.319331.

WU, S.C.; HAUG, E.J. (1988). Geometric non-linear substructuring for dynamics of flexible mechanical systems. International journal for numerical methods in engineering, v.26, p.2211-2226.

YANG, T.Y.; SAIGAL S. (1984). A simple element for static and dynamic response of beams with material and geometric nonlinearities. International journal of solids and structures, v.20, p.851-867.

YIGIT, A.S. (1994). The effect of flexibility on the impact response of a two-link rigidflexible manipulator. Journal of sound and vibration, v.177, p.349-361. 
ZHONG, Z-H.; NILSSON, L. (1996). A unified algorithm based on the territory concept. Computer methods in applied mechanics and engineering, v.130, p.1-16.

ZYWICZ, E.; PUSO, M.A. (1999). A general conjugate-gradient-based predictorcorrector solver for explicit finite-element contact. International journal for numerical methods in engineering, v.44, p.439-459.

\section{BIBLIOGRAFIA COMPLEMENTAR}

ARGYRIS, J.H.; STDOLTSINIS, J.; PIMENTA, P.M.; WUSTENBERG, H. (1984). Natural finite element techniques for viscous-flow motion. Computer Methods Applied Mechanics and Engineering, v.45, p.3-55.

BANGASH, M.Y.H. (1993). Impact and explosion. Florida, CRC Press.

BATHE, K.J. (1996). Finite element procedures. New Jersey, Prentice Hall.

BERGAN, P.G.; HORRIGMOE, G.; KRAKELAND, B.; SOREIDE, T.H. (1978). Solution techniques for nonlinear finite-element problems. International journal for numerical methods in engineering, v.12, p.1677-1696.

BREBBIA, C.A.; DOMINGUEZ, J. (1992). Boundary elements: an introductory course. 2.ed. Southampton, Computational Mechanics Publications.

CHIOU, Y.J.; WANG, Y.K.; HSIAO, P.A.; CHEN, Y.L. (2002). Large displacement analysis of inelastic frame structures by convected material frame approach. Structural engineering and mechanics, v.13, p.135-154.

CILONE, A.D. (1993). Sobre o comportamento em serviço de estruturas planas de concreto armado. São Carlos. 251p. Tese (Doutorado) - Escola de Engenharia de São Carlos, Universidade de São Paulo

ClOUGH, R.W.; PENZIEN, J. (1993). Dynamics of structures. 2.ed. New York, McGraw-Hill.

CORRÊA, M.R.S. (1991). Aperfeiçoamento de modelos usualmente empregados no projeto de sistemas estruturais de edifícios. São Carlos. 331p. Tese (Doutorado) Escola de Engenharia de São Carlos, Universidade de São Paulo.

DAFALIAS, Y.F. (1987). Issues on the constitutive formulation at large elastoplastic deformations .1. kinematics. Acta mechanica, v.69, p.119-138.

DAFALIAS, Y.F. (1988). Issues on the constitutive formulation at large elastoplastic deformations .2. kinetics. Acta mechanica, v.73, p.121-146.

ELIAS, Z.M. (1986). Theory and methods of structural analysis. New York, John Wiley \& Sons. 
GERE, J.M.; WEAVER Jr., W. (1981). Análise de estruturas reticuladas. Rio de Janeiro, Guanabara Dois.

GLOWINSKI, R.; RODIN, E. Y.; ZIENKIEWICZ, O. C., eds. (1979). Energy methods in finite element analysis. Chichester, New York, John Wiley.

GREEN, A.E.; NAGHDI, P.M. (1979). Note on invariance under superposed rigid body motions. Journal of Elasticity, v.9, p.1-8.

HSIAO, K.M.; YANG, R.T. (1995). A co-rotational formulation for nonlinear dynamic analysis of curved Euler beam, Computer \& structures, v.54, p.1091-1097.

HUANG, B.Z.; ATLURI, S.N. (1995). A simple method to follow post-buckling paths in finite element analysis. Computers \& structures, v.57, p.477-489.

MAGNUSSON, A.; SVENSSON, I. (1998). Numerical tratment of complete loaddeflection curves. International journal for numerical methods in engineering, v.41, p.955-971.

MAMAGHANI, I.H.P.; USAMI, T.; MIZUNO, E. (1996). Inelastic large deflection analysis of structural steel members under cyclic loading. Engineering structures, v.18, p.659-668.

MAZZILLI, C.E.N.; BRASIL, R.M.L.R.F. (1995). Effect of static loading on the nonlinear vibrations of a 3-time redundant portal frame - analytical and numericalstudies. Nonlinear dynamics, v.8, p.347-366.

ONATE, E.; MATIAS, W.T. (1996). A critical displacement approach for predicting structural instability. Computer methods in applied mechanics and engineering, v.134, p.135-161.

PARISCH, H. (1989). A consistent tangent stiffness matrix for three-dimensional nonlinear contact analysis. International journal for numerical methods in engineering, v.28, p.1803-1812.

PAULA, C.F. (2001). Contribuição ao estudo das respostas numéricas não-lineares estática e dinâmica de estruturas reticuladas planas. 121p. Tese (Doutorado) - Escola de Engenharia de São Carlos, Universidade de São Paulo.

PIPES, L.A.; HARVILL, L.R. (1970). Applied mathematics for engineers and physicists. 3.ed. Tokyo, McGraw-Kogakusha.

REID, S.R.; REDDY, T.Y. (1978). Effect of strain-hardening on large plasticdeformation of a cantilever. Journal of applied mechanics-transactions of the ASME, v.45, p.953-955.

RIGO, E. (1999). Métodos de otimização aplicados à análise de estruturas. 110p. Dissertação (Mestrado) - Escola de Engenharia de São Carlos, Universidade de São Paulo. 
RIKS, E. (1984). Some computational aspects of the stability analysis of nonlinear structures. Computer methods in applied mechanics and engineering, v.47, p.219-259.

RODRIGUES, R.O. (1997). Análise dinâmica bidimensional não-linear física $e$ geométrica de treliças de aço e pórticos de concreto armado. São Carlos. 275p. Tese (Doutorado) - Escola de Engenharia de São Carlos, Universidade de São Paulo.

SPIEGEL, M.R. (1992). Manual de fórmulas, métodos e tabelas de matemática. 2.ed. São Paulo, Makron Books. (Coleção Schaum)

TANG S.C.; YEUNG K.S.; CHON C.T. (1980). On the tangent stiffness matrix in a convected coordinate system. Computer \& structures, v.12, p.849-856.

WARBURTON, G.B. (1976). The dynamic behaviour of structures. 2.ed. Oxford, Pergamon Press.

WONG, M.B.; TINLOI, F. (1990). Analysis of frames involving geometrical and material nonlinearities. Computer \& structures, v.34, p.641-646.

WRIGGERS, P.; SIMO, J.C. (1990). A general procedure for the direct computation of turning and bifurcation points. International journal for numerical methods in engineering, v.30, p.155-176.

WYLIE, C.R.; BARRETT, L.C. (1995). Advanced engineering mathematics. 6.ed. New York, McGraw-Hill.

YU, T.X.; JOHNSON, W. (1982). The plastica - the large elastic-plastic deflection of a strut. International journal of non-linear mechanics, v.17, p.195-209.

\section{PUBLICAÇÕES ELETRÔNICAS CONSULTADAS}

ANSYS 5.5 (1998). Theory Reference. 9.ed.

ANSYS 5.5 (1998). Elements Reference. 10.ed.

AUBURN University (2002). Disponível em: <http://www.eng.auburn.edu/department/ me/courses/nmadsen/egr182a/pliers30.html >. Acesso em: 9 de set.

BROCK Institute for Advanced Studies: banco de dados (2003). Disponível em: $<$ http://www.brockeng.com/mechanism/>. Acesso em: 3 de jul.

IST (2003). Disponível em: <http://www.math.ist.utl.pt/ calves/cursos/Eqdiford.htm>. Acesso em: 26 de set.

The University of Texas at Austin (2002). Disponível em: <http://farside.ph.utexas.edu/ teaching /301/lectures/node49.html $>$. Acesso em: 9 de set.

XREFER (2001): banco de dados. Disponível em: <http://www.xrefer.com/>. Acesso em: 9 de nov. 


\section{APÊNDICE 1 - TRANSFORMAÇÃO DE COORDENADAS}

As equações desenvolvidas durante a tese são montadas no sistema de coordenadas global destrógeno ${ }^{1}$. Porém, na maioria dos problemas numéricos analisados nos capítulos anteriores os elementos finitos estão inclinados em relação ao sistema de coordenadas global, ou seja, possuem um sistema de coordenadas local diferente do global. Para possibilitar a compatibilidade de graus de liberdade entre os diversos elementos finitos, faz-se necessário transformar todas as coordenadas dos elementos do sistema de coordenadas local $(\bar{X} \bar{Y})$ para o sistema de coordenadas global $(X Y)$, conforme o apresentado na figura 1. O procedimento de transformação de coordenadas consiste em projetar os eixos coordenados globais nos eixos coordenados locais. A matriz que faz esta projeção é chamada de matriz de transformação de coordenadas $R$.

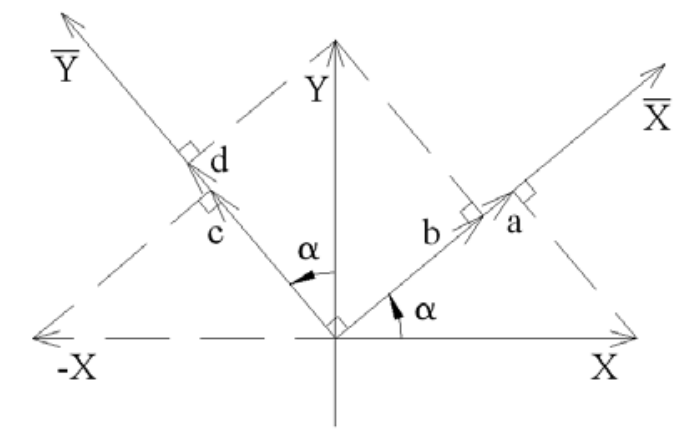

Figura 1 - Transformação de coordenadas do sistema local para o global

Para um nó do elemento finito:

$\bar{X}=a+b=\cos \alpha \cdot X+\operatorname{sen} \alpha \cdot Y$

$\bar{Y}=c+d=-\operatorname{sen} \alpha \cdot X+\cos \alpha \cdot Y$

$\bar{Z}=Z$

\footnotetext{
${ }^{1}$ Com orientação dos eixos definida segundo a regra da mão-direita.
} 


$$
\left\{\begin{array}{l}
\bar{X} \\
\bar{Y} \\
\bar{Z}
\end{array}\right\}=\left[\begin{array}{ccc}
\cos \alpha & \operatorname{sen} \alpha & 0 \\
-\operatorname{sen} \alpha & \cos \alpha & 0 \\
0 & 0 & 1
\end{array}\right]\left\{\begin{array}{l}
X \\
Y \\
Z
\end{array}\right\}
$$

Considerando-se o sistema iterativo de equações apresentado no capítulo 3, com a matriz Hessiana $(h)$, vetor de resíduos $(g)$ e o vetor de correção de posições $(\Delta \bar{X})$ montados inicialmente em coordenadas locais.

$$
h \Delta \bar{X}=g
$$

Os vetores podem ser rotacionados para o sistema de coordenadas global.

$h R \triangle X=R G$

Visando-se a obtenção de um sistema de equações simétrico, multiplica-se a equação (6) por $R^{T}$.

$R^{T} h R \Delta X=R^{T} R G$

A matriz R é ortogonal, ou seja:

$$
R^{T}=R^{-1}
$$

Portanto:

$R^{T} R=R R^{T}=I$

Esta propriedade é muito importante na transformação de matrizes diagonais, como a matriz de massa, pois o resultado da transformação será a própria matriz.

A equação (7) pode ser escrita no sistema de coordenadas global. $H \Delta X=G$

Observa-se que foi utilizada a propriedade da ortogonalidade da matriz $R$ na obtenção da equação (10). A matriz Hessiana escrita inicialmente em coordenadas locais $(h)$ agora pode ser escrita em coordenadas globais $\left(H=R^{T} h R\right)$. Lembra-se, entretanto, que a matriz $R$ deve ser calculada para cada nova posição da estrutura. 


\section{APÊNDICE 2 - SISTEMA DE EQUAÇÕES}

\section{Generalidades}

Nas equações diferenciais aproximadas por métodos numéricos devem ser considerados três aspectos: a consistência, a convergência e a estabilidade. $\mathrm{Na}$ tese utilizou-se o algoritmo de Newton-Raphson na linearização das equações.

$$
g(X)=g\left(X^{0}\right)+\nabla g\left(X^{0}\right) \Delta X \cong 0
$$

No caso, o erro da aproximação na equação não linear é dado por:

$$
E_{n}=\nabla g\left(X^{0}\right)-\left(\frac{g(X)-g\left(X^{0}\right)}{\Delta X}\right)
$$

O algoritmo é consistente se $E_{n} \rightarrow 0$ quando $\Delta X \rightarrow 0$ e possui uma ordem de consistência igual à ordem de truncamento na série de Taylor, ou seja, $E_{n}=O^{n}$.

Durante as iterações o algoritmo não linear é considerado convergente se:

$$
\varepsilon_{n}=\left|\nabla g\left(X^{0}\right)^{-1} g\left(X^{0}\right)\right| \rightarrow 0
$$

E possui ordem de convergência $n, \varepsilon_{n}=O^{n}$. O algoritmo de Newton-Raphson possui ordem de convergência quadrática, devido ao truncamento nos termos de ordem superior da expansão de Taylor.

Segundo a referência IST (2003), a estabilidade está relacionada com a propagação de erros de arredondamento nas iterações. Um algoritmo estável com ordem $n$ de consistência também possui ordem de convergência $n$.

\section{Prescrição de variáveis}

Os sistemas de equações gerados nas formulações são simplificados em sistemas lineares e são resolvidos de forma iterativa. Em uma iteração o sistema adquire a forma:

$$
H \Delta X=I G
$$


Sendo o vetor $\Delta X$ relacionado à correção nas posições nodais, $G$ é o vetor relacionado aos resíduos de forças (inerciais ou elásticas). A matriz $H$ é a Hessiana no problema estático e $I$ é a matriz identidade.

Deve-se separar o sistema em parcelas prescritas (conhecidas) e incógnitas. A maneira utilizada na tese para prescrever posições é semelhante à utilizada no MEC. Supondo-se que as variáveis prescritas sejam indicadas por barras sobrescritas, tem-se os seguintes vetores para o caso da correção em posição $i$ prescrita:

$$
\{\Delta X\}=\left\{\begin{array}{c}
\Delta X_{1} \\
\Delta X_{2} \\
\vdots \\
\Delta \bar{X}_{i} \\
\vdots \\
\Delta X_{N}
\end{array}\right\} \quad\{G\}=\left\{\begin{array}{c}
\bar{G}_{1} \\
\bar{G}_{2} \\
\vdots \\
G_{i} \\
\vdots \\
\bar{G}_{N}
\end{array}\right\}
$$

Pode-se isolar os valores incógnitos à esquerda da igualdade.

$$
\left[\begin{array}{cccccc}
H_{11} & H_{12} & \ldots & 0 & \ldots & H_{1 N} \\
H_{21} & H_{22} & \ldots & 0 & \ldots & H_{2 N} \\
\vdots & \vdots & & -1 & & \vdots \\
H_{N 1} & H_{N 2} & \ldots & 0 & \ldots & H_{N N}
\end{array}\right] \cdot\left\{\begin{array}{c}
\Delta X_{1} \\
\Delta X_{2} \\
\vdots \\
G_{i} \\
\vdots \\
\Delta X_{N}
\end{array}\right\}=\left[\begin{array}{cccccc}
1 & 0 & \ldots & -H_{1 i} & \ldots & 0 \\
0 & 1 & \ldots & -H_{2 i} & \ldots & 0 \\
\vdots & \vdots & & -H_{i i} & & \vdots \\
0 & 0 & \ldots & -H_{N i} & \ldots & 1
\end{array}\right] \cdot\left\{\begin{array}{c}
\bar{G}_{1} \\
\bar{G}_{2} \\
\vdots \\
\Delta \bar{X}_{i} \\
\vdots \\
\bar{G}_{N}
\end{array}\right\}
$$

Como todos os valores à direita da equação são conhecidos, pode-se efetuar o produto da matriz pelo vetor, obtendo-se um novo vetor de mesma dimensão do primeiro.

$H \Delta X=I \bar{G} \Rightarrow A y=b$

No sistema de equações (7) os valores prescritos de $\Delta X$ geram resíduos incógnitos $G$, que no caso estático são resíduos em forças elásticas.

Vale lembrar que na formulação posicional proposta as matrizes são simétricas e, portanto, as operações de troca de coluna apresentadas na equação (6) podem ser simplificadas.

\section{Solução dos sistemas}

$\mathrm{Na}$ solução do sistema linear utiliza-se o método da decomposição $L U$. O sistema de equações pode ser decomposto de acordo com a expressão abaixo.

$$
A y=b \Rightarrow L U y=b \Rightarrow L z=b
$$


Sendo $L$ uma matriz triangular inferior e $U$ uma matriz triangular superior. Resolve-se inicialmente o sistema triangular inferior $(L z=b)$ e em seguida o sistema triangular superior $(U y=z)$.

Este tipo de método de solução de sistemas lineares é muito adequado para o caso de sistemas linearizados por algoritmos do tipo Newton-Raphson, uma vez que as matrizes $L U$ são atualizadas a partir das soluções iterativas do método e não calculadas novamente em cada iteração, como nos métodos de solução de sistemas lineares do tipo Gauss-Jordan.

$\mathrm{Na}$ implementação dos códigos computacionais foi utilizada a biblioteca interna de sub-rotinas matemáticas (IMSL) do compilador FORTAN Powerstation 4.0, da Microsoft Corporation ${ }^{\circledR}$. 


\section{APÊNDICE 3 - MODELO CONSTITUTIVO ELASTOPLÁSTICO}

\section{Comportamento não linear físico (plasticidade)}

Utiliza-se um modelo de plastificação uniaxial misto, combinando os modelos elastoplásticos com encruamento positivo ${ }^{1}$ isótropo e cinemático.

No encruamento isótropo o limite elástico aumenta de acordo com a evolução da plastificação, enquanto no encruamento cinemático o limite elástico permanece constante, porém sofre deslocamento com a evolução da plastificação.

A plastificação em ambos modelos ocorre após a tensão ultrapassar a tensão limite de escoamento.

Encruamento Isótropo

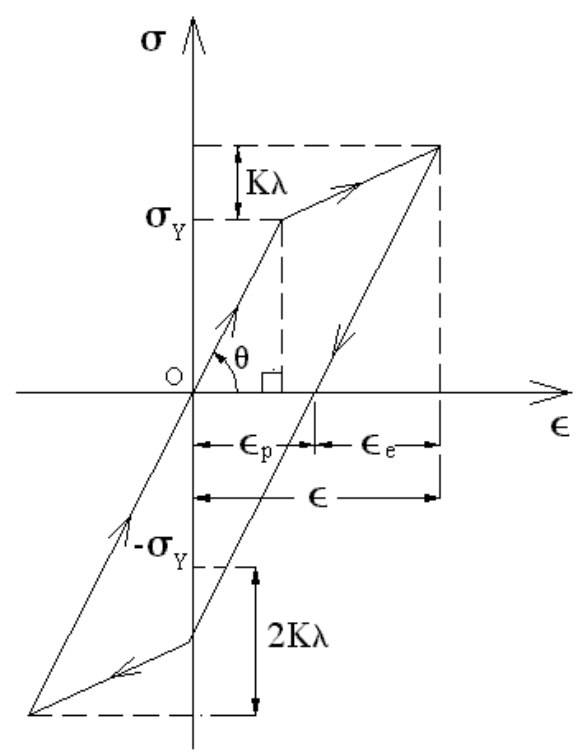

Encruamento Cinemático

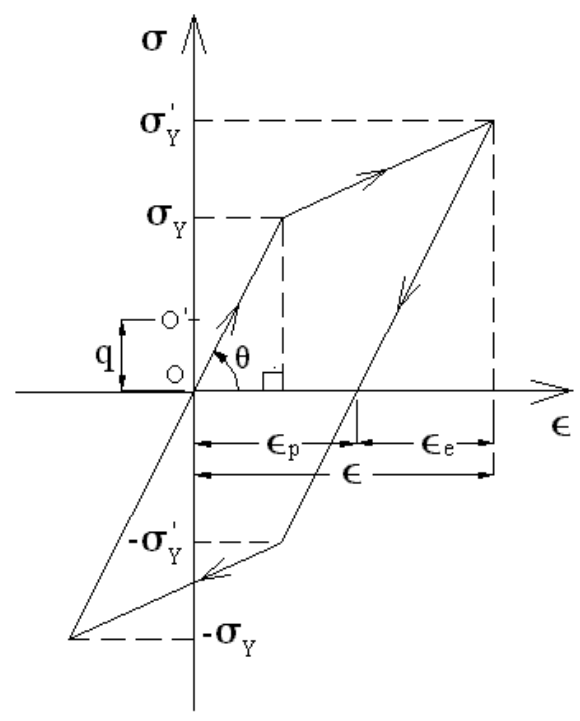

Figura 1 - Modelos de encruamento utilizados na plastificação uniaxial

\footnotetext{
${ }^{1} \mathrm{O}$ material tem a capacidade de resistir a tensões superiores à tensão de escoamento $\left(\sigma_{y}\right)$, de acordo com o modelo de encruamento utilizado.
} 
Para a primeira plastificação admite-se que o material tenha o mesmo comportamento de resposta tanto para tração quanto para compressão. Têm-se as seguintes funções de tensão:

- Encruamento isótropo: $f_{\left(\sigma, \sigma_{y}, \mathrm{~K} \lambda\right)}=|\sigma|-\left(\sigma_{y}+\mathrm{K} \lambda\right)$

- Encruamento cinemático: $f_{\left(\sigma, \sigma_{y}, q\right)}=|\sigma-q|-\sigma_{y}$

- Encruamento misto: $f_{\left(\sigma, \sigma_{y}, q, \mathrm{~K}, \lambda\right)}=|\sigma-q|-\left(\sigma_{y}+\mathrm{K} \lambda\right)$

Os estados de tensão admissíveis devem atender ao seguinte critério:

$f_{\left(\sigma, \sigma_{y}, q, \mathrm{~K}, \lambda\right)} \leq 0$

Sendo $K$, uma constante chamada de módulo plástico, $H$ é o módulo de encruamento cinemático (também constante), $\lambda$ é uma variável interna relacionada à deformação plástica e $q$ outra variável interna relacionada à nova posição do centro do intervalo elástico.

O modelo misto pode ainda simular o comportamento elastoplástico perfeito, caso no qual $H=K=0$.

O comportamento elastoplástico parte de duas hipóteses: a irreversibilidade do processo de plastificação e a proporcionalidade entre taxa de variação de tensão e taxa de deformação

$d \sigma_{(\lambda d \varepsilon)}=\lambda d \sigma_{(d \varepsilon)}$

Considerando-se os modelos de encruamento, figura 1, e a lei de Hooke, tem-se:

$\sigma=E \varepsilon_{e}=E\left(\varepsilon-\varepsilon_{p}\right) \Rightarrow d \sigma=E\left(d \varepsilon-d \varepsilon_{p}\right)$

Sendo $\varepsilon_{e}$ a parcela elástica da deformação e $\varepsilon_{p}$ a plástica.

Aparecem deformações plásticas quando $d \varepsilon_{p} \neq 0$, ou seja, quando $f_{(\sigma, \sigma y, q, K \lambda)}=0$. Por outro lado, se $f_{(\sigma, \sigma y, q, K \lambda)}<0$, então $d \varepsilon_{p}=0$. Quando $f_{(\sigma, \sigma y, q, K \lambda)}>0$ tem-se um estado inadmissível de tensões e deve-se encontrar a resposta para $f_{(\sigma, \sigma y, q, K \lambda)}=0$ no algoritmo iterativo. Define-se uma variável auxiliar em tensões: $\xi=\sigma-q$.

$d \varepsilon_{p}=d \lambda>0 \quad$ se $\quad \xi>0 \quad$ (tração na fibra)

$d \varepsilon_{p}=-d \lambda<0 \quad$ se $\quad \xi<0 \quad$ (compressão na fibra)

Ou ainda:

$d \varepsilon_{p}=d \lambda \operatorname{sign}(\xi)$ 
Das definições anteriores, verifica-se que $d \lambda \geqslant 0$. Sabendo-se que $f_{(\sigma, \sigma y, q, K \lambda)} \leqslant 0$ e se $d \lambda>0$, então $f_{(\sigma, \sigma y, q, K \lambda)}=0$. Se $d \lambda=0$ então $f_{(\sigma, \sigma y, q, K \lambda)}<0$. Obtém-se assim a relação de complementaridade ${ }^{2}$.

$d \lambda f=0$

Em um instante de tempo vale a relação $d f_{(\sigma, \sigma,, q, K \lambda)} \leqslant 0$. Seguindo-se um raciocínio análogo ao utilizado na obtenção da equação (10) chega-se à condição de consistência.

$d \lambda d f=0$

No encruamento cinemático a lei de evolução de $q$ é dada por:

$d q=H d \varepsilon_{p}=d \lambda H \operatorname{sign}(\xi)$

A taxa de variação da função de tensão pode ser desenvolvida por derivação em cadeia.

$$
\begin{aligned}
d f & =\frac{\partial f}{\partial \sigma} d \sigma+\frac{\partial f}{\partial q} d q+\frac{\partial f}{\partial \lambda} d \lambda=\frac{\partial f}{\partial|\xi|} \frac{\partial|\xi|}{\partial \sigma} d \sigma+\frac{\partial f}{\partial|\xi|} \frac{\partial|\xi|}{\partial q} d q+\frac{\partial f}{\partial \lambda} d \lambda \\
& =\operatorname{sign}(\xi) d \sigma-\operatorname{sign}(\xi) d q-\mathrm{K} d \lambda
\end{aligned}
$$

Com base na condição de consistência, equação (11), tem-se:

$$
\begin{aligned}
d f & =\operatorname{sign}(\xi) E\left(d \varepsilon-d \varepsilon_{p}\right)-\operatorname{sign}(\xi) d \lambda H \operatorname{sign}(\xi)-\mathrm{K} d \lambda \\
& =\operatorname{sign}(\xi) E d \varepsilon-\operatorname{sign}(\xi) E d \varepsilon_{p}-d \lambda H-\mathrm{K} d \lambda=0
\end{aligned}
$$

Considerando-se a equação (14), tem-se:

$d \lambda=\frac{\operatorname{sign}(\xi) E d \varepsilon}{E+\mathrm{K}+H} \Rightarrow d \varepsilon^{p}=\frac{E}{E+H+K} d \varepsilon$

Com o valor de $d \lambda$, equação (15), e conseqüentemente de $d q$, fornecido pela equação (11), obtém-se as variações das variáveis $\lambda$ e $q$.

$\lambda=\lambda+d \lambda$

$q=q+d q$

Ou em termos incrementais:

$\lambda=\lambda+\Delta \lambda$

$q=q+\Delta q$

Com os valores de $\lambda$ e $q$ pode-se corrigir os valores das tensões de acordo com o modelo de encruamento utilizado, equações (1) a (3). A deformação plástica é calculada a partir de $\lambda$, na seguinte forma incremental ${ }^{3}$ :

\footnotetext{
${ }^{2}$ Condição de Kuhn-Tucker.

${ }^{3}$ Baseada na equação (9).
} 
$\varepsilon_{p}=\varepsilon_{p}+\Delta \lambda \operatorname{sign}(\xi)$

\section{Integração numérica}

Para o cálculo das componentes da matriz Hessiana e do vetor dos resíduos utiliza-se integração numérica de Gauss unidimensional.

$$
\begin{aligned}
& I=\int_{-1}^{1} f_{(\xi)} d \xi=\sum_{i=1}^{n} f_{(\xi i} w_{i}+E_{n} \\
& E_{n}=\frac{2^{2 n+1}(n !)^{4}}{(2 n+1)(2 n !)^{3}} \frac{d^{2 n} f_{(\xi)}}{d \xi^{2 n}} \quad(-1<\xi<1)
\end{aligned}
$$

Onde $n$ representa o número de pontos de Gauss utilizados, $w_{i}$ o peso de cada ponto $i, \xi_{i}$ a posição normalizada do ponto $i$ e $E n$ o erro de integração da função normalizada $f_{(\xi i}$ para os $n$ pontos de Gauss.

Em intervalos de integração não normalizados, por exemplo, de $L_{1}$ a $L_{2}$, é necessário aplicar-se a seguinte fórmula de transformação:

$$
\int_{L_{1}}^{L_{2}} f_{(x)} d x=\left(\frac{L_{2}-L_{1}}{2}\right) \int_{-1}^{1} f_{\left(\left(\frac{L_{2}+L_{1}}{2}\right)+\frac{\xi}{2}\left(L_{2}-L_{1}\right)\right)} d \xi
$$

As equações (21) a (23) e as tabelas de integração contendo os fatores $\xi_{i}$ e $w_{i}$ foram obtidas em ABRAMOWITZ \& STEGUN (1972).

\section{Tipos de previsões não lineares}

De acordo com KLEIBER (1989), uma equação não linear relacionada a um problema estático após a linearização adquire uma forma semelhante à equação (24).

$\nabla g\left(X^{0}\right) \Delta X=-g\left(X^{0}\right)$

Existem duas possibilidades de algoritmos de solução para o sistema de equações, a explícita (com pequenos incrementos de carga e resposta linear em cada incremento, resultando numa solução sem iterações) e a implícita (com uma solução iterativa) que será a utilizada neste trabalho.

Existem dois algoritmos implícitos baseados em formulações tangentes, o de Newton-Raphson e o de Newton-Raphson modificado. Na figura 2 estão ilustrados dois algoritmos para solução em um passo de carga. A etapa de previsão é igual para os dois e é baseada na última matriz Hessiana conhecida. 

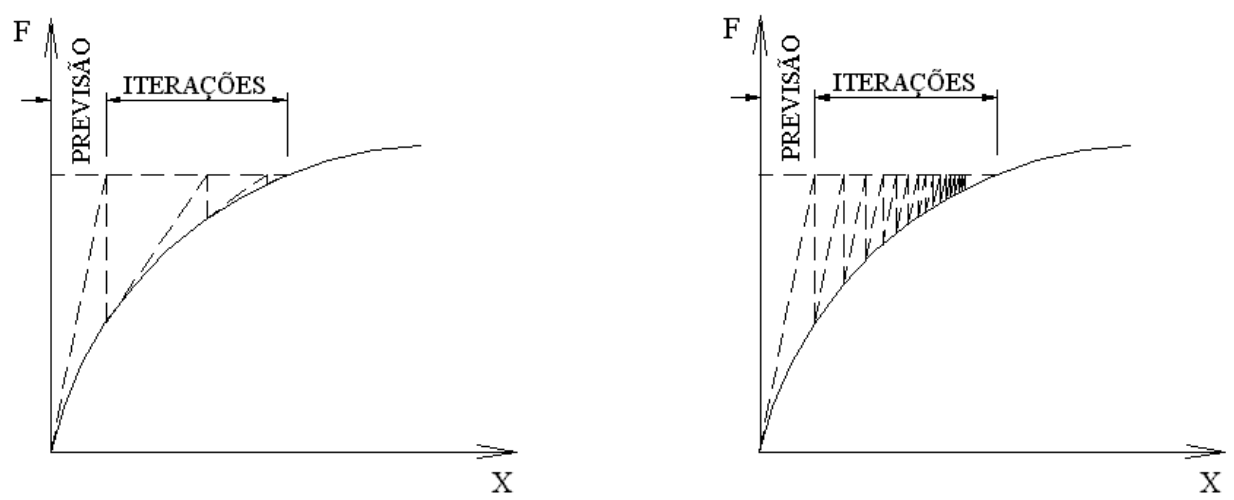

Figura 2 - Algoritmos não lineares implícitos baseados em formulações tangentes

No algoritmo de Newton-Raphson a matriz Hessiana é atualizada a cada iteração; apresenta como vantagem menos iterações para convergir ao resultado e como desvantagem a necessidade de atualização da matriz Hessiana a cada iteração.

No algoritmo de Newton-Raphson modificado a matriz Hessiana permanece constante nas iterações, sendo esta sua principal vantagem, mas a convergência ao resultado necessita de mais iterações.

Neste trabalho, utilizou-se o algoritmo de Newton-Raphson para a não linearidade geométrica e o de Newton-Raphson modificado para a não linearidade física. A escolha do algoritmo de Newton-Raphson modificado para a modelagem da não linearidade física se deve à perda da objetividade da matriz Hessiana em situações com plastificação avançada e a possíveis inversões de tensão dentro das iterações, ocasionadas, por exemplo, em problemas de impacto. 


\section{APÊNDICE 4 - CONEXÃO NODAL}

Os métodos clássicos formulados via elementos finitos para problemas de estruturas reticuladas não possibilitam a consideração de nós com deslocamentos livres, como rótulas. Uma característica interessante nos programas computacionais clássicos baseados no Método dos Elementos Finitos é a capacidade de resolver mais de uma estrutura simultaneamente em um mesmo sistema de equações, com os graus de liberdade das estruturas independentes. Esta independência é obtida através dos próprios dados de entrada do problema. A idéia é fazer uso da possibilidade de resolver estruturas independentes adaptando-a para o caso de nós com deslocamentos livres, através de uma compatibilidade cinemática dos graus de liberdade comuns aos elementos estruturais conectados, BRASIL (1990). Deve-se mencionar que outra maneira de se enxergar a técnica proposta é observar que a parametrização nodal ${ }^{1}$ do funcional de energia que gera as matrizes envolvidas no problema permite total liberdade na associação destes parâmetros aos nós. Assim, dois elementos vizinhos podem possuir nós de extremidade em uma mesma posição geométrica, porém com numeração nodal distinta, significando que os graus de liberdade não estão associados entre si, ou, no caso da técnica proposta, que apenas os graus de liberdade de interesse estejam associados, ficando os restantes livres. A técnica elaborada é geral, podendo ser utilizada em qualquer tipo de modelagem.

Deve-se somar as contribuições das matrizes nos graus de liberdade comuns às estruturas acopladas. No caso dinâmico, as contribuições a serem somadas são nas matrizes de rigidez, massa e amortecimento.

Para montar o sistema é utilizada uma re-numeração dos graus de liberdade nodais conectados. Por exemplo, para o caso de uma rótula, tem-se os seguintes graus de liberdade iniciais e reordenados.

\footnotetext{
${ }^{1}$ Graus de liberdade.
} 

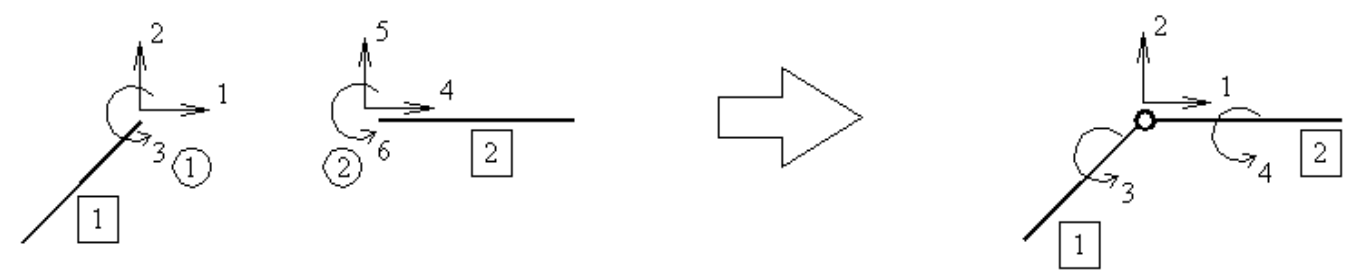

Figura 1 - Graus de liberdade iniciais e reordenados

As parcelas das matrizes Hessianas $(H)$, em coordenadas globais, dos elementos finitos 1 e 2 ilustrados na figura 1 relacionadas aos nós conectados, possuem inicialmente a seguinte forma:

$$
H_{1}=\left[\begin{array}{lll}
A_{11} & A_{12} & A_{13} \\
A_{12} & A_{22} & A_{23} \\
A_{13} & A_{23} & A_{33}
\end{array}\right] \quad H_{2}=\left[\begin{array}{lll}
B_{11} & B_{12} & B_{13} \\
B_{12} & B_{22} & B_{23} \\
B_{13} & B_{23} & B_{33}
\end{array}\right]
$$

Após a conexão dos graus de liberdade, as parcelas relacionadas com os nós conectados adquirem a seguinte configuração:

$$
H=\left[\begin{array}{cccc}
A_{11}+B_{11} & A_{12}+B_{12} & A_{13} & B_{13} \\
A_{12}+B_{12} & A_{22}+B_{22} & A_{23} & B_{23} \\
A_{13} & A_{23} & A_{33} & 0 \\
B_{13} & B_{23} & 0 & B_{33}
\end{array}\right]
$$

No caso dinâmico, acoplam-se também as matrizes de massa $M$ e amortecimento $C$, de maneira análoga.

Para o caso usual de estruturas reticuladas formuladas pelo MEF, tem-se a conexão dos três graus de liberdade comuns aos elementos finitos, em coordenadas globais.
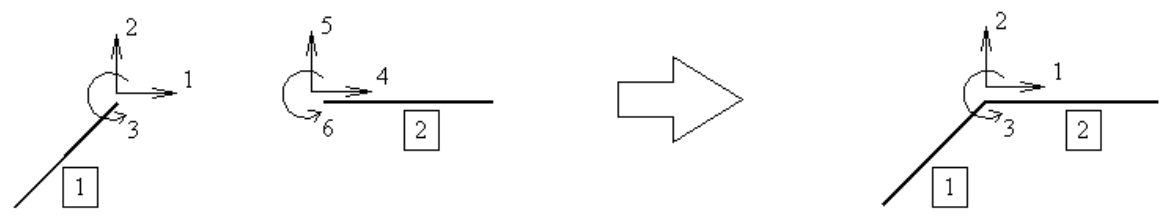

Figura 2 - Conexão nodal sem movimento livre

Quando for necessário reordenar os graus de liberdade ${ }^{2}$, o nó de conexão será chamado de nó duplo, seguindo uma notação clássica do MEC encontrada em VENTURINI (1988) e CODA (2000). O artifício do nó duplo no local da conexão pode ser aplicado em vários de casos de compatibilidade cinemática entre elementos.

\footnotetext{
${ }^{2} \mathrm{Na}$ existência de vínculos internos.
} 

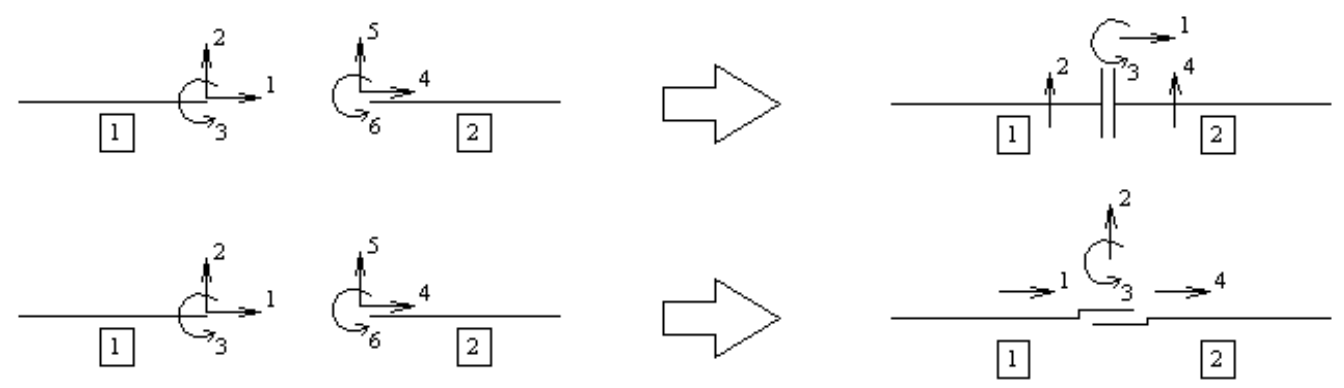

Figura 3 - Casos de conexão nodal com movimentos livres entre dois elementos

Pode-se ainda aplicar o esquema apresentado na conexão parcial ou total de mais de dois elementos, conforme ilustrado na figura 4.

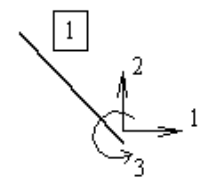

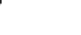

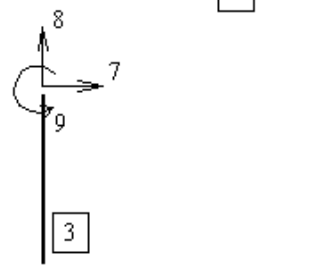

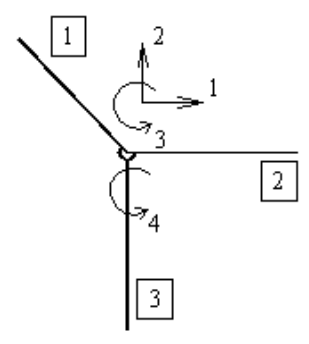

Figura 4 - Conexão parcial entre três elementos finitos

É importante salientar que os outros graus de liberdade do sistema também devem ser reordenados, de acordo com o esquema proposto por GRECO \& CODA (2001).

Este conceito simples pode ser facilmente estendido para formulações de pórticos tridimensionais e com uma pouco mais de esforço para placas e outros tipos de sólidos, levando-se em consideração acoplamentos em coordenadas locais, ver GRECO (2000). 


\section{APÊNDICE 5 - EQUAÇÕES DE INTEGRAÇÃO TEMPORAL DE NEWMARK}

As equações de equilíbrio dinâmico, apresentadas nos capítulos 4 e 5, são equações diferenciais parciais no espaço e no tempo. Na formulação utiliza-se a hipótese de que as variáveis sejam separáveis. A solução da equação de equilíbrio no espaço é feita a partir das funções aproximadoras de posição, apresentadas no capítulo 3. Já a solução da equação de equilíbrio no tempo é obtida a partir de uma discretização do tempo, com a utilização das equações de integração temporal de Newmark.

As aproximações temporais se baseiam em expressões obtidas a partir de simplificações da variável aceleração nos intervalos de tempo. A primeira aproximação utilizada para $\ddot{X}$ é constante.

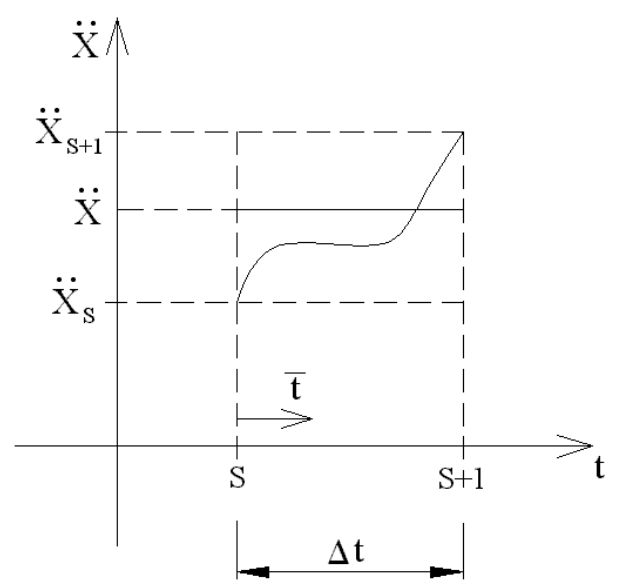

Figura 1 - Aproximação constante da aceleração em um intervalo de tempo

Obtém-se como expressão aproximada para $\ddot{X}$ a média simples entre as acelerações inicial e final do trecho.

$\ddot{X}=\frac{1}{2}\left(\ddot{X}_{S}+\ddot{X}_{S+1}\right)$ 
Onde o sub-índice $S$ se refere ao instante anterior e $S+1$ ao instante atual. Integra-se a equação (1) em relação à variável $\bar{t}$.

$\dot{X}=\frac{1}{2}\left(\ddot{X}_{S}+\ddot{X}_{S+1}\right) \bar{t}+c_{1}$

Como primeira condição inicial tem-se que para $\bar{t}=0, \dot{X}=\dot{X}_{S}$.

$\dot{X}=\frac{1}{2}\left(\ddot{X}_{S}+\ddot{X}_{S+1}\right) \bar{t}+\dot{X}_{S}$

A equação (3) é integrada novamente em relação a $\bar{t}$.

$X=\frac{1}{2}\left(\ddot{X}_{S}+\ddot{X}_{S+1}\right) \frac{\bar{t}^{2}}{2}+\dot{X}_{S} \bar{t}+c_{2}$

Como segunda condição inicial para $\bar{t}=0$, tem-se $X=X_{S}$.

$X=\frac{1}{2}\left(\ddot{X}_{S}+\ddot{X}_{S+1}\right) \frac{\bar{t}^{2}}{2}+\dot{X}_{S} \bar{t}+X_{S}$

Por fim, são aplicadas as condições iniciais no final do intervalo: para $\bar{t}=\Delta t$, $\dot{X}=\dot{X}_{S+1}$ e $X=X_{S+1}$.

$\dot{X}_{S+1}=\frac{1}{2}\left(\ddot{X}_{S}+\ddot{X}_{S+1}\right) \Delta t+\dot{X}_{S}$

$X_{S+1}=\frac{1}{4}\left(\ddot{X}_{S}+\ddot{X}_{S+1}\right) \Delta t^{2}+\dot{X}_{S} \Delta t+X_{S}$

A segunda aproximação utilizada para a variável $\ddot{X}$ é linear.

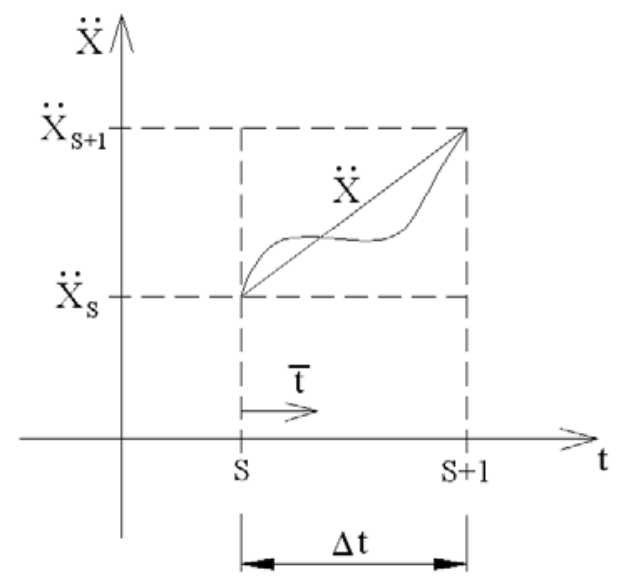

Figura 2 - Aproximação linear da aceleração em um intervalo de tempo

Neste caso, a expressão aproximada é uma equação de reta.

$\ddot{X}=\frac{\bar{t}}{\Delta t}\left(\ddot{X}_{S+1}-\ddot{X}_{S}\right)+\ddot{X}_{S}$

Integra-se a equação (8) em relação ao tempo $\bar{t}$. 
$\dot{X}=\frac{\bar{t}^{2}}{2 \Delta t}\left(\ddot{X}_{S+1}-\ddot{X}_{S}\right)+\ddot{X}_{S} \bar{t}+c_{1}$

Aplica-se a primeira condição inicial em $\bar{t}=0, \dot{X}=\dot{X}_{S}$.

$\dot{X}=\frac{\bar{t}^{2}}{2 \Delta t}\left(\ddot{X}_{S+1}-\ddot{X}_{S}\right)+\ddot{X}_{S} \bar{t}+\dot{X}_{S}$

Integra-se novamente a equação (10) em relação a $\bar{t}$.

$X=\frac{\bar{t}^{3}}{6 \Delta t}\left(\ddot{X}_{S+1}-\ddot{X}_{S}\right)+\ddot{X}_{S} \frac{\bar{t}^{2}}{2}+\dot{X}_{S} \bar{t}+c_{2}$

Impõe-se a segunda condição inicial em $\bar{t}=0: X=X_{S}$.

$\dot{X}=\frac{\bar{t}^{3}}{6 \Delta t}\left(\ddot{X}_{S+1}-\ddot{X}_{S}\right)+\ddot{X}_{S} \frac{\bar{t}^{2}}{2}+\dot{X}_{S} \bar{t}+X_{S}$

São aplicadas, nas equações (10) e (12), as condições iniciais em $\bar{t}=\Delta t$, $\dot{X}=\dot{X}_{S+1}$ e $X=X_{S+1}$.

$\dot{X}_{S+1}=\frac{1}{2}\left(\ddot{X}_{S+1}-\ddot{X}_{S}\right) \Delta t+\ddot{X}_{S} \Delta t+\dot{X}_{S}$

$X_{S+1}=\frac{1}{6}\left(\ddot{X}_{S+1}-\ddot{X}_{S}\right) \Delta t^{2}+\ddot{X}_{S} \frac{\Delta t^{2}}{2}+\dot{X}_{S} \Delta t+X_{S}$

As equações obtidas por aproximação constante, (6) e (7), e aproximação linear, (13) e (14), podem ser condensadas da seguinte maneira:

$$
\begin{aligned}
& X_{S+1}=X_{S}+\Delta t \dot{X}_{S}+\Delta t^{2}\left[\left(\frac{1}{2}-\beta\right) \ddot{X}_{S}+\beta \ddot{X}_{S+1}\right] \\
& \dot{X}_{S+1}=\dot{X}_{S}+\Delta t(1-\gamma) \ddot{X}_{S}+\gamma \Delta t \ddot{X}_{S+1}
\end{aligned}
$$

No caso de aproximação constante: $\gamma=\frac{1}{2}$ e $\beta=\frac{1}{4}$; no caso de aproximação linear: $\gamma=\frac{1}{2}$ e $\beta=\frac{1}{6}$.

Como último comentário importante tem-se a questão das unidades a serem utilizadas. A unidade de tempo é definida a partir da $2^{\mathrm{a}}$ lei de Newton.

$[\mathrm{N}]=[\mathrm{Kg}] \frac{[\mathrm{m}]}{\left[\mathrm{s}^{2}\right]} \Rightarrow[\mathrm{s}]=\sqrt{\frac{[\mathrm{Kg}][\mathrm{m}]}{[\mathrm{N}]}}$

De acordo com a equação (17), para a resposta em tempo ter a unidade correta é necessário manter a razão unitária entre as grandezas $[\mathrm{Kg}][\mathrm{m}]$ e $[\mathrm{N}]$. Este problema ocorre devido ao operador raiz (qualquer razão diferente de 1 altera a unidade de tempo em proporção igual à raiz quadrada). Aconselha-se o uso de unidades no sistema internacional (SI) para se evitar o cálculo da correção no tempo. 


\section{APÊNDICE 6 - MODELO DE ATRITO DE COULOUMB}

O movimento de um corpo elástico, ou rígido, sobre uma superfície rugosa gera forças de atrito no sentido contrário ao movimento. Estas forças geradas são dissipativas e podem ser calculadas através de modelos simplificados, como o de Coulomb ${ }^{1}$, ou modelos mais sofisticados, como os modelos de atrito não linear.

$\mathrm{Na}$ figura 1 é possível observar um corpo em movimento na direção da força aplicada $m \ddot{X}$. Segundo o modelo de átrio de Coulomb, o movimento do corpo sobre uma superfície áspera gera uma força de atrito $\left(\mu F_{\eta}\right)$ no sentido contrário ao movimento e com módulo diretamente proporcional à força normal à superfície $\left(F_{\eta}\right)$.

No caso ilustrado na figura, $m g$ representa a força devido à atração gravitacional da Terra, neste caso a superfície é normal à direção da força exercida pela aceleração da gravidade $(g)$.

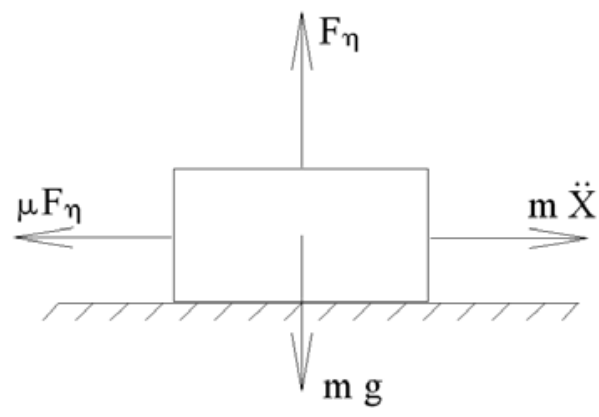

Figura 1 - Bloco elástico em movimento sobre uma superfície horizontal áspera

\footnotetext{
${ }^{1}$ Charles Augustin de Coulomb (1736-1806) - Engenheiro francês responsável pelo modelo de atrito que relaciona diretamente as forças normais às forças de atrito tangenciais a uma superfície, através de coeficientes ditos de atrito. Também responsável pela Lei de Coulomb de atração e repulsão de partículas no Eletromagnetismo.
} 
O coeficiente de proporcionalidade $\mu$ pode ser distinto em coeficiente de atrito estático $\left(\mu_{S}\right)$ e coeficiente de atrito dinâmico $\left(\mu_{K}\right)$. Esta diferenciação ocorre porque, experimentalmente, observa-se que quando o corpo está em repouso a força necessária para iniciar o movimento é maior que a força necessária para manter o corpo em movimento. Logo, a força necessária para vencer o atrito entre o corpo e a superfície é maior quando o corpo estiver em repouso. Na figura 2 apresenta-se um diagrama com as três fases do movimento de um corpo que inicialmente encontra-se em repouso. No trecho 1, a força aplicada no corpo ( $m \ddot{X})$ não é suficiente para romper com a inércia do sistema e o corpo permanece em repouso. O ponto 2 é a situação limite entre o repouso e o movimento, neste instante a força aplicada é igual à necessária para iniciar o movimento $\left(\mu_{S} m g\right)$. Após ultrapassado o ponto 2, inicia-se o movimento do corpo, trecho3, e a força necessária para manter este movimento $\left(\mu_{K} m g\right)$ é menor que a força necessária para romper a inércia.

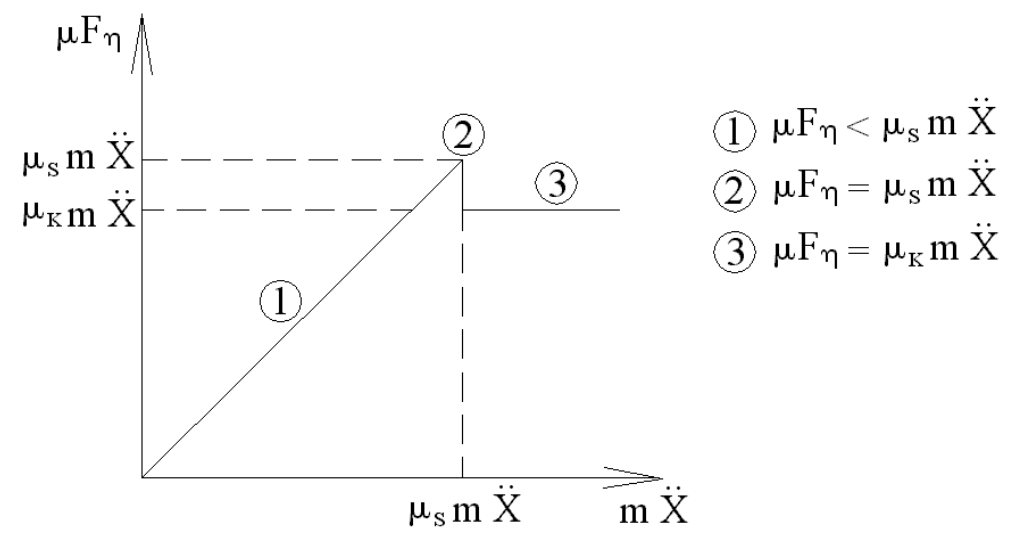

Figura 2 - Aceleração horizontal $\times$ força de atrito desenvolvida

A dificuldade do modelo está em definir os coeficiente de atrito estáticos e dinâmicos para cada problema, de acordo com a rugosidade entre cada tipo de corpo e anteparo. Segundo informações obtidas no endereço eletrônico AUBURN UNIVERSITY (2003), $\mu_{S}$ pode variar de 0.0 , no caso de superfície perfeitamente lisas $\left(\right.$ sem atrito $^{2}$ ), a 1.0 no caso de contato entre corpo e anteparo feitos de borracha. Ainda segundo a fonte consultada, valores usuais para metais variam entre 0.2 a 0.6. Geralmente a diferenças entre os coeficientes de atrito estáticos e dinâmicos para cada

${ }^{2}$ Situação teórica. 
problema específico não são grandes e para efeitos práticos adotam-se coeficientes de atrito dinâmicos iguais aos estáticos. Uma maneira simples de se calcular os coeficientes de atrito estáticos experimentalmente pode ser encontrada no endereço eletrônico THE UNIVERSITY OF TEXAS AT AUSTIN (2003). De acordo com a figura 3, colocando-se o corpo no anteparo inclinado é possível, variando-se a inclinação $(\theta)$ do anteparo, calcular o coeficiente de atrito estático.

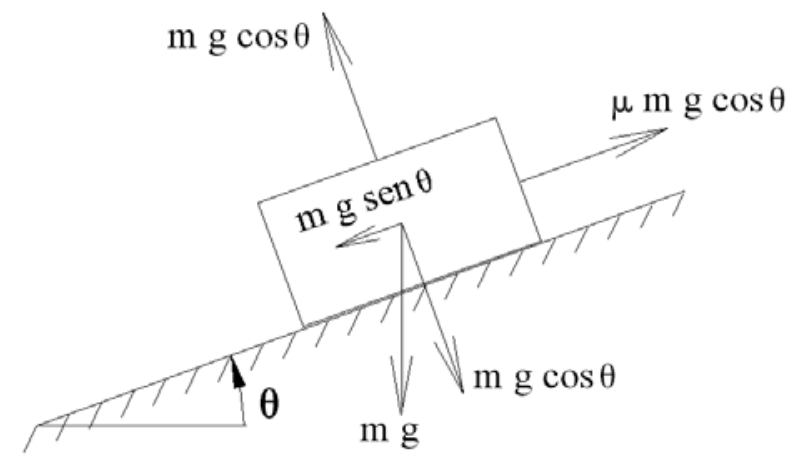

Figura 3 - Bloco apoiado em uma superfície inclinada

Enquanto a componente de força gerada pela gravidade $(m g \operatorname{sen} \theta)$ não for suficiente para romper com a inércia do sistema, maior que a força gerada pelo atrito $\left(\mu_{S} m g \cos \theta\right)$, o corpo permanecerá em repouso.

$F_{\tau}=m g \operatorname{sen} \theta<\mu_{S} m g \cos \theta$

$\mathrm{Na}$ eminência do movimento, a componente de força gerada pela gravidade é igual à força gerada pelo atrito.

$F_{\tau}=m g \operatorname{sen} \theta=\mu_{S} m g \cos \theta$

A partir desta inclinação limite, o corpo iniciará seu movimento. Portanto tem-se pela equação (2) que o coeficiente de atrito estático pode ser calculado experimentalmente através do ângulo de inclinação do anteparo.

$\mu_{S}=\frac{\operatorname{sen} \theta}{\cos \theta}=\tan \theta$ 


\section{ÍNDICE}

Ângulo de retorno, 76

Algoritmo de identificação do impacto, 68

Algoritmo de retorno, 68, 103

Amortecimento, 42

Carga crítica, 4

Cinemática de Euler-Bernoulli, 16

Cinemática de Reissner, 5

Coeficiente de retorno, 74

Condição de consistência, 141

Condições de contorno, 1, 107

Condição de Kuhn-Tucker, 141

Condição de penetração nula, 77

Condições iniciais, 1, 107

Consistência, 136

Convergência, 83, 136

Critério de tolerância, 19, 46

Distribuição das forças de contato, 103

Divergente do funcional de energia, 17

Encruamento positivo, 139

Energia de deformação total, 12

Energia cinética, 42

Energia potencial das forças externas, 12

Estabilidade, 136

Estabilidade do algoritmo de integração

temporal, 83

Estrutura alvo, 67

Estrutura reticulada, 1

Forças de contato, 78,81

Funcional de energia potencial total, 12, 42

Funções de Liapunov, 119

Impacto nodal, 106
Integração temporal de Newmark, 45, 81, 147

Matriz de amortecimento, 43, 80

Matriz de massa, 43

Matriz de restrição de contato, 79

Matriz Hessiana, 18, 46

Medida de deformações objetiva, 13

Método de Newton-Raphson, 18, 46, 80

Módulo plástico, 140

Módulo de encruamento cinemático, 140

Multiplicador de Lagrange, 78

Objetividade, 25

Parâmetros nodais, 17, 43

Plastificação, 33, 48, 139

Ponto Fonte, 69

Ponto limite, 4

Ponto de bifurcação, 4

Princípio da energia potencial total estacionária, 11, 43

Relação de complementaridade, 141

Snap-through, 5

Snap-back, 5

Tensão de escoamento, 31, 139 